NATIONAL LABORATORY

MANAGED BY UT-BATTELLE

FOR THE DEPARTMENT OF ENERGY

\title{
Carbon Lock-In: Barriers To Deploying Climate Change Mitigation Technologies
}

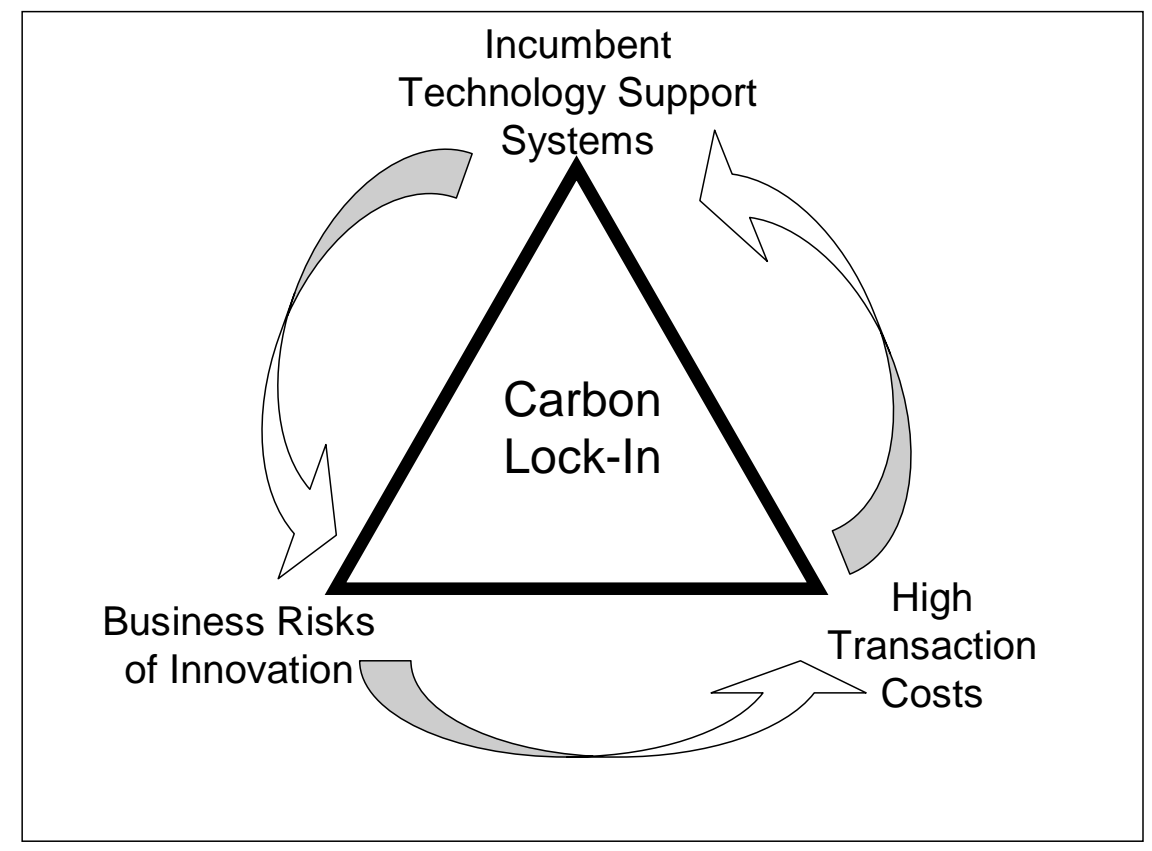

Prepared by:

Marilyn A. Brown

Jess Chandler Melissa V. Lapsa

Benjamin K. Sovacool

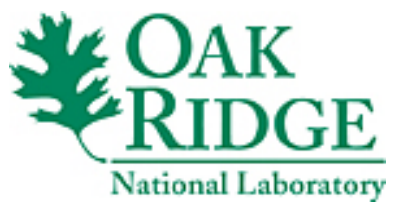

November 2007

Revised January 2008

Sponsored by:

U.S. CLIMATE CHANGE TECHNOLOGY PROGRAM

www.climatetechnology.gov 


DOCUMENT AVAILABILITY
Reports produced after January 1, 1996, are generally available free via the U.S. Department of
Energy (DOE) Information Bridge.
Web site http://www.osti.gov/bridge
Reports produced before January 1, 1996, may be purchased by members of the public from the
following source.
National Technical Information Service
5285 Port Royal Road
Springfield, VA 22161
Telephone 703-605-6000 (1-800-553-6847)
TDD 703-487-4639
Fax 703-605-6900
E-mail info@ntis.gov
Web site http://www.ntis.gov/support/ordernowabout.htm
Reports are available to DOE employees, DOE contractors, Energy Technology Data Exchange
(ETDE) representatives, and International Nuclear Information System (INIS) representatives from
the following source.
Office of Scientific and Technical Information
P.O. Box 62
Oak Ridge, TN 37831
Telephone 865-576-8401
Fax 865-576-5728
E-mail reports@osti.gov
Web site http://www.0sti.gov/contact.html

This report was prepared as an account of work sponsored by an agency of the United States Government. Neither the United States Government nor any agency thereof, nor any of their employees, makes any warranty, express or implied, or assumes any legal liability or responsibility for the accuracy, completeness, or usefulness of any information, apparatus, product, or process disclosed, or represents that its use would not infringe privately owned rights. Reference herein to any specific commercial product, process, or service by trade name, trademark, manufacturer, or otherwise, does not necessarily constitute or imply its endorsement, recommendation, or favoring by the United States Government or any agency thereof. The views and opinions of authors expressed herein do not necessarily state or reflect those of the United States Government or any agency thereof. 


\title{
Engineering Science and Technology Division
}

\section{CARBON LOCK-IN: BARRIERS TO DEPLOYING CLIMATE CHANGE MITIGATION TECHNOLOGIES}

\author{
Marilyn A. Brown,* Georgia Institute of Technology \\ Jess Chandler, Georgia Institute of Technology \\ Melissa V. Lapsa, Oak Ridge National Laboratory \\ Benjamin K. Sovacool, National University of Singapore
}

November 2007

Revised January 2008

\author{
Prepared by \\ OAK RIDGE NATIONAL LABORATORY \\ Oak Ridge, Tennessee 37831-6283 \\ managed by \\ UT-BATTELLE, LLC \\ for the \\ U.S. DEPARTMENT OF ENERGY \\ under contract DE-AC05-00OR22725
}

*Corresponding author:

Dr. Marilyn A. Brown

Professor. School of Public Policy

Georgia Institute of Technology

DM Smith Building

685 Cherry Street, Room 312

Atlanta, GA 30332-0345

email: marilyn.brown@pubpolicy.gatech.edu

Phone: 404-385-0303 



\section{CONTENTS}

LIST OF BOXES …

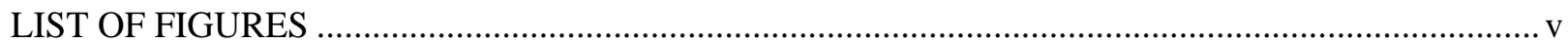

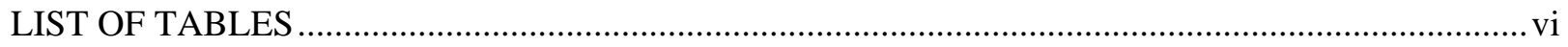

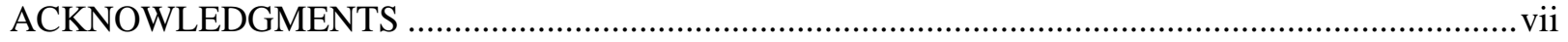

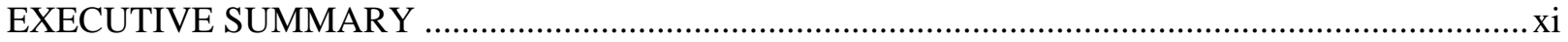

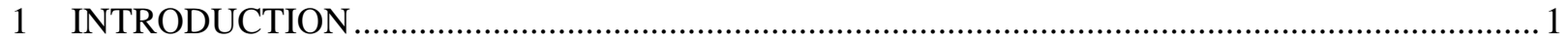

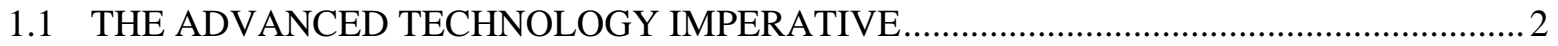

1.2 THE RANGE AND SCOPE OF GHG-REDUCING TECHNOLOGIES ............................... 3

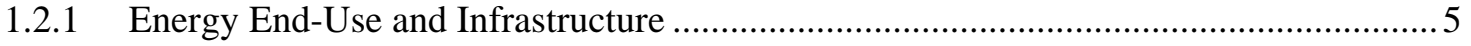

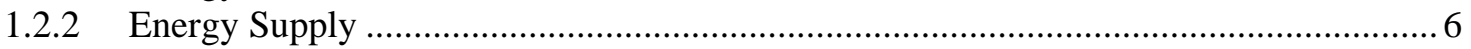

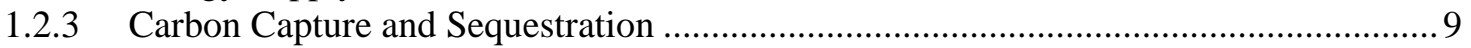

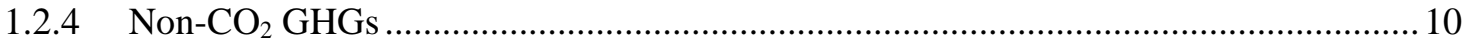

1.2.5 Potential Contributions to Emissions Reductions......................................................... 12

1.3 MOTIVATION, RESEARCH APPROACH, AND ORGANIZATION

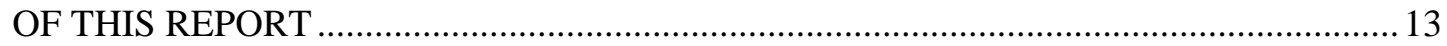

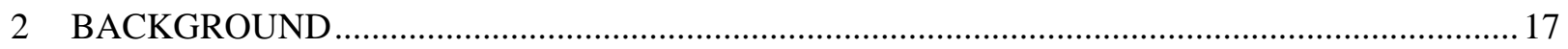

2.1 THE COMMERCIALIZATION AND DEPLOYMENT PROCESS ................................... 18

2.1.1 The Gap Between Typical Current Use and Today’s Best Practices............................19

2.1.2 The Lag Between Today's Best Practices and Technically

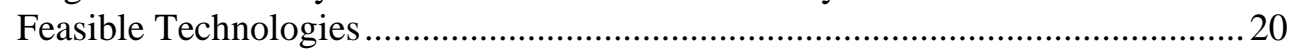

2.2 TYPES OF COMMERCIALIZATION AND DEPLOYMENT BARRIERS ............................22

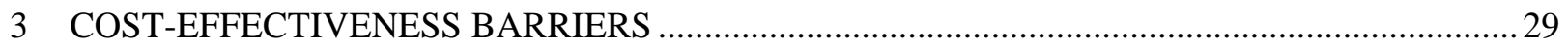

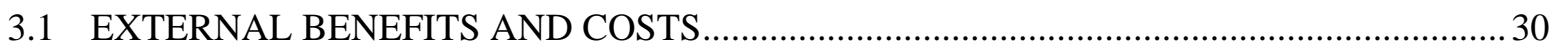

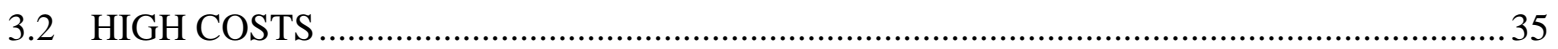

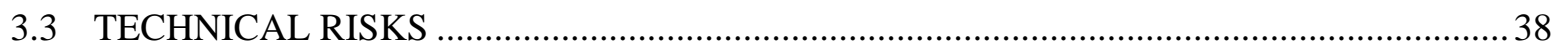

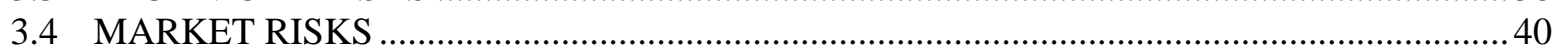

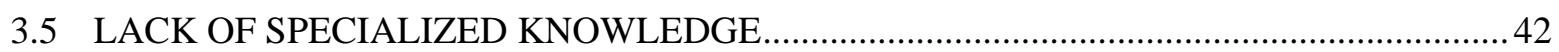

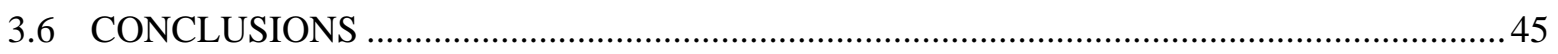

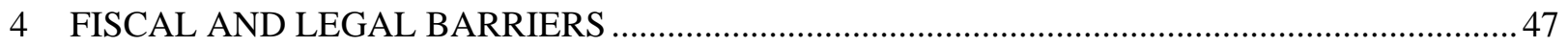

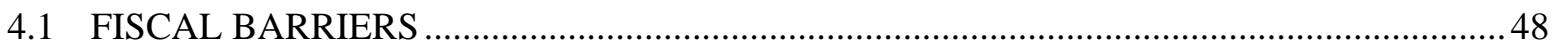

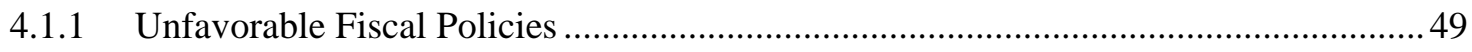

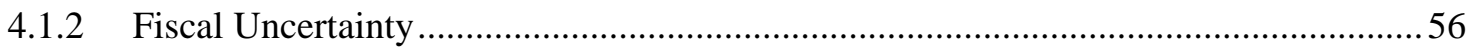

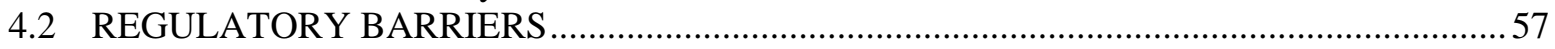

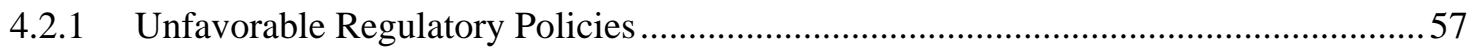

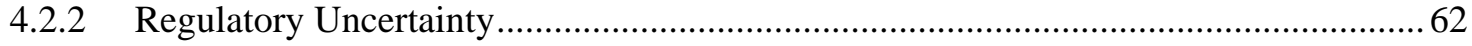

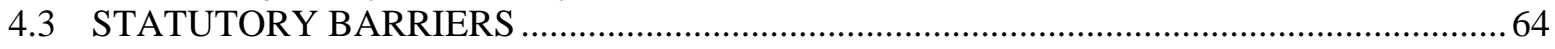

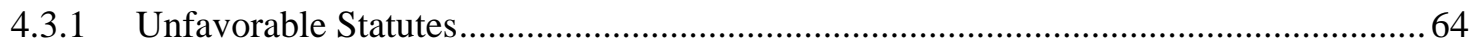

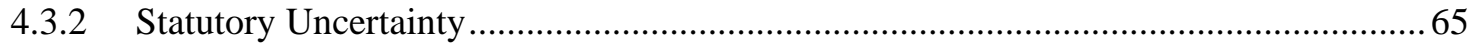

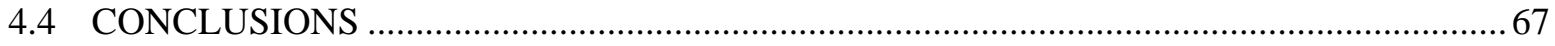

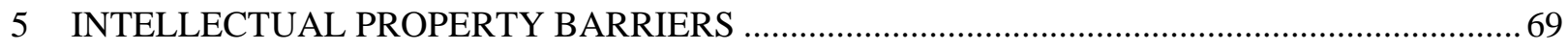

5.1 HIGH INTELLECTUAL PROPERTY TRANSACTION COSTS ..................................... 70

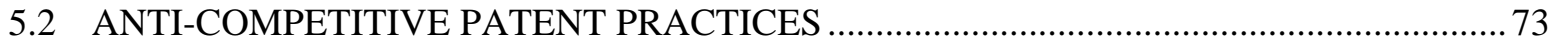

5.3 WEAK INTERNATIONAL PATENT PROTECTION .......................................................... 76 
5.4 CONFLICTS ARISING IN PUBLIC-PRIVATE PARTNERSHIPS ................................... 76

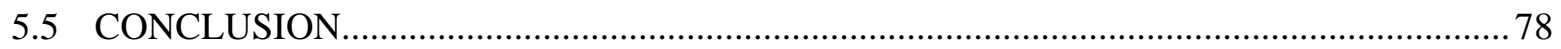

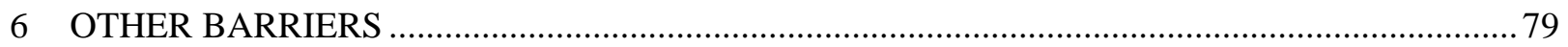

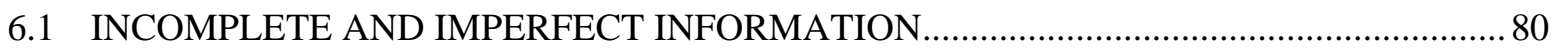

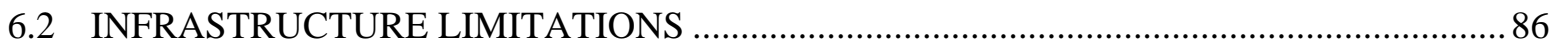

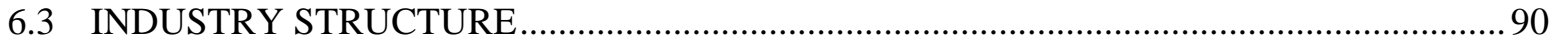

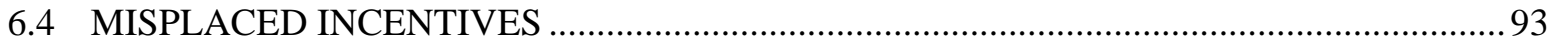

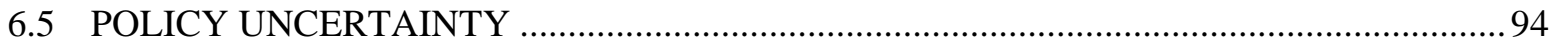

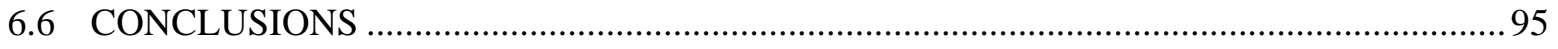

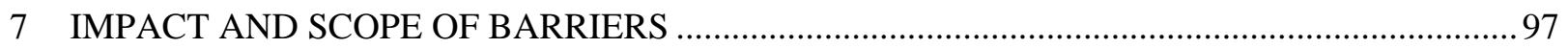

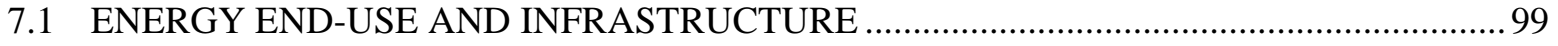

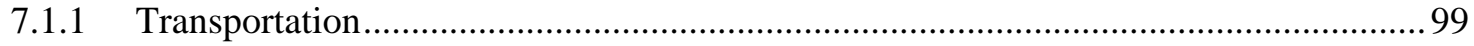

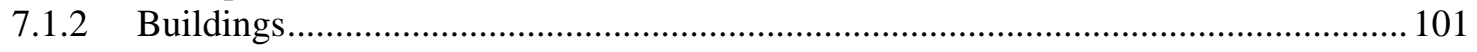

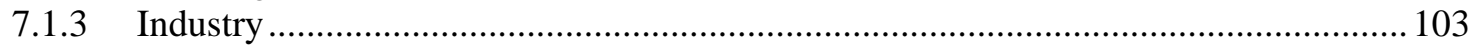

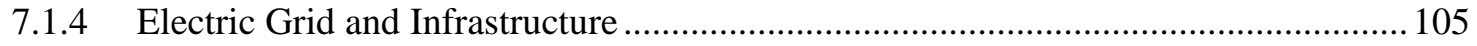

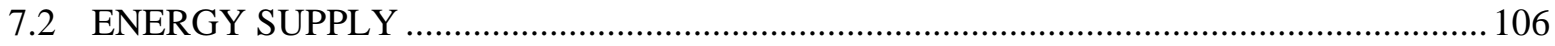

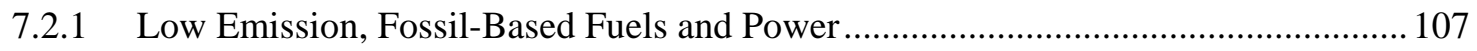

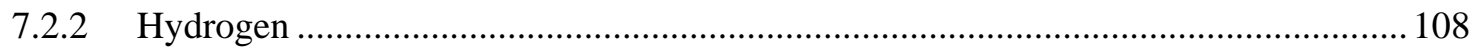

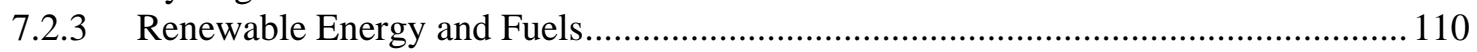

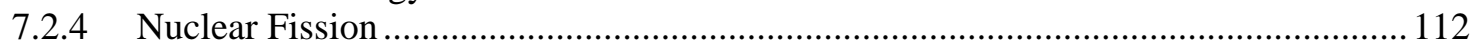

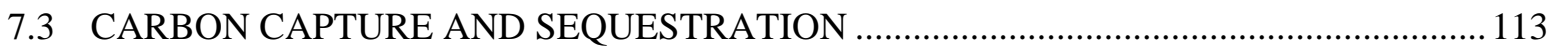

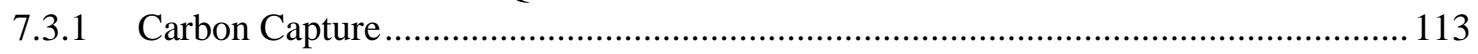

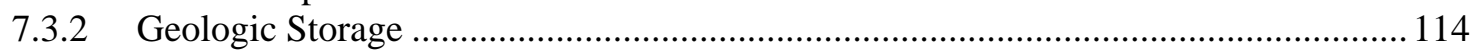

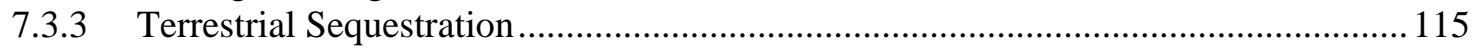

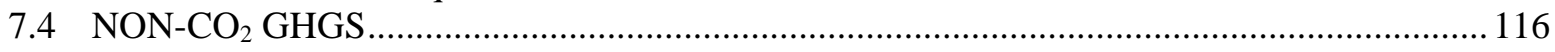

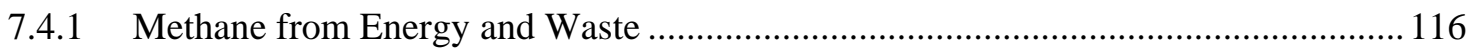

7.4.2 Methane and Nitrous Oxide Emissions from Agriculture ....................................... 118

7.4.3 Emissions of High Global-Warming Potential Gases............................................. 119

7.4.4 Nitrous Oxide Emissions from Combustion and Industrial Sources ........................... 120

7.5 THE MOST COMMON AND CRITICAL BARRIERS.................................................... 121

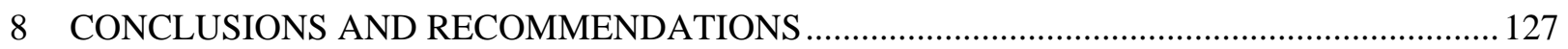

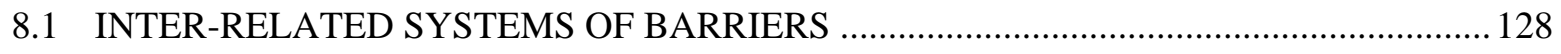

8.2 POTENTIAL SOLUTIONS AND METHODS TO REDUCE BARRIERS...........................129

8.2.1 Potential Solutions to Cost-Effectiveness Barriers............................................... 130

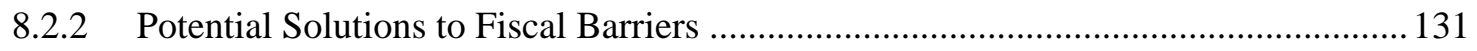

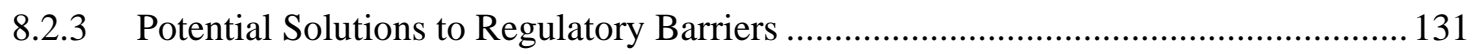

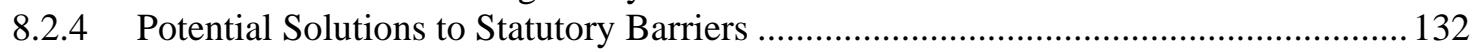

8.2.5 Policy Options to Address Intellectual Property Issues ........................................... 132

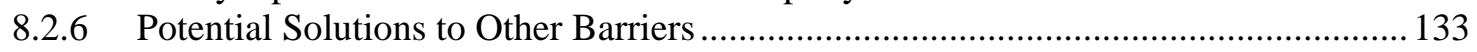

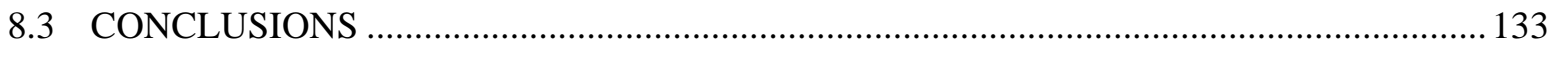

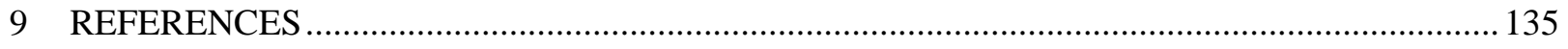

APPENDIX A - LIST OF EXPERTS INTERVIEWED ................................................................. A-1

APPENDIX B - FISCAL, REGULATORY, AND STATUTORY IMPEDIMENTS TO

CLEAN ENERGY TECHNOLOGIES ........................................................................................... 


\section{BOXES}

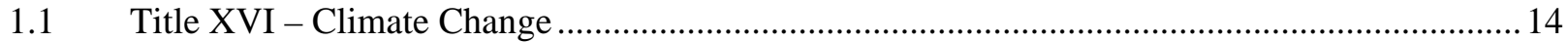

5.1 Hybrid solar lighting: The challenge of assembling an IP portfolio .......................................... 72

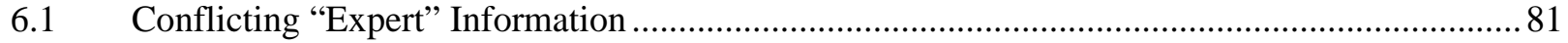

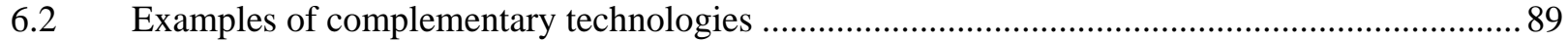

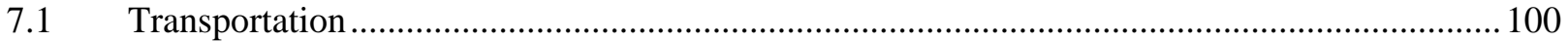

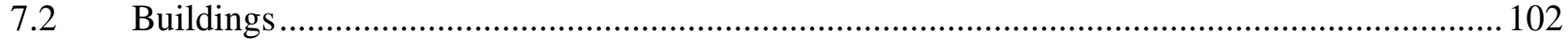

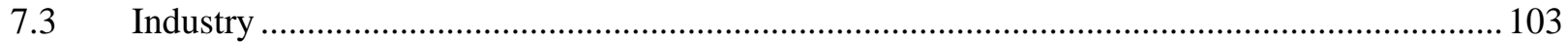

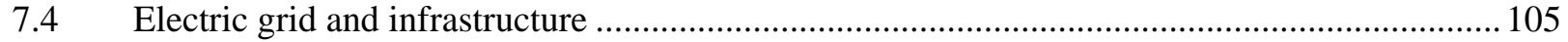

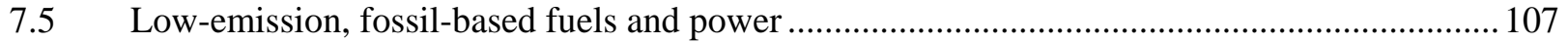

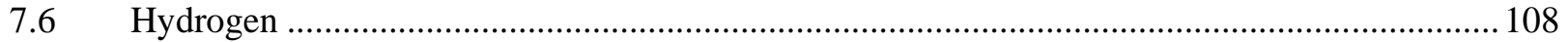

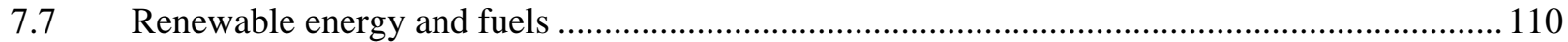

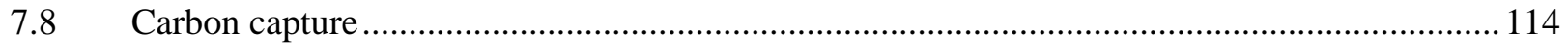

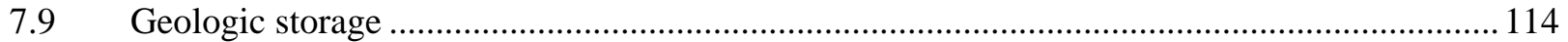

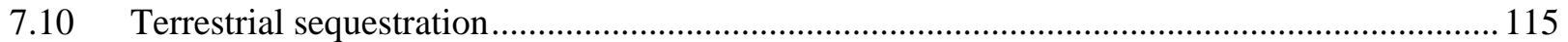

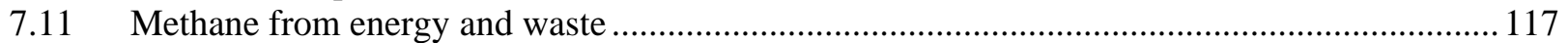

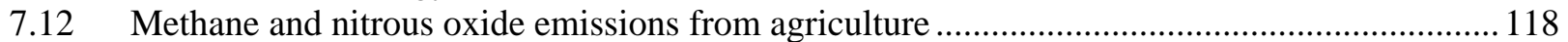

7.13 Emissions of high global-warming potential gases................................................................ 119

7.14 Nitrous oxide emissions from combustion and industrial sources ......................................... 121

\section{FIGURES}

ES.1 Typology of barriers to the deployment of GHG-reducing technologies ...................................

ES.2 Number of experts citing each type of barrier .....................................................................

ES.3 Critical and important barriers by CCTP goal area.................................................................

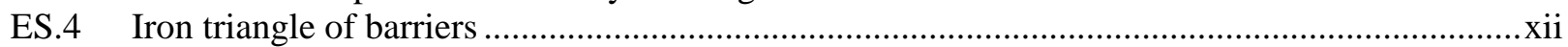

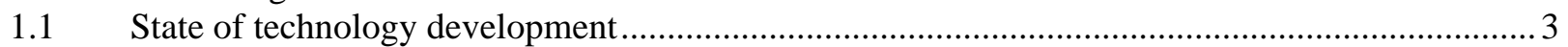

$1.2 \quad$ U.S. petroleum production and consumption 1970-2030 …...................................................5

1.3 The Building America pathway to net zero energy homes ................................................... 5

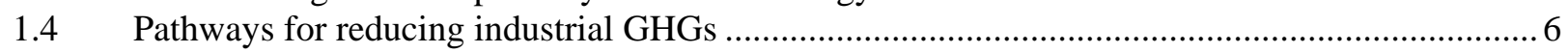

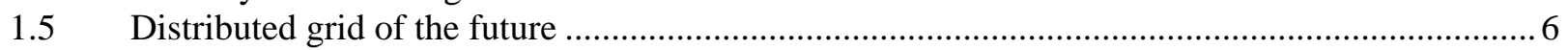

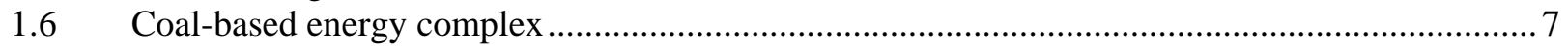

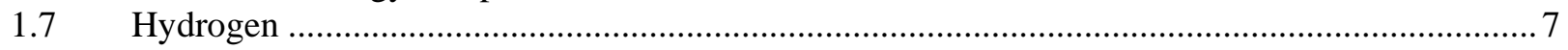

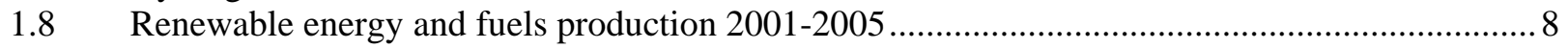

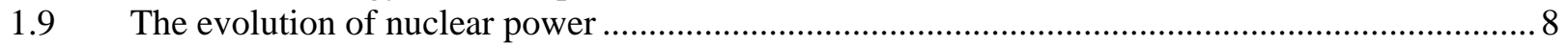

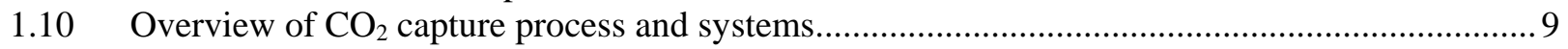

1.11 Graphical representation of geologic storage...................................................................... 9

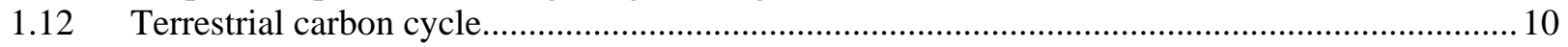

1.13 Components of non-CO $\mathrm{CO}_{2}$ U.S. GHG emissions from agriculture, 2000 ...................................11

1.14 High-GWP gas emissions in the U.S. by source ................................................................... 11

1.15 U.S. $\mathrm{N}_{2} \mathrm{O}$ emissions from combustion and industrial sources, 2005 ......................................12

1.16 Cumulative emission reduction contributions between 2000 and 2100

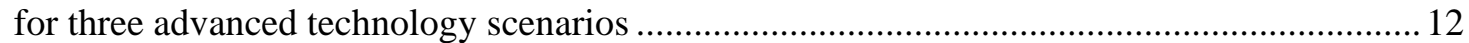

2.1 The path from basic research to market saturation ................................................................... 18

2.2 The supply push and demand pull of technology deployment.................................................. 19

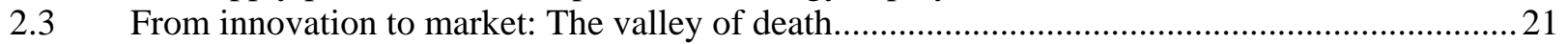

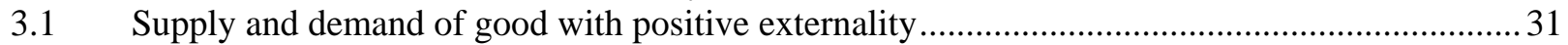

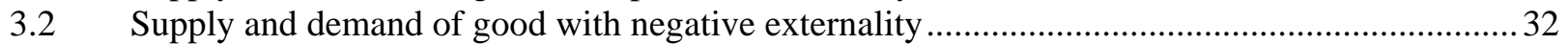

3.3 Mountaintop removal coal mining project in West Virginia .................................................... 32 


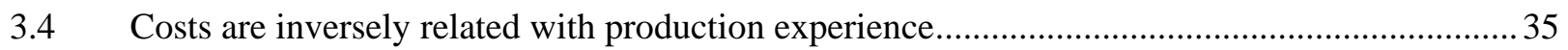

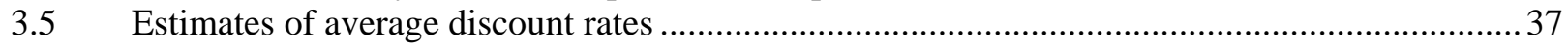

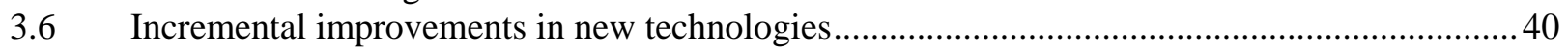

4.1 Projected cost of new generation and energy efficiency improvement ...................................5 51

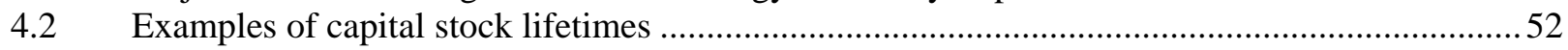

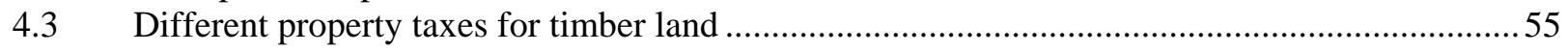

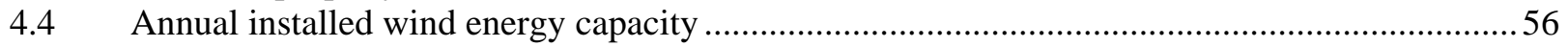

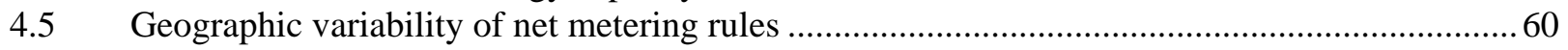

4.6 Low-density zoning promotes travel related $\mathrm{CO}_{2}$ Emissions.................................................61

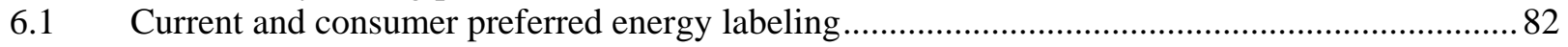

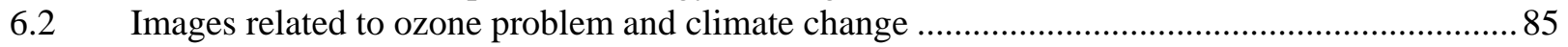

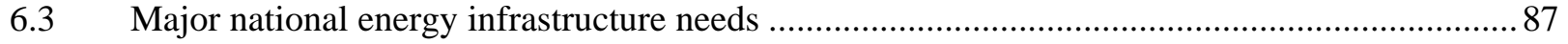

6.4 Multiple stakeholders and decision-makers in the building sector ........................................... 92

$7.1 \quad$ Number of experts citing each type of barrier ......................................................................... 98

7.2 Critical and important barriers by CTP goal area ............................................................... 122

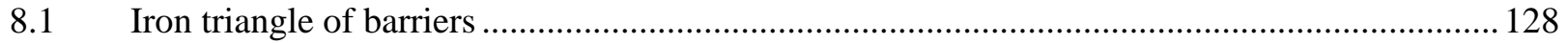

\section{TABLES}

1.1 Change in U.S. methane emissions from energy and waste .................................................10

1.2 Estimated timing of advanced technology market penetrations ................................................ 13

2.1 Typology of barriers to the commercialization and deployment of

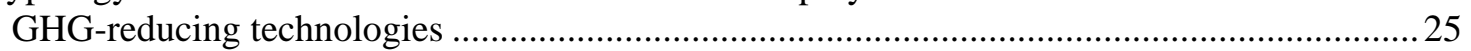

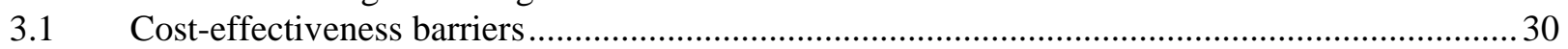

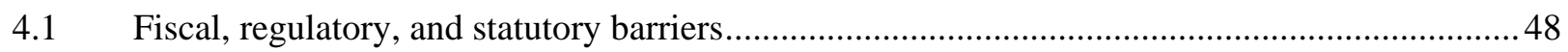

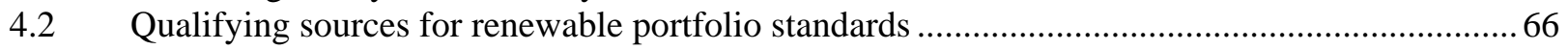

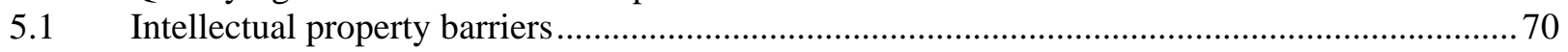

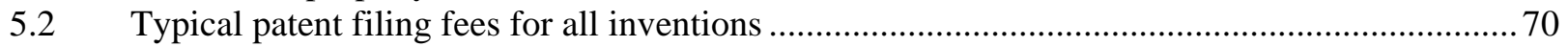

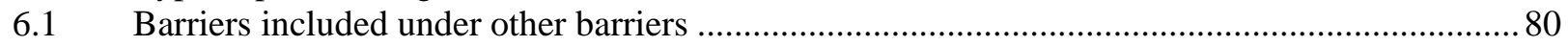

7.1 Major barriers inhibiting deployment of GHG-reducing technologies ................................... 124

7.2 Major barriers inhibiting deployment by CCTP goal area..................................................... 126 


\section{ACKNOWLEDGMENTS}

This report was sponsored by the U.S. Climate Change Technology Program (CCTP). We wish to acknowledge Dr. Robert Marlay, Director of DOE's Office of Science and Technology Policy and Deputy Director of CCTP, who saw the value in funding this study and who contributed to its design and execution. Many other colleagues contributed to aspects of this study, and their insights are greatly appreciated:

- Graham Pugh, Lindsay Roland, Russ Conklin, Steve Eule, and David Berg (DOE)

- $\quad$ Burt Koske (INL)

- Doug Arent (NREL)

- Matt Antes and Joan Pellegrino (Energetics Inc.)

This report would not have been possible without the willing involvement of the experts who were interviewed and whose ideas we strove to capture and summarize in this document. Their names and affiliations are provided in Appendix A. In addition, Inja Paik (DOE/Office of Science and Technology Policy), Dave Bjornstad (Oak Ridge National Laboratory), and Joan Pellegrino (Energetics Inc.), provided valuable and detailed reviews of the report.

Finally, we wish to thank Charlotte Franchuk for assistance with the report's references and formatting. Her attention to the details of manuscript production was invaluable. 



\section{EXECUTIVE SUMMARY}

The United States shares with many other countries the objective of stabilizing greenhouse gas (GHG) concentrations in the Earth's atmosphere at a level that would prevent dangerous interference with the climate system. Many believe that accelerating the pace of technology improvement and deployment could significantly reduce the cost of achieving this goal. The critical role of new technologies is underscored by the fact that most anthropogenic greenhouse gases emitted over the next century will come from equipment and infrastructure built in the future. As a result, new technologies and energy sources have the potential to transform the nation's energy system while meeting climate change as well as energy security and other important goals.

Given the need for large-scale GHG emission reductions, the challenge is to move toward actions that go beyond technology R\&D to strategies that target the rapid and large-scale absorption of low-carbon technologies into the economy. Most technological innovations do not survive the transition from invention to marketplace success. While they may be technically feasible, various obstacles prevent them from gaining market share. In addition, best practices representing already proven cost-effective approaches to GHG mitigation are significantly underutilized. The longevity of much of the energy infrastructure - from power plants to the building stock - prolongs the operation of obsolete technologies, and other impediments cause suboptimal choices to be made when technologies do finally turn over. The result is large-scale "carbon lock-in.”

Since carbon dioxide and other greenhouse gases originate from essentially every sector of the economy, GHG-reducing technologies are broad and diverse. In some cases, what sets them apart is the "public benefits" nature of the harmful emissions they are able to avoid. In the absence of a market for GHG emission reductions, there is limited motivation to invest in climate-friendly technologies and their usage generally falls short of the socially optimal level. GHG-reducing technologies also face many of the same deployment challenges as other emerging technologies. Because of the societal value place on the rapid market up-take of these technologies, we need to identify the obstacles preventing their deployment. This requires understanding the technology deployment process in general, and illuminating specific impediments faced by GHG-reducing technologies in particular.

\section{RESEARCH GOAL AND APPROACH}

The principal goal of this report is to identify and describe the barriers impeding the commercialization and deployment of climate change mitigation technologies. The impetus for this investigation lies in the critical role of advanced technologies in addressing the climate challenge and the increasing clarity that efforts are needed to accelerate their rapid adoption.

Developed in parallel with the National Strategy for the Commercialization and Deployment of GHGreducing Technologies (DOE, 2007), this report responds specifically to Title XVI, Section 1610(g) of the Energy Policy Act of 2005 (Public Law 109-58), which calls on the Administration to prepare a report describing barriers to GHG intensity reducing technologies considering "in the aggregate -

(A) the cost-effectiveness of the technology;

(B) fiscal and regulatory barriers;

(C) statutory and other barriers; and

(D) intellectual property issues.”

To identify deployment barriers, it was first necessary to circumscribe the GHG-reducing technologies suitable for deployment. The primary source for this inventory of climate change mitigation technologies is the U.S. Climate Change Technology Program Strategic Plan (CCTP, 2006), published in September 
2006, which focuses on advanced technology research and development needs for mitigating GHG emissions. The Strategic Plan describes 15 technology sectors contributing to four CCTP goals: reducing emissions from energy end use and infrastructure, reducing emissions from energy supply, capturing and sequestering carbon dioxide, and reducing emissions of non- $\mathrm{CO}_{2}$ GHGs.

The wide range of technologies and markets covered by the 15 sectors necessitated a multifaceted research approach. Our assessment of barriers to low-carbon technologies began with a review of the literature, which is plentiful and diverse. The review spanned the published research on:

- Commercialization and technology transfer;

- Barriers to the deployment of new technologies;

- Market penetration of climate change mitigation technologies; and

- Intellectual property and law.

The literature review was followed by interviews with 27 experts from government, national laboratories, industry, universities, and consulting firms. These interviews provided a more current overview of market and technology conditions and associated barriers, along with an ability to probe more deeply into the nature of market imperfections and to uncover illustrative deployment failures and successes. In addition, input from the multi-agency CCTP Working Group provided assistance with the cross-walk between deployment barriers and technology sectors.

In order to follow the requirements of the legislation, we retained the barrier categories listed in the Act, separating (B) and (C) into two categories each (see Fig. ES.1 for the typology). Further, we describe 20 types of deployment barriers and more than 50 detailed barriers (not shown in the figure) that are more specific in their scope. For example, under the heading of cost effectiveness, the deployment barrier "high costs" is divided into two detailed barriers: high up-front costs and the high cost of financing. Similarly, "market risks" are divided into four detailed barriers: low demand typical of emerging technologies, uncertain cost of production, the possibility of new competing products, and liability risks.

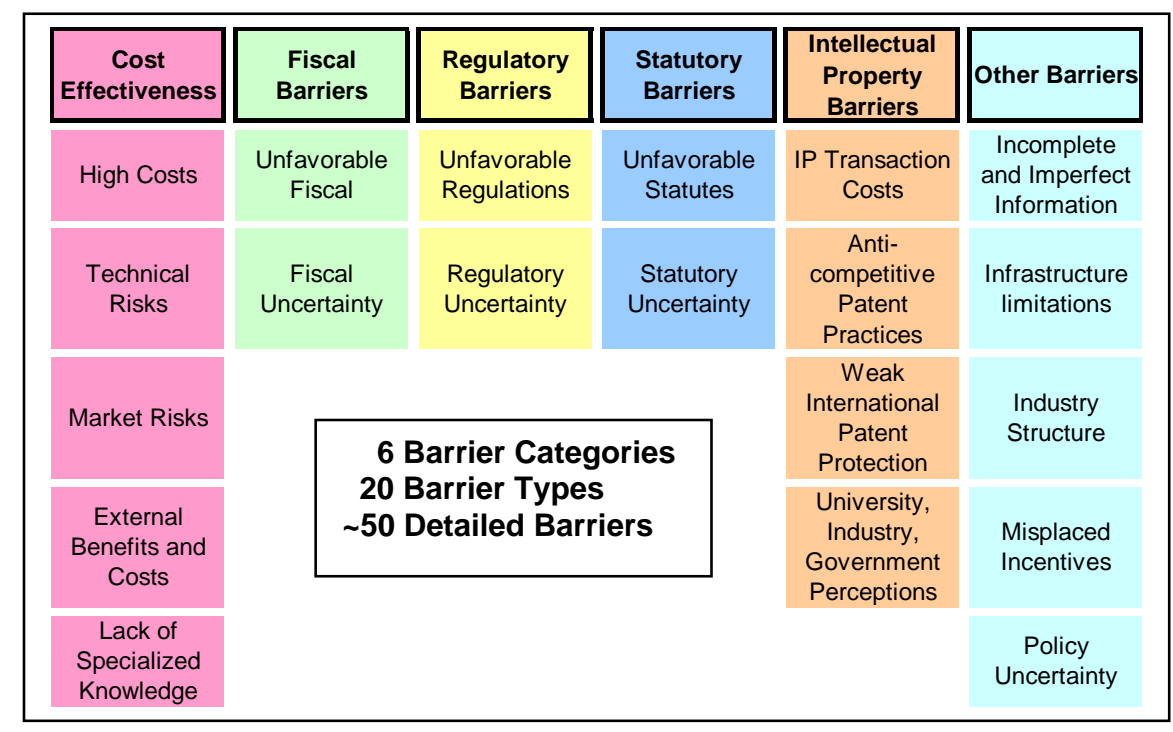

Fig. ES.1. Typology of barriers to the deployment of GHG-reducing technologies 


\section{FINDINGS}

One way to assess the relative impact of these impediments is to consider how many experts mentioned barriers of a particular type during the interview process. The interview protocol involved listing the six categories of barriers and asking the experts: "Do any of them impede the commercialization and deployment of technologies in your area of expertise?” Affirmative statements were followed with questions to elucidate greater detail on the particular barrier and how it is seen by the expert to impede the technology's success. The results of this interview procedure are shown in Fig. ES.2. Many experts emphasized the role of cost-effectiveness,

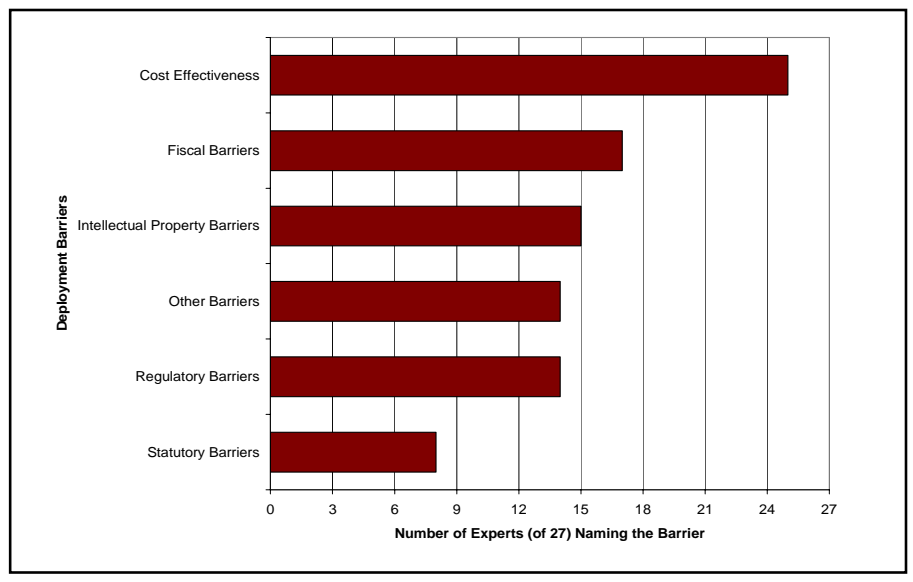

Fig. ES.2. Number of experts citing each barrier category particularly problems associated with high costs and the external benefits of GHG reduction.

Another way to assess the importance of each barrier is to examine the scope of its impacts - ranging from narrow and targeted (e.g., impacting only a specific market application) to economy-wide and broad (e.g., impacting the cost of all fossil fuels). A cross-walk between the 20 deployment barriers and the 15 technology sectors is shown in Fig. ES.3.

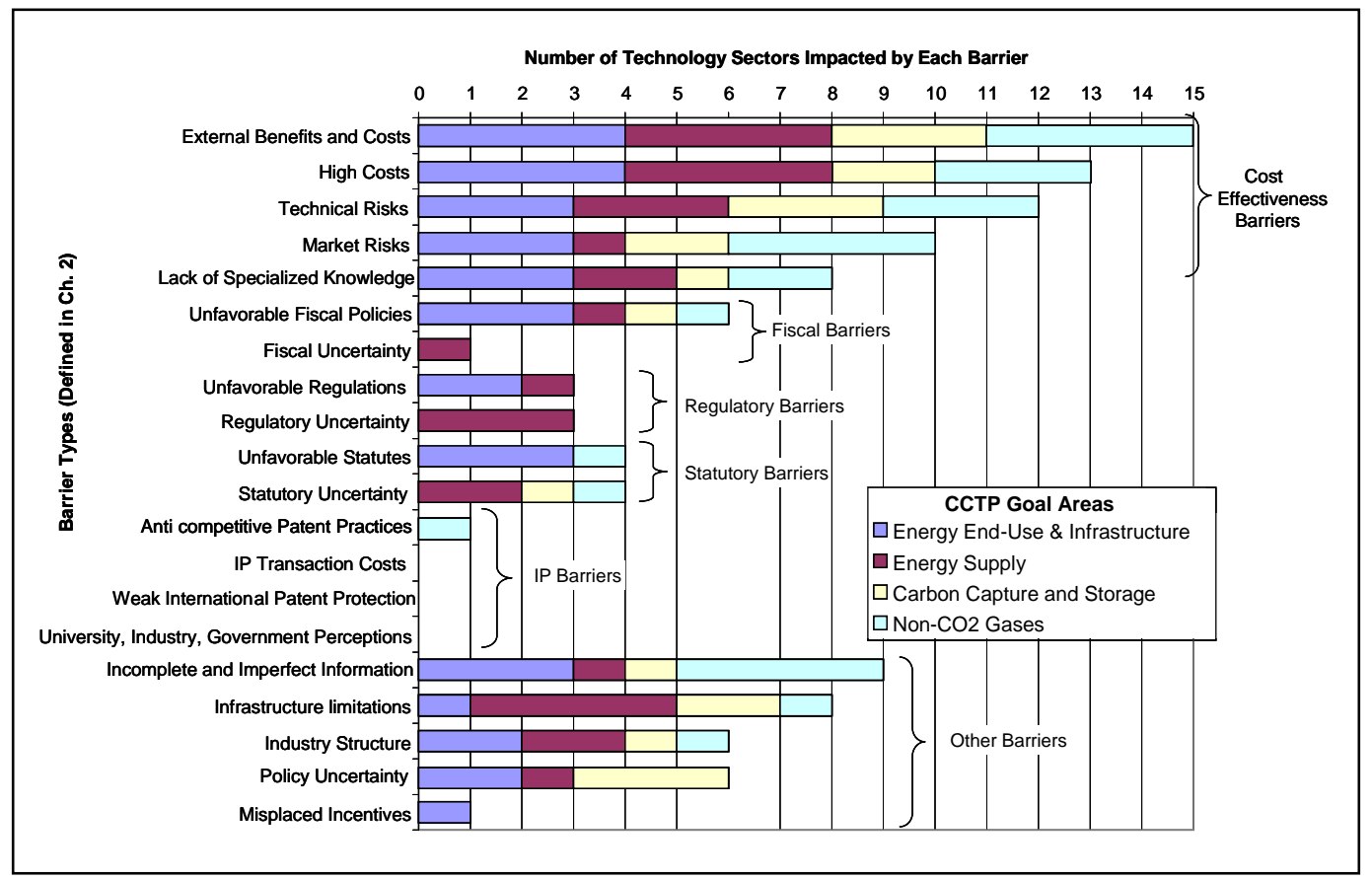

Fig. ES.3. Critical and important barriers by CCTP goal area Source: CCTP, 2007

On the one hand, many of the barriers are judged to be critical impediments to deployment in only a narrow range of technology sectors. On the other hand, ten barriers are found to have particularly broad 
impacts, affecting five or more of the 15 technology sectors and spanning three or four of the CCTP goal areas. The most notable among these are the existence of external benefits and costs and the high costs associated with the production, purchase and use of low-carbon technologies. The principal external benefits are the GHG emission reductions (e.g., from substitutes for high GWP gases and carbon sequestration) that the owners of the technologies are unable to appropriate. The principal external costs are the unpriced GHG emissions from fossil fuel consumption, which make it difficult for higher priced, GHG-reducing technologies such as wind energy and power generated from recycled heat to compete. High costs refer not only to intrinsic features of a technology such as extra components or unusually high levels of precision manufacturing that raise the costs required to produce or use it, but also to price penalties deriving from related barriers such as market and technical risks that raise the cost of financing.

Technical and market risks are also critical deterrents to deployment in many technology sectors. Most novel technologies are handicapped by uncertain performance that can forestall adoption and use. Market risks hinder the innovation process generally and pervade the highly competitive electric and liquid fuels markets where numerous alternatives are being promoted.

Also widespread in their applicability are incomplete and imperfect information, lack of specialized knowledge, and infrastructure limitations, which are common impediments to deployment. The shortage of technology performance information coupled with decision-making complexities and bundled benefits present key deployment barriers for nearly half of the CCTP sectors. Similarly, inadequate workforce competence, compounded by the high cost of developing specialized knowledge throughout the supply chain, poses barriers to the deployment of many CCTP technology sectors. Supply chain issues and other infrastructure limitations are also characteristic of new technologies, which often require new methods of delivering parts, services, and supplies. The underdeveloped infrastructure for delivering alternative transportation fuels to users is a case in point.

The uniqueness of the barriers faced by different types of technologies highlights the fact that specific deployment policies and programs may be required. At the same time, economy-wide actions may be more efficient in addressing common barriers in a broad, systematic fashion in ways that could significantly accelerate and expand the uptake of GHG-reducing technologies. This tension between highly specific versus general policy interventions requires careful consideration.

Barriers hinder technology commercialization and deployment in different ways: by locking in incumbent technologies, by escalating the business risks of innovation and by increasing transaction costs associated with change. These powerful and restraining influences reinforce one another as shown in Fig. ES.4.

- Incumbent technology support systems: systems of positive feedback between government, financial institutions, suppliers, and existing infrastructure support and sustain status-quo technologies even in the face of superior substitutes.

- Business risks of innovation: inventions and innovations face an array of obstacles in the marketplace, and since many GHG-reducing technologies are relatively new, these obstacles can strongly impact them.

- High transaction costs: costs associated with gathering and processing information, developing patent portfolios, obtaining permits, and designing and enforcing contracts can all be prohibitive during the early stages of a technology's deployment.

Further reinforcement of incumbent technologies is provided by the policy environment that tends to support the status quo. GHG-reducing technologies are often subjected to unfavorable treatment by fiscal, regulatory, and statutory policies, and they are impacted by policy uncertainty that causes marketplace inefficiencies and a reluctance to innovate. 


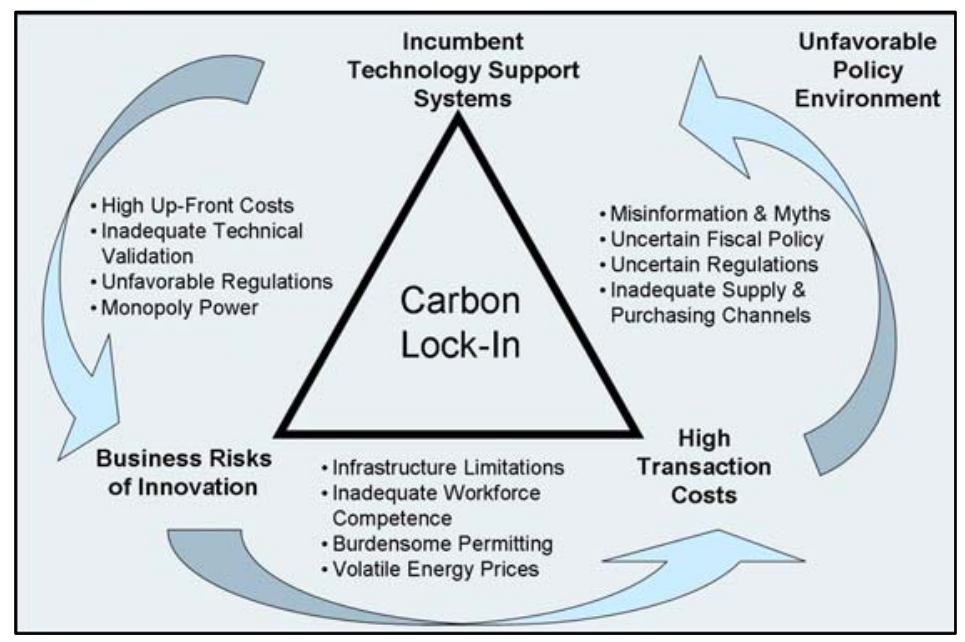

Fig. ES.4. Iron triangle of barriers

Tackling these systematic forces requires different forms of intervention. For example, overcoming lockin of incumbent technologies suggests the need to decouple government organizations from the systems that support mainstream technologies, while overcoming business risks of innovation requires reduction of costs and financing hurdles. Some of the options available to address the numerous barriers and forces that impede the progress of GHG-reducing technologies are described in the summary chapter.

\section{CONCLUSIONS}

Tackling climate change promises to be one of the most significant technological challenges of the twenty-first century. It will require scientific and engineering genius to produce entirely new energy systems that avoid emitting greenhouse gases while simultaneously powering global economic growth. Success will also necessitate institutional, economic, social and policy innovations to foster the widespread and rapid deployment of technology solutions. A thorough understanding of the impediments currently hampering GHG-reducing technologies is a necessary precondition for the effective implementation of technology and policy innovations.

Barriers to the deployment of climate mitigation technologies are wide-ranging. First and foremost is the economy-wide market failure caused by the absence of a price on GHG emissions. In combination with other cost-effectiveness issues, these are the most critical and pervasive deployment barriers. However, additional obstacles play important roles as well, including financial, technical, and market risks, infrastructures and supply chain gaps, misplaced incentives, and imperfect information.

These barriers impede progress across the complete spectrum of GHG-reducing technologies and operate at every stage of the commercialization and deployment process. Some obstacles are broad in scope, others are more targeted; some appear amenable to policy solutions, while others may not be. Indeed, some barriers are the result of existing regulations, statutes, and fiscal policies that unfavorably treat climate change mitigation technologies. In addition to reforming these existing policies, federal policymakers should consider the traditional policy instruments as well as the novel climate policies being launched in local and state test-beds across the country and in other countries. By designing policies to address the numerous and specific deployment barriers impeding GHG-reducing technologies, the immense economic and technical potential of climate mitigation solutions can be more fully realized. 



\section{1}

The impetus for this investigation lies in the critical role of advanced

technologies in addressing the climate challenge and the increasing clarity that efforts are needed to accelerate their rapid deployment.

\section{Introduction}

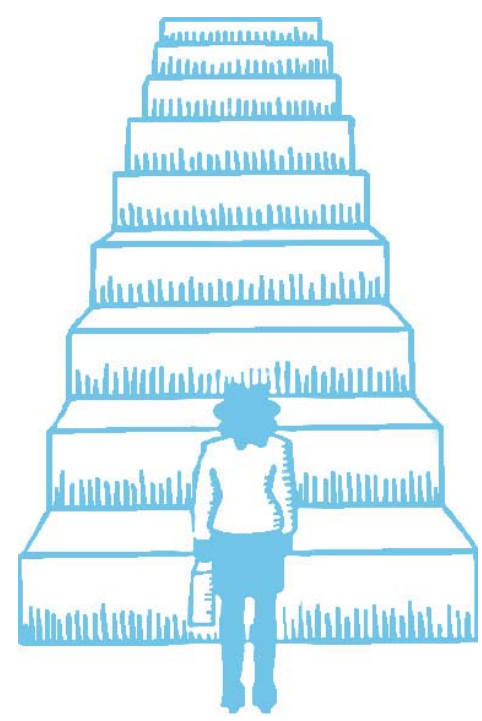

With relatively free trade, highly mobile capital, property rights protections and limited governmentownership of energy industries, the United States boasts a remarkably well functioning energy marketplace. Relative to the developing world, U.S. markets are adept at absorbing new technologies, driven by market forces and individual economic interest.

Introducing new climate-friendly technologies to the marketplace involves "managing a resource that no one owns, that everyone depends on, and that provides a wide range of very different-and often public - benefits to different people in different regions over very long periods” (CBO, 2003 p. 25). Because nobody can be excluded from the climate mitigation benefits of GHG-reducing technologies, there is insufficient motive to invest in these technologies. In the absence of public intervention, investments in climate-friendly technologies fall short of the socially optimal level. 
Many GHG-reducing technologies involve novel and sometimes radical departures from prior practice. As such, they must overcome a wide range of technical and market risks to gain widespread commercial use. Risks must be minimized because success requires displacing the market shares of established and mature incumbent technologies with demonstrated performance records. Barriers to innovation have been found to impede progress across the range of GHG-reducing technologies and operate at every stage of the commercialization and deployment process. The impetus for this investigation lies in the critical role of advanced technologies in addressing the climate challenge and the increasing clarity that efforts are needed to accelerate their rapid deployment.

\subsection{THE ADVANCED TECHNOLOGY IMPERATIVE}

In 1992 the United States signed the United Nations Framework Convention on Climate Change (FCCC), recognizing the need "to achieve stabilization of greenhouse gas concentrations in the atmosphere at a low enough level to prevent dangerous anthropogenic interference with the climate system.”" Since signing the FCCC accord, U.S. greenhouse gas concentrations have continued to increase along with the scientific evidence that climate change presents a serious global risk demanding an urgent response.

Most anthropogenic greenhouse gases emitted over the next century will come from equipment and infrastructure built in the future to meet the growing demand for energy. Global energy demand is forecast to grow from 421 quads in 2003 to 722 quads in 2030 (EIA, 2006b, p. 1). As a result, new technologies and fuels such as hydrogen fuel cells, biorefining, clean coal, a next generation of nuclear power and advanced concepts in building, industry, transportation, and electric energy storage (along with other, not yet thought of technologies) "have the potential to transform our economy in fundamental ways that can address not just climate change, but energy security, air quality, and other pressing needs" (CCTP, 2006). Accelerating the deployment of these GHG-reducing technologies provides a unique opportunity to transform and modernize the nation's energy system, consistent with meeting carbon stabilization goals.

Many believe that it is not possible to stabilize greenhouse gas concentrations without new and improved technologies (Hoffert et al., 2002; Grubb et al., 2006; Montgomery, 2006). Further, if many technologies are successfully developed in parallel with early action to promote deployment, the cost of stabilization could be significantly reduced. Assumptions about the availability of future technologies is a strong driver of stabilization costs in most climate change models (Nakicenovic and Riahi, 2003; Weyant, 2004; Richels, 2007). Edmonds et al. (2004) studied stabilization at $550 \mathrm{ppmv} \mathrm{CO}_{2}$ and showed that the accelerated pace of technology improvements and deployment could produce a reduction in costs of a factor of 2.5 in 2100 relative to a baseline incorporating the "business as usual" rate of technical change.

Given the goal of large-scale emission reductions, the challenge is to move toward actions that go beyond technology R\&D to global technology deployment. Pacala and Socolow (2004) clarify the magnitude of the deployment challenge by breaking the emissions problem into "wedges" that can each be addressed by a current technology or practice. This approach makes it clear that even when using current GHG reducing technologies and practices, incentives or strong regulatory intervention are required to build to the level of prevalence necessary to reduce emissions by any meaningful amount. Technological advances could reduce these deployment costs significantly by providing more cost-competitive alternatives.

It is both possible and highly desirable to complement technology R\&D investment with programs and policies to support the deployment of new technologies that emerge from R\&D efforts. These efforts need to be grounded in an understanding of barriers to deployment and nested within institutional infrastructures that are designed and supported for that purpose.

\footnotetext{
${ }^{1}$ United Nations Framework Convention on Climate Change art. 2, May 9, 1992, S. Treaty Doc. No. 102-38, 1771 U.N.T.S. 107.
} 


\subsection{THE RANGE AND SCOPE OF GHG-REDUCING TECHNOLOGIES}

Since carbon dioxide and other greenhouse gases originate from essentially every sector of the economy, GHG-reducing technologies are both numerous and diverse. ${ }^{2}$ In some cases, what sets them apart is the public good ${ }^{3}$ nature of the GHG emissions they could avoid. Indeed, some alternatives to high global warming potential (GWP) gases do not have any market benefit at this time, thus their only use is reducing GHG emissions.

Additionally, GHG-reducing technologies are in various stages of development and deployment, ranging from today's off-the-shelf best practices to technically feasible next generation technologies. Thus, on the one hand, deployment activities are needed to address the significant underutilization of existing best practices. On the other hand, enabling environments are needed to accelerate the translation of research into deployable products and to enhance their ultimate market penetration. These challenges are illustrated in Fig. 1.1, using examples from different areas of technology.

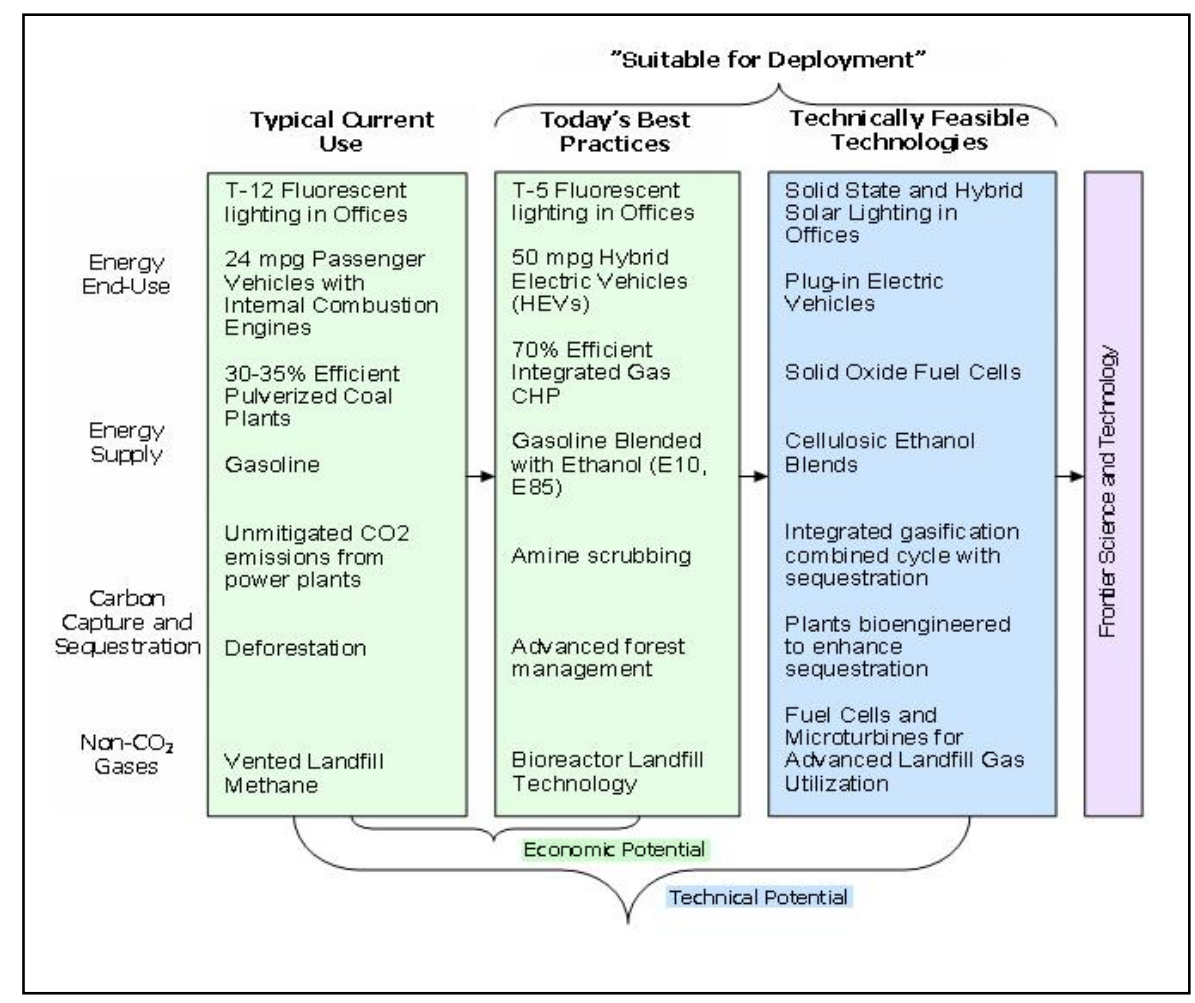

Fig. 1.1. State of technology development (with illustrative technologies)

\footnotetext{
${ }^{2}$ GHG-intensity reducing technologies refer to technologies that decrease GHG emissions per unit of economic output. (Intensity means emissions per unit of economic output.) Title XVI of EPAct 2005 calls for an examination of GHG intensity-reducing technologies. However, due to the many assumptions and caveats related to considering emissions intensity, this report focuses on technologies that reduce GHG emissions regardless of their positive or negative impact on the overall level of economic activity.

${ }^{3}$ A public good is a good or service that has two principal characteristics. First, one person's consumption of it does not reduce the amount of it available for other people to consume. This characteristic is called "inexhaustibility." Second, once such a good is provided, it is difficult to exclude other people from consuming it, a characteristic called "nonexcludability." Because public goods are unpriced, markets tend to under produce them.
} 
As this report focuses on barriers to deployment of GHG-reducing technologies, it limits its scope to technologies that have been found to be "suitable for deployment" based on technical maturity.

Technologies that are still in basic R\&D stages are excluded from this assessment - even though their use may eventually offer GHG reductions.

Wedged between typical current technologies and the products of "frontier science and technology," are two stages of technologies "suitable for deployment." These two stages and their "book-ends" represent a continuum of technology evolution:

- Typical current use refers to the technologies used today. These include technology choices made years ago under different price and policy environments with more limited technology options, as well as typical choices being made today under market conditions and policies that may or may not favor current best practices.

- Today's best practices represent the most advanced climate mitigation technologies that are costeffective and available today.

- Technically feasible technologies are defined as the best-performing technologies being prototyped and demonstrated that are technically feasible but have not yet been proven and indeed may not yet be cost-competitive.

- Products of frontier science and technology have not yet achieved the technical or economic performance necessary to attract funding for demonstration, let alone full-scale implementation.

All of these technology-use states tend to move in time toward higher levels of technology performance. A continuing issue in most countries is the appropriate balance of effort between moving the technology frontier farther out, shifting the current best practices closer to the technology frontier, and moving the typical technology use closer to current best practices (see Fig. 1.1).

When evaluating the potential for additional GHG-reducing technologies to be deployed in future years, two types of estimates can be derived from these technology states:

- Technical potential refers to the GHG reduction that could be achieved as a result of the complete penetration of all applications that are technically feasible.

- Economic potential is defined as that portion of the technical potential that is judged to be costeffective.

As the technology frontier expands, so does the technical potential for GHG reduction. But only after these technologies become cost-competitive do they have the potential to become best practices with the economic potential for widespread GHG mitigation. The ability of this potential to be translated into real mitigation, however, also depends on many factors including the absence of overriding barriers to deployment.

The U.S. Climate Change Technology Program Strategic Plan (CCTP, 2006) separates these technologies into four categories by goal: reducing emissions from energy end use and infrastructure, reducing emissions from energy supply, capturing and sequestering carbon dioxide, and reducing emissions of non$\mathrm{CO}_{2}$ GHGs. Below, we briefly discuss each technology goal area, providing examples of technologies that are "suitable for deployment." 


\subsubsection{Energy End-Use and Infrastructure}

Reducing emissions from energy utilization involves technologies that are more efficient, those that are produced through less energy-intensive processes, and those that act as a precursor to enable the deployment of less GHG emitting technologies (e.g., energy storage devices, sensors, and control technologies). Infrastructure technologies for GHG reduction reduce energy waste in the distribution of energy or goods.

Transportation. Transportation of people and goods accounts for a significant share of $\mathrm{CO}_{2}$ emissions, 32 percent in the U.S. and 20 percent globally (IEA, 2006; EIA, 2006a). Growth in this sector is expected to continue, both in the developed and developing world (EIA, 2006b). More efficient transportation technologies can reduce fuel consumed and emissions produced by transportation. Broader application of suitable technologies can provide significant reductions; for example, hybrid electric vehicles (HEVs) use a combination of electric and mechanical power to reduce greenhouse gas (GHG) emissions by nearly one-half compared to conventional gasoline

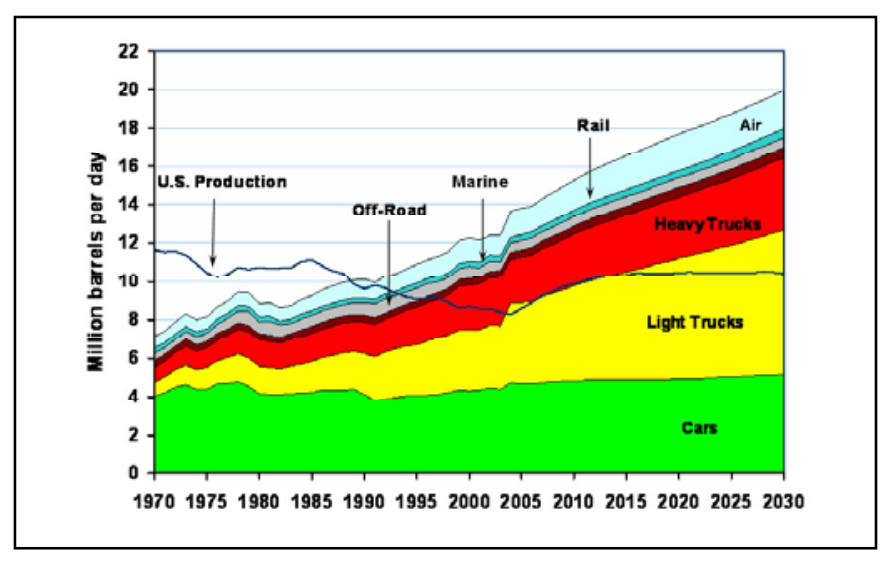
vehicles.

Fig. 1.2. U.S. petroleum production and consumption 1970-2030 Source: Diegel and Davis (2006) and EIA (2006a)

Buildings. The built environment - consisting of residential, commercial, and institutional buildings accounts for about one-third of primary global energy demand and is a major source of energy-related GHG emissions, mainly $\mathrm{CO}_{2}$. In the United States, the energy services required by residential and commercial buildings contribute approximately 38 percent of $\mathrm{CO}_{2}$ emission. EIA expects energy use and $\mathrm{CO}_{2}$ emissions in this sector to continue to expand as GDP grows and demand increases for building services (CCTP, 2006). Advances in technologies for this sector that are common to many building types, such as lighting and HVAC can reduce GHG emissions. This is illustrated by compact fluorescent lamps (CFLs) for homes and T-5 fluorescent systems for offices that are cost-effective today and can use 75 percent less energy than incandescent bulbs (ENERGY STAR $\left.{ }^{\circledR}, 2007\right)$.

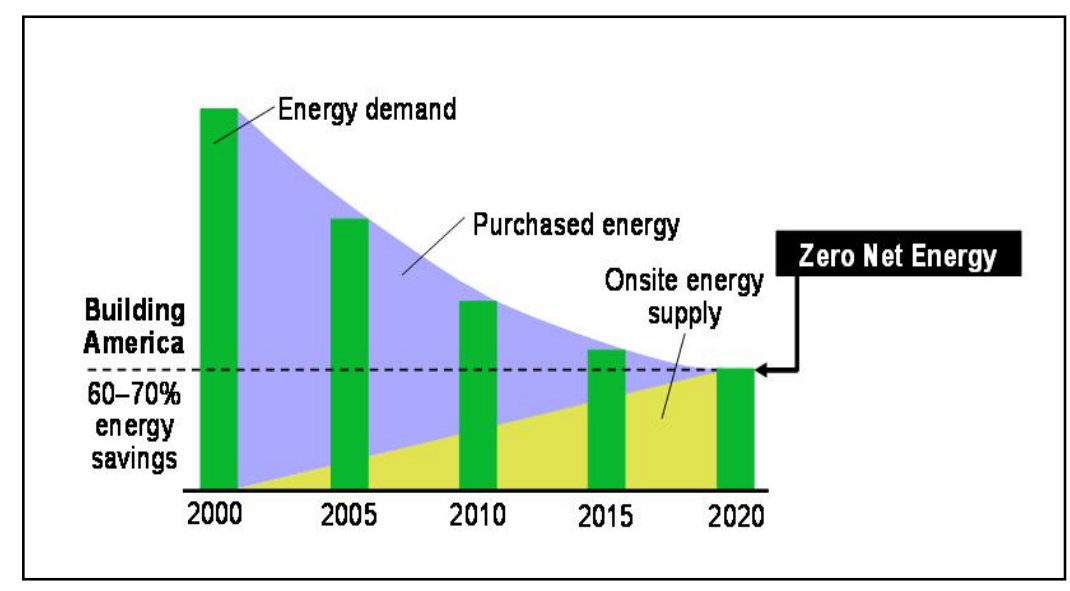

Fig. 1.3. The Building America pathway to net zero energy homes Source: DOE, 2005 
Industry. Heavy industry is generally more energy-intense than light manufacturing, but both parts of this sector combine to be the largest consumer of energy worldwide, accounting for over 50 percent of energy consumed globally (EIA, 2007b). The industrial sector can reduce emissions through technologies that increase the efficiency of process heating, or process and design enhancements that can improve quality, reduce waste, reduce the intensity of material use, and increase in-process material recycling (CCTP, 2006). For example, pressure swing adsorption enables the recovery of nitrogen and other chemicals in polyolefin plants, providing for 100 percent recovery of nitrogen and hydrocarbons and an annual savings of 81.5 billion Btu

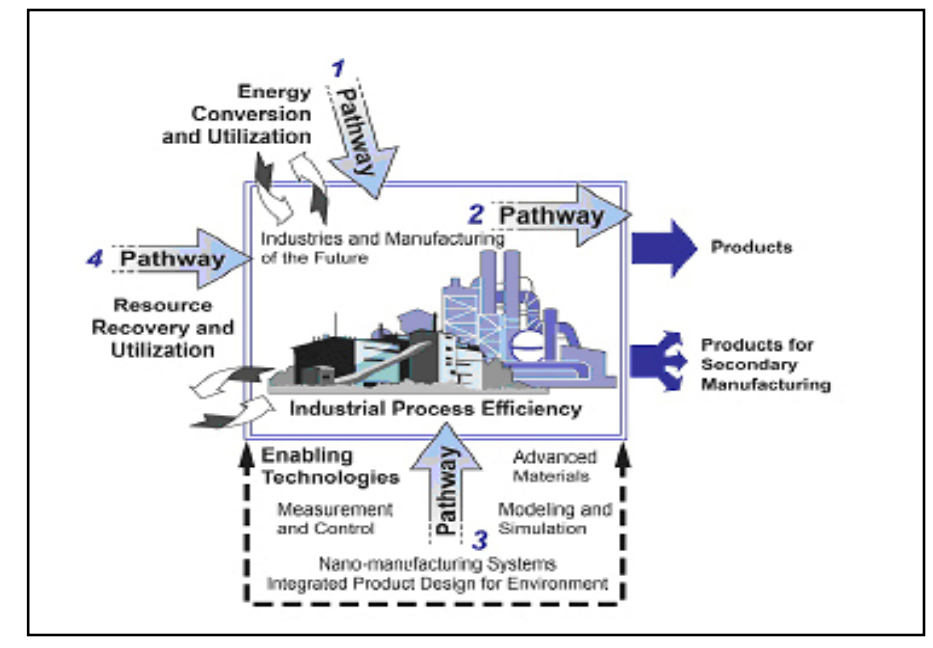

Fig. 1.4. Pathways for reducing industrial GHGs Source: CCTP, 2006 (DOE/EERE, 2007).

Electric grid and infrastructure. In the United States, the demand for electricity is increasing at a rate

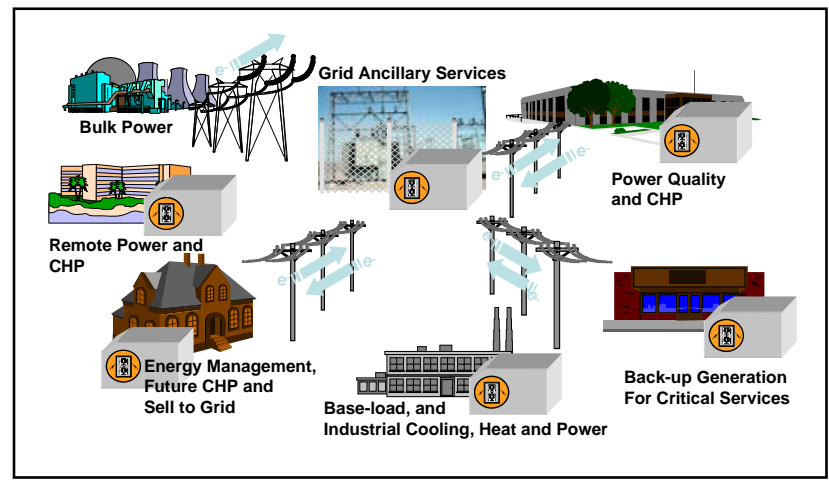

Fig. 1.5. Distributed grid of the future Source: CCTP, 2006 that could eventually out pace the current transmission capacity; electricity demand is projected to increase by 19 percent from 20032012 (EIA, 2005). To accommodate growing demand and greater reliance on regionally concentrated renewable sources, the future electricity transmission infrastructure needs to evolve into an intelligent and flexible system that enables the use of a varied set of baseload, peaking, and intermittent generation technologies. High temperature superconducting (HTS) cables can transmit electricity with half the energy loss of conventional cables, and distributed generation offers the ability to productively use the waste heat from distributed generation (CCTP, 2005).

\subsubsection{Energy Supply}

Reducing GHG emissions of energy supply requires transitioning from high emissions fossil fuels to those with "low or net-zero $\mathrm{CO}_{2}$ emissions." Many options have been proposed for making such a transition including: non-emitting sources for electricity generation such as nuclear fission or renewable technologies, carbon-free sources for hydrogen generation, replacing fossil fuels with bio-based fuels, and developing operational nuclear fusion or space solar power.

Low emission, fossil-based fuels and power. Because fossil fuels are so plentiful and easily converted into usable mechanical energy, they are expected to maintain hold on a large share, about 80 percent, of the energy market (IEA, 2006; EIA, 2007a). Efforts to improve fossil-fuel use have focused on clean and efficient coal technologies, such as gasification and combined-cycle plants, co-production efforts, and high efficiency improvements. A specific example is oxygen-enhanced combustion, which is a type of 
advanced combustion system, can reduce $\mathrm{NO}_{\mathrm{x}}$ emissions and facilitate carbon sequestration (CCTP, 2005).

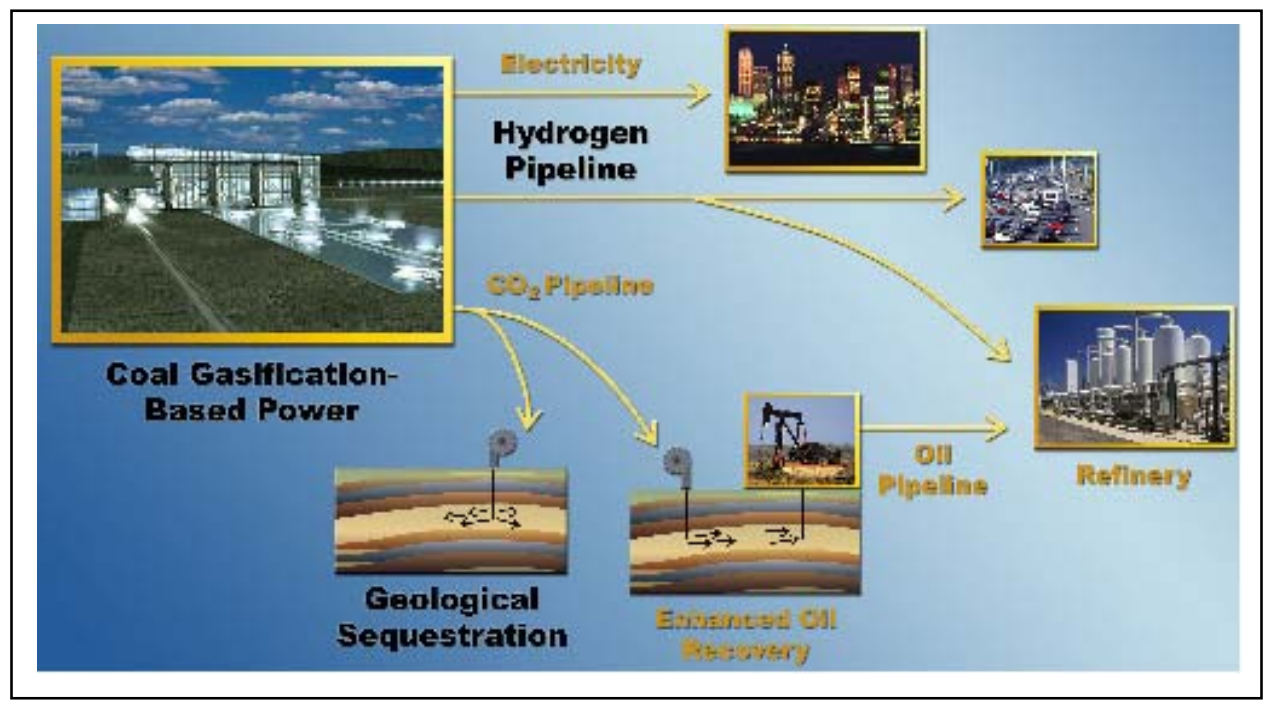

Fig. 1.6. Coal-based energy complex Source: DOE, 2004

Hydrogen. Hydrogen has the potential to be an attractive non-carbon energy carrier for both the transportation sector and stationary applications through the use of fuel cells. Advancing hydrogen to a point where it displaces conventional fuels will depend not only on successfully overcoming technology barriers related to hydrogen production, storage, and fuel cells, but also on developing a substantial hydrogen delivery infrastructure. Today, more than 90 percent of the hydrogen produced in the United States for industrial purposes is derived from steam reforming of natural gas; however, there are other options for future production, such as partial oxidation or thermal reforming (Ogden, 1999, p. 239). Once the hydrogen is produced, advanced technologies can convert it to mechanical energy; for example, proton exchange membrane (PEM) fuel cells are being demonstrated in bus and taxi fleets around the world as well as indoor-operating forklifts (CCTP, 2005).

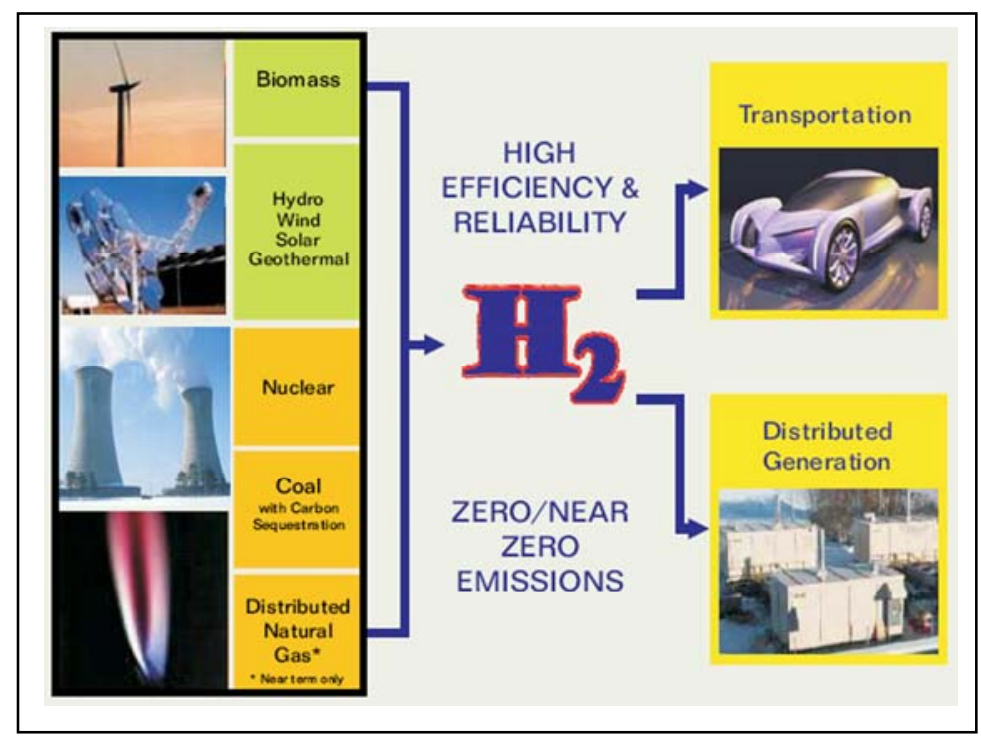

Fig. 1.7. Hydrogen

Source: DOE, 2006b 
Renewable energy and fuels. Considerable flexibility in uses for renewable fuels, thermal energy, and power offers opportunities for combining GHG reductions with other needs in the long term; these technologies can be modular and used in combination with others. Renewable technologies include wind, solar thermal and photovoltaics, geothermal power and heat pumps, small hydroelectric; for a particular example, significant untapped wind resources remain with advanced turbine and blade designs for offshore and lowspeed wind energy. In the area of renewable fuels, ethanol from corn has increased in market share while cellulosic ethanol promises to expand the source base to include woody biomass and newspaper waste.

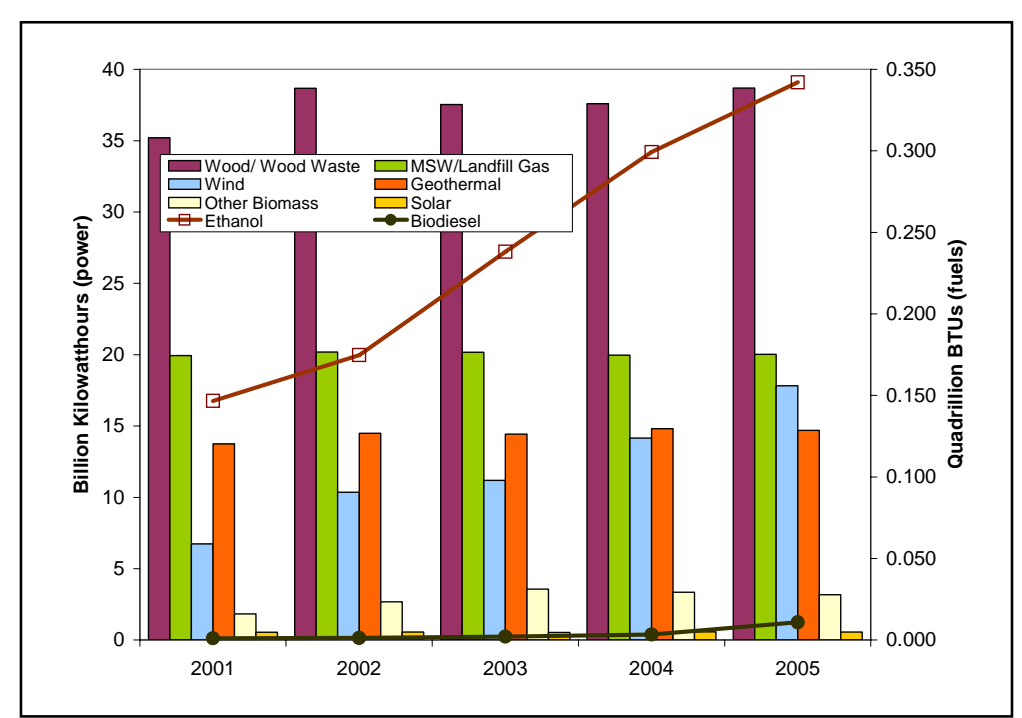

Fig. 1.8. Renewable energy and fuels production 2001-2005 Source: Based on data from EIA, 2007c, Table 4 \& 11

Nuclear fission. Nuclear fission is already a significant source of non-GHG emitting electricity production worldwide; in 2005, 443 operating nuclear fission power plants ${ }^{4}$ produced over one-quarter of the world's electricity. Nearly a quarter of these (103) is operated in the United States and provides about 20 percent of the nation's electricity (EIA, 2007a). Nuclear power plant licenses are being extended to 60 years and several consortia have submitted Early Site Permit applications for new plants using Generation III or III+ technologies to the Nuclear Regulatory Commission (NRC) for review. Examples of Generation III+ technologies include the General Electric (GE) Advanced Boiling Water Reactor (ABWR) and the Westinghouse AP600 and AP1000 plants, which offer shorter construction times and improvements in safety, reliability, operation, and maintenance.

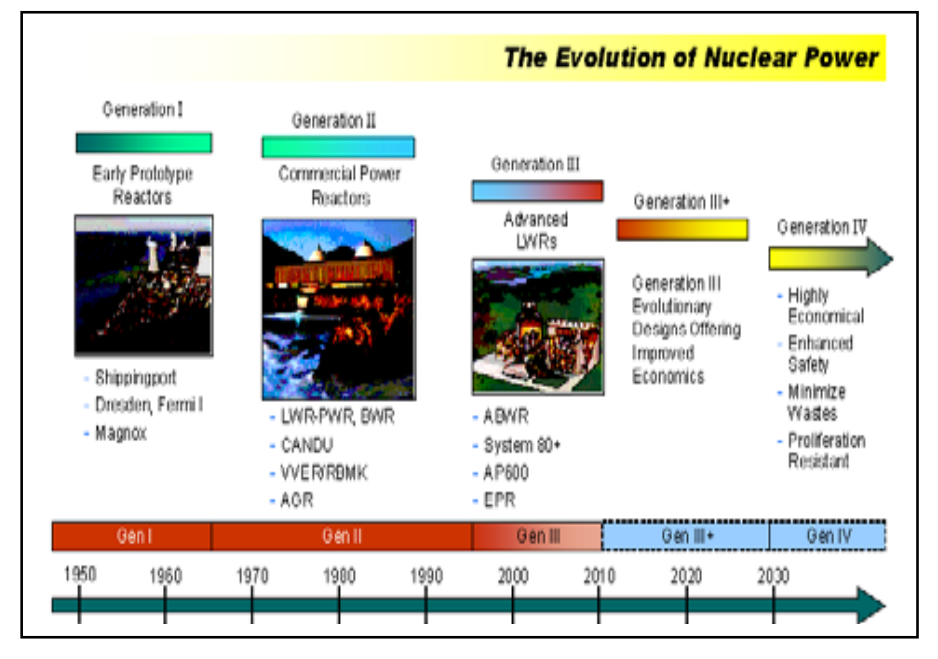

Fig. 1.9. The evolution of nuclear power

Source: U.S. DOE Nuclear Energy Research Advisory Committee (BERAC) and the Generation IV International Forum (GIF), 2002

\footnotetext{
${ }^{4}$ Worldwide, nearly 30 new reactors are under construction - mostly in China and India (IAEA, 2006; WNA, 2006).
} 


\subsubsection{Carbon Capture and Sequestration}

Due to the widespread use of hydrocarbon fuels, capturing the emissions rather than releasing them may be a near-term option. Carbon dioxide emissions could be directed into deep-geologic storage to avoid introducing those emissions into the air. Carbon dioxide might also be removed from the air using terrestrial sinks as when carbon dioxide is sequestered by soils, trees, and oceans.

Carbon capture. Carbon capture could be used at coal-fired power plants to remove carbon from the plant's emissions. Capture from coal gasification is already being demonstrated on a commercial level in the U.S.; a coal gasification (for syngas) plant captures more than 200 million standard cubic feet (scf) per day of carbon dioxide, using pre-combustion capture, in a 96 percent pure stream. ${ }^{5}$ Another suitable technology is post-combustion capture which involves separation of $\mathrm{CO}_{2}$ from flue gases, accomplished by using amine-based chemical absorbents.

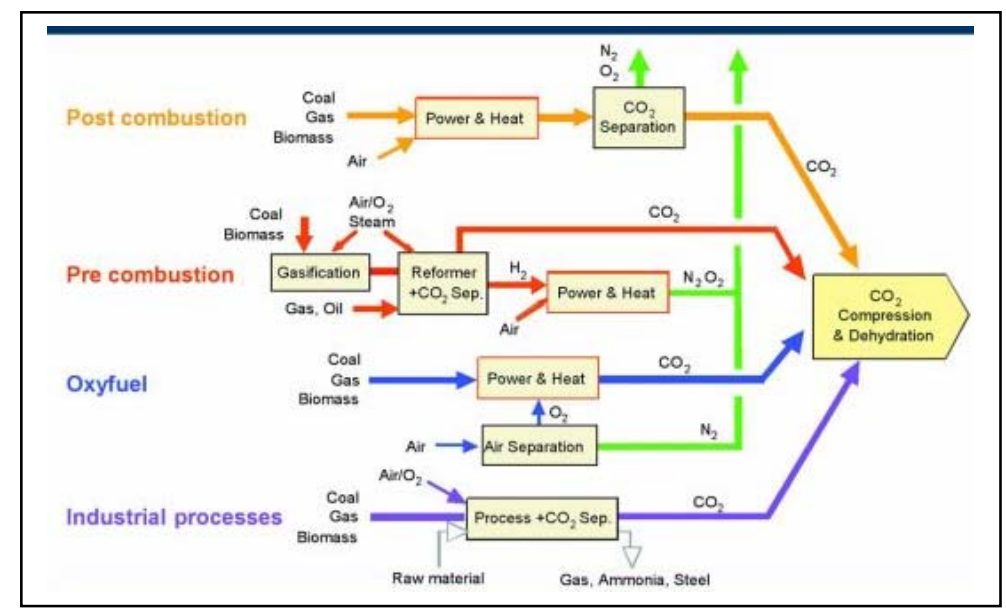

Fig. 1.10. Overview of $\mathrm{CO}_{2}$ capture process and systems Source: IPCC, 2005

Geologic storage. Long-term geologic storage of carbon dioxide is one possible way to avoid GHG emissions even with continued production of GHGs. Geologic storage would include some form of injection into suitable geologic sites, such as saline formations, deep seam coal beds, or depleted oil and gas wells. For example, $\mathrm{CO}_{2}$ injection has been used since 1972 and accounts for 50 percent of enhanced oil recovery (EOR) projects in the United States. ${ }^{6}$

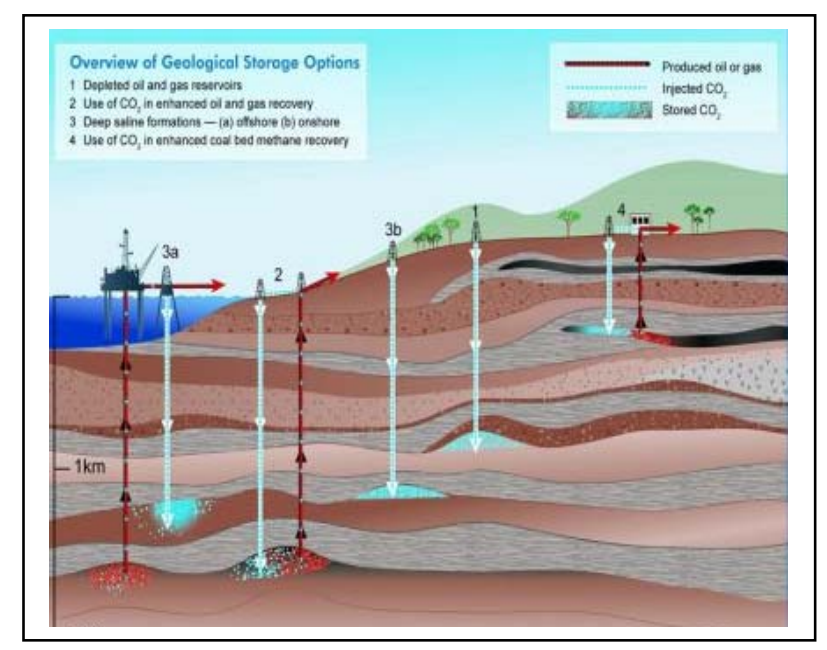

Fig. 1.11. Graphical representation of geologic storage Source: IPCC, 2005

\footnotetext{
${ }^{5}$ Dakota Gasification Company provides data on all products from the coal gasification plant; they state that carbon dioxide production is more than 200 million standard cubic feet per day. The 96 percent number is their reported mole\% in a typical result over more than 400 samples. This data is from an April 2005 update. www.dakotagas.com/Products/index.html

${ }^{6}$ DOE, “Enhanced Oil Recovery/CO $\mathrm{CO}_{2}$ Injection,” http://www.fossil.energy.gov/programs/oilgas/eor/index.html
} 
Terrestrial sequestration. Terrestrial sequestration is the storage of carbon dioxide in vegetation and soils; these forms are already estimated to be storing one-third of anthropogenic carbon emissions (DOE Terrestrial Sequestration Research ${ }^{7}$ ). U.S. potential terrestrial sequestration estimates from cropland, grazing land, and forest lands combined range from nearly $300 \mathrm{TgC}$ to nearly $500 \mathrm{TgC}^{8}$ For forestlands, forest management practices such as afforestation, reforestation and the mitigation of deforestation all preserve stand-level forest carbon stocks minimize carbon loss.

\subsubsection{Non- $\mathrm{CO}_{2}$ GHGs}

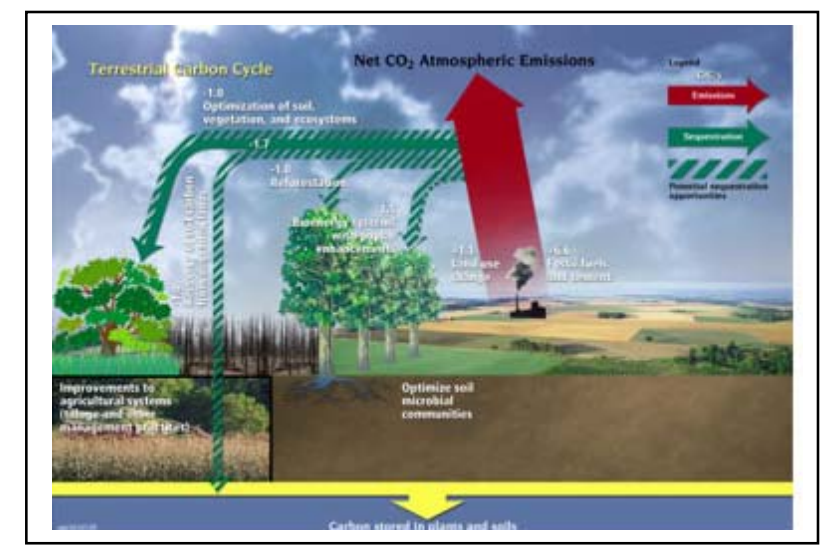

Fig. 1.12. Terrestrial carbon cycle

Source: http://www.science.doe.gov/Sub/speeches/ speeches/carbon_images/slide8.jpg

Other gases besides carbon dioxide must be considered in any plan to reduce GHG emissions. Methane $\left(\mathrm{CH}_{4}\right)$, nitrous oxide $\left(\mathrm{N}_{2} \mathrm{O}\right)$, ozone $\left(\mathrm{O}_{3}\right)$, and sulfur hexafluoride $\left(\mathrm{SF}_{6}\right)$ are some of the other gases that have been identified as causes for increased radiative forcing. Methane can be collected and used as a fuel. Additionally, methane and nitrous oxide emissions can be reduced by directed agricultural management strategies that optimize fertilizer applications and reduce soil tillage. Technologies that reduce particulate matter and avoid leaks in systems carrying potential GHGs can also lead to reductions in emissions.

Methane from energy and waste. Methane emissions from the energy and waste sectors (i.e., coal mining, oil and natural gas systems, landfills, and wastewater treatment) accounted for 31 percent of global non- $\mathrm{CO}_{2}$ GHG emissions and nearly 50 percent of global methane emissions in 2000 (CCTP 2006). A technology that could decrease emissions from landfills is bioreactor systems; a demonstration project using bioreactor technology showed a tenfold increase in methane recovery and an associated reduction in time required for waste stabilization and composting of the landfill (CCTP, 2005).

\begin{tabular}{|l|c|c|c|}
\hline \multicolumn{4}{|c|}{$\begin{array}{c}\text { Table 1.1. Change in U.S. methane emissions from energy } \\
\text { and waste (Tg CO }\end{array}$ equivalent) } \\
\hline \multicolumn{1}{|c|}{ Source } & $\begin{array}{c}1990 \\
\text { Emissions }\end{array}$ & $\begin{array}{c}\mathbf{2 0 0 5} \\
\text { Emissions }\end{array}$ & $\begin{array}{c}\text { \% } \\
\text { Change }\end{array}$ \\
\hline Landfills & 161.00 & 132.00 & -18 \\
\hline Wastewater Treatment & 24.8 & 25.4 & +2 \\
\hline Coal Mining & 81.9 & 52.4 & -36 \\
\hline Natural Gas and Oil & 158.9 & 139.6 & -12 \\
\hline Total & 426.6 & 349.4 & -18 \\
\hline
\end{tabular}

(Source: EPA 2007)

\footnotetext{
${ }^{7}$ http://www.fossil.energy.gov/programs/sequestration/terrestrial/, accessed 8/6/07

${ }^{8}$ Estimates based on summed potentials presented for croplands at 55-164 TgC (Lal et al., 1998), grazing lands at 29-110 TgC (Follett et al., 2001), and forest lands at 210 TgC (Joyce and Birdsey, 2000). Estimates of potential savings from dedicated bioenergy croplands from 91-152 TgC (Tuskan and Walsh, 2001) are excluded in this sum.
} 
Methane and nitrous oxide emissions from agriculture. Globally, agricultural sources of methane and nitrous oxide (i.e., crop and livestock production, fermentation of livestock manure, and rice production) contribute an estimated 5,428 $\mathrm{Tg} \mathrm{CO}_{2}$ equivalent and account for nearly 60 percent of global non- $\mathrm{CO}_{2}$ emissions (CCTP, 2006). Methane produced from manure can be reduced through processing by digester technologies similar to those used in domestic wastewater treatment plants; the biologic processes used in the digesters allow for controlled collection of methane which can be used to generate electricity.

Emissions of high global-warming potential gases. In the U.S., high-GWP gases represented 13 percent of total non- $\mathrm{CO}_{2}$ GHG emissions in 2000, more than three times the global percent (CCTP, 2006). Some high-GWP gases, like

hydrofluorocarbons (HFCs) are being used as replacements for chemicals (like CFCs) that deplete the stratospheric ozone layer (like in refrigeration). Other high-GWP synthetic gases

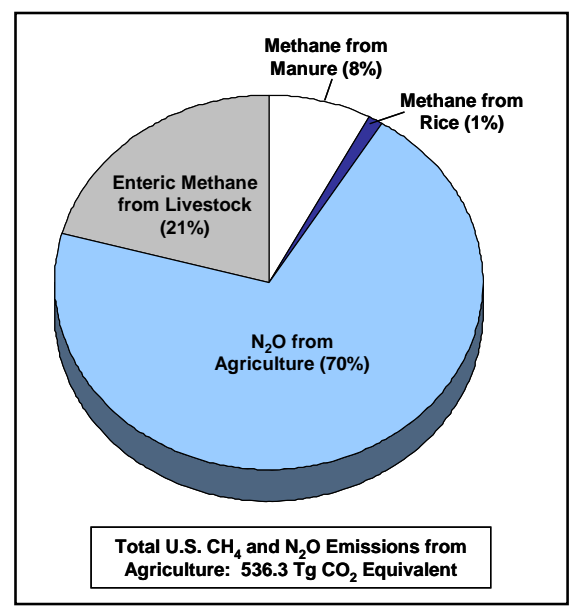

Fig. 1.13. Components of non- $\mathrm{CO}_{2}$ U.S. GHG emissions from agriculture, 2000 Source: EPA, 2007 are generally used in industrial applications for processes such as cleaning that are critical to plant operation. Many technologies have been developed recently that could reduce or eliminate the use of high-GWP gases; illustratively, distributed refrigeration reduces the need for excessive refrigerant piping (and hence leakages).

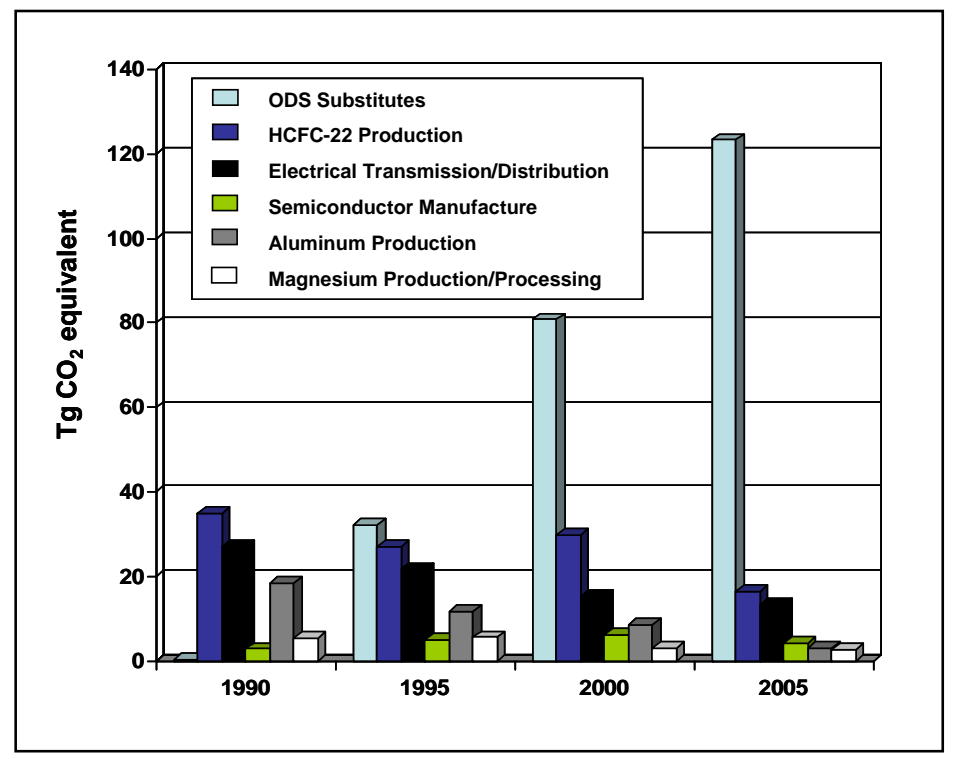

Fig. 1.14. High-GWP gas emissions in the U.S. by source (Tg $\mathrm{CO}_{2}$ equivalents) Source: EPA, 2007

Nitrous oxide emissions from combustion and industrial sources. Globally, stationary and mobile source combustion of fossil fuels and industrial production of acids accounted for about four percent of global non- $\mathrm{CO}_{2}$ emissions in 2000, or $390 \mathrm{Tg} \mathrm{CO}_{2}$ equivalent (CCTP, 2006). In production of nitric acid (for applications like fertilizer) the suitable technology of non-selective catalytic reduction (NSCR) is very effective at controlling nitrous oxide emissions but only installed in 20 percent of the nitric acid plants. 
Many analysts recommend that the development and deployment of mitigation technologies be accompanied by comparable investments to increase the resilience of economic and social systems to climate extremes. Such adaptation approaches include developing more drought-resistant crops, hardening sea walls, and developing communication systems to facilitate disaster response. In addition, geoengineering approaches are important insurance strategies in case of catastrophic climate change warranting interventions to natural systems. Examples include seeding the atmosphere with nanoparticles to reflect sunlight and provide a dose of emergency cooling and fertilizing the ocean with iron to increase the absorption of carbon dioxide from the

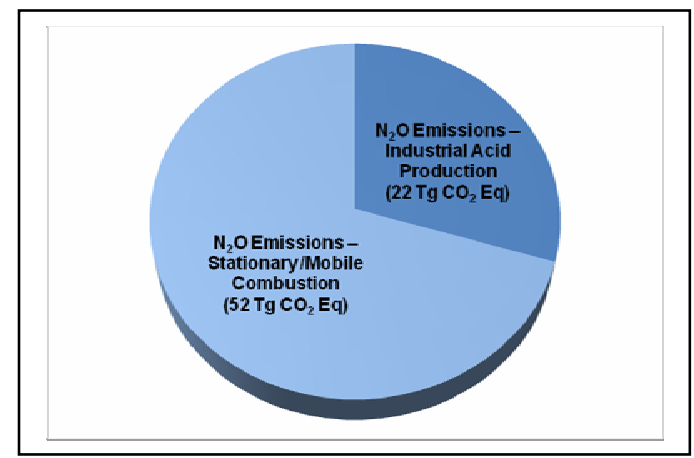

Fig. 1.15. U.S. $\mathrm{N}_{2} \mathrm{O}$ emissions from combustion and industrial sources, 2005 Source: EPA, 2007 atmosphere. While adaptation and geo-engineering approaches are important and merit investigation, this report limits its scope to mitigation technologies that reduce GHG emissions.

\subsubsection{Potential Contributions to Emissions Reductions}

Given the magnitude of the climate change challenge, each of the four technology goal areas described above needs to contribute to stabilizing GHG concentrations. Numerous "gigaton” solutions are needed, each of which will involve transforming and modernizing the nation's energy system in fundamental ways. For example, one gigaton of emissions reductions could be delivered by 1,000 zero-emission 500 MW coal-fired power plant with carbon capture and storage. Another gigaton of reductions would result from 50 times the current global capacity of wind or energy crops 15 times the size of Iowa (Pacala and Socolow, 2004). These solutions in many cases represent more than just the next generation of technology. They will require paradigm shifts in how we generate and use energy and land today as well as acceptance of entirely new, transformational concepts. To encourage development in these important technology areas, a strong National Strategy for commercialization and deployment is essential.

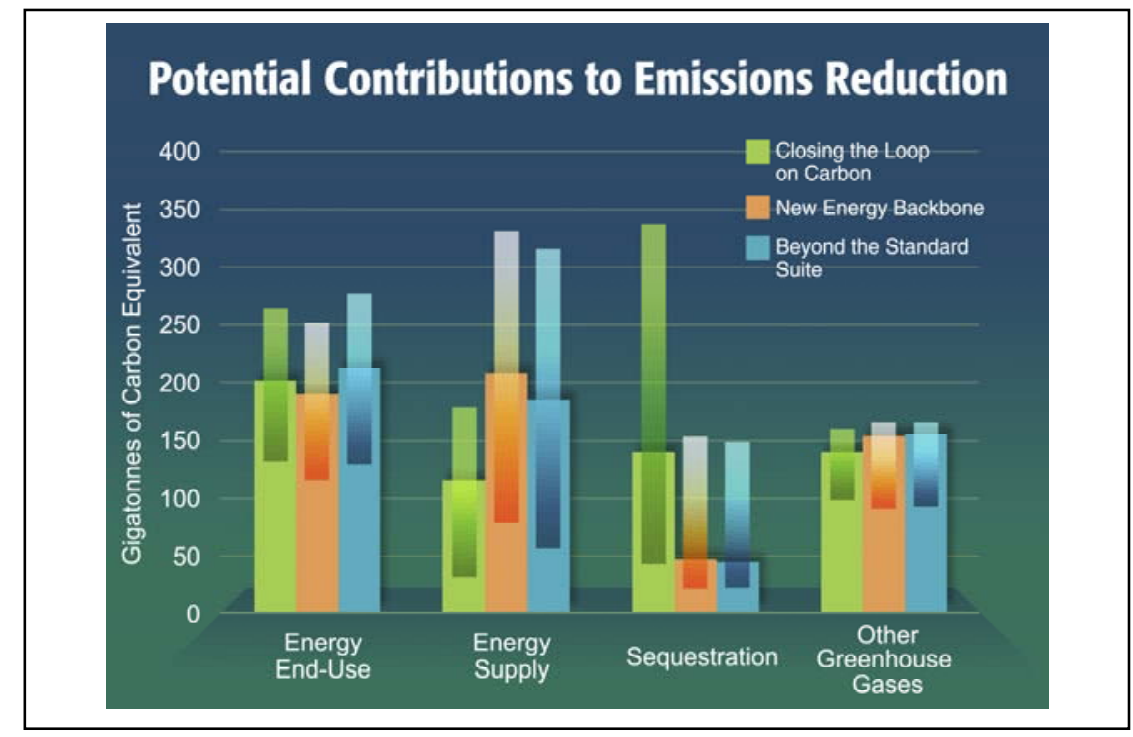

Fig. 1.16. Cumulative emission reduction contributions between 2000 and 2100 for three advanced technology scenarios

Source: CCTP, 2006, p. 51 
Scientific evidence is accumulating that suggests emission reductions need to begin in the near-term to prevent dangerous anthropogenic interference with the climate system. Alternative timelines of advanced technology market penetrations are shown in Table 1.1 for each area. These deployment timelines are described in terms of the time period when the first gigaton of incremental emissions mitigation is needed. In a highly constrained climate scenario, emission reductions from energy end-use technologies are seen as beginning in the 2010-2020 timeframe, followed by emission reductions from other gases, energy supply and carbon sequestration. In this case, the nation will require a vigorous across-the-board deployment thrust. Lower climate constraints would enable a more staged ramp-up of deployment activities and emission reductions. As Table 1.1 illustrates, the deployment timelines vary for each technology area.

\begin{tabular}{|l|c|c|c|c|}
\hline \multicolumn{4}{|c|}{ Table 1.2. Estimated timing of advanced technology market penetrations* } \\
\hline \multicolumn{1}{|c|}{ CCTP Strategic Goal } & $\begin{array}{c}\text { Very high } \\
\text { Constraint }\end{array}$ & $\begin{array}{c}\text { High } \\
\text { Constraint }\end{array}$ & $\begin{array}{c}\text { Medium } \\
\text { Constraint }\end{array}$ & $\begin{array}{c}\text { Low } \\
\text { Constraint }\end{array}$ \\
\hline $\begin{array}{l}\text { Goal \#1: Reduce Emissions from Energy End Use } \\
\text { and Infrastructure }\end{array}$ & $2010-2020$ & $2030-2040$ & $2030-2050$ & $2040-2060$ \\
\hline Goal \#2: Reduce Emissions from Energy Supply & $2020-2040$ & $2040-2060$ & $2050-2070$ & $2060-2100$ \\
\hline Goal \#3: Capture and Sequester Carbon Dioxide & $2020-2050$ & 2040 or Later & 2060 or Later & Beyond 2100 \\
\hline Goal \#4: Reduce Emissions of Non-CO ${ }_{2}$ GHGs & $2020-2030$ & $2050-2060$ & $2050-2060$ & $2070-2080$ \\
\hline
\end{tabular}

Source: Clarke et al., 2006

*The low to very high constraint scenarios vary according to the 100 -year cumulative $\mathrm{CO}_{2}$ emission reductions, ranging from about 300 to about 1,000 GtC-eq. The stabilization levels are approximately 450 ppmv, 550 ppmv, 650 ppmv, and 750 ppmv. ${ }^{9}$

\subsection{MOTIVATION, RESEARCH APPROACH, AND ORGANIZATION OF THIS REPORT}

Numerous barriers prevent the rapid and complete commercialization and deployment of GHG-reducing technologies. Recognizing this fact, the Energy Policy Act of 2005 (EPAct) requires that the Administration prepare a report describing these barriers; those portions of the law applicable to this effort are included in Box 1.1.

This report begins by describing the commercialization and deployment processes as a backdrop to identifying barriers that prevent a more efficient diffusion of GHG-reducing technologies in the United States (Section 2.1). This is followed by a description of the types of commercialization and deployment barriers that have been identified to date. It then presents a typology of six barriers that provide structure for the remaining sections: cost-effectiveness barriers, fiscal barriers, regulatory barriers, statutory barriers, intellectual property issues, and “other” barriers (Section 2.2).

\footnotetext{
${ }^{9}$ According to Leon E. Clarke (personal communication, October 6, 2007) the precise stabilization levels do not exactly match these, and can vary a little between scenarios because the contributions of other gases can vary and the goal was to reach a consistent radiative forcing target across scenarios. Also, the $650 \mathrm{ppmv}$ and $750 \mathrm{ppmv}$ scenarios do not reach stabilization until well after the study period (up through 2100) so the end of period concentrations are less than the final stabilization levels. With reference technology, 450 ppmv and 550 ppmv are almost exactly reached, but the concentration is several ppmv higher with advanced technology because of the reduction in radiative forcing from non- $\mathrm{CO}_{2}$ gases.
} 


\section{Box 1.1 Title XVI - Climate Change \\ Subtitle A - National Climate Change Technology Deployment \\ Energy Policy Act of 2005}

Section 1601(f)(3):

"Not later than 1 year after the date of enactment of this section and annually thereafter, the Advisory Committee shall submit to the Committee a report that describes-

(A) the findings of the Advisory Committee; and

(B) any recommendations of the Advisory Committee for the removal or reduction of barriers to commercialization, deployment, and increasing the use of greenhouse gas intensity reducing technologies and practices."

Section 1601(g)(1):

"[T]he Committee shall develop recommendations that would provide for the removal of domestic barriers to the commercialization and deployment of greenhouse gas intensity reducing technologies and practices"

Section 1602(g)(2):

"In developing the recommendations under paragraph (1), the Committee shall consider in the aggregate-

(A) the cost-effectiveness of the technology;

(B) fiscal and regulatory barriers;

(C) statutory and other barriers; and

(D) intellectual property issues."

Section 1601(g)(4):

"Not later than 18 months after the date of enactment of this section, the Committee shall submit to the President and Congress a report that-

(A) identifies, based on the report submitted under subsection (f)(3), any barriers to, and commercial risks associated with, the deployment of greenhouse gas intensity reducing technologies; and (B) includes a plan for carrying out demonstration projects.”

This typology and the compilation of illustrative examples that follow result from a multifaceted research approach. The research began with a review of the literature on barriers to low-carbon technologies, which is plentiful and diverse. The review spanned the published literature on:

- Commercialization and technology transfer;

- Barriers to the deployment of new technologies;

- Market penetration of climate change mitigation technologies; and

- Intellectual property and law.

The literature review was followed by interviews with 27 experts from government, national laboratories, industry, universities, and consulting firms (see Appendix A). These interviews provided a more current overview of market and technology conditions and associated barriers, along with an ability to probe more deeply into the nature of market imperfections and to uncover illustrative deployment failures and successes. In addition, input from the multi-agency CCTP Working Group provided assistance with the cross-walk between deployment barriers and technology sectors. 
Sections 3 through 6 probe more deeply into each of the categories of barriers, explaining in more detail how they impede deployment and illustrating their impact on different types of GHG-reducing technologies. Section 4 covers three of the categories of barriers (fiscal, regulatory, and statutory) because they are alike in being the product of legislatures and regulators while simultaneously operating at crosspurposes to the Federal government’s commitment to stabilize GHG concentrations at safe levels.

Recognizing that some technologies face a wide array of barriers to deployment while others are hindered by a few critical obstacles, Section 7 "turns the table" and takes a technology perspective to the topic of barriers.

The concluding Section 8 begins by identifying the deployment barriers that appear to be the most common and therefore the most important to understand and address. This is done in part by assessing the frequency that particular types of barriers were mentioned during the 27 interviews and the range of GHG-reducing technologies that are impacted by individual barriers. This process helps divide those barriers that are relatively specific to individual technologies and market sectors from obstacles that have more economy-wide implications. Attention then turns to the EPAct 2005 requirement that the report provide "recommendations that would provide for the removal of domestic barriers to the commercialization and deployment of greenhouse gas intensity reducing technologies and practices." While the development of policy solutions is not the principal focus of this report, ${ }^{10}$ Section 8 nevertheless describes various "classes" and "categories" of potential policy mechanisms that could address some of the more important deployment barriers.

\footnotetext{
${ }^{10}$ The development of a deployment strategy for GHG-reducing technologies is the subject of a separate analytic effort.
} 



\section{2}

By identifying

barriers to the

successful

deployment of

climate change

mitigation

technology,

investors, sponsors, and policy analysts

can seek and

develop more

effective

mechanisms for

moving technologies

into the

marketplace.

\section{Background}

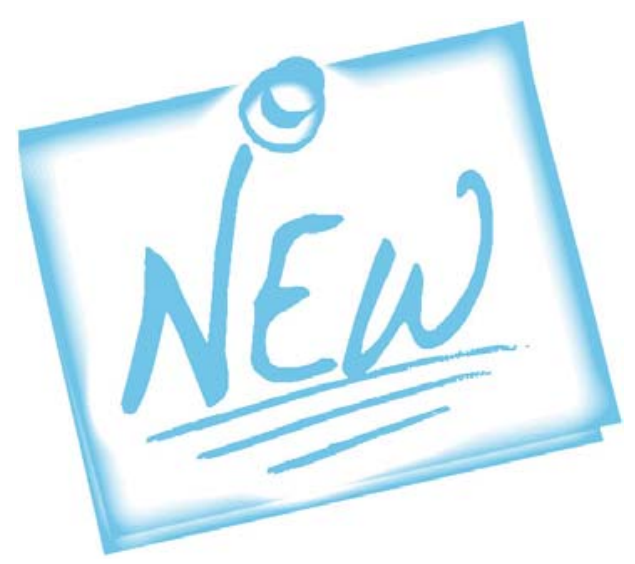

The path from basic research to market penetration of a new technology is complex, iterative, and nonlinear. The term "commercialization" generally refers to the process of introducing a new technology into the market, while the subsequent market penetration of the technology is generally referred to as “deployment." Deployment policies and programs in the context of this report refer to government interventions motivated by the desired social benefit of reducing GHG emissions and intended to accelerate the diffusion and adoption of GHGreducing technologies that are otherwise impeded from achieving widespread market application. 


\subsection{THE COMMERCIALIZATION AND DEPLOYMENT PROCESS}

The commercialization and deployment process begins with "basic research" and "science," which provides the underlying foundation of knowledge that can lead to fundamental new discoveries. This part of the research continuum tends not to be problem-driven, but rather involves scientific study and experimentation to advance understanding. The next stage of "applied research" is problem-driven and is intended primarily to solve specific technical challenges impeding progress in technology development. This "strategic" research applies knowledge gained from more fundamental science research to the more practical problems associated with technology R\&D (see Fig. 2.1).

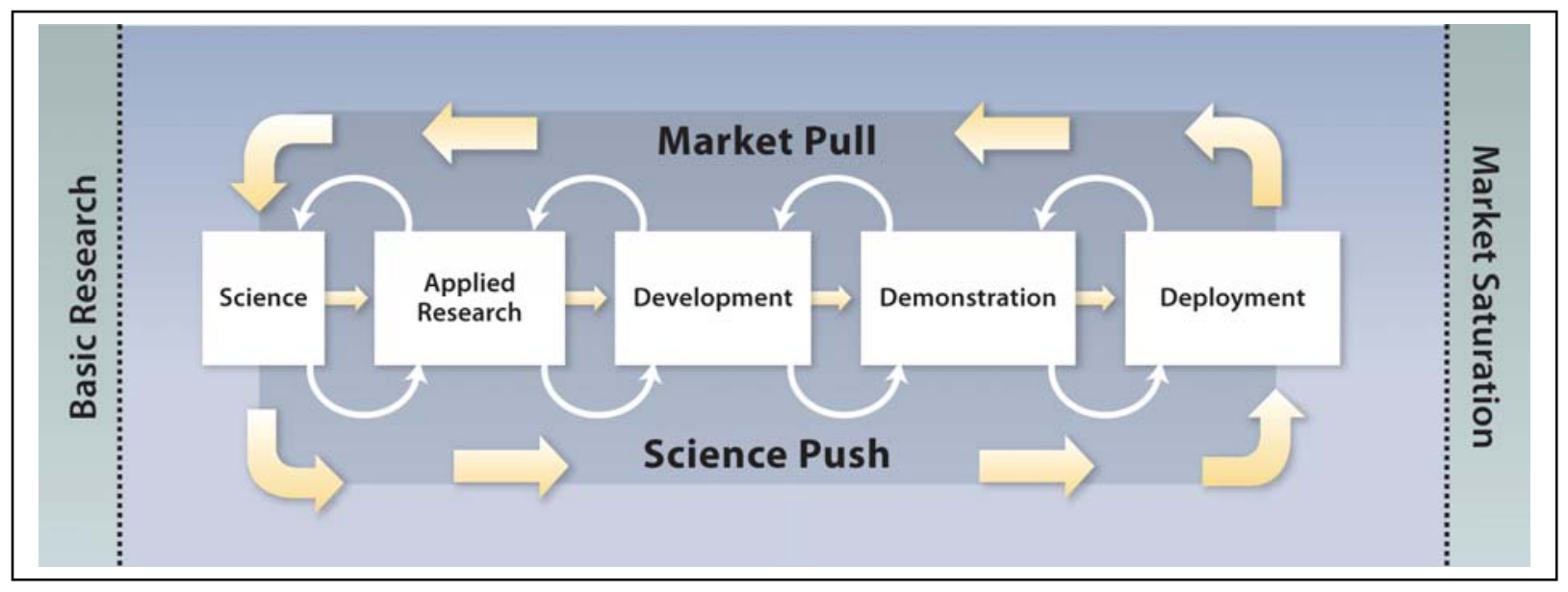

Fig. 2.1. The path from basic research to market saturation

The following stage of “development” includes applications engineering and possibly field testing. "Demonstrations" are then needed to evaluate the technology's performance in real-world operating systems. This may be followed by further production engineering to improve the fit between market conditions and technology characteristics. Finally, “deployment” activities are undertaken, including the development of distribution channels, targeted niche marketing and supply chain alignment, followed by cost reductions and broader market development to ultimately achieve widespread "market saturation." Time and effort spent in each stage along this path to market saturation varies by technology, and innovation does not occur without interaction with external forces.

Technology deployment involves interplay between "market pull” factors, where the marketplace is seeking to satisfy certain demands by drawing from the technology portfolio, and "science push" factors, where scientists, technology developers and vendors are seeking to increase the use of their products by offering new, better, or cheaper services (Fig. 2.2). In the early stages of technology development, public/private partnerships are often used to ensure that market signals and the needs of the targeted industries will be met by the results of the R\&D. As the development effort progresses, feedback loops and communication from potential suppliers and customers play a role in shaping the effort. Finally, horizontal research alliances may emerge to integrate the effort across multiple industry sectors and markets. Dodgson, Gann, and Salter (2005) found that innovation researchers typically failed to acknowledge the importance of these external interactions, alliances, and integrated behaviors until recently. Further, they suggest that the broader implication of these communications is a move from individual and corporate innovation to a more open innovation model relying on interdependent actors. 


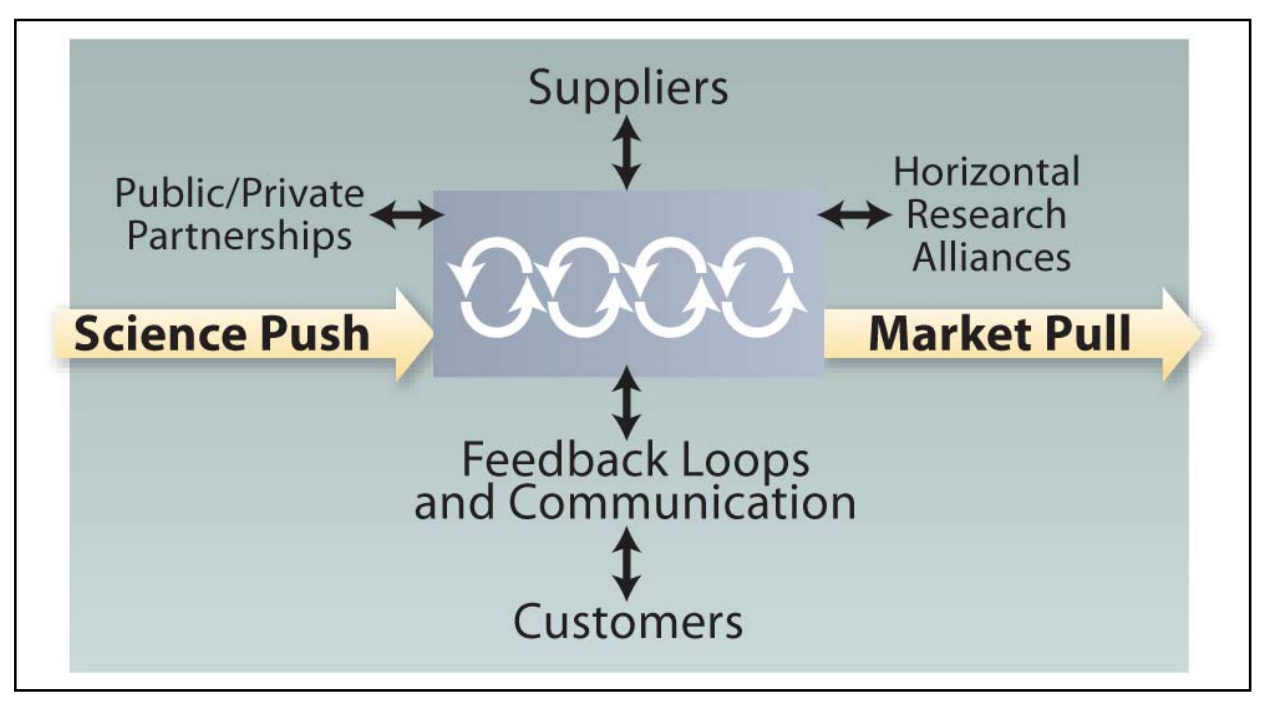

Fig. 2.2. The supply push and demand pull of technology deployment

The importance of market pull throughout the process was clearly illustrated by Norberg-Bohm (2000), who documented that historically successful government technology programs for dual military and commercial use were boosted through a combination supply push and demand pull policies. Most GHGreducing technologies do not have the "benefit" of having government as the largest consumer, so alternative forms of market pull are necessary.

\subsubsection{The Gap Between Typical Current Use and Today's Best Practices ${ }^{11}$}

Incidents of the significant gap between current and best practices are numerous in the energy field, as shown in Fig. 1.1. Consider two additional examples in some detail: atmospheric fluidized bed combustion (AFBC) systems and combined heat and power (CHP) systems.

Banales-Lopez and Norberg-Bohm (2002) comment that AFBC systems have been around since the mid1960s, but that the electric utility sector rarely uses them. In a fluidized bed boiler, AFBC systems introduce the combustion at the bottom of a furnace, distribute it across the chamber by a porous base or air distributor, and move the air upward through a bed composed of inert particles (such as coal ash, limestone byproducts, and fuel particles). When the pressure is sufficiently low, the bed particles start to behave as liquid particles, allowing for both increased efficiency of generation and pollution abatement. AFBC technologies are quite mature, and have long been noted to hold numerous benefits: they enable fuel flexibility since lower grade fuels can be consumed, negate the need for end-of-pipe environmental controls, and allow for in-bed-capture of sulfur dioxide and intrinsic reduction of nitrogen oxide emissions. Despite these benefits, however, AFBC technologies have seen only "negligible” use in the utility sector, with around only six units (with a total capacity of $660 \mathrm{MW}$ ) currently commissioned by utilities. Why have AFBC technologies seen such little use? In their thirty-year assessment of such technologies, Banales-Lopez and Norberg-Bohm (2002) conclude that generally higher capital costs compared to pulverized coal boilers, unfamiliarity with the technology, and the risk aversion and conservatism of utilities have acted as significant impediments to the diffusion of AFBC systems.

Analogously, CHP systems produce thermal energy and electricity from a single fuel source, thus recycling normally wasted heat through cogeneration (a process in which heat and electricity are both useful end products) and trigeneration (in which electricity, heating, and cooling are produced). Sovacool

\footnotetext{
11 “Best Practices” in this report refers to both practices and technologies.
} 
and Hirsh (2007) note that CHP technologies consistently generate electricity at almost double the efficiency of conventional utility gas turbine generators and have lower labor and capital costs (when comparing central power generation costs plus transmission and distribution costs). Nonetheless, such technologies characterize only around three percent of utility electricity generation capacity. While it is recognized that not all industrial generators are in need of process heat, those that use both may still not take advantage of the benefits of CHP systems due to variable and inconsistent policy incentives, difficulty in setting environmental and permitting standards, lingering utility monopoly rules, industry resistance to change, and public misunderstanding (Sovacool and Hirsh, 2007; Hirsh and Sovacool, 2006).

In both cases, after several decades of development, the penetration rates for AFBC and CHP systems remain small. These two technologies are not the only cases of economically attractive technologies that have not penetrated the market as fully as their potential would indicate. In an analysis of the market penetration of 20 energy technologies, Lund (2006) found that penetration rates vary greatly, and policies can have a nontrivial effect. He found market penetration rates varying from 4 to over 40 percent per year with dominance by a new technology taking from less than 10 to more than 70 years. Further, he shows that the shortest penetration times were generally found for end-use products such as compact fluorescent lamps, which have experienced rapid dissemination. This may be due in part to the short lifetime of enduse products, like light bulbs and computers, compared to primary use products, like buildings or generating plants. While there have been exceptions, the market has generally been slow to accept GHGreducing technologies.

Effective technology deployment depends fundamentally on partnerships among a variety of institutions and parties. The most important public sector role is often leadership rather than funding, for instance persuading industry to collaborate in achieving social goals that are longer-term than normal industry investment perspectives and helping consumers to understand issues and options related to technology choice. Luiten (2001) found that government intervention was least helpful when momentum for the technology was already high, but government intervention was useful to increase deployment of technologies with low momentum in the market and that are not part of the industry's core mission.

While this report highlights barriers to successful deployment of GHG-reducing technologies, it is important to note that numerous supporting policies are already in place. A recent inventory identified more than 280 Federal programs, policies, and initiatives currently in place to address barriers to the commercialization and deployment of GHG-reducing technologies and practices (CCTP, 2007). These programs reflect a broad and collaborative climate change strategy that emphasizes technology innovation, financial incentives, voluntary partnerships, and international participation. More than a dozen Federal agencies are leading efforts directed at encouraging the commercialization and deployment of cleaner, more energy-efficient technologies for end-use and energy supply, promoting carbon capture and sequestration, and less GHG-intensive practices.

\subsubsection{The Lag Between Today’s Best Practices and Technically Feasible Technologies}

Most technological innovations do not survive the transition from invention to marketplace success. The loss of technically feasible technologies in part stems from the fact that many feasible technologies lack commercial viability. Nonetheless, the undue loss of practicable technologies slows improvement from what are considered best practices today. Many technologies could achieve cost-effectiveness and penetrate markets if not for the "Valley of Death," which refers to investors' lack of appetite to invest in technologies as they advance from invention to commercialization because of the difficulty of managing 
market, regulatory, and other risks sufficiently to justify the needed financial investment. ${ }^{12}$ Thus, this valley is defined by the relative shortage of investment in readying technologies for the marketplace and in building operating businesses around them. It has been suggested that as many as 95 percent of new technologies do not make it across the valley illustrated in Fig. 2.3 (Bane and Blain, 2001). While Fig. 2.3 has "cash flow" as the vertical axis, it is important to understand that cash only flows once the technology is available in the market; before this time, the axis is more appropriately "available resources." Because of the financial difficulties experienced during the valley of death, Markham (2002) and others suggest that making public-sector resources available when a technology is first moving from the lab into commercialization is particularly critical.

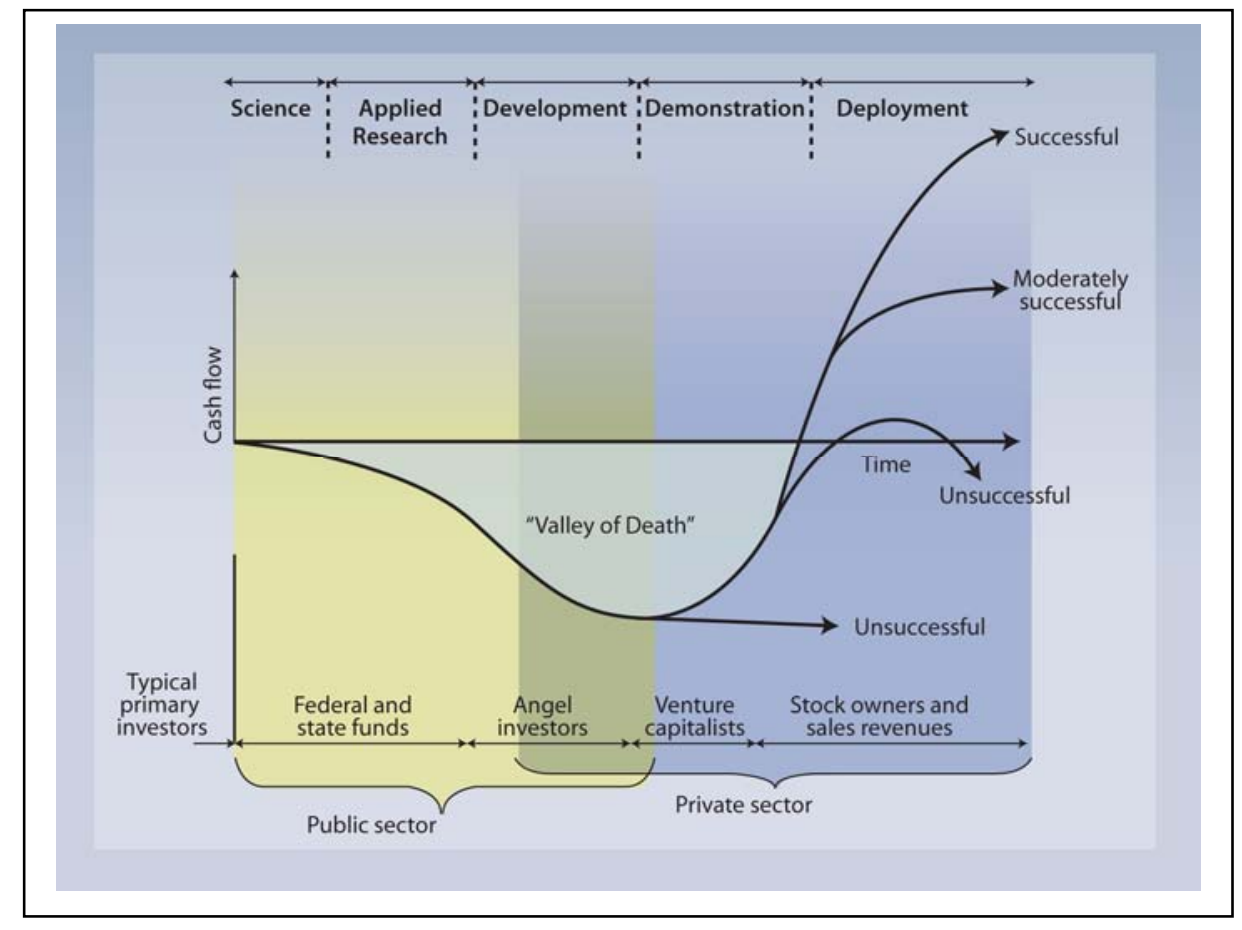

Fig. 2.3. From innovation to market: The valley of death

Source: Revised from Murphy and Edwards (2003, Fig. 1, p. 16)

Lisa Kuttila, director of the Science and Technology Corporation at the University of New Mexico explained, "federal funding often gets cut before a new discovery can be further developed. That leaves a gap that blocks promising technology from reaching a market...money from investors is hard to find at that point because there's no return on the investment - it's only aimed at advancing the technology enough to see if it's potentially marketable” (as reported by New Mexico Business Weekly, 2006). There is typically a point in technology development where the basic research has been completed, additional money is needed to see if the technology has commercial promise, and return on investment cannot be readily projected because technology developers cannot manage critical risks effectively. Universities and National Laboratories have helped to fill this void with innovation institutes and partnerships, but they have limited resources and cannot (and should not) support all promising technologies.

\footnotetext{
${ }^{12} \mathrm{D}$. R. Berg presented the idea of choke point in the flow of investment and capital for technology innovation as "the neck of the hourglass" - more recently known as “the Valley of Death” - to EPA’s National Advisory Council for Environmental Technology Transfer, September 22, 1988.
} 
Berg and Ferrier (1998) describe how a combination of efforts can bridge the Valley of Death:

- The public sector can remove inherent barriers (e.g., regulations that constrain innovation), invest in $\mathrm{RD} \& \mathrm{D}$, reduce information constraints, and accept some financial and policy risk during commercialization and early commercial use; and

- Angel investors, strategic investors, venture capitalists, and investment banks can invest, alone or in combination with government, when they can align risks with rewards.

Collaboration can reduce government picking of winners and corporate welfare because private sector involvement will minimize public investment in failing technologies (Murphy and Edwards, 2003). ${ }^{13}$

Technologies developed principally to mitigate GHG emissions face additional challenges in the Valley of Death because to a large extent GHGs are not priced in the marketplace and technologies to reduce them generally do not have existing markets to produce capital to "pick them up" on the other side. "Public R\&D cannot drive commercial uptake, market pull forces are weak because product differentiation is not a key market driver, and the promise of emission controls does not form a credible, long-term basis of sufficient security against which most firms could take substantial risks in the face of skeptical shareholders” (Grubb, 2004) and uncertain financial returns.

As technologies mature, technical risks decline: advances in technical maturity yield gains in performance certainty, cost reduction, operational improvements, and pave the way for institutional transformations, among other benefits (Sagar and van der Zwaan, 2006). Learning alone cannot yield all of the necessary improvements, as regulatory barriers, inefficiencies in the transfer of information, standard industry practices, and market inertia constrain market penetration. Each of these possibilities comes into account regardless of success in overcoming technical risks. Nemet (2006) argues while learning is important, uncertain learning rates limit policy development that anticipates the use of new technologies.

Government has shown willingness to demonstrate technologies in many fields, from the telegraph system in 1843 to nuclear power plants in the 1950s. Demonstrations are a stepping stone to technology adoption because they answer questions about uncertain performance, cost, demand, externalities, and related institutions (Baer et al., 1997). Technical failures during highly visible demonstrations can end the commercialization prospects of a technology (Brown et al., 1993). Successful demonstration projects involving the reduction of GHGs can pave the way for public and private cooperation on technologies that become ready for commercialization.

\subsection{TYPES OF COMMERCIALIZATION AND DEPLOYMENT BARRIERS}

The literature on barriers to GHG-reducing technologies is plentiful and diverse. It ranges from broad discussions of economy-wide barriers to technology-, region-, or industry-specific discussions of obstacles to technology deployment. Most reviews fall into the latter category and are therefore difficult to assemble and assimilate into a systematic overview or single framework. The predominant literature is advocacy-oriented and describes the obstacles faced by a particular technology, making generalizations difficult.

However, there are a few review articles that attempt to synthesize lessons about deployment barriers in a broad sweep of energy sectors.

\footnotetext{
${ }^{13}$ Anecdotally, the Department of Energy includes both “Find Big Money” and "Find Big, Big Money” in the entrepreneurial stage of technology development (DOE, 2000).
} 
Reviews of impediments to "clean energy technologies” have identified a wide range of barriers commensurate with the broad sweep of technologies being considered. For instance:

- The Carbon Trust (2005) suggests that clean energy technologies tend to be impeded by four types of barriers: financial costs/benefits; hidden costs/benefits; real market failures; and behavioral/organizational non-optimalities.

- In the Scenarios for a Clean Energy Future (Interlaboratory Working Group, 2000), market failures are distinguished from other obstacles. Market failures are defined as conditions of a market that violate one or more neoclassical economic assumptions such as perfect competition and perfect information that define an ideal market. Market failures include misplaced incentives; distortionary fiscal, regulatory, and statutory policies; unpriced costs and benefits; and costly, imperfect and asymmetric information. Many argue that the existence of market failures is a precondition for government intervention. Others argue more broadly that if a social goal needs to be achieved, any barrier to its implementation could be the object of public policy. Examples of such barriers include the high cost of capital; an insufficient return on investment; supply chain gaps; and high transaction costs.

Several reviews have focused on renewable and/or distributed energy. In this context:

- Painuly (2001) provides an extensive table of barriers/failures to renewable energy penetration, highlighting in particular the problem of missing market infrastructure that may increase costs.

- Beck and Martinot (2004) identify the following types of barriers to renewable energy: subsidies for conventional forms of energy, high initial capital costs, imperfect capital markets, lack of skills or information, poor market acceptance, technology prejudice, financing risks and uncertainties, high transaction costs, and a variety of regulatory and institutional factors.

- Sovacool (2006) interviewed more than 60 experts working for utilities, in government agencies, and the national laboratories and identified 38 non-technical barriers to the deployment of distributed generation and renewable energy technologies.

There have also been several reviews of barriers to energy efficiency. For instance:

- Hirst and Brown (1990) suggest that some barriers are structural while others are behavioral: "structural barriers result from the actions of many public and private sector organizations and are primarily beyond the control of the individual end-user. Behavioral barriers, on the other hand, are problems that characterize the end-user's decision making, although they may also reflect structural constraints." The structural barriers spill over into technology choices where individuals may be making decisions within legal and regulatory constraints.

- In reflecting on barriers to the efficient use of energy, Weber (1997) developed a typology with three categories. Institutional barriers are caused by state and Federal government agencies and local authorities. Market failures are obstacles resulting from conditions related to supply and demand. Finally, organizational barriers are obstacles operating within firms.

- More recently, Prindle (2007) attempted to identify the most influential factors that inhibit behaviors or investments that would increase both energy efficiency and economic efficiency. That is, he focused on market failures. Following a literature review and discussions with economists, the range of market failures was narrowed to three types that were believed to be the most influential: principal-agent barriers, information/transaction cost barriers, and externality cost barriers. Subsequent case studies of barriers to the deployment of energy-efficient technologies in OECD countries concluded that principal-agent barriers were the most influential, impacting up to 90 percent of the energy used in many major markets. 
The typology of barriers developed for this report adheres to the language of the Energy Policy Act of 2005 (EPAct), as shown in Box 1.1. Thus, we have identified barriers not by their market characterization, but according to the breakdown in Section 1601(g) of Title XVI: "(A) the costeffectiveness of the technology; (B) fiscal and regulatory barriers; (C) statutory and other barriers; and (D) intellectual property barriers. For ease of treatment, we divide categories (B) and (C) into their two parts to arrive at six categories altogether. We further divide these six categories into 20 barriers and approximately 50 sub-barriers to aid in their description (Table 2.1).

Many of the 20 barriers are inter-related. While they are grouped into the six categories given in EPAct Title XVI, even these categories are not mutually exclusive. The cross-cutting nature of these barriers is illustrated below.

- High costs are impacted by market and technical risks associated with commercialization or commercial deployment of a technology. To purchasers of the technology, high cost means that some combination of the capital cost of the technology, its cost of operations, or other aspects of a project that employs the technology yield a product that costs too much relative to other technologies or products that perform essentially the same purpose. The high cost barrier is a function of endogenous costs (e.g., the nature of the fabrication process and its materials requirements), but it also reflects fiscal and regulatory uncertainties. Infrastructure limitations can also contribute to high costs, as when critical infrastructure is inadequate or supply channels are insufficient.

- Market risks refer to uncertainties associated with the cost of a new product vis-à-vis its competitors, and the new product's likely acceptance in the marketplace. It includes the risk of long-term demand that falls short of expectations, possibly as a result of misplaced incentives or unfavorable fiscal policy, statutes or regulations. Market risks may be particularly high under certain industry structures: fragmented industries are generally slow to adopt innovation, and industries characterized by monopolies aggressively defend incumbent technologies.

- Incomplete and imperfect information results from a lack of trusted information about technology performance. This information barrier is particularly characteristic of new and unproven technology, which creates an environment of uncertainty and technical risk that the innovation will be able to perform to specifications. Financial markets respond by increasing the cost of financing, resulting in high costs. Trusted information is limited because stakeholders, constituents, supply chain providers, and user communities have not yet emerged in the early stages of a technology's deployment.

The six categories of deployment barriers are discussed in the following sections of the report. In section 8 we return to the notion of interdependent and reinforcing barriers and make an effort to identify those that represent the most sweeping challenges to the success of GHG-reducing technologies. By identifying barriers to the successful deployment of climate mitigation technology, investors, sponsors, and policy analysts can seek and develop more effective mechanisms for moving technologies into the marketplace. 
Table 2.1. Typology of barriers to the commercialization and deployment of GHG-reducing technologies

\section{Cost-Effectiveness Barriers}

External Benefits and Costs

External benefits of GHG-reducing technologies that the owners of the technologies are unable to appropriate (e.g., GHG emission reductions from substitutes for high GWP gases and carbon sequestration). External costs associated with technologies using fossil fuels (e.g., GHG emissions and health effects from small particles) making it difficult for higher priced, GHG-reducing technologies to compete.

High up-front costs associated with the production and purchase of many low-

High Costs carbon technologies; high operations and maintenance costs typical of first-of-akind technologies; high cost of financing and limited access to credit especially by low-income households and small businesses.

Risks associated with unproven technology when there is insufficient validation of technology performance. Confounded by high capital cost, high labor/operating

Technical Risks cost, excessive downtime, lack of standardization, and lack of engineering, procurement and construction capacity, all of which create an environment of uncertainty.

Low demand typical of emerging technologies including lack of long-term product

Market Risks purchase agreements; uncertainties associated with the cost of a new product vis-àvis its competitors and the possibility that a superior product could emerge; rising prices for product inputs including energy feedstocks; lack of indemnification.

Lack of Specialized

Inadequate workforce competence; cost of developing a knowledge base for Knowledge available workforce; inadequate reference knowledge for decision makers.

\section{Fiscal Barriers}

Unfavorable Fiscal Policy

Distortionary tax subsidies that favor conventional energy sources and high levels of energy consumption; fiscal policies that slow the pace of capital stock turnover; state and local variability in fiscal policies such as tax incentives and property tax policies. Also includes various unfavorable tariffs set by the public sector and utilities (e.g., import tariffs for ethanol and standby charges for distributed generators) as well as unfavorable electricity pricing policies and rate recovery mechanisms.

Fiscal Uncertainty

Short-duration tax policies that lead to uncertain fiscal incentives, such as production tax credits; uncertain future costs for GHG emissions. 
Table 2.1. Typology of barriers to the commercialization and deployment of GHG-reducing technologies (Cont'd.)

\section{Regulatory Barriers \\ Unfavorable Regulatory \\ Policies}

Regulatory Uncertainty
Distortionary regulations that favor conventional energy sources and discourage technological innovation, including certain power plant regulations, rules impacting the use of combined heat and power, parts of the federal fuel economy standards for cars and trucks, and certain codes and standards regulating the buildings industry; burdensome and underdeveloped regulations and permitting processes; poor land use planning that promotes sprawl.

Uncertainty about future regulations of greenhouse gases; uncertainty about the disposal of spent nuclear fuels; uncertain siting regulations for off-shore wind; lack of codes and standards; uncertainty regarding possible future GHG regulations.

\section{Statutory Barriers}

Unfavorable Statutory

Policies

Statutory Uncertainty
Lack of modern and enforceable building codes; state laws that prevent energy saving performance contracting.

Uncertainty about future statutes including renewable and energy efficiency portfolio standards; unclear property rights relative to surface injection of $\mathrm{CO}_{2}$, subsurface ownership of $\mathrm{CO}_{2}$ and methane, and wind energy.

\section{Intellectual Property Barriers}

High Intellectual Property Transaction Costs

Anti-competitive Patent Practices

Weak International Patent Protection

University, Industry, Government Perceptions
High transaction costs for patent filing and enforcement, conflicting views of a patent's value, and systemic problems at the USPTO.

Techniques such as patent warehousing, suppression, and blocking.

Inconsistent or nonexistent patent protection in developing countries and emerging markets.

Conflicting goals of universities, national laboratories, and industry concerning CRADAs and technology commercialization. 


\section{Table 2.1. Typology of barriers to the commercialization and deployment of} GHG-reducing technologies (Cont'd.)

\section{Other Barriers}

Incomplete and Imperfect Information

Lack of information about technology performance - especially trusted information; bundled benefits and decision-making complexities; high cost of gathering and processing information; misinformation and myths; lack of sociotechnical learning; and lack of stakeholders and constituents.

Inadequate critical infrastructure - including electric transmission capabilities and long-term nuclear fuel storage facilities; shortage of complementary technologies

Infrastructure Limitations that encourage investment or broaden the market for GHG-reducing technologies; insufficient supply and distribution channels; lack of O\&M facilities and other supply chain shortfalls.

Industry Structure

Natural monopoly in utilities disenabling small-scale competition; industry fragmentation slowing technological change, complicating coordination, and limiting investment capital.

Misplaced incentives when the buyer/owner is not the consumer/user (e.g.,

Misplaced Incentives landlords and tenants in the rental market and speculative construction in the buildings industry) - also known as the principal-agent problem.

Policy Uncertainty

Uncertainty about future environmental and other policies; lack of leadership

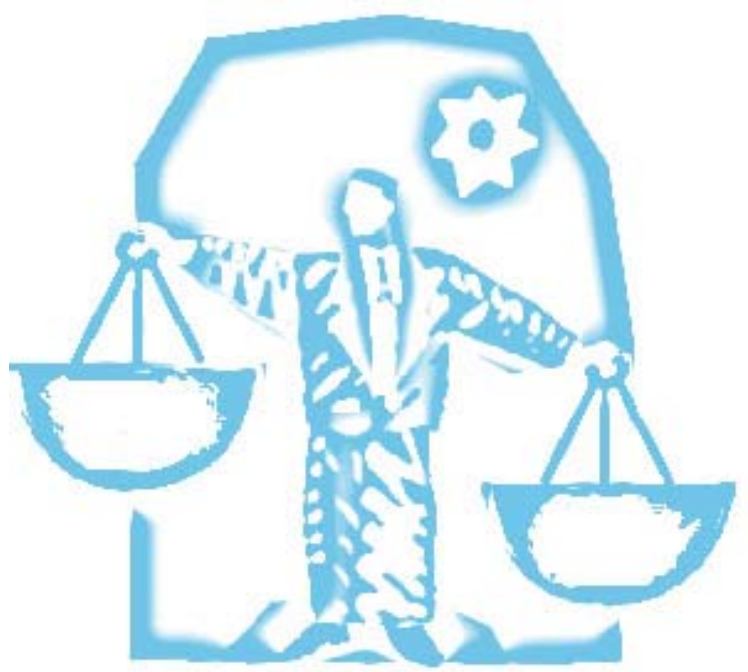





\section{3}

Cost-effectiveness is an important

predictor of the

success or failure of technologies,

systems, practices, and ideas. Higher

expenses can come in the direct form of higher costs for equivalent units, or they can come cloaked in

externalities, uncertainties, or transaction and opportunity costs.

\section{Cost-Effectiveness Barriers}

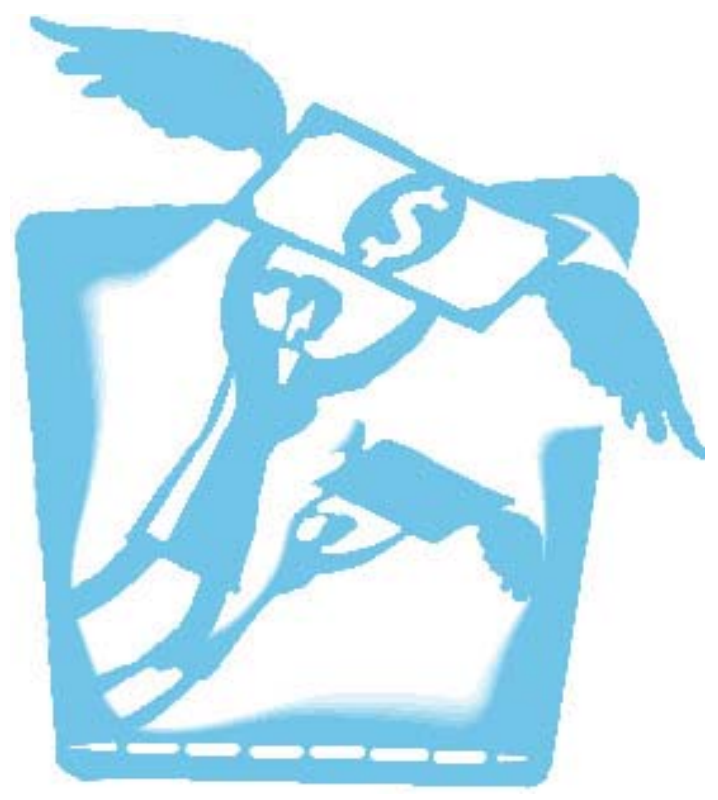

Barriers related to the cost-effectiveness of GHGreducing technologies often present potent hindrances to their deployment. These barriers to market entry and widespread penetration include high costs as well as technical and market risks. Schmalensee (2006) relates these barriers to either the lack of a performance advantage for the same price or the lack of a price advantage for the same performance. The existence of environmental externalities and the need for specialized knowledge present difficulties for GHG-reducing technologies attempting to compete in today's market. These five types of cost-effectiveness barriers are summarized in Table 3.1. 


\section{Table 3.1. Cost-effectiveness barriers}

\section{Cost-Effectiveness Barriers}

External Benefits and Costs

External benefits of GHG-reducing technologies that the owners of the technologies are unable to appropriate (e.g., GHG emission reductions from substitutes for high GWP gases and carbon sequestration). External costs associated with technologies using fossil fuels (e.g., GHG emissions and health effects from small particles) making it difficult for higher priced, GHG-reducing technologies to compete.

High up-front costs associated with the production and purchase of many low-

High Costs carbon technologies; high operations and maintenance costs typical of first-of-akind technologies; high cost of financing and limited access to credit especially by low-income households and small businesses.

Risks associated with unproven technology when there is insufficient validation of technology performance. Confounded by high capital cost, high

Technical Risks labor/operating cost, excessive downtime, lack of standardization, and lack of engineering, procurement and construction capacity, all of which create an environment of uncertainty.

Low demand typical of emerging technologies including lack of long-term product purchase agreements; uncertainties associated with the cost of a new

Market Risks product vis-à-vis its competitors and the possibility that a superior product could emerge; rising prices for product inputs including energy feedstocks; lack of indemnification.

Lack of Specialized Knowledge

Inadequate workforce competence; cost of developing a knowledge base for available workforce; inadequate reference knowledge for decision makers.

\subsection{EXTERNAL BENEFITS AND COSTS}

The efficient operation of markets may be compromised by the existence of unpriced benefits and costs. These "externalities" are benefits or costs resulting from a market transaction that are received or borne by parties not directly involved in the transaction. Externalities can be either positive, when an external benefit is generated, or negative, when an external cost is imposed upon others.

In the marketplace for GHG-reducing technologies, both positive and negative externalities operate as barriers to deployment. External environmental benefits exist because GHG-reducing technologies mitigate climate change and therefore reduce societal costs of warmer and more extreme weather. However, producers and consumers of these technologies are not rewarded for their climate mitigation benefits. On the other hand, external environmental costs impact the market for GHG-reducing technologies because greenhouse gases result from the consumption of fossil fuels. However, polluters do not pay for the resulting societal damages. This "free ride" makes it difficult for the higher-priced GHGreducing technologies to compete. In general, goods generating positive externalities are under-produced and goods generating negative externalities are over-produced (Weimer and Vining, 2005, pp. 91-95). The free market fails to encourage enough $\mathrm{CO}_{2}$ abatement because firms are not rewarded for the GHG emissions they displace, and the market fails to discourage climate-damaging emissions because polluters do not pay for the damage they cause. 
Externalities associated with GHG emissions reflect the intergenerational gap between emissions and their effects, as well as difficult analytical and ethical issues of measuring costs and benefits. For these reasons, climate change has been called "the greatest and widest-ranging market failure ever seen" (Stern, 2006, p. i).

External environmental benefits. When the marginal private benefit (MPB) of a good or service is lower than the marginal social benefit (MSB) (i.e., when positive externalities exist), then the good or service tends to be under-produced. As Weimer and Vining (2005) illustrate in Fig. 3.1, the result is a loss of social surplus equal to the area defined by “abd." This surplus exists because the market equilibrium will be at point "b" where the private demand curve crosses the supply curve (quantity $Q_{e}$ ) while the socially optimal equilibrium is at point “a” (quantity $\mathrm{Q}_{0}$ ). The supplier, of reduced GHG emissions in our case, cannot capture the full social value and under-produces. This is one of the principal market failures that prevents investments in substitutes for high GWP gases and in carbon capture and sequestration technologies. Because no value is placed on displacing, capturing, or storing greenhouse gases, the cheapest thing is to release them into the atmosphere.

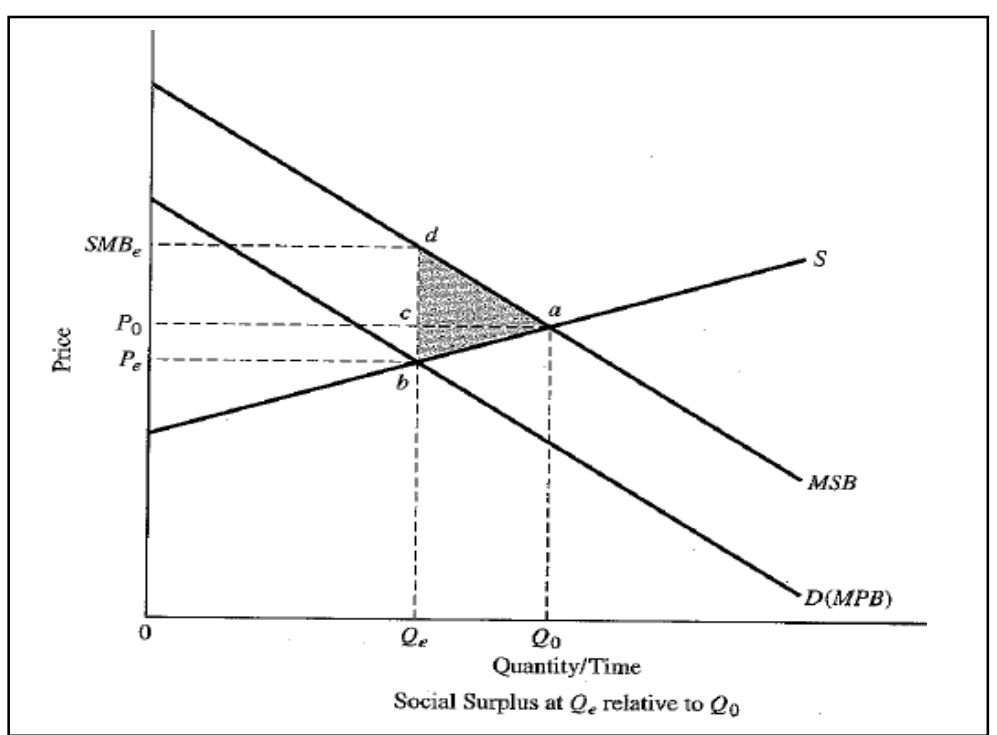

Fig. 3.1. Supply and demand of good with positive externality Source: Weimer and Vining, 2005, Figure 5.8

In the case of high GWP gases used in aluminum, magnesium, and other industries, it is difficult to change practices when the primary benefit - reduction of high-GWP gases - is a social good that does not generate any return-on-investment to the manufacturer. These external benefits prevent industry from innovating, since the principal driver for investing in improved processes is increased profit.

The situation is similar for $\mathrm{CO}_{2}$ capture and sequestration because other than for GHG mitigation there is little reason to purchase these products or use these technologies. As Hovorka (2006) put it, "Until there's a price signal associated with carbon capture, until companies can show that the capturing and storing carbon is cost-effective for them, it is not going to happen.” The diverse owners of current and future terrestrial sequestration resources like forests, croplands, and grasslands cannot capture the social benefits of improving the sequestering capacities of their resources as there is not a market for carbon. Until such a market exists, external benefits will remain a barrier. Consider the incomplete or nonexistent markets for carbon sequestration in forestry. The possibility of these markets being significantly valuable is not considered when there is a real market for forestry products that is at odds with the incomplete or nonexistent market for sequestered carbon (Bishop, 1998).

External environmental costs. Economic efficiency requires that for a given level of production of a product or service, marginal social benefits (MSB) and marginal social costs (MSC) must be equal. This occurs where marginal social costs and demand (D) intersect, as shown in Fig. 3.2. When products levy external costs on individuals who are not part of the transaction - that is, when marginal social costs are greater than marginal social benefits, the good or service tends to be over-produced. As Weimer and 
Vining illustrate in Fig. 3.2, the result is a loss of social surplus equal to the area defined by "ace.” Oversupply is illustrated by the difference between the quantity supplied at the market equilibrium, $\mathrm{Q}_{\mathrm{e}}$, and the socially optimal equilibrium quantity, $\mathrm{Q}_{0}$.

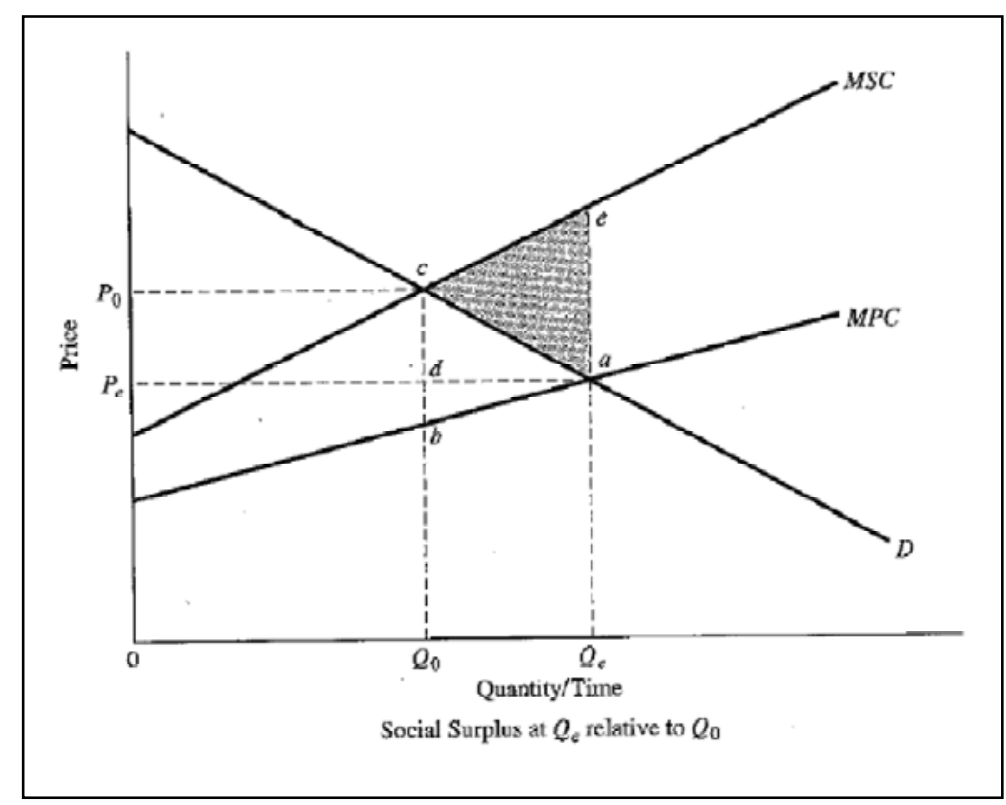

Fig. 3.2. Supply and demand of good with negative externality Source: Weimer and Vining, 2005, Figure 5.7

Unpriced environmental costs include a host of environmental impacts associated with the production, conversion, transportation, and use of fossil energy in addition to the emission of GHGs. For example, oil and natural gas production in the Gulf of Mexico exposes aquatic and marine wildlife to low-level releases of many chemicals through the seafloor accumulation of drilling muds and cuttings (Cooper and Sovacool, 2007). Mountaintop removal for mining coal in Appalachia has cracked building foundations, destroyed streams and other wildlife habitats, blighted landscapes, and diminished water quality (Cooper and Sovacool, 2007; EPA, 2006). Mountaintop removal and valley fill has become quite common; Fig. 3.3 illustrates this problem.

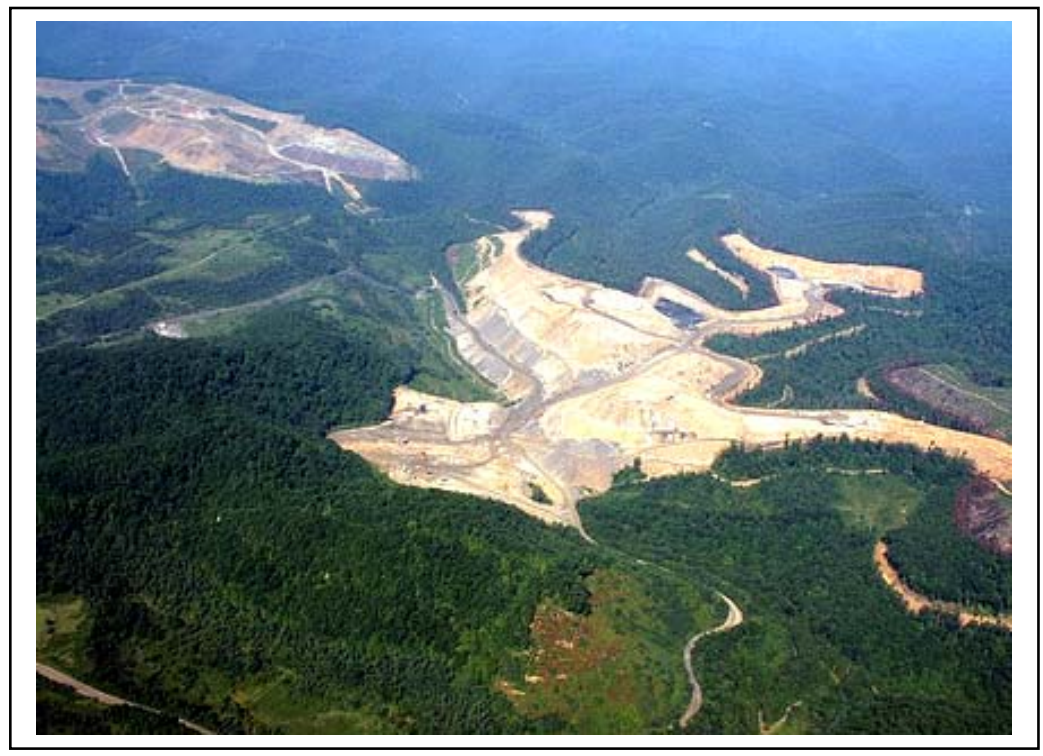

Fig. 3.3. Mountaintop removal coal mining project in West Virginia Source: ilovemountains.org 
Acid rain caused by the $\mathrm{SO}_{2}$ and $\mathrm{NO}_{\mathrm{x}}$ emissions of power plants continues to destroy fish and wildlife, despite great progress in reducing air pollution from three decades of "clean air” legislation. Between 1989 and 2003, $\mathrm{SO}_{2}$ emissions from electricity generation and combined heat and power systems has decreased dramatically from 17.1 million tons in 1989 to 11.7 million tons in 2003. These reductions were accomplished by installing pollution control devices at coal plants and industrial facilities, relying more on low-sulfur coal, and transitioning to cleaner fuels such as natural gas. Similar reductions are now needed in particulate matter, nitrogen dioxide emissions, and greenhouse gas emissions (Brown, 2007).

Because the market does not place any negative value on GHG emissions, fossil energy prices remain artificially low and more energy is consumed than is socially optimal. It is difficult to estimate the costs of such externalities, but fuel prices would rise significantly if they were to reflect their full social costs. With higher fuel prices, investments in energy efficiency, renewable and nuclear power, and alternative fuels such as ethanol and biodiesel would be more cost-competitive. When a market value exists for GHG reductions, traditional energy industries, like electric utilities and oil companies, will find a way to benefit from low-carbon energy alternatives. Reducing GHG emissions does not drive their behavior yet because there is essentially no market for GHG mitigation (Brent, 2006).

Of course, GHG-reducing technologies can also impose negative external environmental effects from their production and use. In fact, almost all technologies and actions have some impact on the environment positive or negative. Examples of negative environmental externalities associated with GHG-reducing technologies include: mercury in compact fluorescent bulbs, birds and bats killed by wind turbine blades, loss of biodiversity from large-scale monocultural biomass production, and long-term radioactivity and heat from used nuclear fuel.

Other externalities. Externalities are not only related to traditional environmental concerns. Many externalities are also social in nature, including education, research and national security. These externalities often compete for alternative policies and attention; for example, to promote health of the poor, lower energy prices are a goal that directly conflicts with the idea of reducing energy consumption overall as lower energy prices lead can lead to increased consumption. Policy makers tend to respond in different ways depending on how externalities are framed and which populations are effected.

The public goods nature of education and training is another example of unpriced benefits that, when under-produced, can hinder the deployment of GHG-reducing technologies. Investments by employers in creating a well educated, highly trained workforce are dampened because of the firm's inability to ensure that the employee will work long enough for that firm so as to repay its costs. The difficulties of selecting and installing new energy-efficient equipment compared to the simplicity of buying energy may prohibit many cost-effective investments from being realized. This is a particularly strong barrier for small and medium-sized enterprises. In many firms (especially with the current trend towards lean firms) there is often a shortage of trained technical personnel that understand and can explain the ability of energy-efficient technologies to generate a stream of cost savings that more than pay for any up-front installation premium.

Similarly, research and development (R\&D) efforts tend to provide societal benefits greater than those that can be captured by the entity doing the research and development. Even though researchers can patent their ideas, the problem of spillover of benefits exists (Newell, 2006). The unpriced benefits that accrue to society rather than the researcher discourage private investment in R\&D (Interlaboratory Working Group, 2000). Jaffe et al. (2005) summarize why companies might see this externality as a barrier: "a firm that invests in or implements a new technology typically creates benefits for others while incurring all the costs.” The degree to which firms reduce R \& D as a result of this externality varies.

In contrast, the public goods nature of national security is an example of an unpriced cost that, were it to be valued, would result in more favorable markets for alternative fuels. As it is, the national security and 
balance-of-payments implications of oil imports are not fully incorporated in fuel oil and gasoline prices. Under relatively tight market conditions, the physical concentration of oil reserves in a relatively small number of countries generates the potential for physical and price-setting supply disruptions. These market conditions impose national security costs by reducing foreign policy flexibility and complicating military strategy, especially during periods of rising oil demand and tightening world markets. Parry and Darmstadter (2004) estimate the premium paid for oil - that is, the costs to the U.S. from an extra barrel of petroleum consumption relative to the private costs paid by oil users. The premium has two main components, one reflecting US monopsony ${ }^{14}$ power in the world oil market and the disruption costs from potential future oil price. They note that recent estimates put the total premium at between around $\$ 0$ and \$14/barrel, equivalent to between 0 and 30 cents/gallon of gasoline; their best assessment is that the premium is around $\$ 5 /$ barrel.

Incomplete policies to internalize externalities. While the United States has not established a national market for GHG emission reductions, regional markets are emerging and some emissions trading programs have been established. For example, seven northeastern states are currently participating in the Regional Greenhouse Gas Initiative (RGGI), which is focused on regional trading of power plant carbon emissions. This group began in 2003 and intends to grow in scope, to include other gases, and in size, to include other states and perhaps Canadian provinces (RGGI, 2006). Similarly, the state of California launched a GHG reduction plan with the September 2006 adoption of the Global Warming Solution Act, which has a goal of reducing emissions to 1990 levels by 2020. This legislation requires that the state monitor and enforce emissions reductions from those sources deemed feasible to observe (California, 2006).

In addition, GHG-reducing technologies have received significant R\&D assistance and tax subsidies in recent years. The federal government spends about $\$ 3$ billion/year on climate change technology development and \$2 billion/year on climate change science. In 2003 and 2004, the U.S. government spent approximately $\$ 3$ billion/year on tax subsidies for GHG-reducing technologies, including for instance the renewable energy production tax credits. With the passage of EPAct in 2005, an additional \$14.5 billion of incentives are authorized over the ten-year period covered by the legislation (Marlay, 2005). For example, there are:

- $\quad$ tax credits for new advanced lean burn and hybrid electric cars and trucks,

- \$2000 for new homes using 50 percent less heating and cooling energy than IECC code 2004 supplement,

- production tax credits for renewable energy,

- nuclear licensing risk insurance, and much more.

However, these subsidies are seen by some to be of insufficient magnitude relative to the costs of global climate change, and may appear to be a hodgepodge of varying policy instruments with no sense of equalization (for additional discussion, see the discussion of Fiscal Barriers in Section 4). Some GHGreducing technologies are being over incentivized, others under incentivized. As a result many consumers and technologists consider the subsidies to be cost ineffective and wasteful (Newell, 2006). In contrast, providing a broad-based price on GHG emissions (possibly through a carbon cap and trade system or tax) could create a level playing field for all fuel and technology options (NCEP, 2004). Without such a market for greenhouse gas reductions, the commercialization and deployment of GHG-reducing technologies will likely remain impeded.

\footnotetext{
${ }^{14}$ In reality, the oil market has many buyers. The reference to the U.S. as a monopsony is due to the large amount of oil consumed in the U.S. relative to the rest of the world such that changes in quantity of oil consumed in the U.S. can impact worldwide prices.
} 


\subsection{HIGH COSTS}

If GHG-reducing technologies were cost competitive with conventional technologies - all other things being equal - they would have equal potential for being adopted. ${ }^{15}$ However, many GHG-reducing technologies are not able to compete on a cost basis with conventional technologies.

High costs are a barrier faced by most new and emerging technologies that have not yet benefited from improvement via learning or from development of mass markets to bring significant economies of scale. Their capital investments take time to pay off, yet they must compete with existing products that have fully depreciated production facilities and can therefore underprice the new products. In addition, the cost of capital tends to be high because of technical and market risks and uncertainties, and the cost of support services such as O\&M are costly because they are still under development.

High up-front costs. GHG-reducing technologies often have inherently higher up-front costs due to the need for additional features and subsystems required to achieve GHG reductions. Additional features or systems can increase the capital to operating expense ratio. For example, $\mathrm{SF}_{6}$ is a high GWP gas used in the magnesium industry as a cover gas. $\mathrm{SO}_{2}$ is being considered as an alternative, but it is more toxic and therefore requires additional monitoring (and cost) to deal with the health and safety issues. There are no simple drop-in substitutes (Rand, 2007). Similarly, DeLaquil (1996) finds that high up-front costs make capital intensive solar-electric projects "not appear as attractive to investors as expense intensive conventional technologies when compared using discounted cash-flow analysis.”

On a basic level, new technologies can be envisioned at the top of a learning slope characterized by their

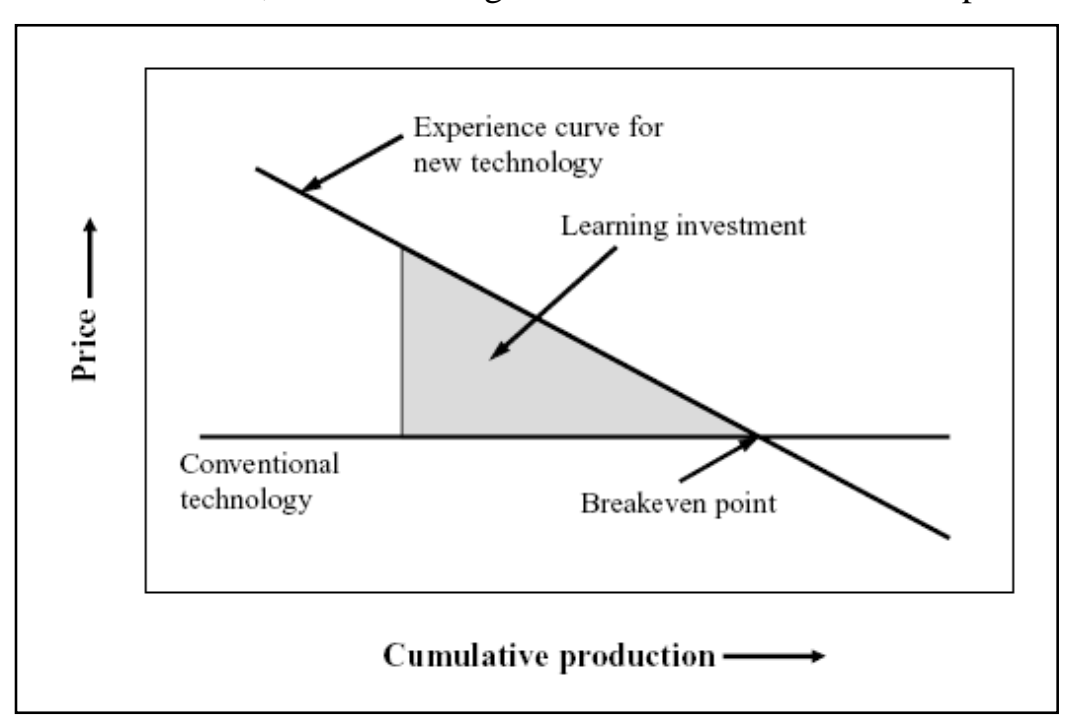

Fig. 3.4. Costs are inversely related with production experience Source: Gallagher, Holdren, and Sagar, 2006, Fig. 6 high costs and low production compared to incumbent technologies which are at the bottom of the hill with low costs and high cumulative production - as shown in Fig. 3.4 (Gallagher, Holdren, \& Sagar, 2006). Using a centurial history of pulverized coal technology, Yeh and Rubin (2007, p.2003) show stages of technological learning being "rapid growth, maturity, plateau (stasis), and reinvigoration," which they offer can bound projections of learning and cost-reductions over time for other technologies. High up-front costs are also typical of low-GHG energy supply options, green buildings, and clean vehicle technologies.

Nuclear power illustrates the problem of high upfront costs typical of low-GHG energy supply options. Nuclear fission power has demonstrated years of extremely low relative fuel costs (compared to coal, oil, and natural gas) and other operating and maintenance costs, but the high upfront costs make investment difficult. A new nuclear plant today would cost perhaps $\$ 3$ billion to construct, and the licensing, design, planning, and building requirements are so extensive that it would not open until 2015, according to

\footnotetext{
${ }^{15}$ Note: other factors go into the complicated decision of technology adoption. In this simplifying case, we are assuming competition between technologies completely identical in all regards except their GHG-reduction ability.
} 
Christopher Crane, president of Exelon Nuclear (Friedman, 2007, p. 67). This long construction cycle dilutes utility earnings - especially for small utilities, hindering investment (D. Brown, 2007).

Other examples high up-front costs for low-GHG energy supply are clean coal and solar photovoltaics. The capture, separation, and sequestration of carbon from integrated gasification combined cycle plants can add as much as 40-80 percent to the costs of a coal plant with no current cost recovery option (CCTP, 2006). In addition, "application of $\mathrm{CO}_{2}$ capture technologies in a power plant is highly costly in terms of efficiency and net power output reduction" (Kakaras et al., 2007). This power reduction penalty can be as much as 20 percent (MIT, 2007). Similarly, solar PV today is too expensive by a factor of 2 to 4 to compete with fossil fuels. If PV's learning curve of 20 percent continues (i.e., if costs reduce by 20 percent every time production doubles), this low-carbon technology could be cost-competitive by 2020 (Rohatgi, 2007). Further, PV technology may continue to be aided by advancements in silicon production spurred by digital media production (Gallagher, Holdren, and Sagar, 2006). However, research has shown that although PV costs have decreased considerably over the past decades, continued decreases will be dependent upon the size of the market and where PV is on the learning curve (Nemet, 2006).

Many green building technologies are cost effective on a life cycle basis but are often not adopted because consumers are unwilling to pay the higher upfront costs, or because the first costs are born by someone other than the ultimate user (Schmalensee, 2007). For example, commercial buildings are generally bid out for construction; low bids (winning bids) include basic building requirements, not energy efficient design or elements. Additionally, the property owner may not know if higher up front expenditures in improved building design will translate to increased value or equity in the property later. Similarly, in the residential housing market, speculative builders invest in houses with the hope of attracting homebuyers; higher upfront costs associated with "green" features may not be valued by home buyers due to complexities associated with decisions such as home purchases and the inability to "warrant" efficiency levels.

As clean vehicles, hybrid electric and plug-in electric vehicles have a cost premium of several thousand dollars over their internal combustion engine counterparts. Carbon composites and other lightweight materials used in these vehicles cannot yet compete on a cost basis with steel, and this material cost is an example of inherently higher costs. Similarly, hydrogen vehicles are still requiring further development because storage systems are too heavy and costly to provide the desired driving range (DOE, 2006b).

It is important to note that while GHG-reducing technologies may be hindered by their characteristic high costs, many still find niche markets. That is, despite the higher cost, these technologies are adopted to some degree, with sales driven by a particular attribute or quality that appeals to a niche group of consumers (e.g. 'green' consumers). For example, over 350 of the new all-electric sports car, Tesla, have been purchased at a cost around \$100,000 each. Elon Musk, the entrepreneur selling these vehicles admits they are reaching a small market; "[t]he average net worth of the first 120 customers is over $\$ 1$ billion" (quoted in Duncan, 2007). The real difficulty for a new technology is pushing beyond the niche market to become a more mainstream technology and enjoy the reductions in costs that come with learning and large scale production.

High cost of financing. The high cost of capital and constrained credit markets are also significant barriers to mitigation technologies. GHG-reducing technologies have to compete for financial and technical resources against projects that achieve other company goals and against familiar technologies. Financial constraints can hinder diffusion of technologies within industries; a technology may not spread across its potential market due to the constraints of expected adopters which do not all have the same ability to raise capital (Canepa and Stoneman, 2004). In addition, if the technology involved is new to the market in question, even if it is well-demonstrated elsewhere, the problem of raising capital may be further exacerbated. 
Capital market barriers can inhibit efficiency purchases. Although, in theory, firms might be expected to borrow capital any time a profitable investment opportunity presents itself, in practice firms often ration capital - that is, they impose internal limits on capital investment. The result is that mandatory investments (e.g., required by environmental or health regulations) and those that are most central to the firms' product line often are made first. Projects to increase capacity or bring new products to the market typically have priority over energy cost-cutting investments (Dias, 2006).

Not only is there competition internal to firms looking to adopt GHG-reducing technologies, but there is competition in financial markets for equity financing. "While all investment is characterized by uncertainty, the uncertainty associated with the returns to investment in innovation is often particularly large...A firm attempting to raise investment capital to fund the development of new technology will therefore find such investors skeptical about promised returns, and likely to demand a premium for investment that carries such risks” (Jaffe, Newell, and Stavins, 2005). To be clear, while the new technology is fighting for equity financing to be produced at all, the incumbent technology's production process is being improved with in-house money from previous sales. Unruh (2000, p. 823) states, "In general, financial institutions prefer making loans to companies with collateral and a proven ability to service debt. However, companies with these prerequisites tend to be dominant design producers, and therefore funds are most readily available to successful firms within the existing network. On the other hand, when funding is sought for technological innovation that diverges from the existing dominant design, it frequently comes from venture capital or government research programs with much stricter conditions or higher costs."

Different energy producers and consumers have varying access to financial capital and at different rates of interest. Capital is typically easier to raise and less costly for incumbent firms and technologies, which contributes to the technology "lock-in" phenomenon (Unruh, 2000). In general, energy suppliers can obtain capital at lower interest rates than can energy consumers - resulting in an "interest rate gap." Differences in these borrowing rates may reflect differences in the knowledge base of lenders about the likely performance of investments as well as the financial risk of the potential borrower. At one extreme, electric and gas utilities are able to borrow money at low interest rates while at the other extreme, lowincome households may have no ability to borrow funds, resulting in an essentially infinite discount rate for investments in energy efficiency. Train (1985) surveyed the literature on discount rates and found that,

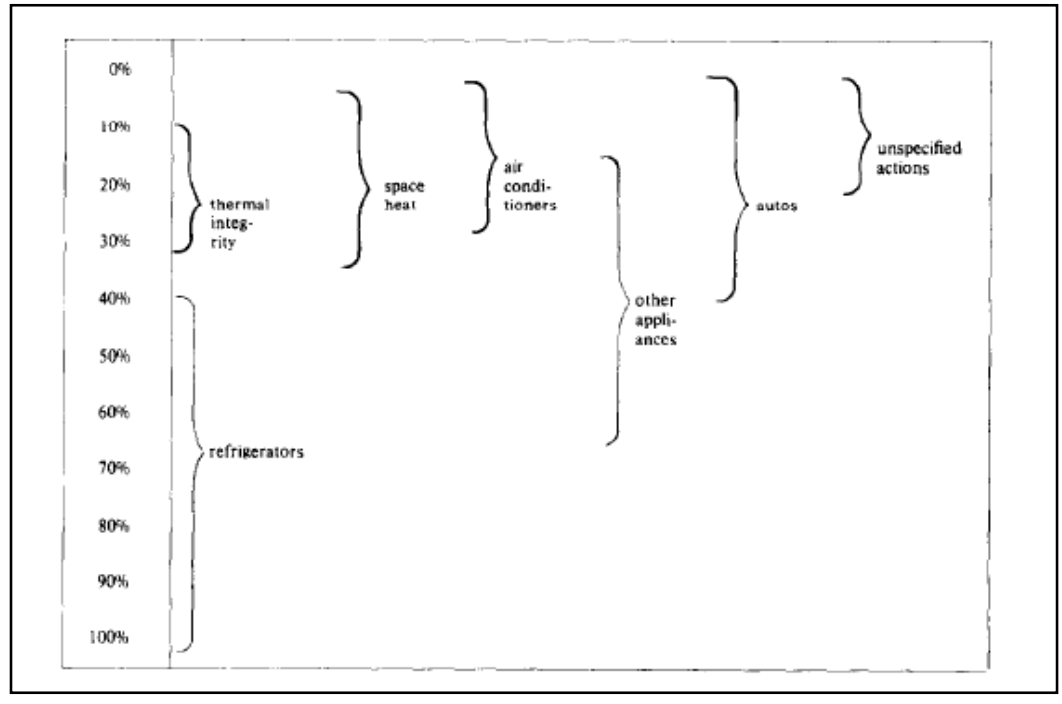

Fig. 3.5. Estimates of average discount rates Source: Train, 1985 in general, discount rates for efficiency investments tend to decrease as income increases. Low-income persons have little access to capital and are often unable to calculate life cycle costs. These differences contribute to the wide range of discount rates shown in Fig. 3.5.

The limited availability of capital in general, combination with the limited access of low-income households and small businesses to capital markets in particular hinders the penetration of many alternative energy technologies. Credit for household-scale renewable energy systems, for instance, is particularly scarce in rural areas 
(Beck and Martinot, 2004). Available loan terms may be too short relative to the equipment or investment lifetime. In contrast, financing for larger conventional energy projects is readily available.

The market for energy efficiency (including residential, commercial, and industrial consumers) faces interest rates available for efficiency purchases that are much higher than the utility cost of capital. In addition, it has been shown that firms typically establish internal hurdle rates ${ }^{16}$ for energy efficiency investments that are higher than the cost of capital to the firm. Elliott (2006) relates that while typical return on investment (ROI) requirements are between 10-12 percent, firms approach efficiency investments with the view that the costs are doubled and savings halved; this results in an implicit ROI for efficiency investments upwards of 30 percent.

Similarly, the discount rate that consumers appear to use in making many energy efficiency decisions is higher than the interest rate at which consumers could borrow money. Implicit discount rates are higher for efficient technologies than for conventional technologies (Dias, 2006). Typically, consumers require investments in energy efficiency to pay back in three years or less (Levine et al., 1995). This discount rate gap has been widely observed in the literature and is reflected in some key energy models such as the Energy Information Administration's National Energy Modeling System. Information asymmetry, institutional barriers, short time horizons, and non-separability of energy equipment all contribute to the discount rate gap, and each is amenable to policy interventions that could move the rates down towards auto-loan, mortgage, and opportunity costs. For illustration of this gap, consider heat pump units which are available in a range of efficiencies and costs; homeowners may choose the cheapest model allowed by local building codes rather than the cheapest model on a life cycle cost basis due to a high implicit discount rate.

Large technologies, like power plants, exhibit a different form for the initial hurdle to be overcome. These technologies are generally able to be adopted following a 'proof of principle' demonstration. Because such a demonstration often requires a one-time investment of great magnitude, this hurdle is called the "mountain of death" in contrast to the "valley of death" that refers to the more generic shortfall of funds when government support has tapered off and private funds are not yet available (NorbergBohm, 2000).

To summarize, high costs have many causes. Because uncertainty and risk tend to inflate capital costs, new and emerging technologies are often more expensive than pre-existing technologies. Until they achieve significant market penetration, their costs are often non-competitive. Some technologies also have inherently higher costs due to their high-precision method of production, additional subsystems, and unusual materials or other components. Increasing the market size for these technologies is not likely to translate to lower costs unless it also leads to a next generation of technological innovation that reduces costs or improves performance.

\subsection{TECHNICAL RISKS}

Technical risks can be major barriers when there is insufficient validation of a technology's performance, and they often hinder the introduction of new technologies. Without validated technical information, the less proven technology will find it hard to compete with incumbent products and approaches. In addition, with high technical risks come difficulties in attracting the investment capital needed for product improvements and production cost-reductions.

Insufficient validation of technology performance. Insufficient validation of technology performance hinders many GHG-reducing technologies. While some carbon mitigation approaches are fairly mature

\footnotetext{
${ }^{16}$ Hurdle rate refers to the expected rate of return on a potential investment that is required by the investor.
} 
and well understood such as afforestation and forest management approaches to biosequestration (Murray, 2006), that does not necessarily eliminate technical risk. For example, bio-sequestration has other characteristics that may reduce its attractiveness as a mitigation option, such as issues of permanence and fragmentation, which are discussed elsewhere in this report.

Other GHG-reducing technologies are first-of-a-kind and face technical risks associated with unproven technology. Because their reliability is uncertain, investors and users such as utility companies tend to push toward opting for more familiar rather than new technology options (Braitsch, 2007). Generally, this sort of risk declines after some number of units have been adopted and used for a period of time. A decline in risk and cost is associated with nth-of-a-kind adoptions (where $\mathrm{n}$ varies by technology), and this trajectory is commonly represented in energy models such as EIA's National Energy Modeling System. ${ }^{17}$ In addition to the improved validation that comes with sheer number of units in the marketplace, technologies may still be perceived as risky if there is little experience with them in a particular application or region. For example, the lack of visible installations and familiarity with renewable energy technologies can lead to perceptions of greater technical risk and therefore higher capital costs than for conventional energy sources.

Lack of monitored demonstrations. Even after extensive laboratory and field testing, many seemingly worthwhile innovations fail to take hold because they have never been demonstrated in the kind of operating environment typical of its intended users. Without validated information documenting the technology's technical feasibility, reliability, durability, compatibility, ease of use, and cost-effectiveness, the less proven technology will have difficulty competing in the marketplace (Brown et al., 1993). Unsupported testimonial data about the performance of a new GHG-reducing technology generally carries little weight in the industry at large. The provision of technical performance data by "third party monitors" such as governmental agencies and trade groups, on the other hand, can significantly reduce perceived technical risks. Hybrid solar lighting (see Box 5.1 and Lapsa et al., 2007) is one of many technologies that are in the process of being demonstrated in an effort to reduce the perception of risk in investment in these technologies.

Scalability Problems. Technical risks are often resolved during the R\&D process only to transition into problems of scalability as the technology moves into the production phase. Technologies that appear sound may fall into deployment pitfalls if scaling up of production facilities does not go as planned or if scaling cannot be maintained with the current design. For example, as wind turbines scale larger, the parts must get lighter because they simply could not support the current engineering; "[a]ll that stuff in the cell has to get lighter, so the way we build these generators has to change” (Vlatkovic quoted in Duncan, 2007). Additionally, moving from laboratory tests to larger scale demonstrations or commercial production removes a great deal of control over the environment. This loss of control can reduce performance in unexpected or undesired ways. Solar photovoltaics clearly demonstrate this issue as laboratory efficiencies of 19 percent for crystal silicon and 10-17 percent for thin films were not duplicated in modules (11-14 percent and 4-8 percent) or in the field (9-13 percent and 3-7 percent) (DeLaquil, 1996). Years of advances in processes have led to increases in efficiencies across the board, but the gap between performance in the laboratory versus the field remains today.

\footnotetext{
${ }^{17}$ An overview of the NEMS model can be found at http://www.eia.doe.gov/oiaf/aeo/overview/index.html
} 


\subsection{MARKET RISKS}

The commercialization and deployment of technologies is largely a private-sector activity to gain market advantage ultimately leading to increased profits. Consumers are not likely to adopt otherwise costly GHG-reducing technologies and practices in the absence of policies or incentives. Market risks include: low demand typical of emerging technologies; uncertain feedstock and product prices; the possibility that a superior technology will emerge making the newly commercialized technology obsolete; and lack of indemnification.

\section{Low demand typical of emerging} technologies. Usually, when new technologies are first launched, niche markets - early adopters - will begin to consume the technology. As awareness of the technology increases and uncertainty decreases, adoption begins to pick up until it reaches a plateau; this model is generally referred to as simply "the Scurve.” However, technology adoption along this curve is certainly not uniform, and this curve can also indicate that the technology is undergoing incremental improvements as adoption increases, as shown in Fig. 3.6.

Like most new products, GHG-reducing technologies generally start with niche markets and over time, and only if successful, do they finally secure larger and longer-term product purchase agreements. As described in section 2 , technological innovation depends on science push and market pull; long-term,

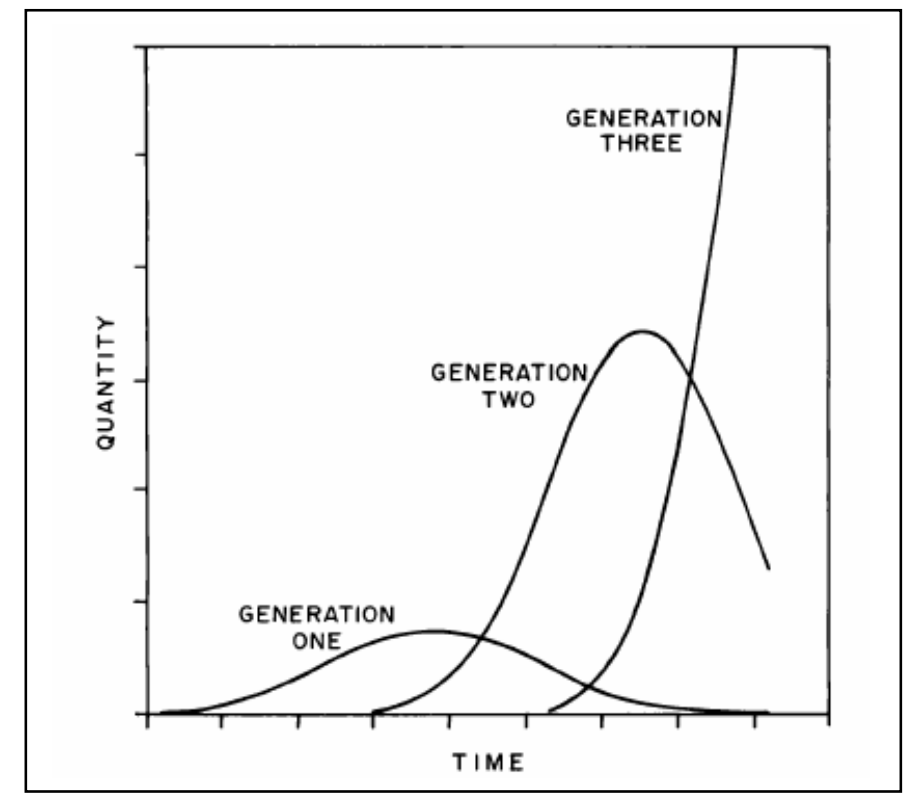

Fig. 3.6. Incremental improvements in new technology Source: Norton and Bas, 1987, Fig. 1 usually government, purchase contracts for novel defense or pharmaceutical technologies encourages innovation in these sectors by providing significant demand pull (Norberg-Bohm, 2000). The risk of low demand for new technologies is that the technology may not be able to obtain financing long enough to move it through the niche market to the point of profitability.

Uncertain costs of production. The volatility of energy prices is highly problematic for the success of many GHG-reducing technologies. Because alternative energy resources tend to be more expensive than conventional fossil fuels, they compete most successfully when the price of fossil energy is high. When prices rise and fall, development of alternative energy resources becomes uncertain. In addition, public subsidies tend to track the up and down trajectory of energy prices. When oil prices go up, government subsidies and private sector investments in alternatives rise; when oil prices drop, the government loses interest and investors in alternatives suffer (Friedman, 2007, p. 51). Investments in ethanol and clean power technologies are cases in point.

The rise in oil prices in 2004 and 2005 gave entrepreneurs an opportunity to develop bioethanol alternatives (e.g. cellulosic rather than corn ethanol). If oil prices drop, these entrepreneurial activities could recede. Entrepreneurs are more nimble than large companies, but they also are more vulnerable. It has been predicted, for example, that a drop to $\$ 30$ per barrel would quench the entrepreneurial fire (Reisert, 2006). Without greater price and policy certainty, it is difficult to know how large the market will be and how to value investments in next generation bioethanol development. Similarly, the large 
investments needed to build wind farms, clean coal, and nuclear plants are handicapped by uncertainties about long-term fossil fuel prices.

Some GHG-reducing technologies use fuel feedstocks and therefore area also vulnerable to the rise and fall of energy prices. Combined heat and power (CHP), for instance use natural gas in reciprocating engines, microturbines, and fuel cell, and when prices for this fossil fuel soar, the viability of CHP plummets. Some regulators are putting in place discounted natural gas prices for CHP application, acknowledging that CHP operates in a clean, baseload power mode (Brent, 2006).

Initial capital costs for GHG-reducing technologies are often higher per unit of energy (i.e. BTU or kW) than for conventional technologies, but on a life-cycle cost (LCC) basis they are often cost competitive. While the initial capital outlay is often well known, the operating costs required over the projected operating life of the technology depend on future fuel costs, operation and maintenance costs, etc. Given the uncertainties associated with forecasting future fuel and other costs, estimates of LCC are often discounted.

In general, companies can afford to invest in GHG mitigation only to the extent that their investments are compensated by lowered energy or raw material costs, or some similar benefit. As a result, most of the mitigation actions taken to date by industry have been "no-regrets" options, i.e., activities that show an economic or other return that compensates for their cost. For example, Nicholson (2004) reported that the projects $\mathrm{BP}$ undertook to lower its $\mathrm{CO}_{2}$ emissions by 10 percent increased shareholder value by $\$ 650$ million. There are, no doubt, many instances when companies have implemented energy efficiency or other projects, in response to market forces or government policy, without being aware of their GHG mitigation benefits.

Another high-level barrier related to cost-effectiveness is the long-term viability of some of the industries that utilize high global warming potential gases, such as perfluorocarbons (PFCs) in the aluminum industry. China is now the largest global producer of aluminum with roughly 100 primary aluminum facilities compared to 11-12 in the United States. The long-term health of the U.S. industry is in question, which makes it difficult to undertake the significant facility upgrades necessary to eliminate PFCs, such as using inert (non-carbon) anodes (Rand, 2006).

The possibility of new competing products. Uncertainties associated with the production costs of new products and the possibility that a superior product might emerge are two of the reasons why firms generally focus on their existing competencies and away from alternatives that could make their present products obsolete. ${ }^{18}$ Capital investments in firms go preferentially toward perfecting the performance and reducing the production costs of existing products. This technology "lock in" phenomenon helps to explain the fact that new enterprises and not incumbent firms are typically the source of radical innovations that displace existing dominant designs (Foster, 1986; Unruh, 2000). Lock-in is also reinforced by financial institutions, which prefer to make loans to companies with collateral and the ability to repay debts characteristics of successful firms within the existing network (Unruh, 2000).

Liability risks. Liability is always an issue; however, new technologies and ideas face barriers with unknown liabilities. Parties involved may not know who is liable in case of a casualty or they may not have estimates for financial loss associated with being the liable party. When failure of a technology may cause harm, liability must be established and the expected magnitude of costs should be known. Investors may be unwilling to become involved in a technology where there is unlimited liability. This barrier has

\footnotetext{
${ }^{18}$ There are always exceptions. How companies remain competitive in their markets varies; some firms may conduct process improvements while others incorporate cutting edge technology into their existing products to create new products. The discussion is a generalization.
} 
been overcome for nuclear fission power with the Price-Anderson Act, which limits the liability of any one utility in the event of an incident. This sort of instrument is known as indemnification, when a party's total liability is limited by some other mechanism.

Most consumers do not face liability levels that necessitate indeminification. Rather, they may face liability or risks related to their existing loans, suppliers, or customers. Actions to minimize risks often cause GHG emission excesses. For instance, some farmers over apply fertilizer as a cheap form of insurance against unfavorable weather (Murray, 2006). Similarly, there is a false conception in buildings and industry that bigger HVAC units give greater reliability; in reality, they are less efficient because oversized units cycle on and off more frequently. Right sizing and best practices for installing HVAC equipment are important to optimize indoor heating, cooling and dehumidification as well as energy efficiency. However, consumers typically do not understand this and mistakenly opt for "bigger is better" with negative results for both comfort and energy performance (Coakley, 2006).

Liability risks are becoming apparent in terrestrial sequestration. Storing carbon in vegetation puts it into a volatile state, as with fire or harvesting that can re-release the carbon, creating a potential liability. With carbon markets, landowners may already have been paid for the storage, so there are complex issues of repayment in the case of loss. One of the impediments to sequestration improvements, then, is markets for insuring standing forests are rather thin with few participants (Murray, 2006). In major timber regions such as New Zealand and, more recently parts of the southern U.S., some insurance markets for timber have developed, but coverage is not widespread. As a result, there's little current ability to extend an existing insurance infrastructure to include carbon, though that could change if carbon markets generate value at risk in (and therefore insurance demand for) standing forests.

\subsection{LACK OF SPECIALIZED KNOWLEDGE}

Specialized knowledge is necessary for success of nearly all technologies. For established technologies, this knowledge is usually transferred in colleges or technical schools or through apprenticeship programs. However, in many markets for GHG-reducing technologies, there is a limited supply of skilled personnel who can install, operate, and maintain the required equipment and systems and few, if any, training programs are in place; the problem is even more pronounced for novel technologies. While specialized knowledge for workers is probably the largest and most critical gap, knowledge gaps also exist for businesses and scientists. Business managers lack knowledge of how or even why to explore GHGreducing technologies over status quo technologies, and scientists lack entrepreneurial skills needed for project development and management; both of these contribute to dampening the ability of some GHGreducing technologies to expand.

Lack of specialized knowledge is not cited specifically in most literature on this subject, but rather it is wrapped into infrastructure issues. Experts in many fields, including buildings, solar photovoltaics (PV), nuclear fission, and industrial efficiency identified lack of specialized knowledge - or investment in human capital - as a critical barrier to commercialization and deployment of GHG-reducing technologies.

While not discussed in detail here, there is belief that some technologies never leave the lab because of the lack of business knowledge among scientists and researchers (Barash, 2007). This may explain why such a small percentage of entrepreneurs are starting businesses to "pursue the commercialization of an innovative new process, product, or service” (Council on Competitiveness, 2007). ${ }^{19}$

\footnotetext{
${ }^{19}$ With 15 percent of all new U.S. start-ups falling into this category, the U.S. has the highest participation in this sort of entrepreneurship in the world, but it is still a small set of new businesses (Council on Competitiveness, 2007).
} 
Inadequate workforce competence. Lack of technical knowledge to produce skilled workers to install, operate, maintain and evaluate technology is generally considered to be a product of inadequate or unavailable training programs. Worker training program quality and availability are very technology and location specific. Some of the variability in these programs is described below with technology specific examples; technologies not described here may face similar knowledge barriers.

In the buildings industry, few small enterprises have access to sufficient training in new technologies, new standards, new regulations, and best practices. Local government authorities tend to face this difficulty as well with building officers working without skills necessary for maintenance and installation of technologies which increase efficiency. The auto and truck repair and service labor force lacks knowledge required to support advanced power train designs and alternative fuels; similarly, transition to a large-scale hydrogen economy would require that training and certification systems are developed to address the technical, safety, and environmental challenges (NAE, 2004).

The PV industry lacks not only trained workers but adequate purchasing channels - consumers can not find complete systems or get them installed or maintained (Rohatgi, 2006). The Interstate Renewable Energy Council is working with related organizations to identify where standards and certification are necessary and provide assessment of existing training programs. Only eight states (CA, CO, ME, NC, NV, NY, OR, and TX) had providers in 2006 for NABCEP PV Entry Level Certificate of Knowledge - a basic training program in photovoltaics (Weissman and Laflin, 2006).

The nuclear industry is concerned about not only trained nuclear engineers and operators but the availability of qualified construction and fabrication talent. Many of these craftsmen, like welders, boiler makers, and heavy equipment operators go through multi-year apprenticeships to do quality work, and there are doubts that the current supply of craftsman would be sufficient to meet expected fission plant demand. The craftsmen shortage is related to possible supply chain issues as the United States lacks some heavy machining capacity necessary for production of certain fission reactor parts. Trained engineers, in nuclear and other fields, are in high demand for reviewing nuclear licensing applications as well as fulfilling applied engineering roles in nuclear power plants and auxiliary industries (Rushton, 2006).

Economic sectors that are large or diverse, like agriculture and forestry, lack specialized knowledge on specific technologies and practices simply due to the difficulties of disseminating information to the body. The diversity of these two sectors impacts technologies related to terrestrial sequestration, methane recovery, and nitrous oxide emissions from agriculture.

Industries which utilize high GWP gasses in their processes face additional knowledge barriers because there are not existing substitutes that can be dropped into the current system; these industries must maintain the status quo, face substantial costs for conversion of processes, or invest heavily in health and safety analysis to protect against substitute gases which are more toxic.

Beyond technical training, the U.S. is producing proportionally fewer domestic scientists and engineers as indicated by declining percentages of U.S. citizens earning doctoral degrees in science and engineering fields (Council on Competitiveness, 2007). Loss of professional research scientists could decrease our innovation capabilities and may be linked to declining technical ability in general. This could be quite problematic considering the wide variety of technical jobs created by new energy needs.

The Sunday Times (2007), a U.K. paper, recently had a feature section on energy careers, highlighting the international need for highly trained personnel, including engineers - aerospace, environmental, mechanical, nuclear, petroleum, etc, and many other technical trades. For example, pipefitters, linemen, electricians, and other craftsmen and technicians help to build and maintain energy equipment and facilities. Traditionally less skilled laborers are also necessary for construction and physically intense 
offshore work. Outside of labor, analysts, managers, and policy professionals project the future and manage ongoing work.

Inadequate reference knowledge of decision-makers. The knowledge barriers that business managers face are exacerbated by the absence of motivation to obtain the knowledge and absence of trust of those who may be able to impart knowledge. "The number one issue with increasing end-use efficiency is the shortage of qualified energy managers and analysts" (Elliott, 2006). Business managers in commercial and industrial sectors are facing knowledge barriers, but commercial managers are more likely to adopt new technologies because the main efficiency improvements are related to common technologies, like lighting and air conditioning. Industrial managers, however, have very specific energy consuming (and GHG emitting) technologies that do not have off-the shelf improvements. Additionally, industrial sectors may not trust companies like energy services companies (ESCOs), which specialize in energy efficiency technologies, because these companies do not have industry specific knowledge to provide accurate estimates to the manager; these same managers may lack resources to hire in-house energy experts (Elliott, 2006). This is partially due to the small (line-item) cost of energy consumption that industry managers face; “they don't appreciate that these costs can be controlled, and that it can be a way to increase profit margins" (Dias, 2006).

Some technologies face widespread misconceptions at the managerial level. Wind, for example, has proven to be reliable and profitable in Europe and parts of the United States, but it is still often considered to not be a useful major contributor due to its variability. Ed DeMeo (2006) of Renewable Energy Consulting Services states, "Most high level leaders don't have wind in their vocabulary in any meaningful way. They think of it as a niche technology."

Clearly, lack of specialized knowledge plays a role in hindering commercialization and deployment of GHG-reducing technologies; the extent of the barrier imposed seems to be very technology specific. Many technologies would likely benefit from development of training codes and standards that could be used to ensure that a skilled workforce is available. Also, industry, forestry, and agriculture may benefit from creation of social networks to foster trust and speed the distribution of GHG-reducing technology knowledge among members.

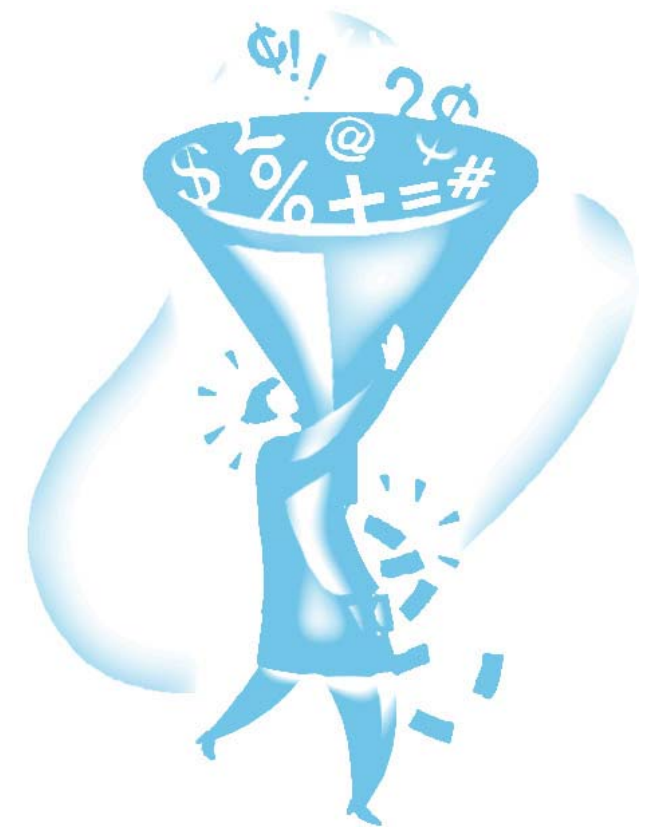




\subsection{CONCLUSIONS}

Cost-effectiveness is an important predictor of the success or failure of technologies, systems, practices, and ideas. Higher expenses can come in the direct form of higher costs for equivalent units, or they can come cloaked in externalities, uncertainties, or transaction and opportunity costs. Not only do large-scale investments (e.g., IGCC plants) face this difficulty, but so do smaller investments such as energy-efficient technologies that tend to have high initial costs offset over time by lower operating costs. Such cost hurdles are particularly challenging for small businesses and low-income households. Externalities contribute to these cost barriers, especially for GHG-reducing technologies that provide significant positive externalities (or avoid significant negative externalities) in their intended application.

Commercialization and deployment of new technologies is a process wrought with uncertainty. In general, new technologies face high technical risks because their performance in different applications or scales is often unknown. These uncertainties diminish as scale-up operations and demonstrations are successful. Uncertainties relative to the market also exist. For example, dynamic diminishing returns faced by multiple competing technologies create uncertainty over which option will "win.” Technologies may face unpredictable costs when they require the development of complementary technologies - like electric storage, or when entering a market where the incumbent technology is facing uncertain costs like transportation fuels. Further, liability uncertainties can result in limited development or adoption of technologies; this is particularly apparent in sequestration technologies.

There is an array of transaction and opportunity costs associated with GHG-reducing technologies that further limits their cost-effectiveness. For example, GHG-reducing technologies generally have more difficulty acquiring financing and also lack turn-key operations to assist with deployment. As the technology matures, fewer resources will be required to search for financing or to develop specialized knowledge. All of these cost challenges limit the deployment of GHG-reducing technologies. Without addressing cost-effectiveness, technologies either fail to make it out of the "valley of death" or they penetrate niche markets and then stall. Developing a mechanism to internalize the GHG externality could significantly improve their prospects. 



\section{4}

\section{Policy interventions}

in energy markets

have produced an

array of "public

failures" that need

to be reformed.

These failures are of

special interest

because they are at

cross-purposes with

the stated U.S. goal

of reducing $G H G$

intensity.

\section{Fiscal and Legal Barriers}

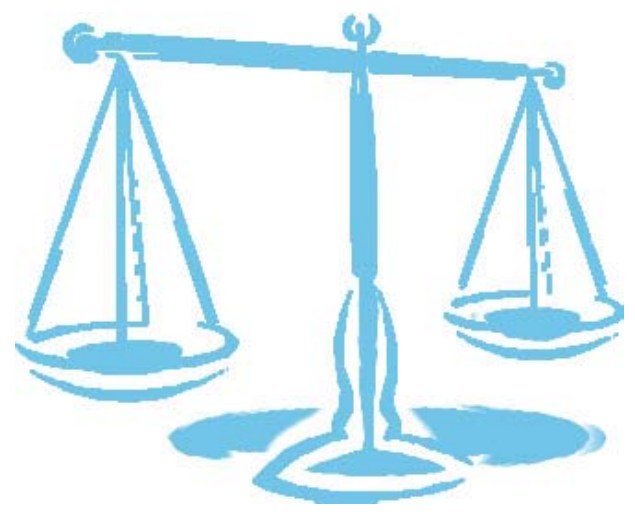

While there are many barriers to the commercialization and deployment of clean energy technologies, those that are imposed by legislatures and regulators are particularly of interest as they operate at cross-purposes with stated U.S. goals. These barriers to the deployment of clean energy technologies come from fiscal policy, regulation and statutes. In the aggregate, they act to confuse investors, consumers, inventors, and producers.

In some cases these policies are unfavorable because they place clean energy technologies at a disadvantage. Sometimes this is done by favoring competing technologies or when the intended favorable outcome is undermined by policy design flaws, loopholes, or burdensome procedures. In other cases policies are uncertain because of state and local variability, fluctuating short-term policies, and extended debates about alternative future policy scenarios that can forestall commitments to clean energy or accelerate investments in carbon-intensive energy options. 
Table 4.1. Fiscal, regulatory, and statutory barriers

\section{Fiscal Barriers}

Unfavorable Fiscal Policy

Distortionary tax subsidies that favor conventional energy sources and high levels of energy consumption; fiscal policies that slow the pace of capital stock turnover; state and local variability in fiscal policies such as tax incentives and property tax policies. Also includes various unfavorable tariffs set by the public sector and utilities (e.g., import tariffs for ethanol and standby charges for distributed generators) as well as unfavorable electricity pricing policies and rate recovery mechanisms.

Fiscal Uncertainty

Short-duration tax policies that lead to uncertain fiscal incentives, such as production tax credits; uncertain future costs for GHG emissions.

\section{Regulatory Barriers}

Distortionary regulations that favor conventional energy sources and discourage technological innovation, including certain power plant regulations, rules impacting

Unfavorable Regulatory Policies the use of combined heat and power, parts of the federal fuel economy standards for cars and trucks, and certain codes and standards regulating the buildings industry; burdensome and underdeveloped regulations and permitting processes; poor land use planning that promotes sprawl.

Uncertainty about future regulations of greenhouse gases; uncertainty about the Regulatory Uncertainty disposal of spent nuclear fuels; uncertain siting regulations for off-shore wind; lack of codes and standards; uncertainty regarding possible future GHG regulations.

\section{Statutory Barriers}

Unfavorable Statutory Policies

Statutory Uncertainty
Lack of modern and enforceable building codes; state laws that prevent energy saving performance contracting.

Uncertainty about future statutes including renewable and energy efficiency portfolio standards; unclear property rights relative to surface injection of $\mathrm{CO}_{2}$, subsurface ownership of $\mathrm{CO}_{2}$ and methane, and wind energy.

\subsection{FISCAL BARRIERS}

Fiscal barriers are impediments related to taxation and public revenue and debt policies promulgated by governments that impact markets in which a clean energy technology is expected to compete. They can take many forms such as tax incentives and penalties, liability insurance, leases and land rights-of-way, waste disposal, and guarantees to mitigate project financing or fuel price risk. While fiscal policies are imposed in pursuit of the public good, they can become impediments to innovation and competition, and they can be unfavorable to clean energy technologies. In addition, fluctuating and variable tax incentives as well as the possibility of future tax penalties related to GHG emissions all contribute to fiscal uncertainty, which can undermine marketplace efficiency. 


\subsubsection{Unfavorable Fiscal Policies}

Fiscal policies can be used to encourage investment in a particular technology area or to overcome market failures. However, technologies and goals can change quicker than fiscal policy, leading to outdated fiscal instruments, which then incentivize undesired behaviors or technologies. A variety of tax subsidies, differential taxation across capital and operating expenses, unfavorable tariffs, and utility pricing policies illustrate this phenomenon.

Tax subsidies. Existing tax subsidies can act as barriers to the commercialization and deployment of GHG-reducing technologies. For example, subsidies for conventional fuels, both implicit and explicit, can significantly lower final energy prices, putting alternative energy options at a competitive disadvantage unless they enjoy equally large tax assistance.

The transportation sector offers examples of policies that provide tax advantages for conventional energy sources and encourage high levels of energy consumption.

- $\quad$ The internal revenue code provides business deductions for the purchase of large light trucks (> $6,000 \mathrm{lbs})^{20}$ that amount to a tax break - encouraging the purchase of large light trucks when they may not be needed (Greene, 2006). Originally established as a form of tax relief for small business owners, large light trucks (especially, sports utility vehicles - SUVs - which are considered light trucks) are increasingly purchased by families for personal use. This particular issue made waves in the print media in 2003 when the popular luxury vehicle, Hummer H2, was made an example (Wong, 2003; Kamen, 2003, p. A25). In October 2004, the allowable first year tax deduction under IRS section 179 was reduced dramatically (from $\$ 105,000$ to $\$ 25,000$ ), but this smaller incentive is still available for large light trucks. ${ }^{21}$

- The gas-guzzler tax on cars (but not on light trucks) has discouraged the purchase of cars and encouraged the purchase of SUVs. ${ }^{22}$ This tax was created with the Energy Tax Act of 1978; ${ }^{23}$ current taxes, which have been in effect since 1991, range from $\$ 1,000$ to $\$ 7,700$ per vehicle depending on the fuel economy of the car beginning at $22.5 \mathrm{mpg} .{ }^{24}$ By taxing fuel-inefficient cars, this tax policy has effectively eliminated the mass production of gas-guzzling cars, but it has not reduced energy consumption. Because gas-guzzler taxes have not been applied to trucks, they do not have a similar disincentive to eliminate production of gas-guzzler vehicles as "trucks" (Greene, 2006).

Examples in the realm of energy resource development include oil depletion allowances which allow owners to claim a depletion deduction for loss of their reserves. Specifically, oil and gas wells can claim cost depletion and in some cases percentage depletion. ${ }^{25}$ Also, government support for research on the production of liquid fuels from coal and the production of petroleum from shale oil and tar sands can appear as barriers to low-carbon alternative fuels. If successful, this research would promote the continued

${ }^{20} 26$ USC § 179 “Election to expense certain depreciable business assets” provides for depreciation of large trucks.

${ }^{21} 26$ USC § 179, supra note 8 amended in 2004 with P.L. 108-357 § 910(a) to reduce deductions for SUV’s (which are specifically defined in the section) to a maximum of $\$ 25,000$.

${ }^{22}$ Current taxes in effect since 1991: Gas Guzzler Tax is in the Code of Federal Regulations 40CFR600.513-91. This regulation creates a tax rate that is based on an equation. Thus, as the EPA determines the fuel economy of a car, that economy is an input into the equation to determine the rate.

${ }^{23}$ Energy Tax Act of 1978: P.L. 95-618, 92 Stat. 3174, enacted November 9, 1979

${ }^{24}$ More information about the gas guzzler tax and lists of cars subject to the tax can be found at http://www.epa.gov/fueleconomy/guzzler/420f06042.htm

${ }^{25} 26$ USC §§ 611, 613, and 613(A); for more information, see Internal Revenue Service, 2006. Cost depletion refers to depletion based on the basis cost and resource amounts extracted and sold whereas percentage depletion refers to depletion based on income from sales of particular resources. 
use of high-GHG transportation fuels. These fiscal incentives exemplify the problem of conflicting social goals. They exist because of the public desire to promote U.S. oil independence and energy security, but they conflict with the goal of stabilizing greenhouse gas concentrations in the atmosphere.

Unequal taxation of capital and operating expenses. Tax policies that encourage operating expenses and penalize capital expenses serve to slow capital stock turnover, preclude technological change, and result in the over consumption of energy products and the over production of GHG emissions. Examples of this issue are evident in industry, buildings, and energy supply.

In American industry, the current federal tax code discourages capital investments in general, as opposed to direct expensing of energy costs. In addition, the federal tax code forces firms to depreciate energy efficiency investments over a longer period of time than many other investments (e.g., only five years for a new data center). This is partly because energy-efficient products have long depreciable lives, such as 15 years for a new motor or a new industrial boiler. Interestingly, a new back-up generator would be depreciated over three years while a new combined heat and power (CHP) system would be depreciated over 20 years. ${ }^{26}$ The CHP system would provide both reliability and energy efficiency while the back-up generator provides reliability at the expense of energy efficiency and clean air. This is another case of legislation lagging behind (and inhibiting) technological progress. Federal depreciation schedules were put into place more than two decades ago as part of the IRS Reform Act of 1986, and they have not kept up with technological innovations. ${ }^{27}$ Modification of depreciation schedules would remove a significant barrier to industrial efficiency investments, but it would require legislative action (Elliott, 2006).

Similarly, as buildings are capital expenses, these fiscal policies retard buildings turnover in all sectors. U.S. tax rules require capital costs for commercial buildings and other investments to be depreciated over many years, whereas operating costs can be fully deducted from taxable income. ${ }^{28}$ Since efficient technologies typically cost more than standard equipment on a first-cost basis, this tax code penalizes efficiency.

In the electricity supply market, Jenkins et al. (1999) have shown that projects with high capital versus expense ratios have higher tax burdens. Interestingly, this is a market in which a mix of capital-intensive and expense-intensive technologies compete. For example, wind and nuclear plants have proportionately high capital costs while natural gas combined cycle and coal plants have proportionately high fuel (i.e., operating) costs (Fig. 4.1). ${ }^{29}$ Reducing the demand for electricity by improving the efficiency of energy use is the least-cost way to deliver new energy services. Because its capital-to-operating ratio is particularly low, energy efficiency is fiscally disadvantaged as an electricity "resource." The problem is that capital and operating costs receive different tax treatment, and these differences result in unequal tax loads between projects built using different technologies. Jenkins et al. (1999) compared the tax loads associated with constructing and owning eight different renewable power plants ${ }^{30}$ with the tax load of constructing and owning a natural gas-fired generation plant. All but one of the eight renewable projects were found to carry higher tax burdens under the tax codes in place in 1999. Whether or not this remains true today is unclear, given the expanded incentives provided for renewable energy in EPAct and other fiscal policy changes. Assuming capital-intensive technologies still have a differentially higher tax burden

\footnotetext{
${ }^{26}$ Combined heat and power (CHP) refers to methods that utilize just one fuel source to provide both electric and heat energy needs - usually by circulating "waste steam.” For more information, see U.S. EPA http://www.epa.gov/chp/

${ }^{27}$ P.L. 99-514

${ }^{28}$ Non-residential buildings have a life of 39 years in the schedule; 26 USC $§ 168$

${ }^{29}$ EIA does not provide a breakdown of cost categories for energy efficiency; however, other studies have shown that energy efficiency is labor- and not capital-intensive (EIA, 2007a, Figure 56; Kushler et al., 2004, Table 5).

${ }^{30}$ The renewable projects included current and advanced solar central receiver plants, biomass-electric, and flash and binary cycle geothermal projects (Jenkins et al., 1999).
} 
than expense-intensive technologies in the electricity generation market, the competitiveness of both renewable and nuclear technologies is reduced as a result.

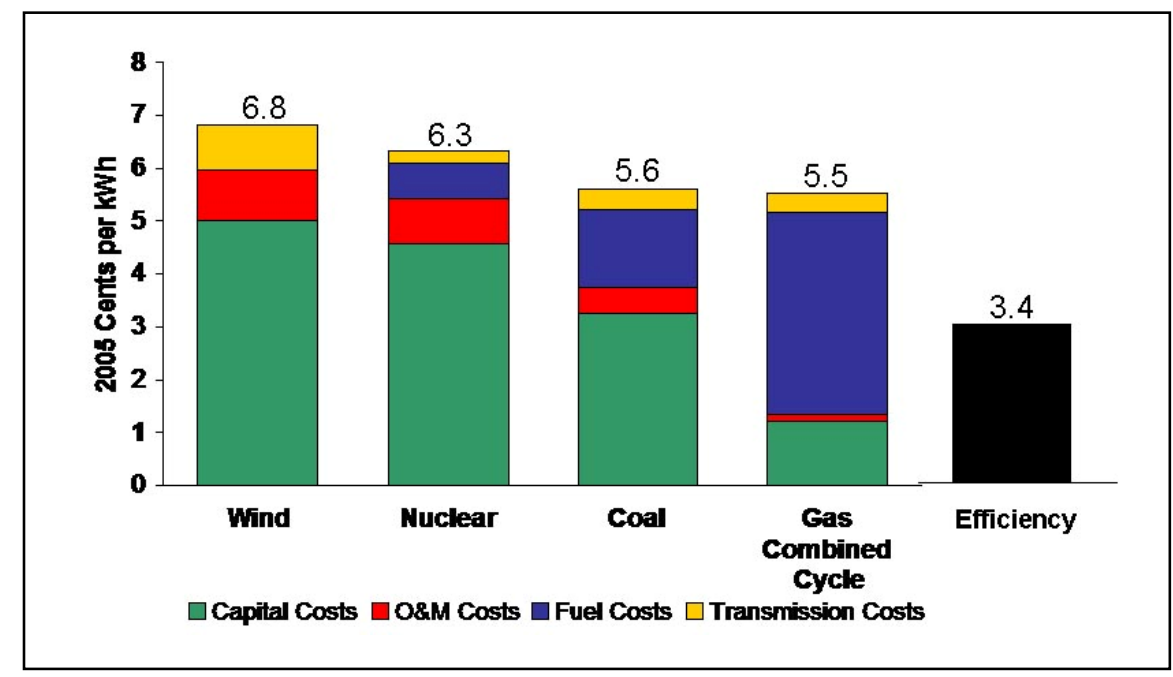

Fig. 4.1. Projected costs of new generation and energy efficiency improvement

Source: Based on data from EIA, 2007a, Fig. 56; Kushler, York, and Witte, 2004, Table 5

Many states have similarly uneven sales tax treatment of capital vs. operating expenses. For instance, most states charge sales tax on residential energy-saving devices but not on residential fuels and electricity. Recognizing this disparity, several states now offer periodic sales tax moratoria for the purchase of ENERGY STAR ${ }^{\circledR}$ appliances. Georgia, Florida, and Virginia have adopted temporary (three- and five-day) sales tax holidays for certain energy-efficient products, and Connecticut has an 18-month tax holiday on home weatherization products (FTA, 2006). Similar holidays are being considered by Illinois, New York, Pennsylvania, Rhode Island, and Vermont (Alliance to Save Energy, 2005a).

Clean energy innovations diffuse slowly through the economy in many cases because of the long lifetime of existing productive capital stock, and because of the major investment in hardware and infrastructure that is required for significant market penetration. Power plants may operate for 40 or 50 years, commercial buildings last almost as long, heavy trucks are driven for 28 years, and cars for 17 years. ${ }^{31}$ As John Holdren (2006) put it: "We've got a \$12 trillion capital investment in the world energy economy and a turnover time of 30 to 40 years. If you want it to look different in 30 or 40 years, you'd better start now." To quicken the pace of change, stock turnover must be accelerated by removal of policies that retard capital investments. Policy options for accelerating turnover include taxing consumption instead of income or decreasing taxes on income from capital investments. "Anything that reduces the effective marginal tax rate on capital investments will result in accelerated capital stock turnover (Lane, 2006).”

Capital stock turnover is obviously paced differently for different technologies, as shown in Fig. 4.2. ${ }^{32}$ The long-lived energy infrastructure systems of highways, buildings, power plants, and transmission lines are distinct from the shorter lifespan of most energy end-use products. This infrastructure longevity contributes to the "lock-in" of incumbent technologies (Unruh, 2002). Companies must take into consideration the risks involved with adopting a new technology, the payback period of a technology, and

\footnotetext{
${ }^{31}$ Cars sold in 1990 had a median lifetime of 17 years and heavy trucks last longer, with an estimated life of 28 years (Davis and Diegel, 2007, Tables 3.8 and 3.10).

32 revised from http://www.calchamber.com/NR/rdonlyres/F7F36D4B-44DB-4545-AE54-59AB8FF72A7C/0/ACCPstudy.pdf, Figure 5.
} 
the appropriate discount rate and transaction costs. Newer, relatively expensive technologies have longer payback periods and represent a greater risk. Thus, "lock-in” not only slows technological change in general but also tends to skew it toward suboptimal choices (Cowan, 1990; Unruh, 2002).

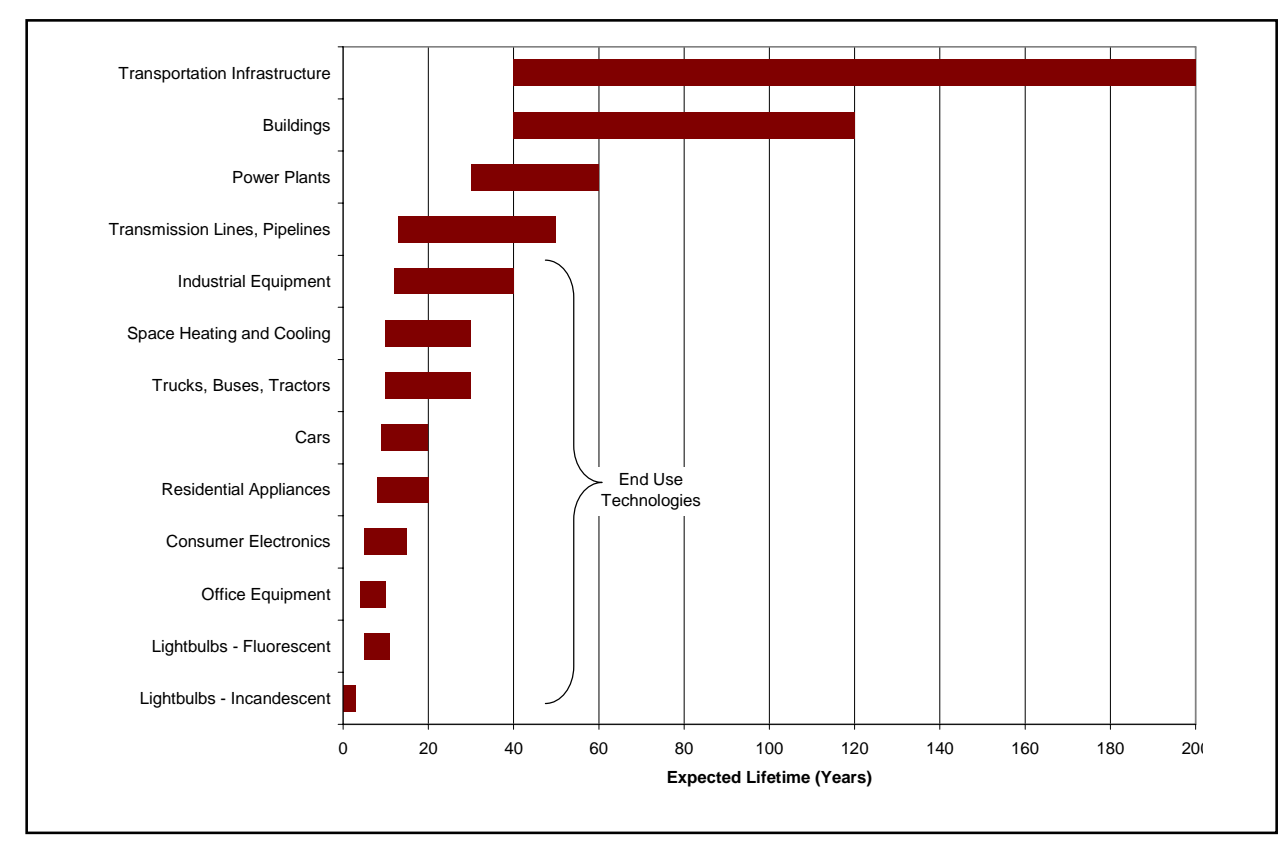

Fig. 4.2. Examples of capital stock lifetimes

Source: revised from http://www.calchamber.com/NR/rdonlyres/F7F36D4B-44DB4545-AE54-59AB8FF72A7C/0/ACCPstudy.pdf, Figure 5

Given that the slow rate of capital stock turnover in many industries has been identified as a key barrier to the introduction of a new generation of carbon mitigation technologies, tax reforms that lower the tax burdens of energy construction projects relative to energy consumption activities warrant consideration (Ruth, 1995; Worrell and Biermans, 2005).

Unfavorable tariffs. Tariffs imposed by government can present a barrier to clean energy technologies. The following examples draw from the markets for alternative fuels and electric power.

The import tariff for ethanol is an example of a policy that raises the cost of ethanol blends produced by domestic refineries. The market for fuel ethanol is heavily dependent on incentives and regulations (Yacobucci, 2007). In 1980, the U.S. Congress imposed a 54 cent per gallon tariff on imported ethanol to promote energy independence. ${ }^{33}$ In addition, the U.S. government provides the domestic ethanol industry with a 51 cent tax credit per gallon, ${ }^{34}$ and EPAct $2005^{35}$ requires refineries to use 4 billion gallons of ethanol in 2007, climbing to 7.5 million gallons in 2012. With the refineries choosing to phase-out MTBE in 2007, the demand for ethanol is even greater than expected, and it is not clear if the domestic supply will be able to meet the growing demand. The import tariff prevents refineries from buying ethanol from wherever it is cheapest on the global market, as from Brazil where ethanol production from sugarcane costs are 40 to 50 percent less than U.S. ethanol production from corn (Yacobucci, 2007).

\footnotetext{
${ }^{33}$ Omnibus Reconciliation Act of 1980. P.L. 96-598

${ }^{34}$ Volumetric Ethanol Excise Tax Credit (VEETC) as part of American Jobs Creation Act of 2004 (P.L. 108-357).

${ }^{35}$ P. L. $109-58$
} 
Independent System Operators (ISOs) also can create tariffs that bar new technologies. These tariffs are effectively connection (market entry) charges although they are not called such. For example, small generators hoping to connect to the grid in the mid-Atlantic area must undergo a review at a cost of $\$ 10,000$ to the generator before being allowed to tap into the ISO-PJM (Pennsylvania, New Jersey, Maryland) interconnection (Sovacool and Hirsch, 2007). Other tariffs levied by individual utilities on customers include standby charges, buyback rates, and uplift fees.

Utility pricing policies. Unfavorable electricity pricing policies and rate recovery mechanisms present obstacles for an array of clean energy technologies; these include the regulated rate structure, lack of time-of-use pricing, and imbalance penalties. The origin of many of these policies often is based on historically long-standing practices that have been incrementally modified over years of regulatory oversight (Tempchin, 2007).

In traditionally regulated electricity markets, electric utilities face little incentive to promote energy efficiency or non-dispatchable distributed generation because utility company profits are a function of sales. Under current rate designs, companies that own transmission lines also benefit from throughput, and find their profits reduced by energy efficiency programs. As Casten and Ayres (2007) explain:

"Regulators approve rates that are supposed to provide a 'reasonable' return on invested capital. This encourages capital investment, regardless of efficiency.... With approved rates in place, the utility's profits hinge on throughput - how much electricity flows through their wires. More sales, more profits. Actions that lead to conservation, appliance efficiency gains, and local generation all penalize utility profits.” Fixing the problem of revenue erosion and decoupling profits from sales is critical to incentivizing the efficient use of electricity.

Problems associated with utility ratemaking practices and their disincentives to energy efficiency were a major focus of the National Action Plan for Energy Efficiency (NAPEE). Developed by a Leadership Group composed of more than 50 leading organizations representing diverse stakeholder perspectives, the Action Plan was released on July 21, 2006. It focuses on these cost recovery problems, noting that regulatory policies governing utilities have more commonly compensated utilities for building power plants and selling energy, while discouraging energy efficiency even when saving energy costs less than generating energy. Ratemaking practices must be reformed for utilities to remain financially healthy while promoting the efficient use of energy by their ratepayers. Specifically, NAPEE recommends that stakeholders "Modify policies to align utility incentives with the delivery of cost-effective energy efficiency and modify ratemaking practices to promote energy efficiency investments (Leadership Group, 2006).”

Electricity pricing policies of State legislatures and regulatory commissions also prevent markets from operating efficiently and create obstacles to low-carbon power choices. For example, the price of electricity in most retail markets today is not based on time of use. It therefore does not reflect the timeof-use costs of electricity production, which can vary by a factor of ten within a single day. Because peaking plants are more expensive to run than baseload plants, retail electricity rates are higher during peak times than during shoulder and off-peak times under time-of-use pricing. Yet most customers in traditionally regulated markets buy electricity under time-constant prices that are set months or years ahead of actual use; as a result current market structures actually block price signals from reaching consumers, and consumers are not responsive to the price volatility of wholesale electricity (Cowart, 2001).

Time-of-use pricing would encourage customers to use energy more efficiently during high-price periods. Similarly, the lack of time-of-use pricing and time-of-use (TOU) rates is a barrier to solar photovoltaics (PV) and other generation resources that provide power disproportionately during on-peak periods, because they are not paid for this added benefit but rather are reimbursed at the same price per $\mathrm{kWh}$ as an 
off-peak resource. Widespread time-of-use pricing would provide significant incentives for distributed generation including renewables. When net-metering is used in conjunction with time-of-use pricing, customers who generate electricity during the day (when use is at peak and prices are high) could offset their costs for electricity used off-peak when prices are low. ${ }^{36}$

Imbalance penalties charged by utilities pose challenges to renewable power profitability because of the intermittency of wind and solar PV. Many power markets were set up to bid a day ahead. The utility contracted to provide so many MWs of power generation, committing to certain power output requirements. If power generation deviated from this projection, severe penalties were levied. These penalties reflected the extra cost incurred to have reserve units running and ready to replace the idle load ( 0.1 to 0.5 cents per $\mathrm{kWh}$ ). In order to allow renewables to compete more effectively, imbalance payments have evolved in some states, and additional reform is needed (Thresher, 2006; Beck and Martinot, 2004). For example, in some parts of California at the end of the month, the scheduled power has to balance out. If the utility is consistently wrong, the imbalance payment has to be paid, but not otherwise.

In sum, because of these utility pricing policies, neither electricity generators, wires companies, nor consumers see the full value of efficiency or distributed generation. Without better price signals, it is challenging for the providers of energy-efficient products and on-site generators to transform consumer markets.

Ineffective fiscal policies. Some fiscal policies simply do not meet their intended objective or are at crosspurposes with their stated goal of stimulating the deployment of clean energy technologies. Tax credits for clean energy investments that cannot be claimed and property taxes that encourage deforestation are cases in point.

Several tax credits passed in legislation cannot be claimed by the targeted markets and therefore fail to achieve the anticipated market penetration of energy-efficient devices and systems. For instance:

- In 2005, EPAct ${ }^{37}$ authorized a tax credit for fuel cells $(\$ 1,000 / \mathrm{kW}$ or 30 percent of the total cost, whichever is less), and the provision was enacted into law effective January 1, $2006 .^{38}$ However, the IRS has yet to establish guidelines that would clarify the eligibility criteria and spell out procedures for claiming the credit (U.S. Fuel Cell Council, 2007). Companies have to spend large amounts of money with consultants to figure out how to use the tax credit. Yet the credit will expire at the end of 2007. Planning cannot be done cost-effectively around two-year tax programs (Logan, 2007).

- Several of the tax credits for individuals have limited value because of the Alternative Minimum Tax (AMT), ${ }^{39}$ which sets a floor for tax liability and can prevent those subject to AMT from claiming credits (Logan, 2007). Examples for individuals are the tax credits for hybrid electric vehicles and residential photovoltaic systems. ${ }^{40}$ Similarly, more and more of the large industry tax credits are becoming less of a viable strategy because of the AMT. Many large companies already

\footnotetext{
${ }^{36}$ With net-metering, the customer is only charged for "net" consumption (Pew Center, http://www.pewclimate.org/what_s_being_done/in_the_states/net_metering_map.cfm, accessed October 26, 2007). Net-metering is also discussed separately in this paper, section 4.2.

${ }^{37}$ Energy Policy Act of 2005 (P.L. 109-58)

3826 USC § 25D "Residential Energy Efficient Property”

3926 USC § 55 “Alternative Minimum Tax Imposed”

${ }^{40}$ A new tax credit created under P.L. 109-58, §§1341-1342 replaced the existing Clean Fuel Tax Deductions under 26 USC $\S$ 179A that were terminated in 2005; these credits that include hybrid electric vehicles are codified in 26 USC § 30B. Tax credits for residential photovoltaic installations are up to 30\% of the cost, with a \$2000 cap for individuals- 26 USC § 25D.
} 
qualify for the AMT so the tax code is not moving industry any further along. ${ }^{41}$ The Energy Policy Act of 1992 provided independent domestic oil developers with relief from AMT, ${ }^{42}$ but did not do so for renewable generation or energy efficiency technologies (Jenkins et al., 1999).

- The maximum business credit deduction has also reached eligible thresholds for many companies. The internal revenue code requires that in any tax year a company may not reduce its payable taxes by more than 50 percent (Elliott, 2001). Firms can carry unused credits over for five years, but many are still maxed out even with this rollover provision (Elliott, 2006). These companies qualify for more tax credits than they can use, so the credits are often not being fully used. Piling more tax credits on is not effective. When considering EPAct 2005 tax credits, ACEEE reduced the expectation by at least a third because they expect at least a third of the firms will not be able to use them (Elliott, 2006).

Ineffective fiscal policies are not just the purview of the federal government; they also exist at the state and local level. Of particular importance to the viability of biomass as a renewable resource for transportation fuels, electricity, and chemicals is the tax treatment of farmland and forests. Many states have property tax laws that provide incentives for landowners to develop their forestland rather than leave the forest standing (Murray, 2006). These development incentives are found when forestlands are taxed based on their location (ad valorem), or are not exempted from taxation when the forests are conserved. Almost all states tax property based on ad valorem values while only four offer exemptions for forestlands (Fig. 4.3). These local land values, and corresponding taxes, may rise due to urban sprawl or other drivers of new residential or commercial building in an area, but the value of the timber stand tends not to increase accordingly. A transition in the ownership structure of forests from vertically integrated forest products companies to investment trusts or investment management organizations is also occurring largely due to the double taxation of harvested timber resources. This fiscally driven shift in land ownership may also contribute to reductions in forestland as investment firms search for the "highest or best use" of property (Hickman, 2007). Future cellulosic ethanol production across the country depends upon the maintenance of forest resources and the landowner-to-timber-industry infrastructure (Reisert, 2006).

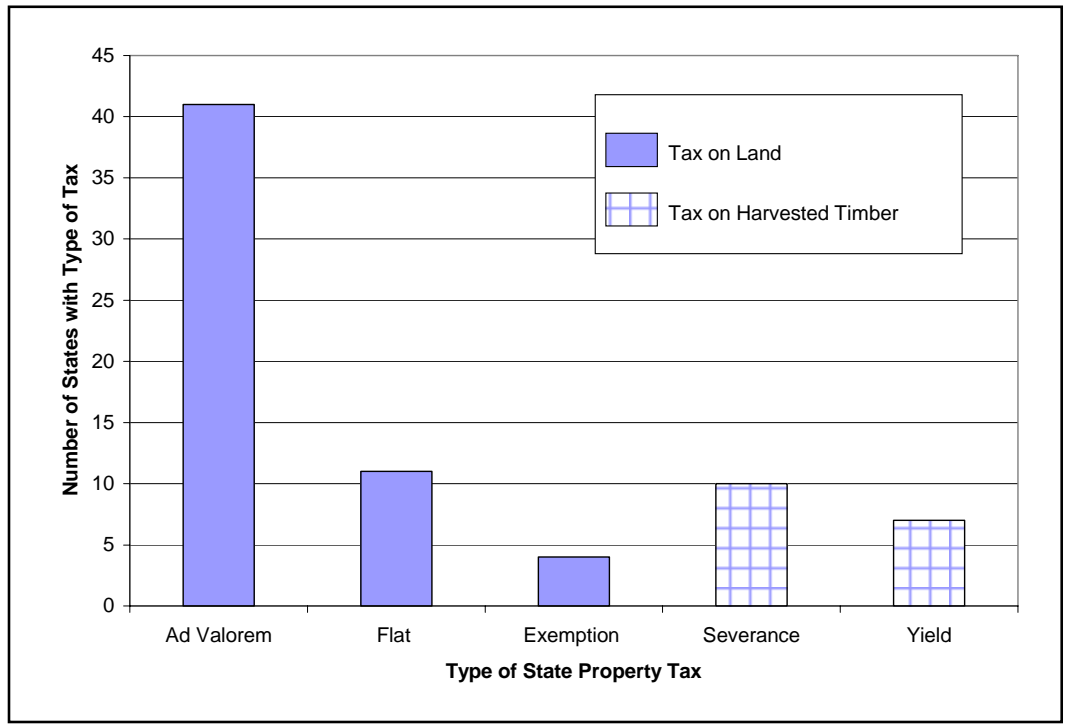

Fig. 4.3. Different property taxes for timber land

Source: Based on data from http://www.timbertax.org/statetaxes/quickreference.asp)

\footnotetext{
${ }^{41}$ The AMT limits the ability of investors and individuals to shelter income from federal taxes. Elliott supra note 19.

${ }^{42}$ Energy Policy Act of 1992 (P.L. 102-486)
} 


\subsubsection{Fiscal Uncertainty}

Policies that subsidize energy technologies on an inconsistent and sporadic basis do not motivate rational market behavior. Similarly, future uncertainty related to penalties for GHG emissions also distort investment options.

Fiscal incentives. Fluctuating and sporadic fiscal incentives lead to uncertainty as well as abandonment of initiatives before their potential can be realized. This is particularly the case for capital-intensive improvements and technologies that require a large investment for an uncertain return.

One example of this is the renewable production tax credit (PTC), which provides a tax credit for each $\mathrm{kWh}$ of electricity generated by qualified technologies. ${ }^{43}$ These tax credits were initially made available for the first ten years of operation for all qualifying plants that entered service from 1992 through mid1999. The subsidy was later extended to 2001, then to 2003, and again with EPAct 2005 to the end of 2007. In 2006, the provisions were extended for an additional two years, ending seven years of onagain/off-again subsidies. Because planning and permitting for new wind turbines takes about two years, expirations of the PTC contribute to investment downturns even if reauthorized shortly afterwards. Fig. 4.4 shows how PTC reauthorization stimulates market activity, and how PTC expiration is promptly followed by declines in capacity additions (AWEA, 2007). The tax credit has created a sellers market resulting in increased competition for the wind production capacity, which is currently sold out into 2008, raising prices due to "supply and demand" by roughly 50 percent to $\$ 1600 / \mathrm{KW}$ today. Further, with the sporadic tax credits, production is geared to the short-term, which is not necessarily the most efficient focusing on an accelerated timetable instead of optimizing production over the long-run by, for instance, investing in longer-term facility needs, systems, and personnel training.

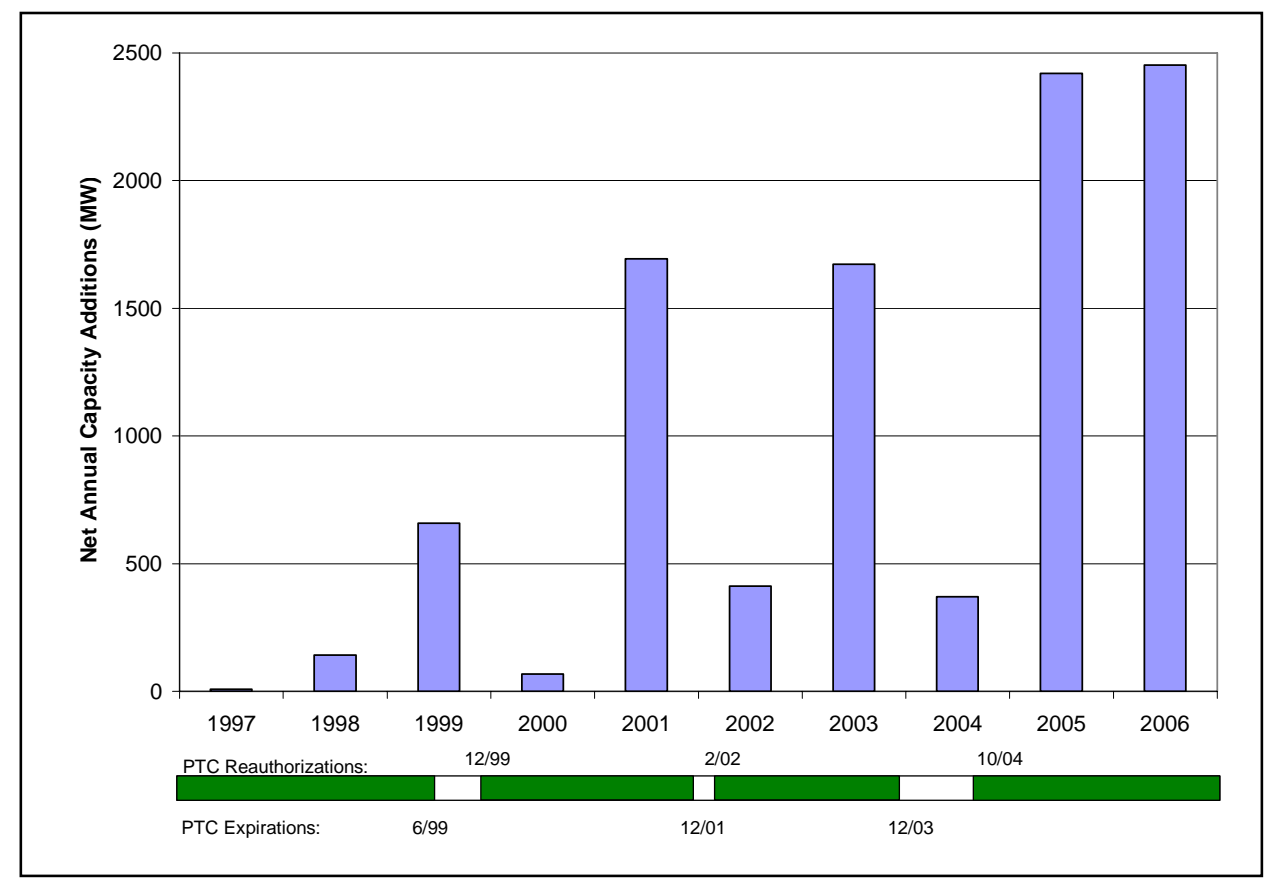

Fig. 4.4. Annual installed wind energy capacity

Source: Based on data from AWEA Wind Power Projects Database

\footnotetext{
${ }^{43}$ Production Tax Credits are defined in 26 USC § 45. EPAct 2005 (P.L. 109-58 § 1301) amended 26 USC § 45; Section 1301 also modifies the definition of "qualified energy resources" in Code section 45(c)(1)
} 
State or local production incentives, similar to the federal PTC, are available in at least five states, adding another layer of geographic diversity and inconsistency. The variability across states for incentives and programs for renewable energy and energy efficiency can be seen using the Databases for State Incentives for Renewables and Efficiency (DSIRE) web data application. ${ }^{44}$

Fiscal penalties. Investors must often choose between certain financial gains and uncertain financial penalties when looking at options for the future. When possible taxation or costing for GHG emissions is unknown, investors may choose to delay adoption of clean energy technologies while their tax treatment is being debated. A clear example of this is the market for $\mathrm{CO}_{2}$ storage and sequestration, but it also occurs in other climate change technology areas. For instance, Chad Holliday, the CEO of DuPont, told Thomas Friedman (2007) that he is reluctant to expand the corporate investment in ethanol because he cannot anticipate what the price of ethanol will be. "What are the regulations going to be? Is the ethanol subsidy going to be reduced? Will we put a tax on oil to keep ethanol competitive? If I know that, it gives me a price target to go after. Without that, I don't know what the market is and my shareholders don't know how to value what I am doing.”

Long-term financial uncertainties are particularly relevant to projects that involve carbon sequestration, where issues of liability over the full duration of projects are largely unresolved. During the operational phase of $\mathrm{CO}_{2}$ storage projects, financial responsibility and liability reside with either the owner of the $\mathrm{CO}_{2}$ and/or the operator of the storage facility. In the long-term, the turnover of responsible parties poses risk and uncertainty to investors and stakeholders. Success may require the establishment of government bonds or trust funds, privately backed insurance funds, or public-private partnerships (Bliss, 2005, pp. 5-6). Until such long-term risk management strategies are established through public-private dialogue, the financial uncertainties will hold back carbon capture and storage (CCS) projects.

\subsection{REGULATORY BARRIERS}

A regulation is a legal restriction promulgated by government administrative agencies through rulemaking supported by a threat of sanction or a fine. Regulations are imposed in pursuit of the public good to produce outcomes that might not otherwise occur, but they can become impediments to innovation and competition. Common examples of regulation include attempts to control market entries, prices, wages, pollution, and standards of production and performance. Regulatory barriers that arise in the market include unfavorable and ineffective regulatory policies that disadvantage clean energy technologies and impede efficient market functioning. In addition, fluctuating, variable, and unpredictable regulations can undermine marketplace efficiency by introducing policy uncertainty.

\subsubsection{Unfavorable Regulatory Policies}

Regulations are typically seen as instruments of change - encouraging innovation, pollution prevention, safety, and standardization. However, they can also be distortionary, onerous, and barriers to progress when they regulate or unequally impact markets in which a technology is expected to compete. This section describes several distortionary performance and connection standards and burdensome permitting processes that handicap the market penetration of clean energy technologies. Additional examples are regulatory loopholes, poor land-use planning, and burdensome permitting processes.

Environmental performance standards. A number of deeply imbedded regulatory systems favor conventional energy sources and technologies. Examples are drawn from regulations in the electric power sector - new source review and input-based emissions standards.

\footnotetext{
${ }^{44}$ DSIRE - http://www.dsireusa.org/, accessed 7/31/07.
} 
As part of the 1977 Clean Air Act Amendments Congress established the New Source Review (NSR) program and modified it in the 1990 Amendments, but exempted old coal plants from the New Source Performance Standards (NSPS) to be set. ${ }^{45}$ NSPS are standards issued by the Environmental Protection Agency (EPA) to dictate the level of pollution that a new stationary source may produce. ${ }^{47}$ These standards are intended to promote use of the best air pollution control technologies, taking into account the cost of such technology and any other non-air quality, health, and environmental impact and energy requirements. These standards apply only to electric generating units that have been constructed or modified since the proposal of the standard. This "grandfathering" has enabled the continued operation of a number of high-emitting plants, and some contend that it has resulted in the underutilization of newer power plants because of their compliance burdens (Stavins, 2006). "NSR thus imposes pollution controls where they are least needed and artificially inflates the value of the dirtiest plants (Gremillion, 2007).”

Many studies show that several percentage points of efficiency improvement can be squeezed out of the current coal fleet. ${ }^{48}$ However, investment in an upgrade could trigger an NSR, and the threat of such a review has prevented many upgrades from occurring (Braitsch, 2007). NSR is a preconstruction permitting program that assures the dual goals of maintaining and attaining air quality and providing for economic growth. These goals are achieved through installation of state-of-the-art control technology at new plants and at existing plants that undergo a major modification. ${ }^{49}$ However, uncertainty about the scope of such requirements has become a significant disincentive to rebuilding existing generating units that could ultimately result in greater energy efficiency or even lower emissions. Altogether, these effects have led some critics to question whether the NSR program and the NSPS have resulted in higher levels of pollution than would have occurred in the absence of regulation (Gremilion, 2007).

On April 2, 2007, the U.S. Supreme Court issued a decision in Environmental Defense v. Duke Energy Corporation, that clarifies these requirements. It imposed an annual new source review test on sources unless and until EPA changes its regulations. On April 25, 2007, the EPA proposed further options to change the emissions increase test used to determine if the NSR permitting program would apply when an existing power plant makes a physical or operational change. Under EPA's new option, if a physical or operational change would not increase an electric generating unit's hourly emission, major NSR would not apply. If a generating unit's hourly emissions would increase, then projected annual emissions would be reviewed using the annual emissions increase provisions in the current rules and a generating unit would be subject to major NSR if the annual emissions would increase but not if annual emissions do not increase. $^{50}$ The unintended "effect" of discouraging plant upgrades could be heightened by this 2007 U.S. Supreme Court decision and follow-up EPA guidelines by closing loopholes that previously allowed power plants to be expanded and upgraded without triggering NSR reviews.

The nation's current regulatory approach to air pollution - using “input-based emission standards" - is also unfavorable to advancing clean energy technologies. "Input-based emissions standards" assess emissions based on fuel inputs into a power plant, and because they pay no attention to how much electricity or heat is provided by the plant, they fail to reward energy-efficient plants, those producing the same amount or more electricity while emitting fewer pollutants (Freedman Watson, 2003). An "outputbased" approach would reward those power generators for producing more useful energy (heat and power) from the same amount of fuel input, while emitting fewer pollutants. Output-based standards

\footnotetext{
${ }^{45} 42$ U.S.C. §§ 7401-7671 (2006).

${ }^{46}$ Clean Air Act Amendments of 1977 (P.L. 95-95; 91 Stat. 685) and of 1990 (P.L. 101-549)

47 "Standards of Performance for New Stationary Sources" 40 CFR 60

${ }^{48}$ U.S. Climate Change Technology Program: Technology Options for the Near and Long Term (CCTP, 2005) is a compendium of technology profiles and ongoing research and development at participating Federal agencies.

${ }^{49}$ Stole Rives Environmental Group, http://www.stoel.com/showalert.aspx?Show=2281, accessed 7/31/07.

${ }^{50}$ EPA's Fact Sheet on New Source Review: Emission Increases for Electric Generating Units can be found at http://www.epa.gov/nsr/fs20070424.html
} 
could advance an array of innovative power technologies including CHP, which puts to productive use much of the heat that is wasted in conventional power plants. Only output-based measurements can capture the total efficiency provided from a single source of fuel producing both electricity and thermal energy. The EPA has a guidance document on how to promulgate and implement output-based standards, the California Energy Commission and the South Coast Air Quality Management District have adopted output-based standards, and other organizations support them. However, only a few state and local air permitting agencies have adopted them, and EPA’s Region 9 refuses to enact them (Brent, 2006).

Connection standards. Connection standards are designed to prevent unnecessary fluctuations in the electric system from improperly functioning, or out-of-phase, electric generators. These standards keep the electric system safe from fires, surges, brown-outs, and black-outs; however, in some cases, their application can be seen as onerous rather than due diligence. Distortionary connection standards, like bans on private wires and metering rules, have historically inhibited the installation of distributed generation (DG) systems in the United States. ${ }^{51}$

For example, consider the universal ban on private electric wires crossing public streets. While this ban maintains safety on roadways by preventing the introduction of wires lower than posted height limits, specifications could be designed to permit private wires. This ban forces would-be power entrepreneurs to use their competitors' wires to deliver electricity to their customers. In combination with generally high prices for moving such power, this ban on private electric wires penalizes local generation, which offers the potential for high-efficiency power delivery (Casten and Ayres, 2007).

The ability to legally connect DG equipment to the grid depends on federal, state, and local rules and regulations. The legal right to connect to the grid is provided for in federal laws such as the Public Utilities Regulatory Policies Act (PURPA) of 1978 and by state net metering statutes. ${ }^{52}$ State-to-state variations in net metering policies cause confusion in the marketplace and raise the cost of completing DG projects. Net metering, an option to overcome barriers caused by variations in metering policies, allows customers with small generating facilities to use a single meter to measure both power drawn from the grid and power fed back into the grid from on-site generation. When a customer installation generates more power than it consumes, power flows into the grid and the meter runs backward. Net metering allows customers to receive retail prices for the excess electricity they generate. When combined with time-of-use pricing, this can result in an attractive value for PV power and other on-site power production (DOE/EERE, 2003a). In states that do not have net metering, a second meter must be installed to measure the electricity flowing back to the host utility, and the utility purchases the power at a rate typically much lower than the retail price - which is a disincentive to the development of distributed generation. ${ }^{53}$

More than 40 states now have net metering laws, which allow a two-way flow of electricity between the electricity distribution grid and customers with their own generation (Fig. 4.5). State-to-state variations in regulations impose significant burdens on project developers (Alderfer and Starrs, 2000). Mueller (2006) examined the policy instruments in use related to CHP adoption and the actual adoption rates for three types of facilities in Illinois: hospitals, schools, and others. He found that organizations tended to search

\footnotetext{
${ }^{51}$ Distributed generation is modular electric power located close to the energy consumer, including photovoltaics, gas turbines, fuels cells, and combined heat and power (Alderfer et al., 2000; Mueller, 2006; Sovacool and Hirsh, 2007).

${ }^{52}$ P.L. 95-617

${ }^{53}$ Many states do not have net metering programs. Other states require net metering only for investor-owned utilities. In a few states, the Public Utilities Commission has mandated net metering programs for all utilities. There are also state-by-state variations in the types of on-site power that are eligible for net metering - photovoltaics and wind almost always qualify, but fuel cells are rarely covered by net metering legislation (DOE/EERE, 2003a).
} 
for CHP to achieve energy savings potential, but they considered regulatory complexity as an obstacle when making the adoption decision.

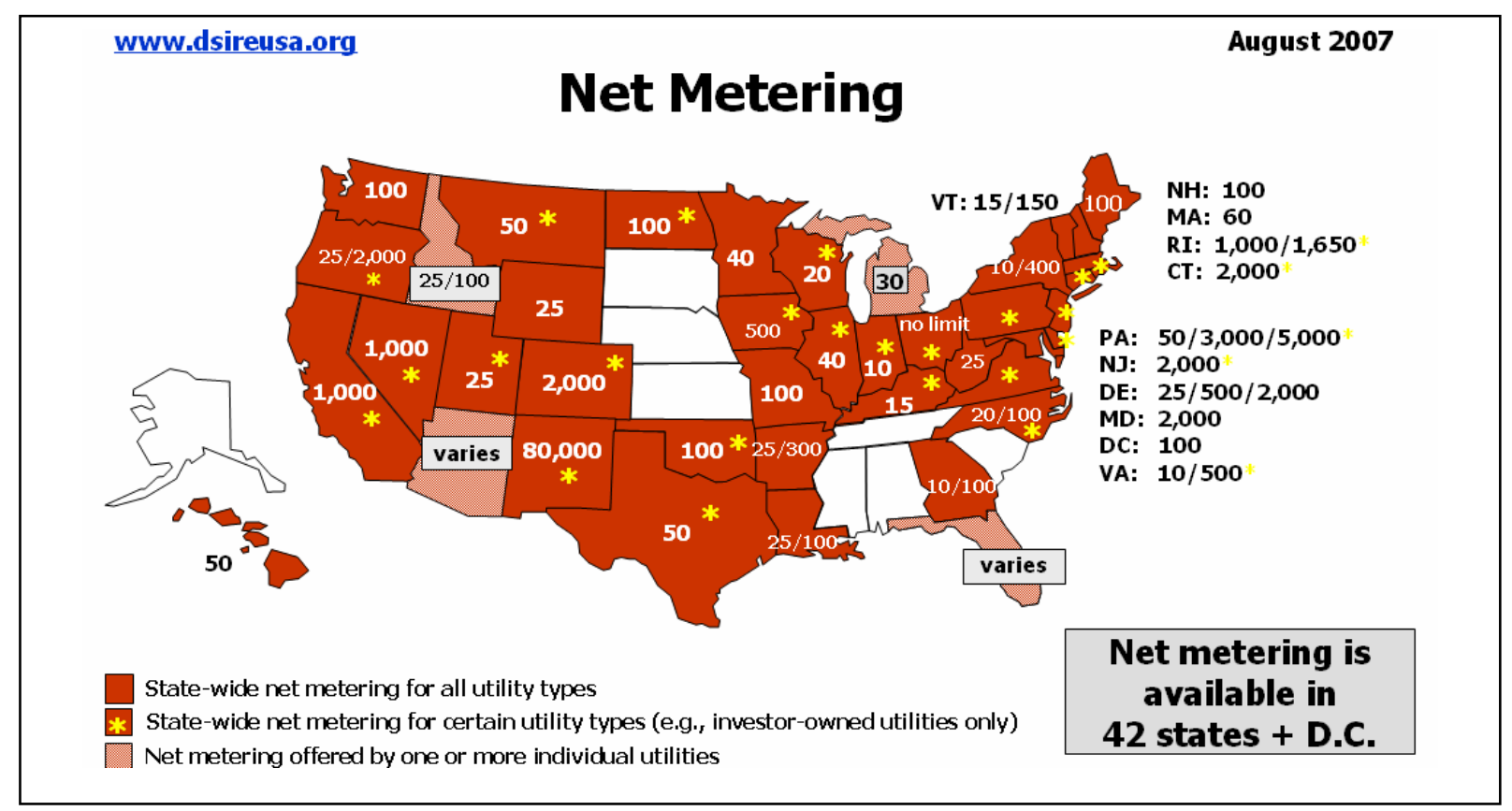

Fig. 4.5. Geographic variability of net metering rules Source: www.dsireusa.org

Regulatory loopholes. Contained within otherwise effective regulations, one often finds particular clauses and specifications that subvert the goals of the laws. Such is the case with the Corporate Average Fuel Economy (CAFE) standards. Several examples illustrate the ways in which the CAFE standards are ineffective or have been redesigned in conflict with the law's original intent of increasing fuel economy. ${ }^{54}$ Specifically, these standards:

- Exempt vehicles over 8500 pounds of gross vehicle weight (e.g., Ford Expedition, Hummer, Lincoln Armada) and ignore large light trucks - such as passenger and cargo vans.

- Preempt states from setting more restrictive fuel economy standards than those in the federal legislation.

- Credit vehicles for flexible fuel (E-85 capability) regardless of how they are fueled after purchase; the National Academies (National Academies Press, 2002, p. 111) found that "The provision creating extra credits for multifuel vehicles has had, if any, a negative effect on fuel economy, petroleum consumption, greenhouse gas emissions, and cost. These vehicles seldom use any fuel other than gasoline yet enable automakers to increase their production of less fuel efficient vehicles.”

- Allow car manufacturers to average fuel economies across a broad array of vehicles which creates an incentive for using very efficient smaller vehicles to offset inefficient larger vehicles. For example, trucks are held to a lower CAFE standard than cars, so Chrysler and Dodge benefit from having the PT Cruiser and the Magnum, which are cars in the eyes of consumers, classified

\footnotetext{
${ }^{54}$ Energy Policy and Conservation Act of 1975 (P. L. 94-163) established corporate average fuel economy (CAFE) standards for new passenger cars
} 
as trucks under rules developed by the National Highway Traffic Safety Administration (NHTSA) in 1975 (Csere, 2004).

Such legal loopholes that undermine the goal of fuel economy can be explained in part by the existence of conflicting policy goals. "There is a marked inconsistency between pressing automotive manufacturers for improved fuel economy from new vehicles on the one hand and insisting on low real gasoline prices on the other (National Academies Press, 2002, p. 113).”

Land use planning. State and local governmental bodies are responsible for land-use planning in the United States. The planning process involves a mosaic of approaches, often displaying limited sensitivity to environmental goals. The automobile-dominant suburban environment, with its large carbon footprint, is the result of unfettered growth, with limited planning attention given to smart growth characterized by sidewalks and bike paths, rail systems and mixed-use developments that shorten the distance to work and promote the use of mass transit. Indeed, Greene (2006) argues that the main motivation for inefficient modes of travel is the built environment created without integrated land planning strategies. As described by the Department of Energy's Smart Communities website, inefficient sprawling urban environments have been created by a combination of "zoning ordinances that isolate employment locations, shopping and services, and housing locations from each other" and "low-density growth planning aimed at creating automobile access to increasing expanses of land." energy consumption, due mostly to increased transportation needs. Fig. 4.6 shows how urban environments compare in terms of transportation $\mathrm{CO}_{2}$ emissions per household.

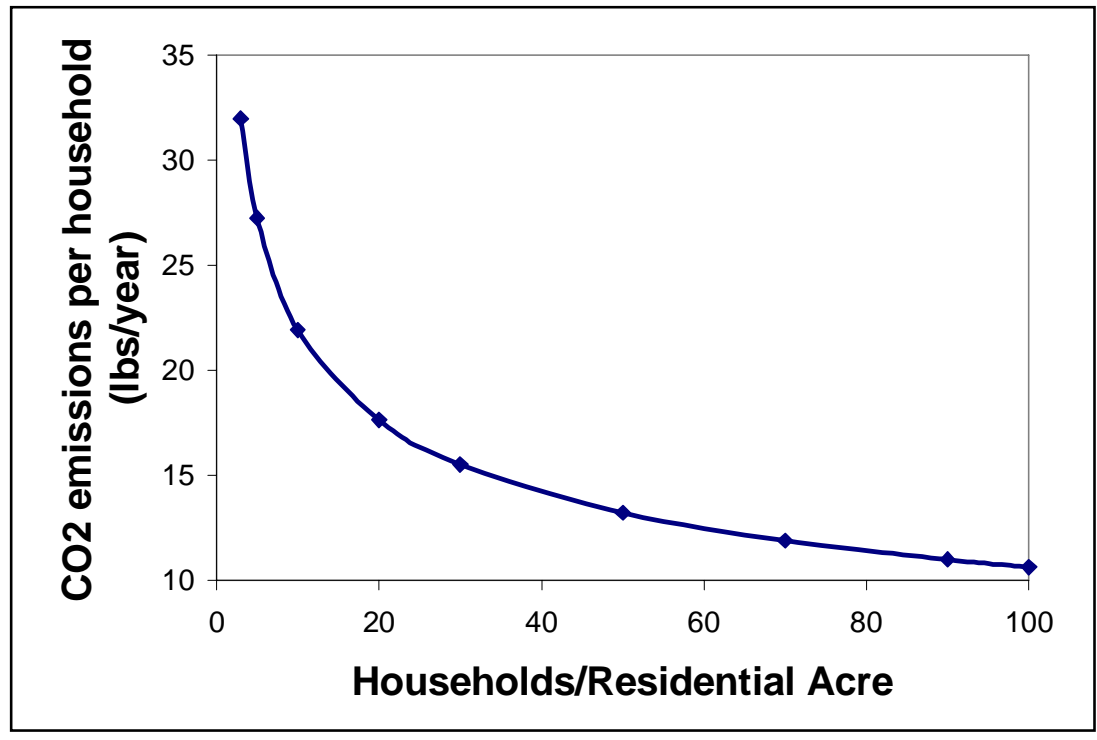

Figure 4.6. Low-density zoning promotes travel-related $\mathrm{CO}_{2}$ Emissions Source: Computed using the San Francisco League of Conservation Voters calculator, http://www.sflcv.org/density/index.html, December 6, 2004

Sprawling urban land use patterns in the U.S. have caused the amount of urbanized land area to grow two to three times faster than the metropolitan area (Fulton et al., 2001). The result is rapid increases in vehicle miles traveled (VMT) and shrinkage of the forest land available to absorb $\mathrm{CO}_{2}$ (Ewing et al, 2007). Zoning for low-density urban development contributes to sprawl and locks in dependence on cars by undermining the ability to support transit and to promote walking and cycling. Most subdivision regulations, parking and street design standards also pose barriers to smart growth projects, as do various

\footnotetext{
${ }^{55}$ http://www.smartcommunities.ncat.org/landuse/luintro.shtml
} 
distortionary fiscal policies such as the link between federal transportation funding and VMT levels. ${ }^{56}$ As Growing Cooler (Ewing et al, 2007, p. 10) explains, "the key to substantial GHG reductions is to get all policies, funding, incentives, practices, rules, codes, and regulations pointing in the same direction to create the right conditions for smart growth.”

Permitting processes. The market penetration of many clean energy technologies is hindered by onerous permitting processes. Examples highlighted below cover geological carbon sequestration and the siting of on-shore wind farms.

Carbon capture and storage (CCS) projects are challenged by inadequate regulatory frameworks typical of new products. Currently, there are no uniform guidelines regulating geologic carbon sequestration projects; as a result, regulatory issues are addressed mostly on a case-by-case basis in contracts for a particular project. Applicants prepare individual statements for underground injection of $\mathrm{CO}_{2}$, and EPA must review each injection well for adequacy (Hovorka, 2006). This creates uncertainty and confusion and raises concern about the long-term environmental and economic integrity of the projects (Robertson et al., 2006). A generic process could streamline these injection projects. Doing "permitting by rule" would be useful. EPA could specify the necessary characteristics in a checklist of requirements so that applications can be more uniform.

Environmental permitting for land-based wind projects falls under the purview of regulations promulgated by a maze of local, county, state, and federal agencies. In addition to the litigation implications of these numerous requirements, each individual permit provides an opportunity for wind projects to be challenged (Koehler, 2007). Permitting processes are also problematic for off-shore wind. In 2005, Minerals Management Services in the U.S. Department of Interior was given authority for offshore wind (and ocean energy) siting. ${ }^{57}$ However, the agency has not yet specified its procedures, creating delays in the permitting process (Thresher, 2006). Since success in the marketplace is facilitated by minimizing the risk of litigation and public opposition, wind projects are particularly handicapped by onerous permitting requirements.

\subsubsection{Regulatory Uncertainty}

Energy markets face numerous uncertainties even when operating within stable tax and regulatory framework. Today's markets are particularly unpredictable due to ambiguities about possible future GHG regulations and tax treatments. Investors, electric utilities, vehicle manufacturers, and other key stakeholders who deal with fuel futures must decide what to build as a next generation of power plants and transportation fuels, not knowing if $\mathrm{CO}_{2}$ and other GHGs will remain unregulated. The $109^{\text {th }}$ Congress processed more than 100 climate change-related proposals, ${ }^{58}$ and the $110^{\text {th }}$ Congress appears to be seeing an even greater level of climate policy activity. When the basis for estimating long-term operating costs and competitive advantage is so uncertain, how are consumers to make "rational" choices about the purchase of new energy-using systems and how are producers to decide whether or not to invest in alternative energy technologies? All of the uncertainties associated with the treatment of GHG externalities are impediments to positive action (Newell, 2006). Examples of regulatory uncertainty impacting clean energy technologies include lack of "waste confidence” for the disposal of spent nuclear fuels; lack of clarity regarding the classification of $\mathrm{CO}_{2}$; uncertain siting regulations for off-shore wind (see discussion under section "permitting processes”); and uncertain codes and standards for hydrogen

\footnotetext{
${ }^{56}$ An overview of the apportionment of funds from the Federal Highway Trust Fund can be found in the GAO 2006 report available at http://www.gao.gov/new.items/d06572t.pdf.

${ }^{57}$ Authority granted in EPAct 2005 (P.L. 109-58)

${ }^{58}$ The Pew Center on Global Climate Change, $109^{\text {th }}$ Congress Proposals, http://www.pewclimate.org/what_s_being_done/in_the_congress/109th.cfm (accessed 8/10/07).
} 
storage and transport. These examples are described below, following a broader description of impacts of regulatory uncertainty.

An increasing number of U.S. companies have been participating in voluntary greenhouse gas emission reduction programs and registries to prepare for eventual federal regulations. But whether or not these early actions will receive credit in any future GHG cap and trade program depends on future congressional legislation. To add further complexity to this already uncertain situation, the existing greenhouse gas emissions reduction registries in the United States differ in ways that could affect the provision of credit under future federal legislation (DiMascio, 2007). These uncertainties contribute to a "wait-and-see” attitude among many GHG emitters.

The speedy deployment of low-carbon technologies, as with many novel products and systems, can also be inhibited by missing or inadequate regulations, monitoring and verification procedures, and insufficient guidelines, codes and standards necessary for coordinating and interconnecting industry networks. Considering the commercialization and deployment of technology in terms of knowledge imbedded in linked systems and subsystems, it is not surprising that novel technologies face unique systems barriers that incumbent technologies no longer suffer because: the dominant technologies already benefit from mature and well understood regulatory systems (Unruh, 2000). When new technologies are getting ready for commercialization, developers need to know how the technology will be treated by the law. Having codes and standards in place before technologies come to the marketplace can ensure uniformity and safety, and reduces business risk. A compelling example of this need for new codes and standards is hydrogen-based products and systems. Standards will be necessary relative to purity, pressure, material thicknesses, as well as the certification of workers and many other features (NREL, 2002).

Nuclear power plant operators face uncertainties as to whether or not they will be allowed to construct and operate new nuclear power plants; these uncertainties include the need for 'waste confidence' and a new regulatory regime. New nuclear plants cannot be built until the federal regulating agency, the Nuclear Regulatory Commission (NRC) provides a statement of 'waste confidence.' Power plant operators have no control over this statement, and favorable waste confidence relies upon another federal body - the U.S. Department of Energy (DOE) (Rushton, 2006). DOE is responsible for taking ownership of used fuel from nuclear power plants; to date, this has not occurred, so nuclear power plant operators are storing fuel onsite in spent fuel pools and dry storage. The NRC has not stated that onsite storage will be sufficiently permanent to result in 'waste confidence.' The NRC is also working under a new regulatory process for certifying new nuclear power plants through the combined construction and operating license; one investor (NRG) has submitted a request for this new license - testing the process. Investors face considerable uncertainty as to how this new process will impact their construction and operating lead time. In this environment of uncertainty, investors must "get in line" for some products well in advance of knowing whether or not they will ever build the plant.

Various definitional and classification issues regarding $\mathrm{CO}_{2}$ sequestration remain unresolved, adding uncertainty to the development of CCS projects. $\mathrm{CO}_{2}$ can either be classified as an industrial product or as a waste product - a distinction that is important because industrial projects are typically subject to less stringent environmental regulations than waste disposal projects (Robertson et al., 2006). Existing federal air regulations do not define $\mathrm{CO}_{2}$ as a pollutant, but some states have already defined $\mathrm{CO}_{2}$ as a waste, an air contaminant, or a pollutant. ${ }^{59}$ Classification inconsistencies could negatively impact CCS development because of the added burden associated with waste management (Bliss, 2005). For example, the federal Marine Protection Research and Sanctuaries Act (MPRSA) governs the legality of carbon dioxide

\footnotetext{
${ }^{59}$ Existing regulations under the Clean Air Act provisions 42 USC §§ 7401-7671
} 
sequestration in the subseabed beneath U.S. territorial waters. ${ }^{60}$ It specifically prohibits "dumping” industrial waste into ocean waters. ${ }^{61}$ Thus, if $\mathrm{CO}_{2}$ is "industrial waste" and if subseabed carbon dioxide sequestration constitutes "dumping into ocean waters," then it is prohibited. However, there is statutory ambiguity about these terms, which contributes to business risks and impedes investment in this clean energy technology (Weeks, 2007).

In general, regulatory uncertainties keep industry from innovating and deter consumers from purchasing clean energy products. In some cases, regulatory uncertainty comes in the form of conflicting policy priorities. As described by the National Academies Press (2002, p. 113), policy inconsistencies limit reductions in fuel consumption, "There is a marked inconsistency between pressing automotive manufacturers for improved fuel economy from new vehicles on the one hand and insisting on low real gasoline prices on the other."

\subsection{STATUTORY BARRIERS}

Typically, statutes command, prohibit, or declare policy in pursuit of the public good, but they can become impediments to markets for clean energy technologies. Statutes are written laws set down by a legislature in response to a perceived need to clarify the functioning of government, improve civil order, answer a public need, codify existing law, or provide special treatment for an individual or company. In addition to the statutes passed by the national or state legislature, lower authorities or municipalities may also enact statutes. While these enactments are subordinate to the law of the whole state or nation, they are nonetheless a part of the body of a jurisdiction's statutory law.

Numerous local, state and federal statutes inhibit deployment of clean energy technologies. Some statutes are unfavorable, while others are uncertain. Due to the strong reliance on regulatory agencies for implementing most policies that impact clean energy technologies, there are instances where the line between statutes and regulations is unclear; for this reason, ineffective statutes are difficult to identify separate from ineffective regulation - described above.

\subsubsection{Unfavorable Statutes}

The lack of modern and enforceable building codes acts as a barrier to the deployment of green building technologies. In addition, procurement policies in many states prevent energy saving performance contracting from using private-sector resources to upgrade the energy integrity of state government buildings.

Lack of modern and enforceable building codes. There is great variability in the level of energy efficiency required by state building codes. For example, eighteen states have adopted the 2003 International Energy Conservation Code, while nine states have energy codes that are more than a decade old or follow no energy code at all (Brown et al., 2005). The dominance of local interests helps explain why there are several thousand different code specifications. These code variations fragment the market and contribute to manufacturing inefficiencies (Hirst and Brown, 1990).

Building standards can be distortionary, in spite of their numerous positive influences including the wellknown success reducing the energy required by household refrigerators (National Academies, 2001). Because codes and standards take a long time to adopt and modify, they sometimes specify obsolete technologies, thereby inhibiting innovation and encouraging obsolete technology. The RESCHECK code for assisting building code implementation allows tradeoffs between technologies to meet the overall

6033 U.S.C. §§ 1401-1445 (2000).

${ }^{61}$ Id. $\S \S 1412(a)$. 
code; in some cases, these tradeoffs lead to distortions when credits are allowed for common practices, preventing improvements in efficiency. ${ }^{62}$ For example, in the upper Midwest there is upwards of 80 percent penetration of condensing gas furnaces. The tradeoffs to meet the code allow savings from this now common high efficiency furnace to be used to offset poor envelopes (Harris, 2006). As a result, this code specification is no longer promoting improved building practices because it has not adapted to technology advances. Codes that are outdated or fail to adapt to changing available technologies can represent lost opportunities to improve energy efficiency.

State procurement policies. Over the past decade, energy service companies have become important players in delivering energy-efficiency upgrades to industrial and commercial markets and government facilities through the use of energy-saving performance contracts (ESPCs) ${ }^{63}$ Increasingly, this contracting mechanism is being used by state and federal government agencies to upgrade the energy efficiency of government-owned buildings. Recognizing the value of this funding mechanism, EPAct 2005 extended the authority of the federal government to engage in ESPCs.

Many state constitutions, however, do not allow the obligation of funds in advance of their being appropriated. In some of these states, this requirement is seen as prohibiting multi-year contracting with energy services companies. Another barrier to third-party financing is the scoring practices of the Congressional Budget Office (CBO). The CBO scores the costs and not the savings of ESPC contracts. The costs are real because they are in the contract, but the savings are not scored because they do not yet exist. There are similar problems with lease-purchases, where the lease payments incorporate the added first cost of the more expensive energy-efficient product, but the scoring does not include the savings (Harris, 2006).

\subsubsection{Statutory Uncertainty}

The expectation of a stream of immediate and future benefits drives most investment and consumption decisions. Uncertainty is a deterrent to investment and it is particularly problematic when new clean energy technologies are being launched into a market where codes and standards have not been developed, policies are expected, statutes fluctuate over time, and "the rules" vary from place-to-place.

Mosaic of clean energy portfolio standards. Differences across state laws add confusion in the marketplace for clean energy technologies. They also thwart the economies of scale that can result from national markets.

Many states have recently adopted Renewable Portfolio Standards (RPS) or Sustainable Energy Performance Standards (SEPS) requiring that a portion of electricity sold by utilities in a state come from particular renewable sources or be avoided through improvements to energy production and energy enduse efficiencies. Because electricity providers do not reside completely within the bounds of states (electricity is an interstate product), variation in these laws can be costly and onerous for utilities. These laws vary not only by their percentage goals and timelines for renewable energy, but also by the renewable resources and technologies that are eligible, see Table 4.2, (Cooper and Sovacool, 2007; Brown et al., 2007).

\footnotetext{
${ }^{62}$ An "envelope" refers to the exterior of a building - i.e. walls, windows, roofing, foundation, and associated insulation.

${ }^{63}$ An energy service company (ESCO) is a business that develops, installs, and finances projects designed to improve the energy efficiency and maintenance costs of facilities. ESCOs generally act as project developers for a wide range of tasks and assume the technical and performance risk associated with the project (source: http://www.naesco.org/, accessed 7/17/07).
} 
Table 4.2. Qualifying sources for renewable portfolio standards

\begin{tabular}{|c|c|c|c|c|c|c|c|c|c|c|c|c|c|}
\hline $\begin{array}{l}\frac{\Phi}{\pi} \\
\text { in }\end{array}$ & $\begin{array}{l}\overline{\widetilde{\varpi}} \\
\text { ర) }\end{array}$ & $\stackrel{\bar{\varpi}}{\searrow}$ & 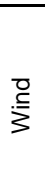 & ฉ & 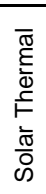 & 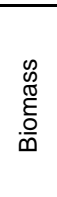 & 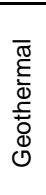 & 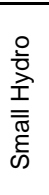 & 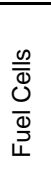 & 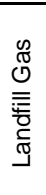 & $\frac{\bar{\pi}}{\stackrel{0}{O}}$ & 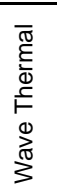 & 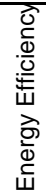 \\
\hline$A Z$ & 15 & 2025 & $\checkmark$ & $\checkmark$ & & $\checkmark$ & & & & & $\checkmark$ & & \\
\hline$C A$ & 20 & 2010 & $\checkmark$ & $\checkmark$ & $\checkmark$ & $\checkmark$ & $\checkmark$ & & $\checkmark$ & $\checkmark$ & $\checkmark$ & $\checkmark$ & \\
\hline $\mathrm{CO}$ & 20 & 2020 & $\checkmark$ & $\checkmark$ & & $\checkmark$ & $\checkmark$ & $\checkmark$ & & $\checkmark$ & $\checkmark$ & & \\
\hline $\mathrm{CT}$ & 23 & 2020 & $\checkmark$ & $\checkmark$ & $\checkmark$ & $\checkmark$ & $\checkmark$ & & $\checkmark$ & $\checkmark$ & $\checkmark$ & $\checkmark$ & \\
\hline $\mathrm{DE}$ & 10 & 2019 & $\checkmark$ & $\checkmark$ & $\checkmark$ & $\checkmark$ & $\checkmark$ & & $\checkmark$ & $\checkmark$ & $\checkmark$ & $\checkmark$ & \\
\hline $\mathrm{DC}$ & 11 & 2022 & $\checkmark$ & $\checkmark$ & $\checkmark$ & $\checkmark$ & $\checkmark$ & & $\checkmark$ & & $\checkmark$ & $\checkmark$ & \\
\hline $\mathrm{HI}$ & 20 & 2020 & $\checkmark$ & $\checkmark$ & $\checkmark$ & $\checkmark$ & $\checkmark$ & & $\checkmark$ & $\checkmark$ & $\checkmark$ & $\checkmark$ & $\checkmark$ \\
\hline IL & 8 & 2013 & $\checkmark$ & $\checkmark$ & & $\checkmark$ & & & $\checkmark$ & & $\checkmark$ & & \\
\hline IA & a & & $\checkmark$ & $\checkmark$ & & $\checkmark$ & & & $\checkmark$ & & & & \\
\hline $\mathrm{ME}$ & $10 \mathrm{~b}$ & 2017 & $\checkmark$ & $\checkmark$ & $\checkmark$ & $\checkmark$ & & & $\checkmark$ & $\checkmark$ & $\checkmark$ & $\checkmark$ & \\
\hline MD & 9.5 & 2022 & $\checkmark$ & $\checkmark$ & $\checkmark$ & $\checkmark$ & $\checkmark$ & & $\checkmark$ & $\checkmark$ & $\checkmark$ & $\checkmark$ & \\
\hline MA & 4 & 2009 & $\checkmark$ & $\checkmark$ & $\checkmark$ & $\checkmark$ & & & & $\checkmark$ & $\checkmark$ & $\checkmark$ & \\
\hline $\mathrm{MN}$ & 25 & 2025 & $\checkmark$ & & & $\checkmark$ & & & & $\checkmark$ & & & \\
\hline MT & 15 & 2015 & $\checkmark$ & $\checkmark$ & $\checkmark$ & $\checkmark$ & $\checkmark$ & & $\checkmark$ & $\checkmark$ & $\checkmark$ & & \\
\hline NV & 20 & 2015 & $\checkmark$ & $\checkmark$ & $\checkmark$ & $\checkmark$ & $\checkmark$ & & $\checkmark$ & & $\checkmark$ & & $\checkmark$ \\
\hline $\mathrm{NJ}$ & 22.5 & 2021 & $\checkmark$ & $\checkmark$ & $\checkmark$ & $\checkmark$ & $\checkmark$ & & $\checkmark$ & $\checkmark$ & $\checkmark$ & $\checkmark$ & \\
\hline NM & 20 & 2020 & $\checkmark$ & $\checkmark$ & $\checkmark$ & $\checkmark$ & $\checkmark$ & & $\checkmark$ & $\checkmark$ & $\checkmark$ & & \\
\hline NY & 24 & 2013 & $\checkmark$ & $\checkmark$ & $\checkmark$ & $\checkmark$ & & & $\checkmark$ & $\checkmark$ & $\checkmark$ & $\checkmark$ & \\
\hline OR & 25 & 2025 & $\checkmark$ & $\checkmark$ & $\checkmark$ & $\checkmark$ & $\checkmark$ & $\checkmark$ & $\checkmark$ & $\checkmark$ & $\checkmark$ & $\checkmark$ & \\
\hline PA & 18 & 2020 & $\checkmark$ & $\checkmark$ & & $\checkmark$ & $\checkmark$ & & $\checkmark$ & $\checkmark$ & $\checkmark$ & & $\checkmark$ \\
\hline RI & 15 & 2020 & $\checkmark$ & $\checkmark$ & $\checkmark$ & $\checkmark$ & $\checkmark$ & $\checkmark$ & & $\checkmark$ & $\checkmark$ & $\checkmark$ & \\
\hline TX & C & 2015 & $\checkmark$ & $\checkmark$ & $\checkmark$ & $\checkmark$ & $\checkmark$ & & $\checkmark$ & & $\checkmark$ & $\checkmark$ & \\
\hline VT & $d$ & 2012 & $\checkmark$ & $\checkmark$ & & $\checkmark$ & & & $\checkmark$ & $\checkmark$ & $\checkmark$ & & \\
\hline WA & 15 & 2020 & $\checkmark$ & $\checkmark$ & $\checkmark$ & $\checkmark$ & $\checkmark$ & $\checkmark$ & $\checkmark$ & $\checkmark$ & $\checkmark$ & $\checkmark$ & \\
\hline WI & 10 & 2015 & $\checkmark$ & $\checkmark$ & $\checkmark$ & $\checkmark$ & $\checkmark$ & & $\checkmark$ & $\checkmark$ & $\checkmark$ & $\checkmark$ & \\
\hline $105 \mathrm{MV}$ & & $\mathrm{b}:$ & ad 3 & by 2 & & c: 5,8 & AW & & $\mathrm{d}: \operatorname{loc}$ & I grov & & & \\
\hline
\end{tabular}

Uncertain property rights. Uncertainty about property ownership is a barrier for several clean energy technologies including carbon capture and storage (CCS), coal bed and coal mine methane, and wind generation.

For CCS, the three main areas of property rights are surface (rights pertaining to the location of $\mathrm{CO}_{2}$ injections), sub-surface (rights associated with underground reservoirs), and rights to the $\mathrm{CO}_{2}$ itself (Robertson et al., 2006). The surface and gas rights are generally not under question, but the deep subsurface property rights are not established or not applied consistently. When $\mathrm{CO}_{2}$ is injected underground, it is not clear who needs to be paid and who has the right of refusal. Existing sub-surface rights are not uniform: for oil, the rights are attached to the surface, and the mineral rights are owned separately based on sub-surface rights; water is treated differently. It is unclear how large-scale $\mathrm{CO}_{2}$ injection will be treated. Can the surface owner deny rights? If the injected fluid goes beyond the surface boundaries, the floor space a mile deep in adjacent lots may or may not be available to that well. There is one case that provides a precedent for broad property rights. DOE's FutureGen project has assumed that the well owner must own all of the land footprint over the impacted floorspace. Resolution of the ownership of $\mathrm{CO}_{2}$ storage rights (reservoir pore space) is needed before CCS approaches can proliferate (Hovorka, 2006; Bliss, 2005).

Ownership issues similarly impede the recovery of methane from coal beds and coal mines. If the coal mine draws methane from under properties owned by others, land ownership can be unclear. Ownership of the gas also could raise reporting issues for the mine owner. Statutory uncertainty is created because there is variability among states as to the legal ownership of resources, land, and gas. Owners of the coal, surface land, coalbed methane, and mineral rights may be different entities, complicating negotiations for 
recovery of the gas and access to the land. The Supreme Court found that federal coal leases granted under the 1909 and 1910 Coal Lands Acts did not include coalbed methane as part of the coal lease, impeding potential recovery (Sabino, 2007). The Bureau of Land Management (BLM) is involved in resolving this property rights issue; separate leases may need to be negotiated. EPAct $1992^{64}$ attempted to resolve the issue, providing model legislation, but many states did not adopt it. Mine-by-mine solutions are being developed for a small number of mines (Kruger and Gunning, 2006).

For wind technologies, Wilson (2004) notes a pressing problem related to wind rights contracts for small landowners. Wind rights are generally recognized under two common law doctrines: the united fee ownership rule (the idea that a landowner's property rights extend to everything from the center of the earth to the sky, such as rainfall from clouds over their property) dictates a legal right to harvest the wind that blows across one's land, in contrast, traditional mineral rights doctrine (which establishes that surface rights may remain in the possession of one person or entity, while the right to extract various minerals lies with another) suggests that wind, like oil and natural gas, is a resource that can be sold.

\subsection{CONCLUSIONS}

Policy interventions in energy markets have produced an array of "public failures" that need to be reformed. These failures are of special interest because they are at cross-purposes with the stated U.S. goal of reducing GHG intensity. ${ }^{65}$ This section describes more than 30 of these distortionary barriers that slow or block the market uptake of clean energy technologies (Appendix B).

Numerous unfavorable policies place GHG-reducing technologies at a comparative disadvantage. Sometimes this is done by favoring competing technologies or by precluding technological change and thereby supporting incumbent technologies. Environmental standards enable the continued operation of some of the most polluting generators in the country far beyond their normal life and perversely disincentivize investing in plant upgrades. Conflicting social goals often explain these public failures: cheap energy is preferred over clean energy, and the desire to promote U.S. oil independence trumps the goal of mitigating greenhouse gases. Legal inertia is another cause: laws often trail behind and thereby inhibit technological progress, as is true of building codes, CAFE standards, and tax depreciation schedules.

Unfavorable policies also result from design flaws that undermine their intended outcomes. Sometimes these occur in the form of loopholes as is the case with the fuel-economy standards for the nation's vehicles. In other instances, tax credits for investments in GHG-reducing technologies are authorized but they cannot be claimed. Burdensome procedures add unnecessary sluggishness to the process of technological change. Property taxes for forest land promote deforestation, and land-use planning continues to foster urban sprawl with its expanding carbon footprint.

Policy uncertainty is pervasive in today's energy markets. Investors and consumers face numerous uncertainties and ambiguities about possible future GHG regulations and tax treatments. These uncertainties contribute to a "wait-and-see" attitude among GHG emitters. Uncertainty results from state and local variability, fluctuating short-term policies, and extended debates about alternative future policy scenarios can preempt commitments to GHG-reducing and investments in less carbon-intensive options. Net-metering, environmental permitting, Renewable Portfolio Standards and many other "crazy-quilt" state-by-state policies hinder the development of national markets and the resulting economies of scale so necessary for new technologies to become cost-competitive.

\footnotetext{
${ }^{64}$ P.L. 102-486

${ }^{65}$ The George W. Bush administration in 2002 announced a national goal of reducing GHG intensity (that is, emissions per dollar of real GDP) by $18 \%$ from 2002 to 2012.
} 
Carbon Lock-In

These distortionary fiscal, regulatory, and statutory policies create confusion in the marketplace for energy technologies. A vigorous campaign of policy reform is needed to create a consistent, effective, and predictable policy environment where clear and reinforcing signals encourage the infusion of GHGreducing technologies to prevent large-scale global climate disruption. 


\section{5}

Fighting climate

change promises to

be one of the most

significant

technological

projects in human

history. As a result,

firms may be

reluctant to

participate in

collaborative

agreements or

patent pools since

such acts could be

viewed as

undermining the

financial gains to be

made from

exclusivity. And a

lack of substitutes

for many energy

technologies means

some firms simply

cannot invent

around patents.

\section{Intellectual Property} Barriers

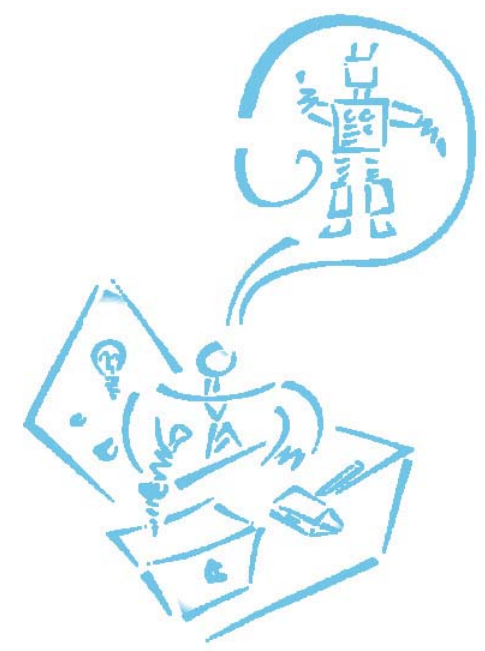

Generally, lawmakers have designed U.S. intellectual property law (IPR) to stimulate innovation, entrepreneurship, and technology commercialization. However, its application can also impede innovation and technological development. High patent filing costs can serve as a financial impediment for inventors and firms with scarce capital including many small businesses. Other impediments include patent manipulation through techniques such as warehousing (owning the patent to a novel technology but never developing that technology) and suppression (refusing to file for a patent so that a novel process or product never reaches the market). Weak international patent protection among developing countries prevents some companies from investing in international energy projects. Finally, conflicting organizational goals and the perception of onerous intellectual property hurdles prevents some companies from collaborating with universities and national laboratories (See Table 5.1). 
Table 5.1. Intellectual property barriers

\section{Intellectual Property Barriers}

High Intellectual Property Transaction Costs

Anti-competitive Patent Practices

Weak International Patent Protection

University, Industry, Government Perceptions
High transaction costs for patent filing and enforcement, conflicting views of a patent's value, and systemic problems at the USPTO.

Techniques such as patent warehousing, suppression, and blocking.

Inconsistent or nonexistent patent protection in developing countries and emerging markets.

Conflicting goals of universities, national laboratories, and industry concerning CRADAs and technology commercialization.

\subsection{HIGH INTELLECTUAL PROPERTY TRANSACTION COSTS}

High patent filing and enforcement costs. The first - and most obvious - IP transaction cost is the expense of filing for the patent itself. Quinn (2006) notes that the cost of filing a patent is really a series of interrelated expenses related to conducting a pre-application patent search, review of the product's patentability, preparation of formal drawings, filing fees with the U.S. Patent and Trademark Office (USPTO), and patent attorney fees. While the transaction costs associated with patent filing will vary depending on the type of technology and breadth of the patent, Quinn estimates that typical costs range anywhere from $\$ 10,000$ to hundreds of thousands of dollars per patent (See Table 5.2).

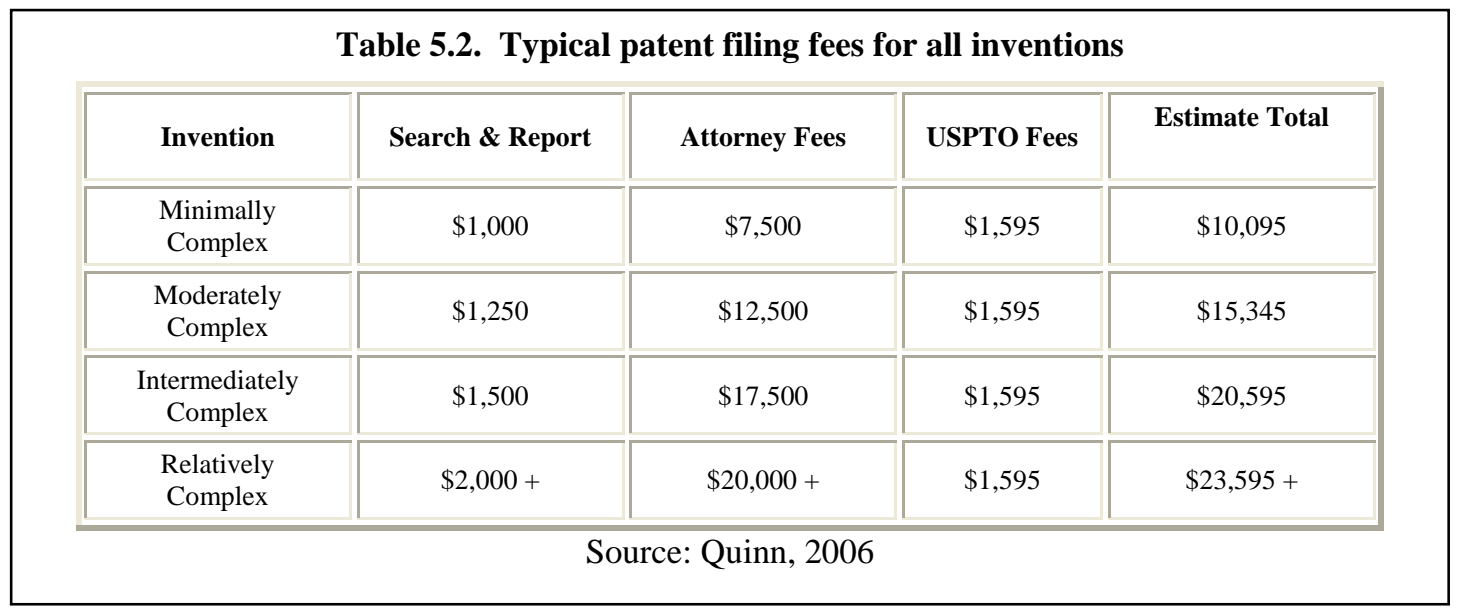

While such expenses may not impede larger technology firms, they do not include the costs associated with patent continuation, maintenance, and enforcement against infringement. Potts (2006) calculates that based on the uncertainties of the patent searching process and the number of amendments and drawings that may be required, inventors and firms can expect to expend an additional $\$ 20,000$ per each foreign country in which patent protection is sought. Furthermore, the patent filing process typically takes between 24 and 36 months, with patent searches taking between one to two months, application preparation one to two months, prosecution one to two years, and issuance three to nine months. 
Moreover, Mowery and Ziedonis (2000) document that the number of patents submitted to the U.S. PTO has increased greatly, especially among universities. This increase in the number of patents has contributed to higher transactions costs for collecting information and rearranging entitlements. Heller and Eisenberg (1998) note that many engineering firms and biotechnology institutions have limited resources for absorbing transaction costs and limited competence in fast paced, market bargaining. Such limited resources make it difficult to harmonize the interests of corporate, laboratory, and university sponsors and may complicate the emergence of standard licensing terms. Gallini (2002) adds that identifying subsequent inventors before the pioneer commercializes the invention may prove difficult, and that researchers may need to commit significant investment before deciding whether their idea is patentable - something they may be reluctant to do since those costs will be sunk before a project is completed. And Mazzoleni and Nelson (1998) comment that higher barriers of entry exist for both smaller and newer firms, a hurdle heightened by the increasing trend for IPR to be granted on discoveries or procedures that are a long way from practical application, in particular on what used to be considered "science."

Furthermore, the transaction costs associated with policing and enforcement of patents deter some firms from innovating. While it is true that infringement cases are rare, Gallini (2002, p. 132) notes that "when research is sequential and builds upon previous discoveries, stronger patents may discourage subsequent research on valuable, but potentially infringing, follow-on inventions.” The expense of conducting a patent infringement case, for instance, typically cost between one and several million dollars. Gallini argues that the costs of patent litigation in the early 1990s accounted for more than \$1 billion (in 1992 dollars), or more than 27 percent of expenditures on basic research by U.S. firms in that year. When firms lose an infringement case, they can be forced to pay millions of dollars in damages or - worse face court ordered injunctions to suspend operation.

Fear of the cost of patent defense litigation had a significant impact on investment in invention for almost half of the 600 small to medium enterprises surveyed by Hanel (2006). Hanel found that 55 percent of small biotechnology firms and 33 percent of large ones reported that patent litigation was a deterrent to innovation, that smaller firms were even more damaged by costly preliminary injunctions, and that firms requesting injunction tended to be twice as large as those that do not. Lerner (1995) concluded that that many firms concerned with the high costs of litigation appear to avoid research areas occupied by other firms all together.

Marechaux (2006) emphasizes that IPR transaction costs such as acquiring information about existing patents, filing with the USPTO, and enforcing patents may not be that large. However, taken collectively, they become almost "insurmountable" for inventors. The costs of moving new technologies from the cradle to the marketplace add up quickly and multiply, so that many people refuse to even start the process of invention. Many researchers have excellent ideas for new technologies that would drastically improve the energy efficiency and security of the country, but cannot get past the IPR starting mark. When these individuals do try to innovate, they spend most of their time negotiating licenses and royalties, finding investors, buying other patents, protecting their ideas from infringement, collecting information and complaining about it that almost no time is left for what counts - the technology itself. Marechaux (2006) concludes that the patent system itself acts as a hurdle, especially when investors can simply leave the U.S. and fund innovators somewhere else. 
The case of hybrid solar lighting (HSL) is an example of a technology innovation at a DOE national laboratory where market deployment barriers include intellectual property issues. HSL was developed and patented at Oak Ridge National Laboratory with sponsorship from the DOE and the Tennessee Valley Authority. Promoted at numerous conferences and technology forums, HSL was licensed in August of 2005 by a local start-up company. To establish niche market pull opportunity, the company - Sunlight Direct, Inc. - is managing a field trial demonstration phase. Sunlight Direct had to develop an intellectual property portfolio at the same time it needed to keep system costs down, a task made even more complicated since HSL involves several different components lending to the efficiency of the system. For a start-up company striving to make ends meet and with no R\&D department, this has been challenging.

Sunlight Direct had to outsource development of a long-term solution to the electronic control board and negotiate licenses to use GPS and self-calibration

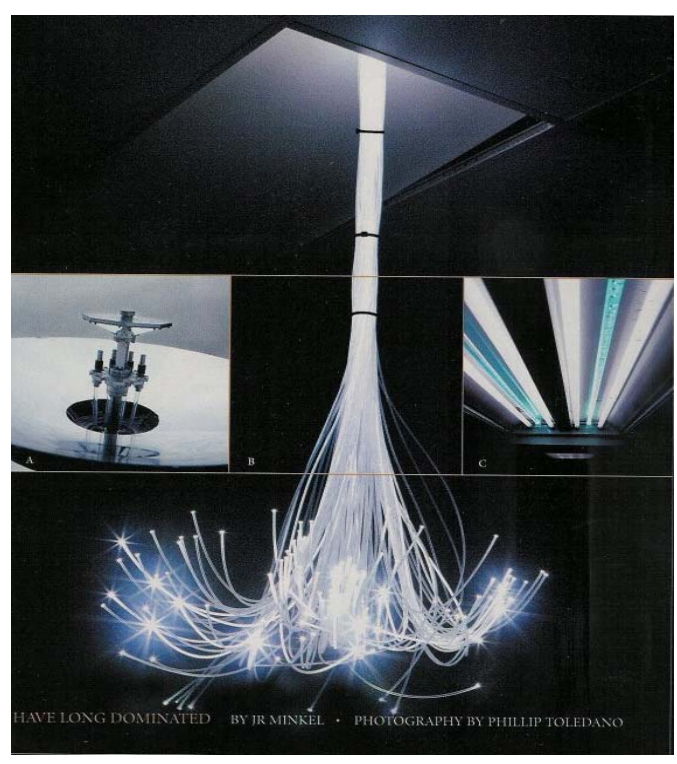

capabilities with a larger company (Lapsa et al., 2007).As a result of this strategic partnering, Sunlight Direct is well positioned for a national roll-out of their product line in 2008.

Box 5.1 Hybrid solar lighting: The challenge of assembling an IP portfolio Photo courtesy of photographer Phil Toledano, http://ptoledano.com

Conflicting views of patent value and ownership. Just as most people overestimate their own assets and disparage the claims of their opponents, most inventors hold an inherent bias towards their own patent, and have difficulty assigning value to the work of others (Heller and Eisenberg, 1998). Such cognitive and attribution biases influence multiple dimensions of the technological development process, from how researchers perceive the profitability of applying for a patent to their view of the necessary breadth of patent protection. For example, inflated expectations about the value of an invention may prevent the inventor and licensee from setting acceptable royalties (Gallini, 2002).

Public/private approaches such as the Advanced Technology Program, for instance, are plagued by the question of who owns the ideas. Focus group studies by the National Academies have shown that the government workers did not trust the industrial partners because they "knew" that the industry partners did not trust them, and vice-versa. Recognizing this problem, the DOE Solar America Initiative (SAI) is trying to get companies to work together towards a common goal. SAI is a large cost-shared program (a 50-50 split of public and private sector resources) that shows great promise and represents a fundamental shift in mode of operation, towards working with industry consortia. ${ }^{66}$

Sometimes attribution biases may swing the other way. Cohen and Noll (1996) suggest that two firms may view the other as likely to win a patent race, so that neither pursues research. Because innovators do not have full access to information, companies and firms may overestimate the danger that their new

\footnotetext{
${ }^{66}$ Before SAI, the emphasis was on solar energy research and development with a goal of expanding impact through component performance improvements. The new program focuses on funding industry partnerships and alliances to accelerate market-ready PV using aggressive cost goals, down-selects, and a new focus on eliminating manufacturing and production barriers (http://www1.eere.energy.gov/solar/solar_america/about.html).
} 
products will inadvertently infringe on patents issued after these products were designed (Shapiro, 2000). When projects are undertaken by separate companies, the risk increases that parallel R\&D practices must be discontinued as soon as an idea is patented.

Systemic problems with the USPTO. Two sets of further barriers relate to structural problems within the U.S. Patent and Trademark Office (PTO) and the recording of federal patents. The PTO houses seven different technology centers, some overlapping with others, with even more subunits within each center. For instance, the PTO has a biotechnology and organic chemistry center and a chemical and materials engineering center. Although certainly not the prevailing view, Bastani and Fernandez (2002) assert that such a high level of complexity - combined with a lack of focused experience among some PTO staff members - frequently results in improper rejection of patents due to the mistaken idea that the idea is not new, as well as overly broad patents that give owners excessive control over a particular area.

Furthermore, Davis (2004) suggests that the large amount of information relating to patents worldwide means that patent office decisions concerning whether inventions fulfill criteria of patentability may be inaccurate, contributing to the granting of invalid or contested patents that waste resources and clog the courts. Indicative of these problems is the fact that nearly one-third of the 355,000 new patent applications received in 2004 involved resubmissions of previous applications (Agres, 2006).

Shapiro (2000) argues that the PTO appears to be allowing more vague patents that do not appear offhand to meet the standards of novelty and non-obviousness. This vast number of vague or improper patents creates a real danger that a single new product or service infringes on multiple patents, and many patents cover products already being used when the patent is issued, making it harder for companies building businesses to invent around such patents. Shapiro comments that the ability for patent holder to seek injunctive relief - or threaten to suspend operations of the infringing company - further degrades technological innovation.

Patents may be granted covering relating to contingencies not currently covered in law; these contribute to uncertainty in how companies can use the patented technology or process. For example, Rand (2006) notes that fluoro-ketone, an emerging alternative to $\mathrm{SF}_{6}$ developed by $3 \mathrm{M}$, is being patented with a design to transfer to $3 \mathrm{M}$ the legal rights to future emission reduction credits from the use of fluoro-ketone (a GHG-reducing product). This has created an element of uncertainty for magnesium companies concerning the patent's validity and has hindered its adoption.

Another set of barriers, not in the PTO, but a still a systemic issue concerns federal recording of patents under the Bayh-Dole Act. The U.S. General Accounting Office (GAO) (2002) has noted that the BayhDole Act requires contractors, grantees, and the recipients of Cooperative Research and Development Agreements (CRADAs) to follow specific reporting requirements regarding disclosure, election to retain title, application for patent, licensing, and commercialization of any invention subject to the act. However, numerous federal agencies and their contractors and grantees - including those at the U.S. Department of Energy - are not complying. The federal government almost never asserts its "march-in rights.” The GAO notes that databases for recording the government's interests in the inventions were inaccurate, incomplete, and inconsistent, meaning that the government was not aware of inventions to which it had royalty-free rights, thereby hindering their use in government sectors.

\subsection{ANTI-COMPETITIVE PATENT PRACTICES}

Apart from some of the structural and economic problems inherent with IPR, many firms use patents as intentional tools to impede innovation and competition. Hanel (2006) notes that increased patenting, ironically, may have more to do with their perceived ineffectiveness. Firms use patents in multiple ways. In addition to protecting returns on specific inventions (the oft quoted claim), firms can use patents to block products of their competitors, as bargaining chips in cross-licensing, or to prevent and defend 
against infringement suites. Three of the more severe anti-competitive practices - warehousing, suppression, and patent blocking - are explored in greater detail below.

Warehousing. Some companies warehouse patent rights in order to extract cash from entities that are found to be infringing such rights. In a process also referred to as "patent trolling," these companies do not actually make or sell anything, but simply own the patent to that they can acquire damages once the patent is infringed (Sabety, 2005).

One of the most subversive warehousing techniques involves the creation of "submarine patents" (Shapiro, 2000; Duffy et al., 1998). Complex technological projects often involve multiple, overlapping inventions. Some firms and inventors will apply for a patent connected to a product or process, but will intentionally ensure that the patent process is never completed (and kept alive in the PTO), thus shielding knowledge of it from competitors. These patents then "surface" when a rival company invents around the area of the patent. Some submarine patents have been sitting in the PTO for decades, a few for more than forty years. An epidemic of submarine patents occurred in the 1980s, forcing the PTO to change the patent term from seventeen years from the date of grant to twenty years from the date of filing in 1995. While these changes have helped minimize the risk of submarine patents, Duffy et al. (1998) comment that opportunity for gamesmanship still looms large since firms can keep the scope of their patent claims confidential for ten years before springing them on American industries.

Shapiro (2000) argues that such submarine patents impede innovation in at least two ways. First, they can create a virtual monopoly on a given process or product and thus elicit monopoly behavior and rising costs. Second, such patents - if they cannot be invented around - act merely as a tax on innovation, and in a large project the cumulative effect of small taxes can become quite large. The problem can be further magnified in a complicated industry where hundreds if not thousands of patents - some already issued, others pending - can read on a given product, creating a veritable "minefield" for inventors.

Suppression. Patent suppression is "any type of conduct or agreement that limits the availability, use, or development of a particular process or product, or that limits or chills the ability of others to create or exploit such an innovative process or product" (Zain, 2006). It results in the nonuse and non-diffusion of technology by those who control it (Saunders and Levine, 2004). It is particularly challenging to research and document, since the courts have been reluctant to view it as unlawful and most of the information never diffuses into public record. Saunders and Levine show that technologies can be suppressed in one of three ways: through acquisition, an exclusive licensing agreement, or an in-house decision to discontinue use or development. Suppression is not always intentional; it can occur for many reasons including inadequate finances, incompetence of patent owners, and delay in the development of inventions (Saunders and Levine, 2004).

Suppression has occurred in a variety of industries and technologies, including the energy sector and technologies such as alternative fuel vehicles, electric lamps, compact fluorescent light bulbs, and photovoltaic (solar) panels. In the 1970s, for instance, Paul Pantone invented a carburetor that incorporated an internal refinery into the engine using a process called thermal resonant cracking. Such an engine could run on unrefined fuels and yielded much less pollution than conventional combustion engines, but was never pursued by the automobile companies that shared its patent. In addition, Tom Ogle developed an automotive system for Ford Motor Company that used a series of hoses to feed a mixture of gas vapors and air directly into the engine. Ford built a small number of prototypes that averaged more than 100 miles per gallon at 55 miles per hour, but the technology was ultimately suppressed (Saunders and Levine, 2004).

Patent blocking. As a final anti-competitive practice, some firms will patent processes and technologies only to block other firms from entering the market. Mazzoleni and Nelson (1998) note that the static 
costs associated with a patent protected monopoly position can deter other firms from trying to invent even "in the neighborhood" of other patents. Patents can more directly block innovation when firms try to patent the entire production process by applying for as many patents as possible for one product (Blind and Thumm, 2004). Competitors have to approach the respective firm and apply for licenses whenever they want to produce anything in that area. Large pharmaceutical companies often adhere to this practice to block entry into their market. Firms can then respond with only three options: (a) trying to invalidate the patents, (b) trying to invent around them, or (c) simply ignoring them and risking an infringement suit. Blind and Thumm surveyed European companies and found that more listed "impeding competitors' patenting and application activities” as an incentive to patent instead of "acquisition of capital.”

Similarly, Cohen, Nelson, and Walsh (2000) surveyed 1,478 R\&D laboratories in the U.S. and found that a majority of firms are starting to rely on patent blocking, especially when numerous, separately patentable inventions need to be combined to produce a single product. The study found that blocking patents was frequently used to extract licensing revenue or to force inclusion in cross-licensing negotiations. For instance, a patent holder with no intent of commercializing the complex product may want to extract rents through licensing. Incumbents can use their patents as bargaining chips to compel their inclusion in cross licensing or at least secure the freedom to move ahead on similar technological efforts without being sued in a sort of "block to play" strategy. For example, in the 1940s DuPont patented more than 200 substitutes for Nylon to protect two of its core inventions (Cohen et al. 2002).

Heller and Eisenberg (1998) caution that patent blocking can create an "anti-commons" where technological innovation is impeded when multiple owners each have a right to exclude others from a scarce resource giving no single entity effective privilege of use. Patents and IPR protection may fortify incentives to undertake risky research, but can go astray when too many owners hold rights in previous discoveries and create obstacles to future research. Here, patents are increasingly viewed as entitlements, resulting in a spiral of overlapping patent claims in the hands of different owners. Heller and Eisenberg (1998, p. 699) caution that "by conferring monopolies in discoveries, patents necessarily increase prices and restrict use...Each upstream patent allows its owner to set up another tollbooth on the road to product development, adding to the cost and slowing the pace of downstream innovation.”

For instance, Appleby (1996) comments that the fuel cell manufacturing industry involves many different agents with varying licenses to facilities and royalties. Participants at a fuel cell plant in Santa Clara, California, included the Electric Power Research Institute, United Power Association, National Rural Electric Cooperation, Sacramento Utility District, Southern California Edison, the California Energy Commission, city of Palo Alto, Arizona Salt River Project, Fuel Cell Engineering Corporation, and the U.S. Department of Energy. The complex series of agreements required to get the project off the ground took years to negotiate.

Robertson, Findsen, and Messner (2006) note similar complexities in carbon sequestration and storage research, where property rights concerning access to project sites are not clearly defined, especially when development relies on different areas of technology (including at the surface injection level, sub-surface reservoir level, and where the $\mathrm{CO}_{2}$ is physically deposited). Most clean coal technologies require multiple patents in many different fields. Companies working on fluidized combustion technology, for instance, must invent or license patents relating to combustion dynamics, fluid dynamics, air dynamics, material science, computational controls, and electronics - just to name a few. Jin and Liu (1999, p. 76) warn that "institutes and universities are too worried about losing their technical advantages or intellectual property rights to cooperate effectively with each other.”

It appears that parts of the American automobile industry face analogous concerns. Greene (2006) believes the need for cross licensing has blocked innovation relating to hybrid vehicle technology. While Ford has used Toyota technology (in the Ford Escape), Ford has resisted purchasing Toyota's technology 
for hybrid vehicles because of hefty licensing fees, and Honda has not been able to successfully negotiate a license to use nickel metal hydride batteries in their hybrid vehicles. Greene (2006) offers the opinion that Honda's difficulties may be due to close relationships between Toyota and PEVE.

\subsection{WEAK INTERNATIONAL PATENT PROTECTION}

U.S. technology firms often cite weak international IPR protections as a significant impediment to both deciding to develop an innovative technology and diffusing that technology into the global marketplace. The International Energy Agency (2005) notes that concerns about weak IPR protection in developing countries deter innovation as firms believe they would be at a competitive disadvantage to diffuse their technology. Many companies do not want to collaborate with overseas partners because participation may attract those that have the most to gain and the least to contribute. These companies see such collaboration as risking unevenness in the sharing capability. Moreover, host companies in developing countries may be reluctant to purchase or acquire technology that they believe competitors could freely copy in their own markets. Thus, weak international IPR protection affects both the supply and demand components of technological diffusion. Gallagher, Holdren, and Sagar (2006) conclude that lack of IPR protections hurts innovation on almost all energy technologies internationally.

For instance, Guerin (2001), Philibert and Podkanski (2005), Hovorka (2006), and Kruger and Gunning (2006) have noted that weak IPR protection has prevented U.S. companies from developing more advanced clean coal technologies (such as more efficient coal washing processes, advanced combustion turbines, and carbon capture and storage systems). IPR concerns connected with clean coal systems are cited as one of the most significant impediments towards diffusing such technologies to China, Indonesia, and other developing countries - especially where new technologies could be reverse engineered or copied.

Popp (2006) notes that research on pollution abatement technologies for sulfur dioxide and nitrogen oxide emissions in the U.S. has been slowed by a perceived need to adapt technologies to foreign markets. The Office of the U.S. Trade Representative (2006) suggests that while U.S. exports of renewable energy and air pollution control technologies (currently totaling more than $\$ 18$ billion in 2005) are eligible as environmental goods for reduced tariffs under the World Trade Organization, the lack of adequate and effective IPR protection in Venezuela, Uzbekistan, Philippines, Columbia, China, and Chile prevented much needed investment in such technologies. Soloman and Banerjee (2006) note that U.S. firms are hesitant to diffuse hydrogen technology even in Europe due to lack of consistent rules and regulations involving IPR.

\subsection{CONFLICTS ARISING IN PUBLIC-PRIVATE PARTNERSHIPS}

Discussed previously in less detail (section 5.1), CRADAs are a form of contract encouraging industries, universities, and government laboratories to work together on developing new technologies. Such agreements require the prior settlement of any intellectual property created by the research in a way that is relatively favorable to all partners. Under these agreements, the laboratory and the industrial or university partner share the intellectual property brought into and created through the CRADA activity. Technical data produced under the CRADA are protected from disclosure for five years after the CRADA is completed. The industrial partner has title to all patents resulting from its own efforts under the CRADA. The laboratory contractor retains rights to inventions developed by the laboratory under the CRADA, but the partner is guaranteed an option on an exclusive license in a negotiated field of use for royalties. Some IPR barriers relate to the CRADA process, including conflicting goals.

For instance, Brooks (1993) notes that some businesses and industrial leaders are reluctant to cooperate with universities because they perceive them as lax in accounting, abusive of government regulations for 
indirect cost allowances and overhead, and lacking an entrepreneurial ethic. Similarly, Rappert, Webster, and Charles (1999) argue that universities are seen as lacking business and marketing experience, and of structuring their work in a manner difficult to be managed.

Paul Gottlieb (2006), assistant general council for technology transfer and intellectual property at the U.S. Department of Energy, notes that industry has expressed displeasure towards having to pay royalties to access and use technology from the national laboratories. Gottlieb believes that such royalties are not used to make money (existing only as an incentive to induce cooperation from government scientists). DOE contractor operated laboratories have the advantage of the flexibility to more readily offer exclusive licenses to technologies arising at the laboratory. Nonetheless, many industrial leaders believe that since their taxes fund government research, they should not have to pay "twice" for it through a license or royalty. Gottlieb notes that other potential partners have expressed frustration with the preference for collaborating in laboratory CRADAs with companies that agree to manufacture CRADA-produced technologies in the United States. This can be a disincentive to partnering with a DOE laboratory.

In parallel, Herrick (2003) argues that some industries have expressed growing dissatisfaction with CRADAs at the national laboratories because increased competition and electricity restructuring means most businesses working on new technologies need rapid payback schedules, so their short-term R\&D objectives do not match the more long-term objectives of the DOE. Furthermore, some firms have expressed frustration in dealing with national laboratories due to the high cost of administering CRADAs, the time it takes to structure worthwhile agreements with the laboratories, and the lack of commercial readiness of the laboratories' technologies.

Additionally, the sheer complexity of the national laboratories may deter collaboration (Jaffe and Lerner, 2001). The quality of laboratory technology and competency may differ, reflecting the nature of disparate laboratory missions (those specializing in basic science or defense may have less experience with and facilities for commercialization). Moreover, the conditions under which contractors can be permitted to patent and license federally funded technologies remains highly controversial, and the relationship between contractors assigned to run facilities and the DOE differs significantly. The locations of the facilities at the national laboratories are highly disparate, some placed near population centers while others exist in remote areas.

Laboratory managers are subject to differing levels of bureaucratic accountability, and their programs are determined by multi-functional DOE offices. The resulting pressures can sometimes make them unresponsive to decentralized decisions required by small businesses and lead to the perception that CRADAs will be excessively micro managed, inflexible, and intrusive. For these reasons, Branscomb concludes that "firms are highly skeptical that the laboratories possess either the culture (sensitivity to cost and market requirements) or the experience (in process technology, design for manufacturing, and the like) necessary to make a contribution a commercial success” (Branscomb, 1993, pp. 113-114).

Crow and Bozeman (1998, pp. 202-210) surveyed 330 interactions between industry and the national laboratories and found that close to 90 percent were very satisfied with the partnership —no doubt an outstanding number. However, 11 percent of companies were extremely dissatisfied with CRADAs. Of these dissatisfied companies, their survey revealed that industrial managers were concerned that CRADAs excluded smaller companies, which could not afford the luxury of expending financial and human capital on CRADAs, and that laboratory expertise was more focused on upstream rather than downstream work. Thus, Crow and Bozeman suggest that the national laboratories are perceived as excellent for basic research but lacking expertise on commercialization and deployment. A more up-to-date assessment based on extensive experience of the venture capital industry with DOE laboratories is that they are highly variable in their commercialization expertise (Grady, 2007). 
Finally, a shift in university focus to include more patenting and enforcement of IPR in collaborations with businesses and national laboratories has created a discussion among scientists and academics about the role of the university. Rosenzweig (1985) notes that the discussion centers on how to prevent the commercialization of university research from undermining the open sharing of knowledge. Many scientists and professors, for instance, believe that teaching and research depend on the absence of barriers to the free and open exchange of knowledge. Foray (1997) argues that many academics believe that openness is needed to facilitate independent replication of findings, promote swift generalization of results, avoid excessive duplication of research, increase the probability of innovation because new knowledge is available to many researchers, and raise the social value of knowledge by lowering the chance that knowledge will reside with people who lack the ability to fully exploit it. Other studies undertaken by Kennedy (2000), Argyres and Liebeskind (1998), and Guena and Nesta (2006) have documented conflicts between those opposed to the commercialization of academic research and those supporting it.

Disputes between faculty members and university administrators seeking to commercialize academic research can become more than just theoretical debates. Powell and Owen-Smith (1998) document that conflagrations between faculty members who prefer an open or accessible license for discovery (which would maximize the breadth of knowledge dissemination in their mind) and entrepreneurial universities (that want a more lucrative, exclusive license) can turn into protracted, legal battles. A 1997 case in California illustrates the financial danger of such conflicts. Two professors won a \$2.3 million (in 1997 dollars) award from the University of California-San Francisco after claming the university defrauded them by licensing their patents to other companies at a discount in exchange for sponsored research support from those companies.

\subsection{CONCLUSIONS}

Many of the IPR barriers facing greenhouse gas reducing technologies do not hold equal weight, and some inherently contradict each other. For example, small firms often cite the strength of current patent laws as a deterrent to innovation, where large multinational firms believe that domestic and international protections for IPR need to be strengthened. Industry leaders view some universities as lacking the proper entrepreneurial ethic needed to promote innovative technologies, where some universities view the commercialization of academic research as a threat to their core educational mission.

Nonetheless, a substantial and growing body of evidence suggests that the relationship between IP, IPR protections, and technological development and diffusion is far absolute. In many cases, patents can further innovation; in others, they may deter it.

Perhaps nowhere are these factors more pronounced than in the energy sector. The restructuring of the electric utility industry has created further incentives against cooperative R\&D. Continually declining public and private support for energy R\&D results in fewer research funds and thus more competition (and an incentive to enforce IP protections). Fighting climate change promises to be one of the most significant technological projects in human history, meaning that firms may be less willing to participate in collaborative agreements or patent pools since such acts could be viewed as undermining the financial gains to be made from exclusivity. And a lack of substitutes for many energy technologies (from materials to fuel conversion processes) means some firms simply cannot invent around patents. For these reasons, IPR issues will likely remain central to discussions concerning the innovation, development, and diffusion of greenhouse gas reducing technologies. 


\section{6}

\section{These factors are \\ much more difficult \\ to specifically \\ identify, measure, and overcome \\ because they \\ generally are part \\ of culture, mixed in \\ with the fabric of \\ our society.}

\section{Other Barriers}

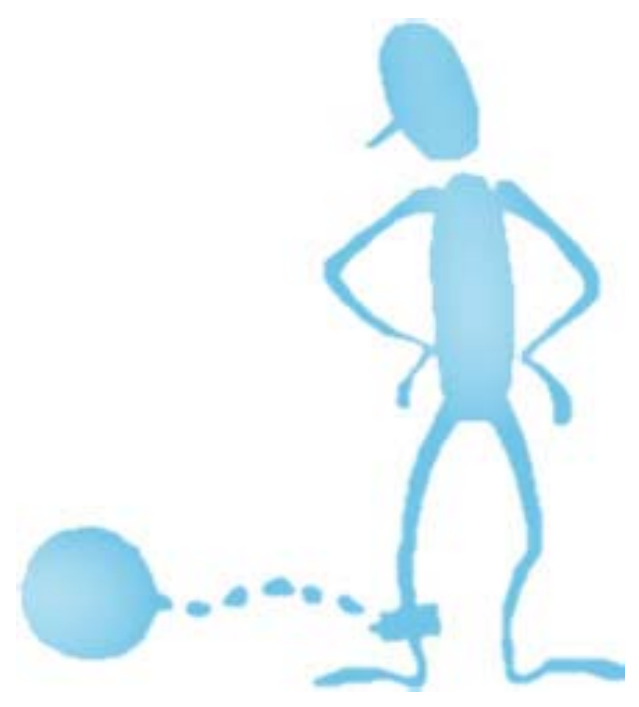

Many additional barriers inhibit deployment of GHG mitigation technologies in ways that are not captured by the categories discussed thus far. They include obstacles resulting from imperfect and costly information as well as infrastructure limitations such as inadequate electricity transmission and shortage of key complementary technologies. This category also includes barriers associated with misplaced incentives, along with those inherent in industry structures such as natural monopolies and fragmentation. Policy uncertainty specifically related to GHGs is another component of this category (Table 6.1). 
Table 6.1. Barriers included under other barriers

\section{Other Barriers}

Incomplete and Imperfect Information

Lack of information about technology performance - especially trusted information; bundled benefits and decision-making complexities; high cost of gathering and processing information; misinformation and myths; lack of sociotechnical learning; and lack of stakeholders and constituents.

Inadequate critical infrastructure - including electric transmission capabilities and long-term nuclear fuel storage facilities; shortage of complementary technologies

Infrastructure Limitations that encourage investment or broaden the market for GHG-reducing technologies; insufficient supply and distribution channels; lack of O\&M facilities and other supply chain shortfalls.

Natural monopoly in utilities disenabling small-scale competition; industry

Industry Structure fragmentation slowing technological change, complicating coordination, and limiting investment capital.

Misplaced incentives when the buyer/owner is not the consumer/user (e.g., Misplaced Incentives landlords and tenants in the rental market and speculative construction in the buildings industry) - also known as the principal-agent problem.

Policy Uncertainty

Uncertainty about future environmental and other policies; lack of leadership

\subsection{INCOMPLETE AND IMPERFECT INFORMATION}

Reliable information about product price and quality allows firms to identify the least costly means of production and gives consumers the option of selecting goods and services that best suit their needs. Yet information about climate-friendly options is often incomplete, unavailable, expensive, and difficult to obtain. With such information deficiencies, investments in GHG-reducing technologies are less likely. Incomplete and imperfect information abounds: lack of trusted information about technology performance; bundled benefits and decision-making complexities; misinformation, myths, and lack of socio-technical learning; and lack of stakeholders and constituents.

Lack of trusted information about technology performance. Given the immaturity of many GHGreducing technologies, acquiring or proving performance information can be a major obstacle. Impediments to the diffusion of GHG-reducing technologies - such as cogeneration and CHP systems, resource efficiency, substitution of materials, recycling, changes in manufacture and design, and fuel switching - remain impeded by high transaction costs for obtaining reliable information (Worrell and Biermans, 2005). Information collection consumes time and resources, especially for small firms, and many industries prefer to expend their human and financial capital on other investment priorities. Thus, many industrial managers and decision makers simply don't believe they have enough time or money to research new technologies.

New enterprises and small businesses do not have the resources to fully learn what other manufacturers are doing. For example, Hovorka (2006) suggests that most firms working on carbon capture and storage remain unaware of alternatives to their own approaches for low-cost carbon sequestration. The companies working on developing the latest amine combination for carbon capture are disconnected from those 
designing cutting edge gasifiers, making it all but impossible to benchmark innovations and determine how individual technologies are maturing.

Elliott (2006) attributes the insufficient investment in industrial efficiency to a lack of trusted information. Managers of manufacturing facilities are overwhelmed by the numerous programs that tout energy efficiency and saving money. They are leery of many of these programs and have assessments on their shelves gathering dust. It is also difficult for companies to trust third parties. A credible characterization of the savings potential of a manufacturing facility is a vital first step and is generally lacking. Manufacturing plants are not getting trustworthy up-front assessments and engineering services focused on energy efficiency because Energy Services Companies (ESCOs) lack industry-specific experience (Elliott, 2006). To be valuable, the consulting firm or ESCO needs a great deal of industry-specific knowledge. Most consultants just talk to the customers and don't try to understand their situation. Numerous consultants come through and promise returns. Since many industrial operations don't have inhouse engineering resources, they have difficulty sorting through all of the advice they are given (Dias, 2006).

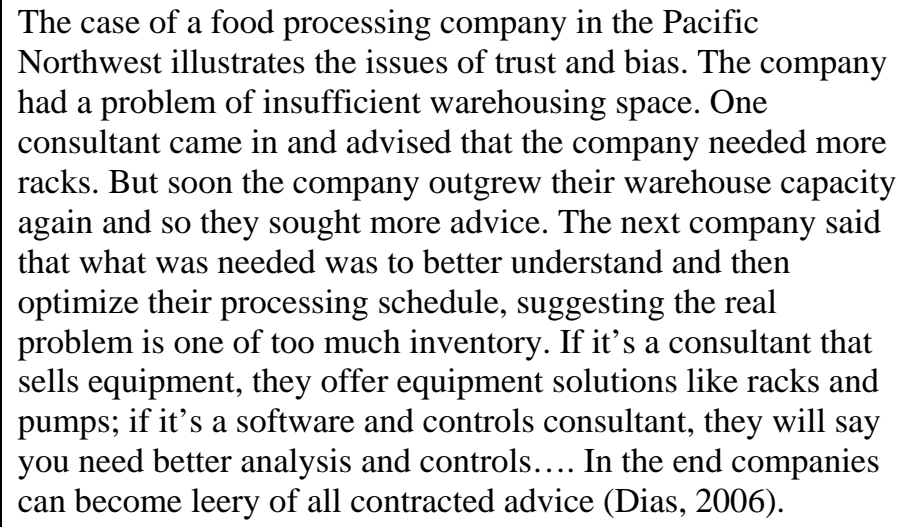

\section{Box 6.1 Conflicting “expert” information}

On the residential and commercial side, lack of confidence may keep consumers from purchasing photovoltaic systems (Rohatgi, 2006). Consumers face so much conflicting information about how these technologies work and how they will integrate into existing consumer systems that they may choose not to participate in this market at all. Van Mierlo and Oudshoff (1999) identified trust, or confidence, barriers to building photovoltaic systems: 1) consumers not trusting motives of sellers of photovoltaic systems; 2) consumers not finding maintenance or installation support; 3 ) consumers having no way to determine the quality of sellers; and 4) unavailability of desired photovoltaic products. Such consumer confusion relates to the bundling of benefits and decision-making complexities described below.

Bundled benefits and decision-making complexities. It is often hard to determine the performance and costs of low-carbon and efficient energy technologies and practices because the benefits are bundled and difficult to disaggregate. For example, residential consumers get a monthly electricity bill that provides no breakdown of individual end-uses, making it difficult to assess the benefits of efficient appliances, televisions, and other products. This situation contributes to making energy savings "invisible," and makes energy-use patterns and load profiles hard to understand and to link to energy bill savings. Appliance energy labels help, as does ENERGY STAR ${ }^{\circledR}$ branding, but studies have shown that many consumers do not understand them. Consumer research showed that people prefer a discrete rather than continuous scale to demonstrate the relative efficiency of the appliance; Fig. 6.1 compares the current and 
preferred labels. ${ }^{67}$ Consumer recognition and general understanding of the purpose of the label has increased over time; in a 2006 study, 68 percent of survey participants recognized the ENERGY STAR ${ }^{\circledR}$ label and 73 percent of household had at least a general understanding of its purpose (EPA, 2007).

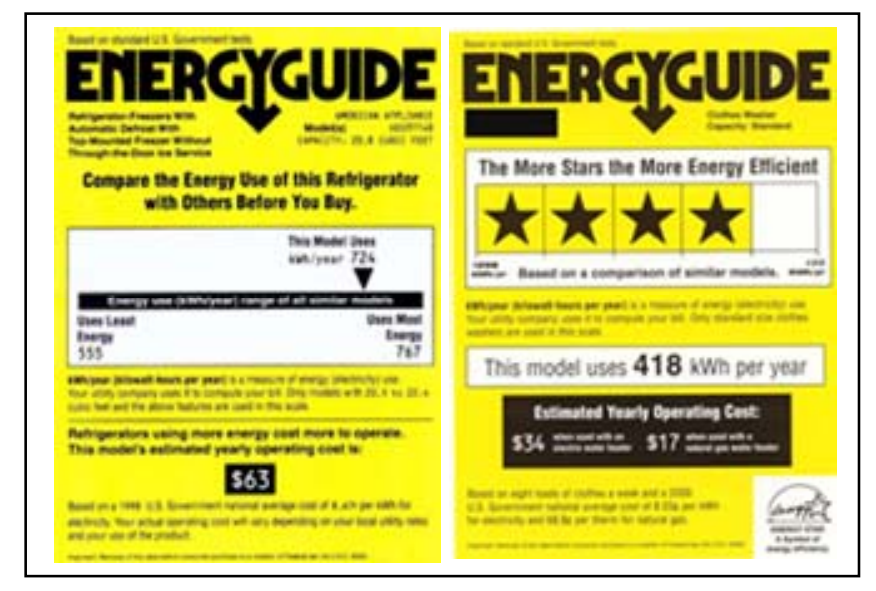

Fig. 6.1. Current and consumer preferred energy labeling Source: ACEEE

Similar circumstances in the commercial buildings' market constrain investor choices. The complexity of design, construction, and operation of commercial buildings makes it difficult to characterize the extent that a particular building is energy efficient. It is also difficult to forecast with precision how much energy could be saved with the installation of new high-efficiency equipment.

Efficiency choices tend to be bundled with other purchases. For instance, the price paid for different levels of vehicle fuel economy is buried in base prices or in the price of complete subsystems such as engines. Further, efficiency differences are coupled with substantive differences in other critical consumer attributes such as acceleration performance, level of luxury, and vehicle handling. Reliable information on the marginal cost of fuel economy may be obtainable, but the effort required for an individual consumer to secure such information could be prohibitive. Based on fuel economy information collected on the www.fueleconomy.gov website, vehicle performance depends on usage patterns. ${ }^{68}$ As a result, to characterize the fuel consumption for 90 percent of drivers of a particular model and year requires varying the average mpg by $7 \mathrm{mpg}$ (e.g., 13 to $27 \mathrm{mpg}$ for an average fuel economy of $20 \mathrm{mpg}$ ). Where you drive, how you drive, the type of trips you take impact fuel consumption (Greene, 2006).

Decision-making complexities can confound consumers and inhibit "rational” decision-making. Even while recognizing the importance of life-cycle calculations, consumers often fall back to simpler first-cost rules of thumb. While some energy-efficient products can compete on a first-cost basis, many of them cannot. Properly trading off energy savings versus higher purchase prices involves comparing the timediscounted value of the energy savings with the present cost of the equipment - a calculation that can be difficult for purchasers to understand and compute. Decision-making complexities are one of the reasons builders generally minimize first costs, believing (probably correctly) that the higher cost of more efficient equipment will not be capitalized into a higher resale value for the building. In an attempt to reflect the economic value of energy efficiency in construction, purchase, and rental decisions, the European Commission's Directive on the Energy Performance of Buildings (2002/91/EC) ${ }^{69}$ requires,

\footnotetext{
${ }^{67}$ http://www.aceee.org/appliancelabeling/index.htm

${ }^{68}$ Vehicle fuel economy information is available at www.fueleconomy.gov

${ }^{69}$ http://europa.eu.int/eur-lex/pri/en/oj/dat/2003/__001/1_00120030104en00650071.pdf
} 
among other provisions, that an energy performance certificate be made available to the owner in case of new construction, or to the prospective buyer or tenant in case of rent or sale.

Another example comes from the transportation sector where both biofuels and alternative designs (electric/hydrogen) for vehicles compete for a public that is not aware of the options. "The public is not well informed about petroleum resources in the long run; they draw their conclusions from what they see on gas station signs.” (Reisert, 2006). Jeff Harris (2006) offers that the transaction costs are too high for individuals to make choices of end-use technologies (in transportation, lighting, and appliances): "Consumers face the problem of information overload and can only deal with so many choices at the same time. However, if asked for their preference, they would choose the product that requires less energy, everything else being equal.”

Misinformation and myths. Along these lines, misinformation and myths are a major barrier to the deployment of alternative energy technologies in the United States. Myths pervade our common knowledge by their frequent repetition in public information avenues, such as newspapers, the internet, talk shows, and neighborly chats. Some of the current energy myths are that: 1) the energy crisis is just hype, 2) the key barriers to new energy technologies are "technical," 3) the hydrogen economy will solve our problems, 4) no further gains are to be had through energy efficiency and 5) climate policy will bankrupt the nation (Sovacool and Brown, 2007). Such myths can have counter-productive consequences. "Portraying the energy crisis as hype thwarts mobilization of the sizeable resources and political will needed to successfully tackle the real and significant energy challenges facing the nation and the world” (Brown, 2007, p. 47).

Renewable resources, from biomass fuels to wind and solar electric generating facilities are often discredited as not capable of meeting a significant share of the nation's energy requirements. For biomass fuels, critics cite the competing needs of fuel and food as overrunning land resources and leading to starvation. Researchers claim that biomass for fuel would require not only overtaking traditional food crop land but clearing current forest land for crop growth (Cook et al., 1991; Keshgi et al., 2000; Giampietro et al., 1997, for example). Further, biomass critics suggest that in addition to biomass derived fuel being impractical on a land basis, it also requires significant water resources and can damage ecosystems for other species, ultimately doing more harm than good (Hoffert et al., 2002; Huesemann, 2004, for example). However, other researchers have found that biomass derived fuels could offset significant portions of transportation fuel demand. Perlack et al. (2005) found that over 30 percent of current demand could be met with biomass fuel by 2050, using renewable non-food or feed resources. Similarly, Lovins et al. (2004) postulates that biomass derived products could replace 20 percent of petroleum demand in 2025. Greene et al. (2004) states that more than 50 percent of transportation sector energy use could be offset by biofuels by 2050. Next generation technology would be a key aspect, as well as using cellulosic biomass resources. The Ag Energy Working Group (2004) offered that 25 percent of the nations total energy needs could be produced within the agriculture sector (including biomass fuels and farm placement of renewable power generation). Debunking the prevailing myth that biomass fuels cannot make a significant contribution, Lynd et al. (2007) conclude that trends towards increasing crop yield, increasing conversion ratios, increasing vehicle fuel economies, and decreasing beef consumption combine to make biomass fuel have potential for providing significant portions of transportation fuel needs.

For wind and solar (as well as small hydro and other renewable power sources), the critical talking points center on unpredictability of power output and lack of or uneven distribution of resources. Government officials, corporate leaders, and utility system planners still think of wind as a niche technology, with its variability and uncertainty as a fatal flaw preventing it from being a major contributor. Yet there is ample experience in Europe with high levels of penetration of wind and other forms of distributed generation. It would be useful for the United States to understand the European story as a way of challenging the lore 
and misperception that utility systems cannot operate reliably with high levels of variable weather-driven generation (DeMeo, 2006).

Culture and lack of sociotechnical learning. It is cultural and social norms that largely dictate how individuals view the world and their options within it. Nye (1997, pp. 7, 250) argues that culture is the primary reason for the highly consumptive nature of American life as other nations have achieved similar quality of life measures with less energy per capita or per state product. "The energy systems a society adopts create the structures that underlie personal expectations and assumptions about what is normal and possible....For Americans, energy was not simply a thing to be used. In each of its successive forms, it became an ideal personal attribute.”

Massive technological changes will require cultural change and movement of social norms. Irv Barash (2007) reminds us that "Edison was seen as having invented toys that were not necessary to society at that time, particularly with respect to the light bulb.” Alongside resistance, there is ignorance. Problems related to energy use and externalities of production and consumption do not catch the attention of the public; Hirst and Brown (1990) suggest that the largely invisible and automatic nature of energy use aggravates the situation of multiple barriers to efficiency.

Experience has shown that adoption of innovations is based on more than cost effectiveness or performance alone. Rather, technology adoption is a complex process that involves a great deal of interpersonal communication (Cummings, 1999). These exchanges and communications are part of building networks and making the industry or society ready for adoption and diffusion. Brooks (1994) calls this socio-technical learning: "since technical knowledge, organizational knowledge, and new relationships among people inside and outside an organization have to be absorbed and 'internalized' in groups of people before an innovation or even a production plant can be sustainable.”

Existing business and governmental structures can also impede the transformation of energy systems. To explain this barrier, Unruh (2000, p.818) has developed the concept of the Techno-Institutional Complex (TIC), where positive feedback between institutional structures and existing technological systems can deter change. "Once locked-in, TIC are difficult to displace and can lock-out alternative technologies for extended periods, even when the alternatives demonstrate improvements upon the established TIC.” While this lock-in presents a barrier to change, it usually cannot prevent the transformation from ultimately occurring, based on historic major shifts in energy systems, transportation methods, and communications technologies (Unruh, 2000).

Technological lock-in can be seen as a function of path dependence and dynamic increasing returns especially those with "network externalities” (Katz \& Shapiro, 1985). Maréchal (2007, p.5189) clarifies that models from the literature of technology adoption show that these network externalities must be strong to lead to lock-in, as "small network externalities can be a source for diversity" in ideas and technologies. This lock-in sort of inertia or incremental change due to socio-technological factors shows up in many areas of research (examples include Kuhn, 1970 and Mulder et al., 2001).

Lack of stakeholders and constituents. Consumers do not typically focus on the GHG emissions intensity of products they consume or actions they take; manufacturers do not worry about the GHG emissions of their industrial processes; similarly, electric utilities in most states are not incentivized to consider their GHG emissions profiles. Global climate change is simply not a major driver of decisionmaking for most businesses and households. Nate Lewis explained to Thomas Friedman (2007) that people are willing to pay a premium for a new technology that improves their life (like new cellphones when they first came out), but not for a change in their power source since "a different way to power my lights does nothing.” This observation demonstrates clearly how the issue of climate change lacks stakeholders and constituents. 
The climate change threat is intangible, invisible, and diffuse. Natural variability also obscures and confuses the relationship between GHG emissions and global climate change, causing skepticism that human activities are contributing to the problem. Compare this with the public's response to stratospheric ozone depletion. Photographs of the ozone holes over the earth's polar regions created a visible image of the negative impact of the release of chlorofluorocarbons, halons, and other ozone depleting chemicals. Knowing that the ozone layer prevents harmful ultraviolet light from passing through the Earth's atmosphere, observations of the growing ozone holes generated worldwide concern leading to adoption of the Montreal Protocol banning ozone depleting chemicals. Air pollutants have similarly tangible impacts (Koonin, 2006). Fig. 6.2 shows a figure of ozone strength and a graph relating potential warming for various gas concentrations; it is much more difficult to understand and relate to a graph than a picture.

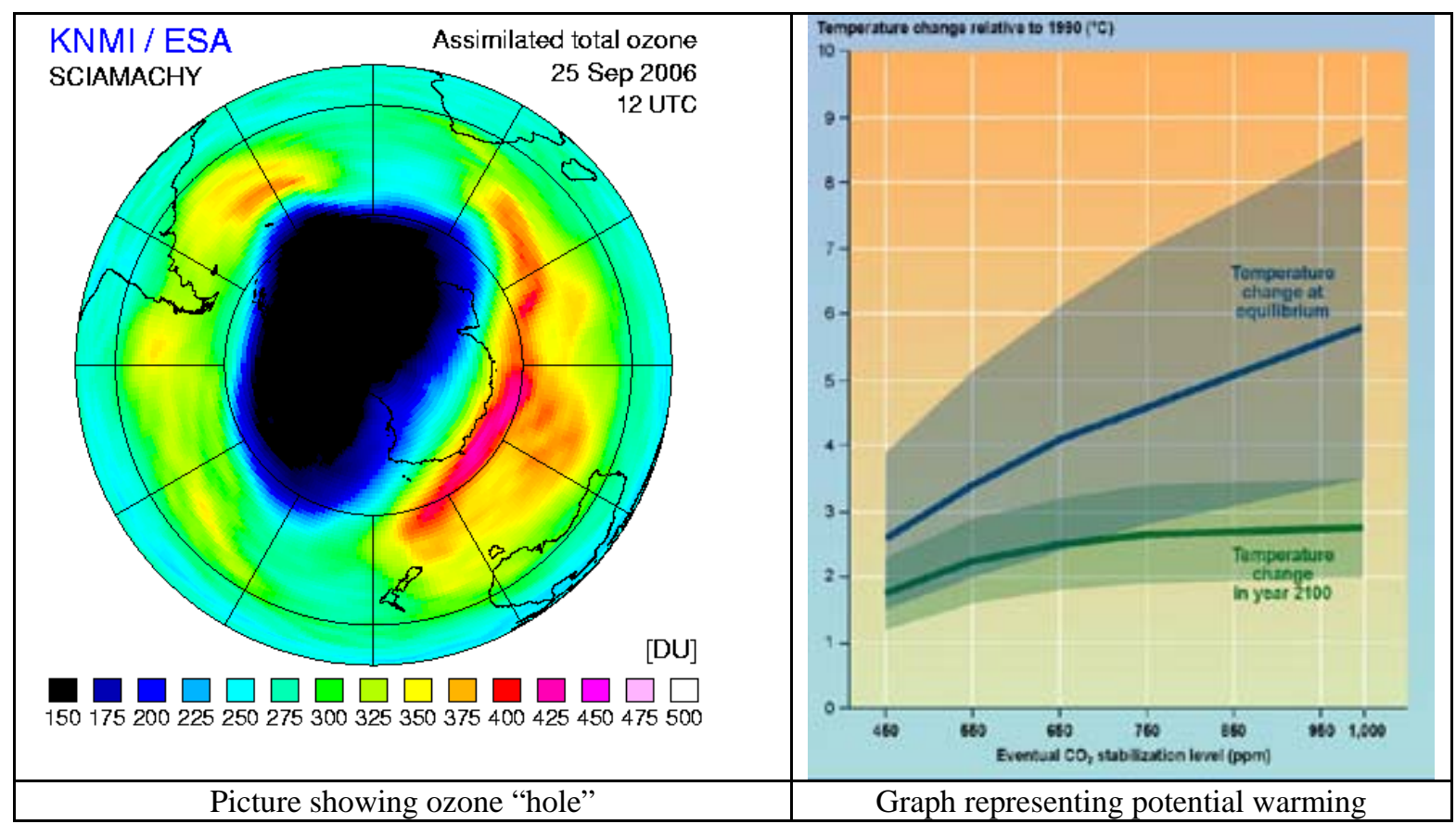

Figure 6.2. Images related to ozone problem and climate change

Source: and IPCC, http://www.ipcc.ch/present/graphics/2001syr/small/05.23.jpg

In most cases, energy is a small part of the cost of owning and operating a building, a factory, or a car. Of course, there are exceptions. For low-income families, the cost of utilities to heat, cool, and provide other energy services in their homes can be a very significant part of their income - averaging 15 percent compared to 4 percent for the typical U.S. citizen. For energy-intensive industries such as aluminum and steel, energy can represent 10-25 percent of their production costs. Many companies in the more energyintensive firms have decided to incorporate energy management as a key corporate strategy. Others have instituted corporate carbon trading programs to reduce their emissions. Many of these companies have made impressive reductions in the carbon intensity of their operations. A means of sharing successful strategies and best practices could help improve overall industry performance and extend benefits to smaller, less profitable firms.

Since energy costs are typically small on an individual basis, it is easy (and rational) for consumers to ignore them in the face of information gathering and transaction costs (Harrington and Murray, 2003, p. 3). Note, however, that if consumers were extremely concerned about life-cycle energy savings and determined to base their purchasing decisions on them, product manufacturers would have a strong 
incentive to provide consumers with better information and with clearer tradeoffs. It can be argued that the lack of such information and choices is simply the consequence of consumer disinterest in climate change and energy issues. However, the potential energy and emissions savings can be important when summed across all consumers. For example, electronic equipment and appliances increasingly operate in a "standby" mode so that they can be turned on quickly. This feature adds only a small fraction to the energy consumed by such devices, but if standby energy losses could be eliminated, the country would avoid operating approximately 20 power plants around the clock (Lovins, 2007). This is one reason why government agencies like EPA and DOE work directly with manufacturers to improve the efficiency of their products. A little work to influence the source of mass-produced products can pay off in significant efficiency improvements and emissions reductions that can rapidly propagate through the economy as market shares increase and production costs fall.

In a special report, The Economist (Duncan, 2007) showcases how businesses are lining up to get on the combating climate change bandwagon. However, this newfound support may disappear altogether without making much of a difference because of its very bandwagon-ness.

Climate change is fashionable, and although fashion has the virtue of being able to transform the dull and worthy into the hip and happening, it is, by definition, transitory. Hollywood stars will probably get bored of their Priuses, and executives may become weary of mouthing green platitudes and move on to whatever branch of corporate social responsibility next catches the popular imagination.

This reflection shows how precarious the situation may be for gaining long-term business and public support for a cause that may not have a large impact in our lifetime.

\subsection{INFRASTRUCTURE LIMITATIONS}

Technologies that are otherwise expected to be successful may still face difficulties commercializing, deploying, or expanding deployment due to infrastructure limitations. Infrastructure limitations, as a barrier, cover a wide range of issues, including: inadequate physical systems and facilities that are critical to the success of a new technology; shortage of key complementary technologies that improve the functionality of a new technology, and insufficient supply and purchasing channels.

Inadequate critical infrastructure. Critical infrastructure refers to a broad sweep of physical systems and facilities that are required for successful diffusion of a technology. Examples include electric transmission and distribution lines, liquid natural gas (LNG) terminals, hazardous waste repositories, hydrogen and ethanol distribution channels, and sensors, measurement and metering devices. Some of these needs are shown in Fig. 6.3, demonstrating that every region of the U.S. faces one or more infrastructure deficiencies that must be addressed to meet national energy and climate change challenges.

Moreover, transformational GHG-reducing technologies tend to require a new generation of infrastructure, of significant difference from expansion or maintenance of existing infrastructure, which can add considerably to their start-up costs. For example, transformational infrastructures include hydrogen storage and distribution networks and carbon dioxide storage sites and systems. Many of these infrastructure limitations are a function of the public's NIMBY (not-in-my-backyard) response, where local interests have trumped what could be considered national needs (NCEP, 2006). 


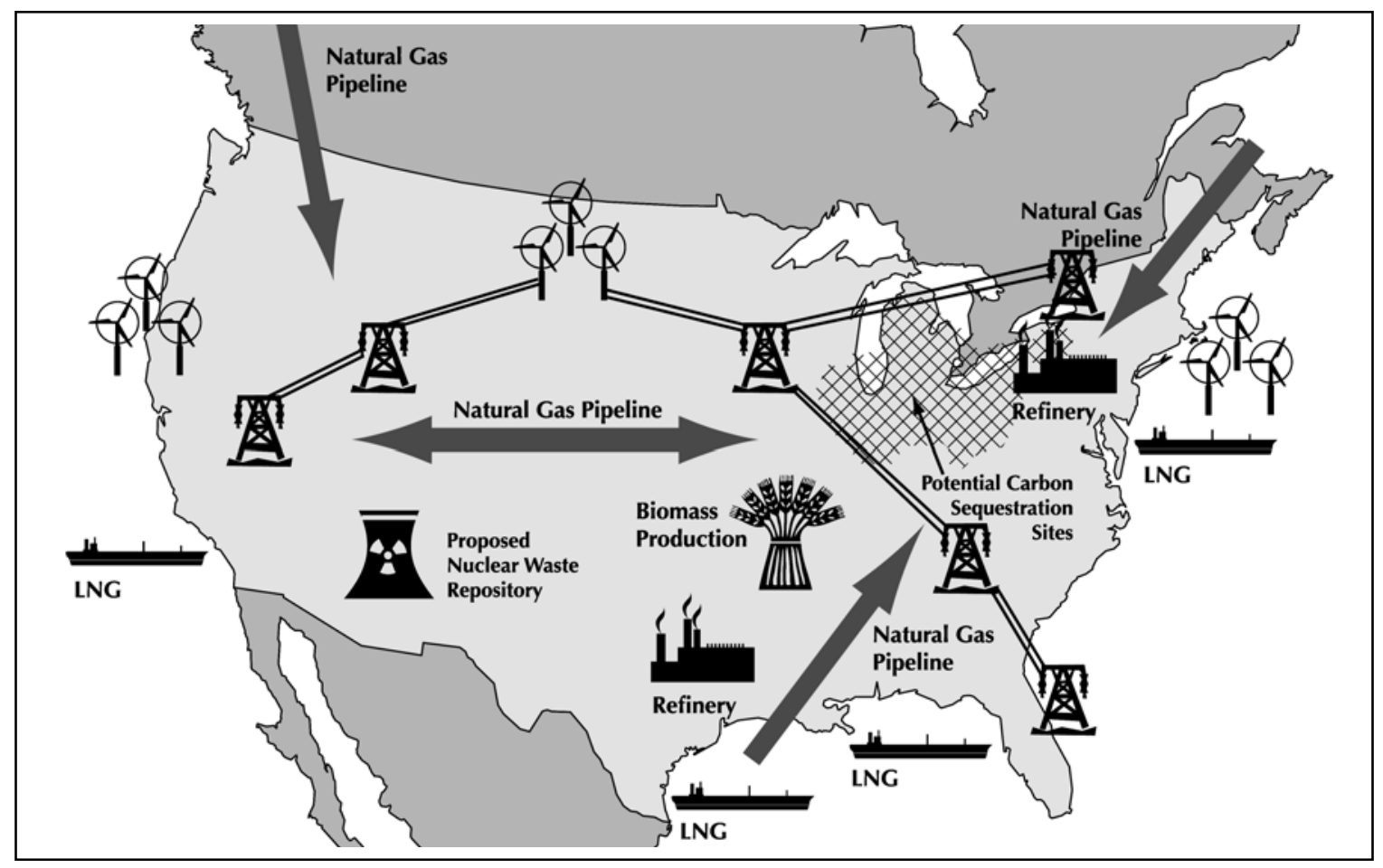

Fig. 6.3. Major national energy infrastructure needs

Source: National Commission on Energy Policy, 2004, Fig. 5.1

At the same time that the nation's demand for electric power is growing rapidly, the high-tech economy is placing greater requirements on increasing levels of power quality and power conditioning. Despite these trends, investment in the transmission and distribution infrastructure has declined with restructuring of the electric industry. As a result, it is not clear that the U.S. transmission grid can meet the need for large increases in remote wind resources or other forms of remotely distributed low-carbon resources. The National Electric Transmission Congestion Study identified two critical congestion areas already existing in 2006, several areas of concern today, and additional potential congestion areas (DOE, 2006a). Two types of solutions can address this critical infrastructure problem: use the existing grid more efficiently and expand the grid for future use. The first solution can provide a bridge to longer term infrastructure expansion (DeMeo, 2006).

Making better use of the existing grid is complicated by the difference between having contractual capacity and actually having a loading on the line. In many areas, the system operators might fully load lines only a few hundred hours a year (usually during a weather event). Much more loading can often be squeezed out, but it requires innovative pricing strategies and an interruptible supplier that could use it. As a result, a "flexible firm" or "conditional firm" concept of access to T\&D and transmission pricing is being debated. If a wind project developer were to approach a transmission operator to buy transmission capacity on a firm basis, the request would be refused because the grid capacity has been spoken for. In actuality, there are many hours when spare capacity is available. Non-firm service to date has not been available for more than three months at a time, which is not sufficient surety for a new wind project. It needs to be made available for 15 years to provide the assurances required by creditors. FERC has expressed interest in longer non-firm service contracts as an interim fix to the addition of more transmission capacity. Flexible firm pricing is important to wind because of its variable output (DeMeo, 2006; Thresher, 2006). 
Wind resource expansion also needs transmission expansion, and so does the country for general strengthening of the electrical infrastructure. To the extent the grid can be upgraded, this will be helpful for wind. If it were upgraded with an eye to where wind is located, that would be even better for expanding wind resources. The upgrade of the transmission system needs to be done with wind viewed as part of the picture, but building transmission for any specific resource alone - including wind - might not be the optimal solution (DeMeo, 2006).

Biofuels also face a location and distribution incongruence with the current system. Ethanol today is most economically produced within about 100 miles of where it's grown because the biomass density is so low. Historically, biomass-to-ethanol plants have been built in the Midwest, which is not coincident with large concentrations of fuel consumption. To realize a significant displacement of petroleum, the produced bioethanol must be shipped long distance to consumption centers. The current pipeline infrastructure is unidirectional from the coasts to demand centers, so this economic transport solution cannot be utilized; in addition, ethanol is not compatible with existing petroleum pipelines. Waterways would be desirable for transport, but their orientation is inconsistent with the necessary routes from producers to existing blenders or refiners. Currently, long-distance shipments of bioethanol are handled via rail or roadways; hauling fuel on the roads is costly, and rails have limited expansion capacity (Arent, 2006). For bioethanol, the distribution infrastructure is clearly insufficient; either wholly new infrastructure will need to be built, or the nation may consider alternatives to transporting bioethanol (i.e., replacing petroleum with bioethanol near production centers).

Two other GHG-reducing technology areas face major transformational infrastructure issues: hydrogen and carbon capture and storage. Hydrogen presents a unique challenge for transmission, storage, and distribution due to its chemical nature; these infrastructure design issues are still undergoing research. Carbon capture and geologic storage, working together, will require significant expansion of $\mathrm{CO}_{2}$ transmission from the points of emission to underground storage sites; it is estimated that 11,000 billion tons of $\mathrm{CO}_{2}$ storage capacity is available within geologic formations (Dooley et al., 2006), but detailed characterization of this potential infrastructure has only begun. There is some existing capability to store $\mathrm{CO}_{2}$ in conjunction with enhanced oil recovery projects - mostly in West Texas and New Mexico. ${ }^{70}$

Another underdeveloped infrastructure requirement that hinders the infusion of GHG-reducing technologies falls in the domain of sensors, measurement and metering devices, and protocols; such equipment is necessary for technologies like carbon capture and storage. Mooney et al. (2004) argue that such costs are likely to be small (under 2 percent of the value of a contract), but other studies forecast higher costs (Smith, 2004). In general, measurement costs per carbon-credit sold decrease as the quantity of carbon sequestered and area sampled increase in size. Methodological advances in measuring percentage soil carbon at the field and regional scales may reduce costs and increase the sensitivity of change detection (Izaurralde and Rice, 2006), but calculations of the carbon stock change also require measurement of changes in soil bulk density, for which affordable and feasible methods are only now under development (Izaurralde and Rice, 2006, Gehl and Rice, forthcoming).

For some technologies, the lack of infrastructure only increases transaction costs associated with the consumption of the product, like photovoltaics. However, for technologies such as hydrogen or geologic storage, deployment will not be possible without developing sufficient transformational infrastructure. This infrastructure is likely to be very costly; for example, Mintz et al. (2002) found that the "hydrogen delivery infrastructure to serve 40 percent of the light duty fleet is likely to cost over $\$ 500$ billion”, and van der Veer (2003) suggests that "to supply just 2 percent of cars with hydrogen by 2020 [will cost] around $\$ 20$ billion.” Because infrastructure tends to benefit more than one technology or supplier at the same time, development and maintenance tends to fall into the economic category of public goods which

\footnotetext{
${ }^{70}$ http://www.fossil.energy.gov/programs/oilgas/eor/index.html
} 
leads to the question of "who will build it?" Reconsideration of how transmission is viewed - perhaps as a market good itself rather than a tool for delivery of market goods, may improve infrastructure limitations by valuing the infrastructure itself. However, this reconsideration is not without issue, and states that have undergone electric restructuring may have important case studies to ensure that widespread decoupling of infrastructure from sales does not create transmission problems.

Inadequate complementary technologies. In this context, a complementary technology is one that enhances the development or use of a GHG-reducing technology, but is not critical to its success. Typically, a complementary technology is one that in combination with the climate mitigation technology will achieve benefits or capabilities that are not available when the technologies are considered separately. ${ }^{71}$ Because of this interdependency, reducing the price of a complementary technology or improving its performance can increase the adoption probability of the technology of interest (Astebro et al., 2005). A set of these complementary technologies was identified in a review of DOE's Climate Change Technology Program (Brown et al., 2006). Many of these complementary or enabling technologies would enhance the deployment of multiple GHG-reducing technologies. The fact that they are currently too expensive, unreliable, or perform inadequately is therefore a major barrier to deploying technologies in many GHG sectors. However, cost, performance, and reliability may not be the only factors preventing development of complementary technologies. In some cases, it may be that complementary technologies are not identified early in the deployment process (Maréchal, 2007).

Insufficient supply and purchasing channels. Supply chain gaps also present barriers to GHG-reducing technologies, including insufficient supply and distribution systems, shortfalls in necessary raw materials and engineered components, and lack of support services, such as operation and maintenance (O\&M).

The nuclear industry, for instance, is concerned that the limited availability of materials and heavy machining capacity may stall a nuclear renaissance. The supplier base is a great concern because many large components, like steam generators, are produced overseas; additionally, some parts, like reactor

\footnotetext{
${ }^{71}$ A good example that demonstrates the importance of complementary technologies is computer operating systems, hardware, and software as described by Shapiro and Varian (1999). The technology developed by Microsoft dominates the market, so other hardware and software firms make their products complement the Microsoft systems; therefore, user adoption of non-Microsoft systems is less attractive because there are fewer complementary technologies for these systems.
} 
vessel heads, can only be fabricated by one company in the world. The shortage of equipment and fabricating technology may be limitations in the future that constrain the growth of a next generation of nuclear reactors in the United States and abroad. However, supporting industries in the nuclear supply chain in the United States are looking to retool and prepare for new production cycles (Rushton, 2006).

Similarly, low emissions fossil technology (clean coal) faces shortage of suppliers. There are no clear one-stop vendors for integrated gasification and combined cycle (IGCC) or supercritical pulverized coal technology as exists for conventional pulverized coal; General Electric is possibly going to step in to fill this void for IGCC (Braitsch, 2007). While there are many vendors offering high efficiency pulverized coal (PC) plants, increased worldwide demand for power has dramatically raised the cost for new coal plants. Even more problematic may be the absence of equipment suppliers for capture technologies that are expected to be utilized to limit emissions from coal plants.

Photovoltaic (PV) systems face a different supply problem - insufficient purchasing channels. PV products are difficult to find, and they are not generally sold as complete systems; this technology would benefit (and is well suited to) being purchased, installed, and serviced by nationwide retailers. The industry needs to move towards simpler and more reliable systems which are easy to maintain, perhaps even plug-and-play (Rohatgi, 2006). Likewise, renewable fuels, like bio-ethanol, cannot be found in many locations outside the Midwest (related to the distribution problem), so consumers cannot purchase non-petroleum fuels. In some cases, the fuel is available, but there are so many restrictions and complications that general consumers cannot use the facility. For example, in Georgia, there are 13 listed E85 stations; of these, only three are public, and one requires a key card at all times while the other two have limited hours of operation. ${ }^{72}$

\subsection{INDUSTRY STRUCTURE}

There are two very different barriers to innovation deployment related to industry structure, including the natural monopoly of some energy industries, which hinders competition, and the fragmented nature of other industries, which slows technological change and limits the availability of investment capital. Natural monopolies and industry fragmentation both impede technological innovation and can be nontrivial.

Natural monopolies. Natural monopolies occur when average cost declines over the relevant range of demand. With declining average costs, a single firm can produce the necessary output at lower cost than any other market arrangement, including competition. The resulting market power and economic inefficiencies associated with natural monopolies are limited when close substitutes for the product are available. In the case of electricity generation where natural monopolies have been dominant, close substitutes do not exist. As a result, small-scale competition is difficult in the electric power sector.

Because of high upfront costs and low operating and maintenance costs, many newer renewable energy and combined heat and power technologies have the structure of natural monopolies. The costs of smallscale facilities are then much larger per unit, so the market will not tend to clear them. PURPA attempts to protect and encourage the development of small-scale renewable electricity production, but also limits the size of these facilities. However, the existing utility monopoly attempts to maintain control over the production and distribution of power - examples of utilities and municipalities opposing small-scale renewables have occurred across the country (Sovacool and Hirsh, 2007). This opposition often is exerted through utility pricing and tariff policies such as standby charges, uplift charges, an interconnection requirements.

\footnotetext{
${ }^{72}$ EERE, DOE, Alternative Fuels Data Center, Station Locator, data found searching by state “Georgia” for E85 at http://afdcmap2.nrel.gov/locator/FindPane.asp, run date: April 18, 2007.
} 
Tariff barriers to distributed generation include excessive standby charges as well as utility buyback rates that do not provide credit for on-peak electricity production (Alderfer and Starrs, 2000). Standby charges are fees levied by a utility service company for the potential use of the company's electricity in the event that the CHP project goes down. These fees are often based on worst-case scenarios depicting the need to maintain capacity to supply DG installation during the highest peak demand. It would be preferable for utilities to convert the standby charge into an energy charge that is activated when the demand is called for because the CHP project is experiencing an outage. If the CHP project goes down unplanned in July or another peak period, then there could be a higher penalty for the energy charge based on a time-of-use rate. For example, when the Children's Hospital in San Diego installed a CHP project, the utility (San Diego Gas and Electric) did not require a standby charge. If in August the system were to go down, the hospital would buy electricity based on energy charges that reflect the cost of electricity at that time (Brent, 2006). This type of arrangement is recommended in “A Blueprint for DG” (Brent, 2003). The variation in utility rate structures makes the financial viability of a CHP installation highly dependent on its location. Standby rates don't necessarily need to be removed to alleviate this barrier; models by Jackson (2007) resulted in significant increases in adoption of CHP technologies, regardless of diffusion path, when standby rates were reduced from a rate that gave the utility immediate price neutrality to one that provided long-run price neutrality.

Utilities also set high uplift charges (a fee that taxes the amount of revenue gained from selling electricity) and demand fees (a charge that penalizes customers for displacing demand from utilities) that discourage the use of distributed power systems (Allen, 2002). A study undertaken by the National Renewable Energy Laboratory found over seventeen different "extraneous" charges associated with the use of dispersed renewable technologies (Alderfer and Starrs, 2000). The senior editor of Public Utilities Fortnightly described such charges as "a major obstacle to the development of a competitive electricity market” (Stavros, 1999, p. 37).

When an individual home, commercial building, or industrial plant generates its own electricity through photovoltaics, gas turbines, or other means, it is often beneficial to connect their power source to the grid so that excess capacity can be sold back to the utility. However, rules and requirements for utility interconnection vary state-to-state, adding transaction costs and uncertainty to the project developer. Consider, for example, a small commercial bakery wanting to install on-site power generation. The ISO in some states require that any excess electricity produced on site be exported through the distribution system to the wholesaler and then to the ultimate consumer, requiring all variety of complicated steps that are unwieldy for a small enterprise (Brent, 2006). National IEEE interconnection standards are being developed and are greatly needed, but they have been under development for nearly a decade (Rohatgi, 2006).

Fragmented industries. Industry fragmentation slows technological change, complicates coordination efforts, and limits investment capital. Agriculture and buildings are fragmented industries that illustrate these barriers to rapid technological diffusion.

The agricultural industry is significant for terrestrial sequestration efforts as well as reducing emissions of other gasses, like methane and nitrous oxide. Many thousands of actors operate in this industry, largely autonomously. Many stakeholders in this sector may not have land resources as their primary occupation - such as hobby farmers or hunting land owners. Murray (2006) clarifies, "The hurdles [for terrestrial sequestration] are more behavioral than technological, compared with other sectors, such as clean energy technologies. GHG mitigation in this sector usually does have opportunity costs; without a mandate or incentives, there is no motivation." Besides the difficulties of motivating individual land owners, there is complexity added due to the need for joint action of many owners to sequester large amounts of carbon. "For instance, sequestration in agriculture only sequesters about a quarter ton of carbon per acre per year, 
so aggregation over thousands of acres is needed to make a difference. As a result, there are typically large transaction costs associated with aggregating carbon credits over fragmented land ownership" (Murray, 2006).

In addition to making widespread change by the farming and forestry industries more complicated, the fragmented nature of these industries also limits access to capital. Individual land owners, for example, cannot access research and development funds nor do they have the time or alternative cash flow to experiment with their land practices. Traditionally, farmers have been offered subsidies to change their behavior, like the Conservation Reserve Program (Kruger and Gunning, 2006). Farmers, as well as private forest owners, may not see incentives to land or resource management necessary for terrestrial sequestration, which may explain the perceived need for large programs to affect change in these industries.

Murray (2006) notes that sequestration of carbon requires large areas of forested or managed agricultural land due to sequestration rates (about a quarter ton carbon per acre per year for agricultural land). Another real barrier relates to the fact that to sequester a lot of carbon dioxide, it needs to be done over a large landscape. For instance, carbon sequestration in agriculture only sequesters about a quarter ton of carbon per acre per year. So aggregation over thousands of acres is needed to make a difference. Land is generally cut up into small parcels, so aggregation over large land area to participate in a carbon market requires joint action. Large transaction costs are associated with joint action. In addition, lots of land is managed by individual owners and not by industrial corporate owners. These individuals with small holds of land do not necessarily manage their land for profit; they are hobby farmers, or hunters, or simply owners of land that has been in the family for generations that they do not use. The pervasiveness of small non-industrial private owners pose unique challenges for improving forest management practices (Murray, 2006).

The building industry has a record of being slow to adopt innovations due, in part to its fragmentation. For example, nearly 500,000 homebuilders operate each year; the five largest of these account for less than 7 percent of new homes, while the top 100 accounted for just another 7 percent (DOE/EERE, 2003b). This fragmentation is problematic because it means that a large number of firms and individuals need to be influenced to have a significant collective because those engaged in building design and construction generally have little interaction with each other. The result is lack of information awareness among builders, consumers, and specialists in the building process (Alliance to Save Energy, 2005b; Loper et al., 2005). Fig. 6.4 portrays the roles of some of the more influential types of decision-makers and stakeholders who affect GHGrelated purchases and building operation decisions. This illustration is necessarily a simplification of the actual maze of influences rooted in the building industry's geographic, vertical, and horizontal fragmentation. ${ }^{73}$ This fragmentation distinguishes the challenges to a lowGHG emitting future in the buildings sector from those in the transportation, industrial, and power generation sectors.

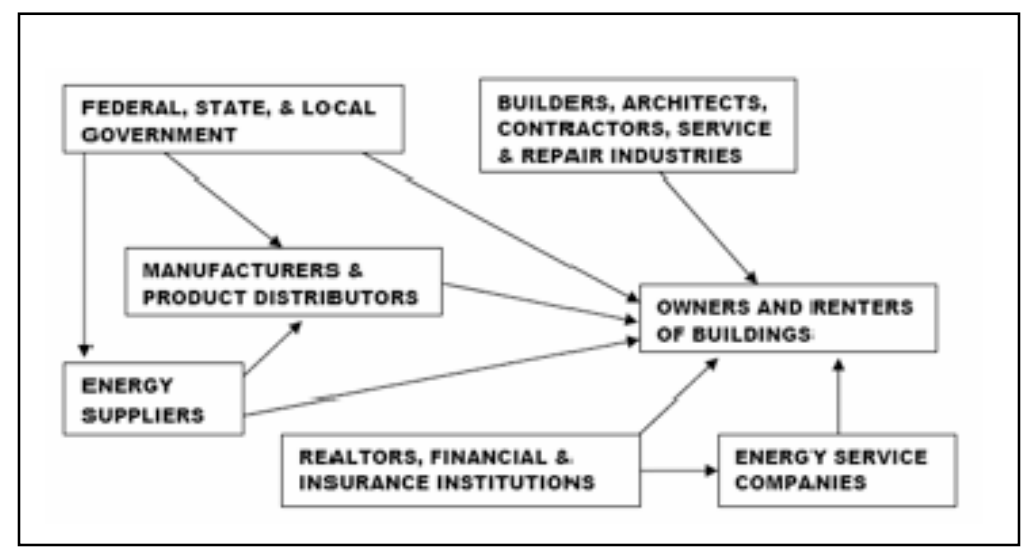

Fig. 6.4. Multiple stakeholders and decision-makers in the building sector Source: Brown, Southworth, and Stovall, 2005

\footnotetext{
${ }^{73}$ For a detailed examination of the U.S. housing industry and the homebuilding process, see Hassell et al., 2003.
} 
Similar problems exist in the solar (photovoltaic) market, where it is difficult to get an otherwise fragmented industry to work together. Even though large firms such as General Electric and British Petroleum are interested in the market, solar energy is not their main line of business. A plethora of small manufacturers commit their limited R\&D resources to address major innovations, but improvement continues to be “incremental” and "sluggish” (Rohatgi, 2006).

Another issue related to industry structure is uncertainty related to the long-term health and viability of an industry. An industry that is barely surviving in the global marketplace may not be able to think about long-term change. The domestic aluminum industry is an example of this problem. Because of the need to focus on near-term competitiveness, it is difficult for plants to undertake the significant facility upgrades necessary to eliminate the PFCs used in processing (Rand, 2006). Policy makers may want to keep industry survivability in mind when designing policies that are intended to reduce GHG emissions.

\subsection{MISPLACED INCENTIVES}

Misplaced incentives occur when the buyer or owner of a technology is not its consumer or user - a phenomenon that is referred to as the principal/agent problem in the economics literature. In general, the principal/agent problem occurs when one party (the agent) makes decisions in a given market, and a different party (the principal) bears the consequences of those decisions. Such market failures were found by Prindle (2007) to be significant and widespread in many end-use markets in both the U.S. and other IEA countries. In many market situations, buyers purchase equipment on behalf of consumers without taking into account their best interests. The resulting misplaced incentives inhibit energy-efficient investments in GHG-reducing technologies:

- Architects, engineers, and builders select equipment, duct systems, windows, and lighting for future building occupants who will be responsible for paying the energy bills;

- Landlords purchase appliances and equipment for tenants who then pay the energy bills;

- Industrial buyers choose technologies that manufacturers use in their factories;

- Specialists write product specifications for military purchases;

- Fleet managers select the vehicles to be used by drivers; and

- New car buyers determine the pool of vehicles available to buyers of used cars.

The involvement of intermediaries in the purchase of energy technologies limits the ultimate consumer's role in decision making and leads to an under-emphasis on life-cycle costs. This is exacerbated in the construction industry where typical fee structures for architects and engineers cause incentives to be distorted in ways that penalize efficiency. Additional first costs are typically needed to enable the installation of superior heating, ventilation, and air-conditioning systems that reduce operating costs. These additional expenditures beyond the typical "rule-of-thumb” equipment sizing used by most engineers result in a net penalty for designers of efficient systems. Even though this type of fee structure has been strongly discouraged in the United States, both the designer and procurer of design services still generally base their fee negotiation on percentage-of-cost curves.

"Nearly one-third (32 percent) of U.S. households rent their homes. Similarly, 40 percent of privately owned commercial buildings are rented or leased. For these segments of the market, landlords have a powerful influence over the energy efficiency of the building structures and their equipment" (Brown, Southworth, and Stovall, 2005). The landlord-tenant relationship is a classic example of misplaced incentives. If a landlord buys the energy-using equipment while the tenants pay the energy bills, the 
landlord is not incentivized to invest in efficient equipment unless the tenants are aware of and express their self-interest. Thus, the circumstance that favors the efficient use of equipment (when the tenants pay the utility bills) leads to a disincentive for the purchase of energy-efficient equipment. The case that favors the purchase of efficient equipment (when the landlord pays the utility bills) leads to a disincentive for the tenants to use energy efficiently (Ottinger and Williams, 2002). About 90 percent of all households in multifamily buildings are renters, which makes misplaced incentives a major obstacle to energy efficiency in urban housing markets.

Misplaced incentives can also involve significant time lag. For instance, new car purchasers have a dominant influence on the design decisions of automakers. Yet they are not representative of the entire driving public, many of whom purchase their vehicles secondhand. In particular, new car purchasers are substantially wealthier than average drivers, which skew their purchase preferences away from fuel economy and towards ride quality, power, and safety. Similar obstacles to energy efficiency exist in the secondary markets for appliances and homes.

Nye (1997) discusses another sort of misplaced incentive; one that involves federal, state, and local government decisions and those of previous generations. These decisions have serious implications on individual citizen choices in the present and future. For example, local government zoning choices have allowed sprawling growth outside of cities; in some cases, the whole history of the city's development is sprawl - like Los Angeles, California.

\subsection{POLICY UNCERTAINTY}

Policy uncertainty refers to the unknown future legal status of GHGs. It is not yet clear if policies addressing such a status will be regulatory or statutory in nature. Investors, electric utilities, and other key stakeholders who deal with fuel futures must decide what to build as a next generation of power plants and transportation fuels, not knowing if $\mathrm{CO}_{2}$ and other GHGs will remain uncontrolled by policies. The $109^{\text {th }}$ Congress processed more than 100 climate change-related proposals (Pew, 2007), and the $110^{\text {th }}$ Congress appears to be seeing an even greater level of climate policy activity. When the basis for estimating long-term operating costs and competitive advantage is so uncertain, how are consumers to make "rational" choices about the purchase of new energy-using systems and how are producers to decide whether or not to invest in alternative energy technologies? All of the uncertainties associated with future and current GHG treatment are impediments to positive action (Newell, 2006).

An increasing number of U.S. companies have been participating in voluntary greenhouse gas emission reduction programs and registries to prepare for eventual federal regulations. But whether or not these early actions will receive credit in any future greenhouse gas cap and trade program depends on future congressional legislation. To add further complexity to this already uncertain situation, the existing greenhouse gas emissions reduction registries in the U.S. differ in ways that could affect the provision of credit under future federal legislation (DiMascio, 2007). These uncertainties contribute to a "wait-andsee” attitude among many GHG emitters.

Various definitional and classification issues regarding $\mathrm{CO}_{2}$ sequestration remain unresolved regulatory issues that add uncertainty to the development of CCS projects. $\mathrm{CO}_{2}$ can either be classified as an industrial product or as a waste product - a distinction that is important because industrial projects are typically subject to less stringent environmental regulations than waste disposal projects (Robertson, Findsen, and Messner, 2006). Existing federal air regulations do not define $\mathrm{CO}_{2}$ as a pollutant, but some states have already defined $\mathrm{CO}_{2}$ as a waste, an air contaminant, or a pollutant. Such inconsistencies could negatively impact CCS development (Bliss, 2005). 
For example, the federal Marine Protection Research and Sanctuaries Act (MPRSA) governs the legality of carbon dioxide sequestration in the subseabed beneath U.S. territorial waters. ${ }^{74}$ It specifically prohibits "dumping" industrial waste into ocean waters. ${ }^{75}$ Thus, if $\mathrm{CO}_{2}$ is "industrial waste" and if subseabed carbon dioxide sequestration constitutes "dumping into ocean waters," then it is prohibited. However, there is statutory ambiguity about these terms, which contributes to business risks and impedes investment in this clean energy technology (Weeks, 2007).

\subsection{CONCLUSIONS}

An assortment of social, organizational, and institutional factors further hinder deployment of GHGreducing technologies beyond the cost-effectiveness, legal, and intellectual property barriers already addressed. These factors are much more difficult to specifically identify, measure, and overcome because they generally are part of culture, mixed in with the fabric of our society.

Social barriers are those that are presented by the decisions and actions of everyday citizens. They can be seen more as social inertia than as society actively avoiding change; these barriers include culture, lack of socio-technical learning, misplaced incentives, and decision-making complexities. The presence of social barriers is not surprising; individual decision making relies on boundedly rational interpretations of choices and outcomes; those technologies and practices that are most familiar are more likely to be chosen again.

Other factors are more organizational than social - being held up by complexity of joint action and lack of trust. Fragmented industries, multiple decision-makers, and promulgation of misinformation and myths contribute to organizational barriers.

Institutional barriers are imbedded in the structure of the current system, which can obstruct market entry and can hinder diffusion with incomplete infrastructure and supply chain limitations. For example, biofuels and carbon dioxide transport infrastructure is not available at the current time, and development of the infrastructure is a cost the new technologies cannot bear. The inadequate electric grid and natural monopoly structure jointly inhibit deployment of GHG-reducing electric generating technologies.

While these barriers may not be as easy to pinpoint for policy solutions as those presented by costs or laws, they must still be addressed in order for deployment of GHG-reducing technologies to be successful. Many government efforts already attempt to provide information to the public as well as create stakeholders to understand the potential benefits of GHG-reducing technologies.

\footnotetext{
7433 U.S.C. §§ 1401-1445 (2000).

${ }^{75}$ Id. $\S \S 1412(a)$.
} 



\section{7}

\section{Many deployment \\ barriers affect \\ relatively limited \\ numbers of \\ technologies, while others are systemic and economy-wide.}

\section{Impact and Scope of Barriers}

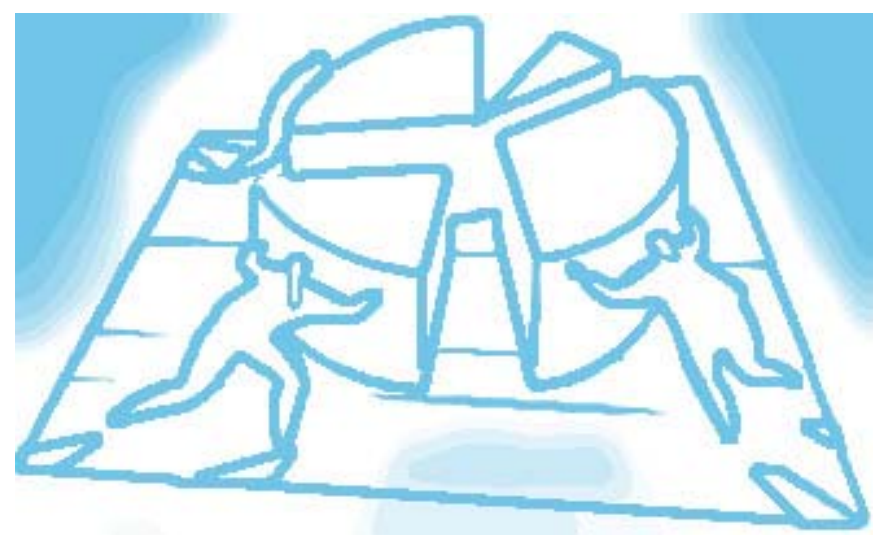

The principal goal of this report is to identify and describe the barriers impeding the commercialization and deployment of GHGreducing technologies. More than 50 such barriers have been identified through a review of the literature, interviews with 27 experts, and feedback from the multi-agency U.S. Climate Change Technology Program Working Group. To understand the implications of this inventory in terms of potential interventions to address these impediments, it is useful to consider a range of questions. 
For example:

- How much of an impact does each barrier have in terms of hindering the deployment of GHGreducing technologies?

- Does the barrier have economy-wide impacts or does it affect only a narrow range and scope of technologies and markets?

- Is the barrier part of an interrelated system of factors or is it an isolated effect?

- How easily and effectively can each barrier be ameliorated or eliminated?

These are analytically difficult questions to address, requiring data collection and modeling activities that are outside of the scope of this study. However, the literature survey and interviews conducted for this report do suggest insights that may help to frame answers to these questions.

One way to assess the relative impact of these impediments is to consider how many experts mentioned barriers of a particular type during the interview process. Recall that the interview protocol involved listing the six categories of barriers and asking the experts: "Do any of them impede the commercialization and deployment of technologies in your area of expertise?” Affirmative statements were followed with questions to elucidate greater detail on the particular barrier and how it is seen by the expert to impede the technology's success. With this method it might be assumed that experts would then identify barriers in all categories as a problem in their area of expertise; however, this was not the case. Experts routinely denied that a category of barriers posed a problem in their area. This process resulted in the frequency count shown in Fig. 7.1.

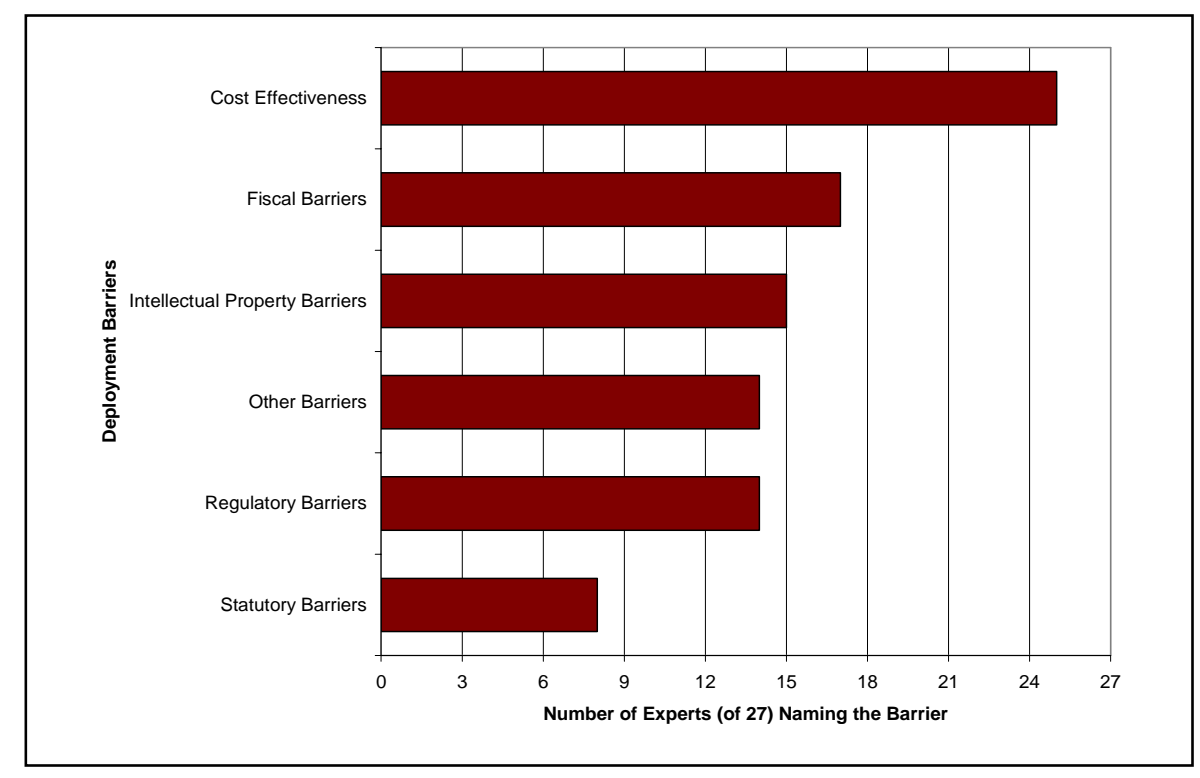

Fig. 7.1. Number of experts citing each type of barrier

At the high end of the spectrum, almost every expert (25 out of 27) mentioned the importance of one or more cost-effectiveness barriers. At the low end, only eight experts noted the existence of a statutory barrier. Each of the remaining four types of barriers was cited by approximately half of the experts. While Fig. 7.1 does not portray the experts' perceived severity of the barrier, it suggests that cost-effectiveness is almost unanimously considered to be important. 
Another way to assess the importance of each barrier is to consider the scope of its impacts across the range of climate change mitigation technologies. Inherently, technologies that reduce GHGs from energy end uses, such as transportation and buildings, will face different impediments to deployment than renewable resources and other energy supply options. Technologies to capture and sequester carbon dioxide face barriers that are different from those that mitigate high GWP gases from industry and nitrogen dioxide from agriculture. While cost challenges, market risks, information gaps, and other issues may be common across many technologies and sectors, others (such as infrastructure limitations or regulatory barriers) may be quite distinct, necessitating tailored approaches to facilitating commercialization and deployment.

The following discussion of barriers is organized around the four goal areas described in the U.S. Climate Change Technology Program Strategic Plan (CCTP, 2006): energy end use and infrastructure, energy supply, carbon capture and sequestration, and non- $\mathrm{CO}_{2}$ greenhouse gases. In addition to drawing on the literature review and the expert interviews, these technology vignettes were strengthened by input and review comments from the multi-agency U.S. Climate Change Technology Program Working Group.

\subsection{ENERGY END-USE AND INFRASTRUCTURE}

End-use energy efficiency is generally seen as offering some of the greater near-term opportunities for large-scale GHG mitigation; indeed, energy-efficient technologies are already displacing carbon emissions. CAFÉ standards, Energy Star ${ }^{\mathrm{TM}}$ ratings, and efforts to help diminish GHG emissions in the most energy-intensive industrial facilities are among the hundreds of programs, policies, and initiatives operating today in this area. Many current activities focus on disseminating information to consumers, developing public-private partnerships, and establishing codes and standards, often in coordination with state and local governments.

However, numerous barriers remain including the high cost of low-GHG technologies and the absence of a market value for GHG reductions. Existing deployment activities provide only weak solutions to the lack of utility incentives for investment in energy efficiency (which is a problem across the full range of industry and building operations and users). Technical risks and lack of specialized knowledge continue to impede best energy practices, underscoring the value of strengthening the technology workforce of the future not only to fortify U.S. competitiveness but also to improve energy productivity. Numerous unfavorable fiscal policies, regulations and statutes are also prevalent in energy end-use and infrastructure technologies. As one example, better price signals and supporting regulations and statutes may be needed before innovative grid technologies can transform power systems and consumer markets. Opportunities also exist to consider land-use planning and incentives to reduce vehicle miles traveled so that they are not offsetting GHG mitigation from advanced technologies. Stronger building energy codes are needed in many states to upgrade new construction practices, and stronger efforts are required to motivate energy improvements in existing buildings. As new and more advanced technologies become market-ready (e.g., plug-in hybrids and nano-manufacturing), deployment activities will need to evolve to address obstacles hindering their market penetration. This is an important area for further work, which can be fruitfully informed by recent research in behavioral sciences and best practices.

\subsubsection{Transportation}

Although new transportation technologies are currently available in the marketplace, their broader application appears to be impeded by barriers such as the high cost of clean transportation technology options, lack of information about the availability and benefits of these technologies, and distortionary regulations that make it difficult for innovative technologies to enter the marketplace. 


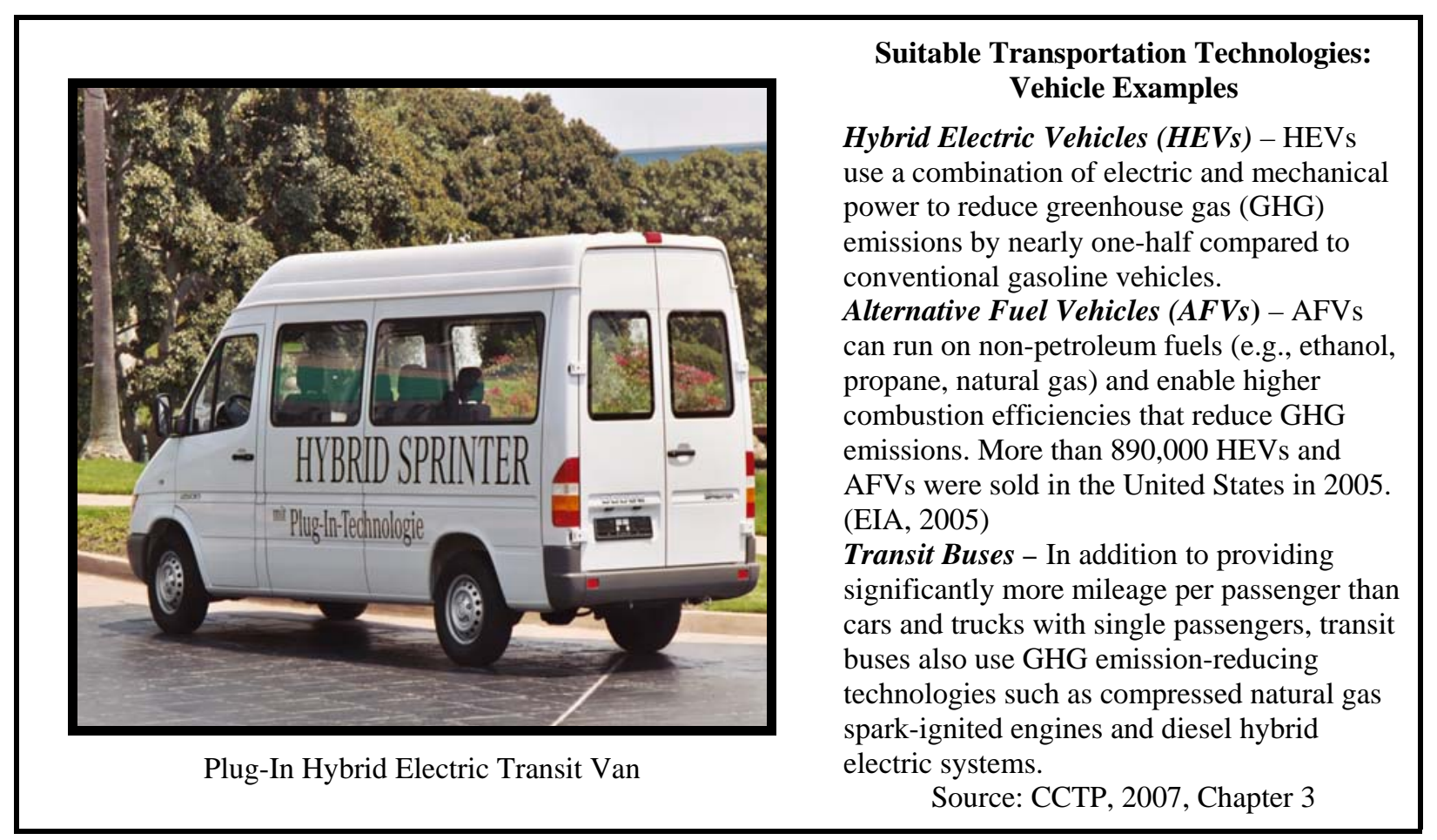

Box 7.1 Transportation

- The high costs of many clean transportation options are an obstacle to rapid market penetration. For example, the current cost (not price) differential of hybrid electric vehicles is about $\$ 3,000$ per vehicle over an internal combustion engine counterpart. Even if current tax incentives shield the consumer from high added costs, incentives would be too costly in the high volume market needed to significantly reduce GHG emissions. While prices of carbon composites and other lightweight materials have fallen, they cannot yet compete on a cost basis with steel. In addition, deployment of carbon fiber in vehicles may be limited due to competing demands by the aerospace and defense sectors.

- Incomplete and imperfect information about the performance of energy-saving transportation technologies is a significant barrier as fuel economy features are often bundled into a single sales price and are difficult for consumers to disaggregate. For example, the price paid for different levels of vehicle fuel economy is buried in base prices or in the price of complete subsystems such as engines. In addition, levels of efficiency are coupled with differences in other consumer needs such as acceleration performance, level of luxury, and vehicle handling. Reliable information on the marginal cost of fuel economy may be available, but not readily accessible to individual consumers.

- Technical risks associated with the unproven performance of novel transportation technologies hinder their deployment, such as the new battery systems used in hybrid electric vehicles. Reliability, durability, and uncertain performance under particular operating conditions all take time to establish and therefore hinder the market uptake of new transportation technologies.

- Volatile petroleum prices (i.e., market risks) and unclear market acceptance create uncertain returns on investment in advanced fuel economy technologies.

- Lack of pipelines, refueling stations, and other distribution channels for alternative fuels in many regions and urban markets is an infrastructure limitation that inhibits the market penetration of low-carbon transportation fuels. For example, ethanol currently cannot be transported through the 
pipelines that carry petroleum products; as a result, ethanol must be distributed by tanker truck or rail, thereby limiting the number of gallons that can be transported and increasing marginal costs. Limited electric grid capacity during peak hours may also hinder the introduction rate of plug-in hybrids that have limited range and require recharging during the day.

- External costs make it difficult for low-carbon transportation fuels to compete. Without a market value placed on reduced or avoided GHG emissions, fuel economy will remain a low priority in new vehicle purchase decisions.

- Unfavorable regulatory policies hinder the deployment of low-carbon technologies in the transportation sector. For example, Corporate Average Fuel Economy (CAFE) legislation gives automakers credits for flex-fuel cars that can run on E-85 (a blend of 85 percent ethanol and 15 percent gasoline), whether or not they actually operate on E-85. With these credits automakers can sell more fuel-inefficient vehicles without any actual GHG benefits. CAFE legislation also preempts states from setting more restrictive fuel economy standards than those in the Federal legislation.

Other barriers include the difficulty of attracting investments when GHG benefits are not rewarded, and lack of specialized knowledge in the auto and truck repair and service labor force required to support advanced powertrain designs and alternative fuels. Further, the transportation sector is greatly influenced by unfavorable statutes promulgated by local planning authorities. Advanced technologies may need to be matched with equally advanced policies that discourage suburban sprawl, single-occupancy vehicles, empty heavy-truck backhauling, and heavy-truck idling.

\subsubsection{Buildings}

While many cost-competitive technologies could reduce GHG emissions in the buildings sector, numerous barriers impede their full deployment.

- The most important barrier to the deployment of energy-efficient building designs and technologies is institutional: the decision-making process is complex and fragmented by numerous players whose interests may not align. These decision makers include investors, owners, occupants, builders, tradesmen, architects, equipment manufacturers, suppliers, lenders during construction, lenders after completion of construction, insurers, codes and standards setters, realtors, and so forth. Each of these participants in the decision-making process has distinct interests and impacts the process at different points in design and construction. Thus, this fragmented industry structure impedes deployment of GHG mitigating technologies; it also contributes to the low level of $R \& D$ investment in the buildings sector.

- Incomplete and imperfect information about the cost-effectiveness and availability of energyefficient building technologies is a key obstacle to their widespread market penetration. Information about energy-efficient building technologies is often incomplete, unavailable, expensive, and difficult to obtain. For example, households receive a monthly electricity bill that provides no breakdown of individual end uses, making it difficult to assess the benefits of efficient appliances and other products. The complexity of design, construction, and operation of buildings makes it difficult to characterize the extent that any particular building is energy efficient. 


\section{Suitable Building Technologies: Lighting Examples}

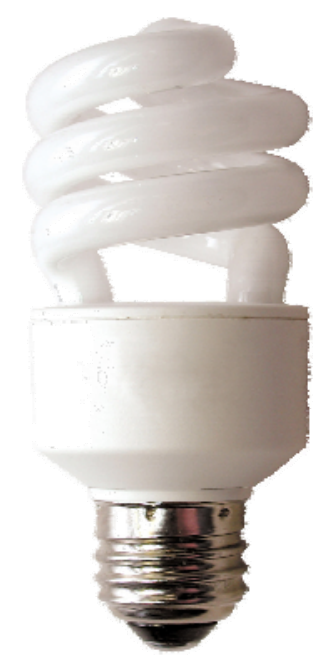

Solid State Lighting - This transformational technology uses semi-conducting materials to convert electricity into light. The luminous efficiency of lightemitting diodes (LEDs) is expected to rival the most efficient white light sources by 2010, and to achieve $160 \mathrm{~lm} / \mathrm{W}$ in cost-effective, market-ready systems by 2025. White LEDs are now approaching performance levels that make them attractive in automobiles, aircraft, elevators, and some task light applications.

Fluorescent Lighting - Compact fluorescent lamps (CFLs) for homes and T-5 fluorescent systems for offices are cost-effective today and can use $75 \%$ less energy than incandescent bulbs. Some applications of light emitting diode (LED) lighting, which is even more efficient, are also cost-competitive. http://www.energystar.gov/index.cfm?c=lighting.pr_li ghting

Hybrid Solar Lighting - This design application is currently being demonstrated in a variety of settings, providing natural sunlight in interior spaces

supplemented only as needed by electric lighting.

Source: CCTP, 2007, Chapter 3

\section{Box 7.2 Buildings}

- The high (first) costs of many advanced technologies and building designs present a barrier to adoption because consumers are often reluctant to pay more upfront to purchase products with lower life cycle costs, especially when lenders do not credit them for lower utility bills later.

- $\quad$ Misplaced incentives are a key barrier to energy-efficient buildings and remodeling. Landlords and builders often do not invest in energy efficiency in new construction, as well as in building renovations and upgrades, because tenants and homebuyers receive the benefits of lower energy bills. About 90 percent of all households in multifamily buildings, for example, are renters, which makes misplaced incentives a major obstacle to energy efficiency in urban housing markets.

- Insufficient validation of the performance of energy-efficient building technologies leads to the perception of technical risks. The cost-effectiveness of advanced building technologies can be highly situation-specific and difficult to predict.

- Market risks include a lack of financing and access to credit on the part of low-income households, small businesses, and government landlords. Investments in energy-efficient building technologies are also hindered by uncertainties associated with future energy prices and by risks related to irreversible investments.

- Unfavorable fiscal policies also inhibit deployment. Lack of cost-recovery mechanisms for energy-efficiency investments hinder electric utilities from promoting such technologies. Fixing the problem of utility revenue erosion from improved energy efficiency and the de-coupling of profits from sales is critical to removing a dis-incentive to energy efficiency.

- Laws (i.e., unfavorable statutes) in numerous states prevent energy saving performance contracting, thereby thwarting the growth of this important mechanism for financing energy efficiency improvements in state-owned buildings. 
Other barriers include lack of specialized knowledge about building system operations and optimization, and policy uncertainty related to the future legal treatment of GHG emissions. that result in relatively slow uptake of new technologies. In addition, variable and outdated and insufficiently enforced state and local building codes represent a type of insufficient market conditioning that inhibits the development of national markets for energy-efficient building design and construction. For example, nine states have residential energy codes that are more than a decade old or follow no residential energy code at all (Brown, Southworth, and Stovall, 2005). Outdated codes preclude the application of recent advances in building science. Finally, an overarching influence on the buildings sector is the long duration of the building stock, which “locks-in” obsolete technologies for decades.

\subsubsection{Industry}

The broader application of industrial technologies that are available for deployment is impeded by barriers such as the relative high risk and costs associated with new industrial technology, external benefits, a lack of specialized knowledge relating to energy-efficient improvements, and inadequate information flow.

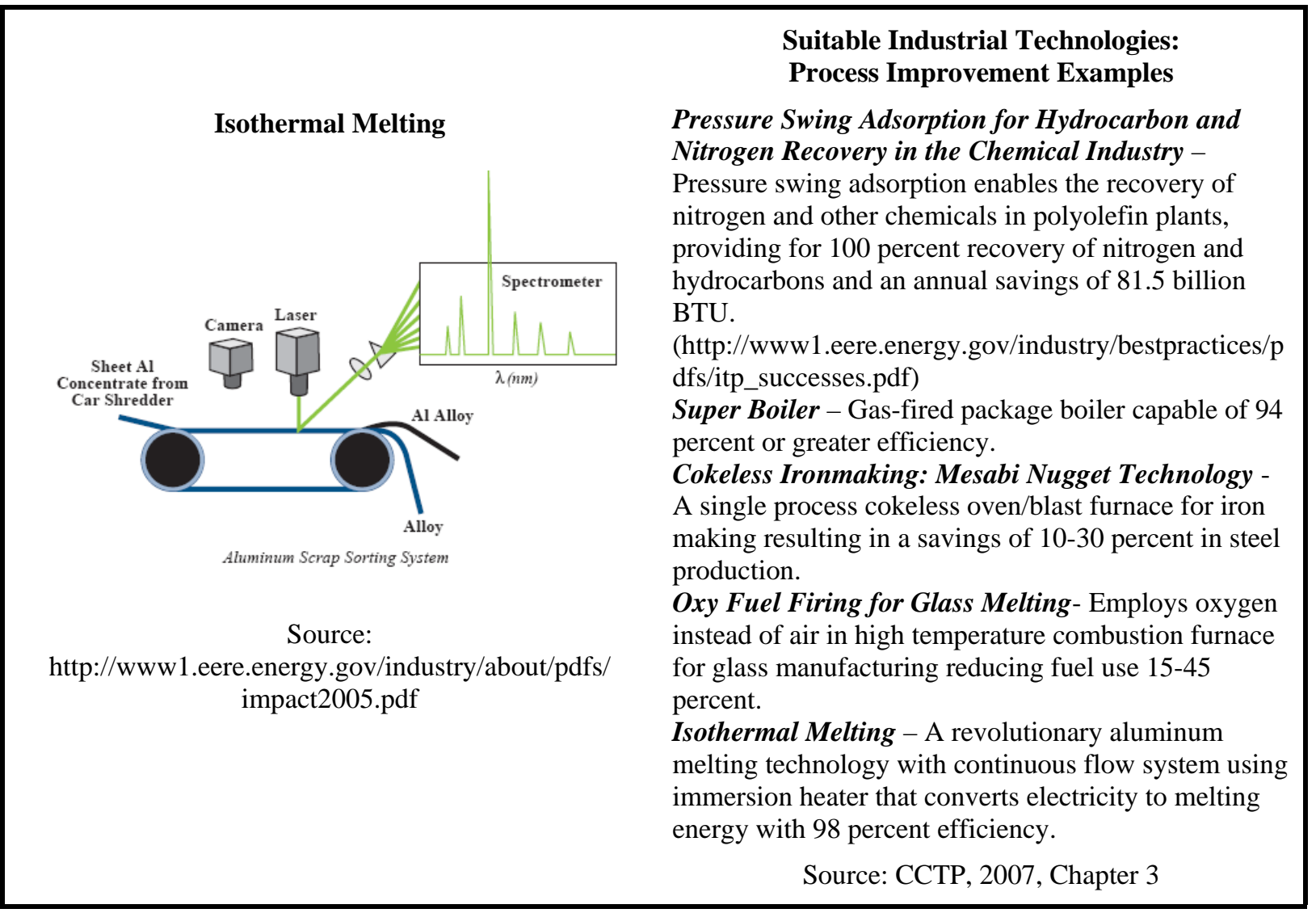

Box 7.3 Industry 
- Companies must consider the technical risks of adopting a new industrial technology. Uncertainties about the benefits and impacts of new technology on existing product lines can be very significant. Small technology changes particularly in large integrated process plants can lead to major changes in process and product performance. In today’s manufacturing environment with 24/7 operations, reliability and operational risks represent major concerns for industry when adopting new technologies. These perceived technical risks result in longer and larger scale field testing of new technologies, more stringent investment criteria, and a slower pace of technology diffusion.

- Relatively high costs for industrial energy-efficiency improvements can be an impediment to investments. New energy efficient technologies many times have longer payback periods than traditional equipment and represent a greater financial risk since there is significant uncertainty in future energy prices. This aspect of risk slows technological change and can result in suboptimal choices. Interest rates available for efficiency purchases are also often much higher than the utility cost of capital for new natural gas plants. Faced with uncertainty about future fuel prices, decision makers may simply avoid investments in new energy systems that require higher initial costs.

- External benefits and costs are difficult to value and inhibit GHG mitigation by industrial plant managers. In general, companies invest in GHG mitigation only when compensated by lower energy or raw material costs or other cost benefits. External environmental benefits are not usually considered in evaluating energy-efficiency investments. Suppliers, who typically introduce innovations to the industrial sector, may be reluctant to expend resources in developing GHG-reducing technologies without an assured market. On top of typical risks posed by competing companies and products, uncertain demand can tip the scale toward unacceptable risk for potential financiers.

- The lack of specialized knowledge related to energy-efficient technologies and their relative benefits is an impediment to adoption. Industrial managers can be overwhelmed by the numerous products and programs that tout energy efficiency, and without in-house energy experts, find it risky to rely on third party information to guide investments. Energy consulting firms often lack the industry-specific knowledge to provide accurate energy and operational cost assessments, and many industrial operations don't have in-house engineering resources to sort through or analyze the information.

- Incomplete and imperfect information is an impediment to the diffusion of energy-efficient industrial technologies. Researching new technology consumes time and resources, especially for small firms, and many industries prefer to expend human and financial capital on other investment priorities. In some cases, industrial managers are simply not aware of energy efficiency opportunities and low-cost ways to implement them.

- Investments in industrial energy-efficiency technologies are hindered by market risks caused by uncertainty about future electricity and natural gas prices and unpredictable long-term product demand.

Additionally, industrial end-use energy efficiency faces unfavorable fiscal policies. Tax credits designed to encourage technology adoption are limited by alternative minimum tax rules, tax credit ceilings, and limited tax credit carryover to following years; these limitations prevent tax credits from being utilized to their full potential by qualified companies. Outdated tax depreciation rules that require firms to depreciate energy efficiency investments over a longer period of time than other investments make these investments appear less cost-effective than other investment options for limited capital. 


\subsubsection{Electric Grid and Infrastructure}

While many advanced electric grid technologies are currently available and suitable for deployment, their market penetration appears to be impeded by many barriers including high costs, unfavorable regulations, external benefits, unfavorable statutes, and tariffs. These obstacles make it difficult for innovative grid technologies to enter the marketplace, as summarized below.

\section{Suitable Infrastructure Technologies: Electric Grid Examples}

High Temperature Superconducting (HTS) Cables - can transmit electricity with near 100\% efficiency and with half the energy loss of conventional cables. (CCTP, 2005)

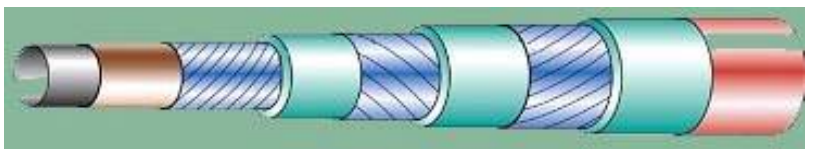

Advanced Sensors, Controls, and Communications - By enabling the diagnosis of local faults and coordination with power electronics and other existing protection schemes, these technologies provide autonomous control and enable isolation and mitigation of faults before they cascade through the system. As the grid incorporates more low-GHG distributed generators, such controls will be increasingly important.

Flywheels - By coupling a motor generator with a rotating mass, energy can be stored for short durations. Conventional flywheels are "charged" via an integral motor/generator, which draws power provided by the grid to spin the rotor of the flywheel. The kinetic energy stored in the rotor is later transformed to DC electric energy by the generator. Flywheels are in use in selected applications, but are not widespread.

Source: CCTP, 2007, Chapter 3

\section{Box 7.4 Electric grid and infrastructure}

- High costs are associated with expanding the grid to provide transmission from remote areas with carbon-free generating systems to load centers. Establishing new electric system corridors is expensive, as is re-conductoring existing lines with higher capacity cables. These high costs are exacerbated by uncertainties about return on investment, technology performance, and future environmental regulations.

- Numerous unfavorable regulations impede improvements to electric grid efficiencies. The ability to legally connect DG equipment to the grid depends on Federal, state, and local rules and regulations. Distributed energy resources located near final consumers typically do not receive credit for not requiring transmission and distribution (T\&D) lines. Utilities often only pay wholesale rates for the power, as if the generating resource was located far from final consumers and required T\&D. Thus, the value of having power located close to the end-use is not captured. The nation's current approach to environmental regulation using "input-based emission standards" also fails to reward efficient production and hence hinders the growth of clean generation. Few states use output-based standards, which reward innovations such as combined heat and power (CHP) systems that productively use much of the waste heat from power production.

- External benefits and costs inhibit displacement of high GWP gases by electric utilities and optimization of the grid to enable low-carbon generation resources. For example, there are limited marketplace incentives for utilities to reduce their use of $\mathrm{SF}_{6}$. In general, electric utilities and wires companies in most states have little incentive to consider their GHG emissions profiles. 
- Making better use of the existing grid is impeded by current contracting and pricing practices that represent unfavorable statutes. In many areas, the system operators might fully load lines only a few hundred hours a year (usually during a weather event). Much more loading can often be squeezed out, but it requires innovative pricing strategies such as "flexible firm pricing." Similarly, the under-utilization of time-of-use (TOU) rates is a barrier to photovoltaics and other DG resources that provide power disproportionately during on-peak periods.

- Unfavorable fiscal policy impeding the growth of DG include excessive standby charges as well as utility buyback rates that do not provide credit for on-peak electricity production. Utilities also set high uplift charges (a fee that taxes the amount of revenue gained from selling electricity) and demand fees (a charge that penalizes customers for displacing demand from utilities), all of which discourage the use of distributed power systems. The variation in utility rate structures makes the financial viability of a CHP installation highly dependent on its location, hindering the development of national markets.

Many of these critical barriers are related to the industry structure which in many places reflects regulated monopoly operation of electric generation and transmission; even in deregulated areas, entry can be difficult, leading to persistent monopoly structure. Policy uncertainty related to the future legal treatment of GHG is also a barrier to investment in low-carbon grid technologies.

\subsection{ENERGY SUPPLY}

Transforming the Energy Supply sector to one that emits fewer net GHG will require deployment of innovative GHG-reducing technologies. Federal efforts are already at work removing barriers to deployment of these GHG-reducing energy supply technologies. These programs tend to involve financial incentives, technology demonstrations, and provision of information. Financial incentives - in the form of tax credits and loan guarantees - reduce the incremental costs of GHG-reducing technologies compared with similar technologies that are not GHG-reducing. About 25 technology demonstration programs address issues of high costs and technical risks in energy supply; technology demonstrations are particularly useful in regards to capital intensive energy supply technologies as they reduce the size of the "mountain of death" related with the first-of-a-kind plant. Information and labeling programs help to overcome the barriers of incomplete and imperfect information and lack of specialized knowledge as well as reduce uncertainties.

Despite these programs, several barriers remain unaddressed, hindering deployment of low-carbon energy supply technologies. High costs are usually addressed through financial incentives, such as tax credits. Existing financial incentives like the Production Tax Credit and loan guarantees are uncertain from year to year, and fall short of meeting the incremental cost of adopting GHG-reducing technologies over conventional technologies. Additionally, advances in areas outside of energy supply may be required as key complementary technologies for overcoming infrastructure limitations on deployment of energy supply technologies; the most obvious example is the electric grid - which is also facing deployment barriers to investment (see End-Use and Infrastructure). Furthermore, opportunities to surmount technical risks and lack of specialized knowledge exist through education and technology demonstration programs. As new technologies for energy supply develop, policies and measures may need to adapt to prevent delay in their deployment; to accompany such adaptation, policy evaluation for existing measures in this area is recommended. 


\subsubsection{Low Emission, Fossil-Based Fuels and Power}

Fossil-based power sources are widely used; indeed, they are the most-used resource for energy worldwide. However, in a future where GHG emissions are to be avoided, significant expansion of methods to reduce the emission of fossil-fuel combustion products must occur. Barriers to significant expansion of efficient co-production technologies include high costs, technical risks, no return on external benefits, and current regulatory policies.

- More efficient power plants such as IGCC systems and SCPC plants require higher capital costs than conventional fossil plants. A recently released design study estimates that the cost of electricity for new SCPC plants with advanced amine capture would increase 81 percent and for new IGCC plants would increase 36 percent versus non-CCS plants. These projected high costs represent major barriers to potential investors.

- Operating experience with these newer designs is also limited. Reliability concerns and perceived technical risks deter investors from the newer designs and toward building proven, familiar plants.

- Because investors cannot capture the benefit of lower carbon dioxide emissions from these power plants (that is, because these emission reductions are external benefits), it is difficult to recover the higher cost of these plants over conventional fossil plants. RD\&D can take these new systems to the point of commercial readiness, but rapid deployment will not occur unless there is a reasonable value associated with carbon capture and storage.

- Unfavorable regulatory policies that grandfather existing units from Clean Air Act requirements discourage new plant construction and encourage continued operation of more polluting power plants. Such policies prevent improvements from technological progression and delay deployment of more efficient designs.

Polk Power Station: IGCC Plant in Tampa, FL (250 MW)

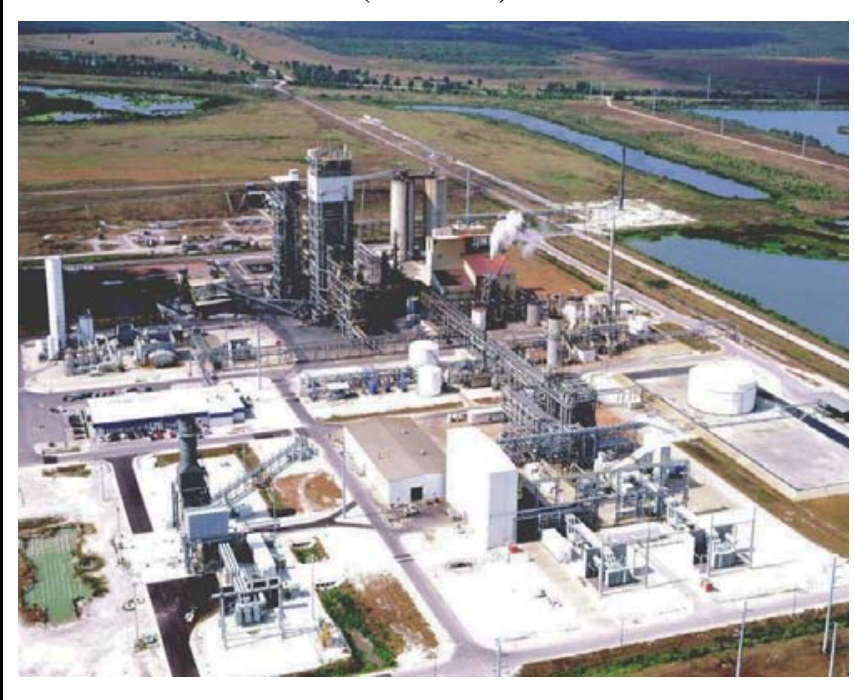

Suitable Low Emission Technologies: Power Systems Examples

Advanced Combustion Systems - Oxygenenhanced combustion can reduce NOx emissions and facilitate carbon sequestration. (CCTP, 2005) Integrated Gasification Combined Cycle (IGCC) - IGCC is a clean coal technology that combines coal gasification and combined cycle technologies to potentially achieve the environmental benefits of gas-fired generation with the thermal performance of a combined-cycle plant, yet with the low fuel cost associated with coal. Compared to pulverized coal power plants, IGCC has been able to not only demonstrate a $20 \%$ reduction in $\mathrm{CO}_{2}$, but also enable easier carbon capture and sequestration.

(http://www.netl.doe.gov/technologies/coalpower/ gasification/pubs/pdf/18.pdf)

Source: CCTP, 2007, Chapter 3

Box 7.5 Low emission, fossil-based fuels and power 
Other barriers affect this sector, including current industry structure, infrastructure limitations in the supply chain (including the absence of a carbon capture equipment industry for fossil-fired units), and policy uncertainty related to possible future GHG markets and regulations. The structure of the power industry is such that newer, smaller types of power production are often overlooked in favor of large, familiar power sources. This industry structure makes entry difficult for distributed generation and stationary fuel cells. Due to fragmented markets and lack of uniformity in codes and standards, distributed generation and stationary fuel cells face a market with insufficient conditioning for deployment success. Additionally, there are broad supply chain issues including the lack of one-stop vendors of IGCC or SCPC plants in the United States. Finally, policy uncertainty regarding future legal treatment of GHGs hinders investment in low-emission fossil systems.

\subsubsection{Hydrogen}

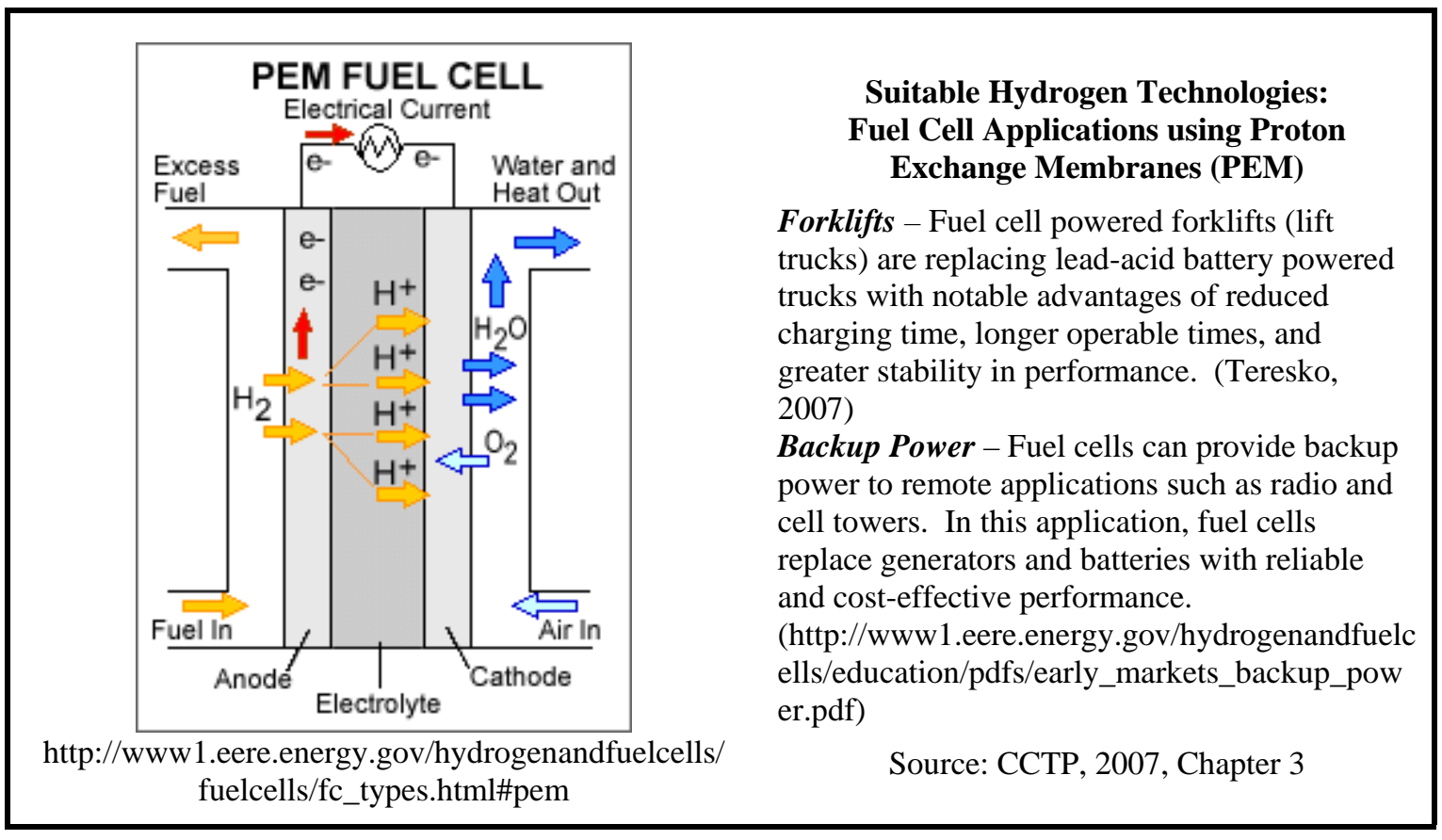

Box 7.6 Hydrogen

Introducing hydrogen into the mix of competitive fuel options and building the foundation for a global hydrogen economy will require a balanced technical approach that not only envisions a plausible large scale commercialization path, but also considers long-run uncertainties. In the transportation sector, this means that there must not only be plants to make hydrogen fuel cell vehicles, dealerships to sell them, and stations to fuel them, but also materials and people to service them, sites to produce the hydrogen, and a system to deliver the hydrogen. A similar group of needed development can be envisioned for stationary applications. The following are key deployment barriers that must be overcome for widespread deployment of hydrogen technologies.

- Hydrogen offers the promise of a non-carbon fuel. Because of the current superiority of carbon fuels in energy density, infrastructure, and public knowledge, a non-carbon fuel will not be adopted unless its carbon mitigation (i.e. external benefits) and other attributes are given a market value. Using hydrogen could not only provide non-emitting transportation and stationary power but (if produced without hydrocarbons) reduce environmental damage from oil and coal retrieval 
as well as improve energy security. Like electricity, the life-cycle GHG emissions associated with hydrogen use would vary depending on the method to produce, store, and distribute it.

- Hydrogen fuel production and key complementary technologies (i.e. those that use hydrogen as fuel or make use of hydrogen fuel possible) face high costs. The economic viability of different production pathways will likely be affected by regional factors, such as feedstock availability and cost, delivery approaches, and regulatory environment. For hydrogen to become a viable energy carrier, advanced hydrogen storage technologies will be required, especially for automotive applications. Current storage systems are too heavy, too large, and too costly to provide adequate vehicle range (DOE 2006b). Because fuel cells currently require platinum for optimal performance, they are inherently costly. Some publicly owned fuel cell manufacturers are selling at a loss to try to increase the market base; this is not a sustainable effort. Materials advances and substitutions are expected to lower costs in the long term.

- Large-scale ubiquitous production of hydrogen from clean energy pathways requires significant scientific advances; their widespread deployment must await the reduction of technical risks. Producing hydrogen with renewable resources currently means high cost and low efficiency - the goal is to produce hydrogen that will be competitive with conventional fuels (\$2 - \$3/kg hydrogen). Renewable production technologies of greatest interest are bio-derived liquid reforming, electrolysis, biomass gasification/pyrolysis, high temperature thermochemical cycles, photoelectrochemical, and biological processes. Additional options are hydrogen production from small scale natural gas reformers, IGCC coal plants with carbon sequestration, and hightemperature nuclear reactors. Each of these options faces its own set of deployment barriers. An embedded technical barrier to the use of hydrogen as a transportation fuel is finding safe, lowcost, lightweight, and low-volume hydrogen storage technologies. Existing high pressure gaseous hydrogen storage systems in prototype hydrogen-powered vehicles offer a shorter driving range or less cargo space than conventional gasoline-powered vehicles. Alternative technologies based on hydrogen-rich materials have the potential to store more hydrogen than a traditional tank of similar size filled with hydrogen gas or liquid, but substantial R\&D is required to develop these concepts further.

- The infrastructure requirements associated with large-scale storage and delivery of hydrogen in both the power and transportation sectors are more challenging than for most fuels. Because of these infrastructure limitations, most hydrogen today is produced on a small-scale at sites located at or near points of use.

Hydrogen technologies also face other barriers to widespread deployment, such as regulatory and statutory uncertainty and inadequate workforce knowledge. Meeting consumer expectations through improved performance is necessary but insufficient to drive deployment of hydrogen technologies. Absent regulations for handling of hydrogen, regulatory uncertainty results in unclear market signals and uncertain "business cases" for these alternative hydrogen fuel cell systems. Development and promulgation of uniform codes and standards is necessary to overcome statutory uncertainty and critical to establishing a market-receptive environment for commercializing hydrogen-based products and systems (NREL, 2002). A lack of specialized knowledge in the current workforce requires that training and certification systems are developed to address the technical, safety, and environmental challenges of a large-scale hydrogen economy (NAE, 2004). 


\subsubsection{Renewable Energy and Fuels}

Despite advances in technologies, renewable power and fuels only makes up about 6 percent of the nation's energy demand and only 3 percent when large hydropower is excluded (EIA, 2007c). While there are many renewable power and fuels technologies that could reduce GHG emissions, the following barriers illustrate significant challenges that currently impede their full deployment. While generalizations are being made to the technology sector as a whole, the relative importance of barriers is highly variable across this diverse suite of technologies.

- Renewable power and fuels technologies provide external benefits such as low or zero carbon emissions that are not currently recognized in the market; although renewable fuels and other biomass are not currently carbon neutral, their emissions are lower than that of conventional fuels. Some utilities offer "green power" programs to consumers, allowing them to pay a premium to help the utility buy renewable generation; however, observed voluntary enrollments are lower than expected, given consumer's "willingness to pay” discovered through market research studies (Bird and Sweezy, 2006).

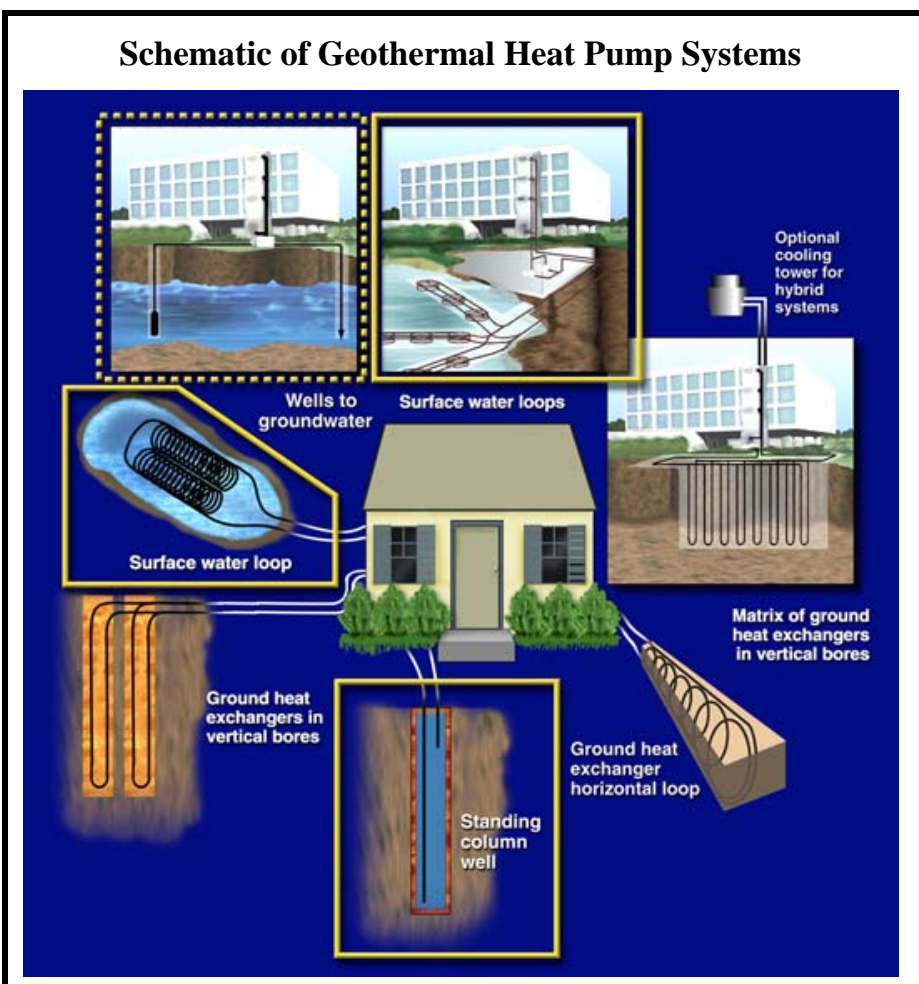

\section{Suitable Renewable Electric Power Technologies:}

Solar Thermal Pool Heaters - Solar thermal collectors have many uses, one of the most popular is pool heating. Low temperature (operating at temperatures below $110 \mathrm{~F}$ ) solar thermal collectors for pool heating represented 15 million square feet of the roughly 16 million square feet shipped in 2005 (EIA, 2006a, 2007a).

Geothermal Heat Pumps - Geothermal heat pumps use low-grade heat in the earth to provide heat in the winter and to act as a heat sink in the summer, using conventional vapor compression and underground piping systems. The potential of geothermal heat pumps in the United States is very large (estimates of greater than 66000 MW available by 2025); usage in 2006 was about 7500 MW (Green and Nix, 2006).

(Source: Oak Ridge National Laboratory)

Box 7.7 Renewable energy and fuels

- Most renewable energy technologies have high (up-front capital) costs and lower (or zero) fuel costs compared to fossil fuel technologies. Capital costs for renewable energy technologies have reduced considerably over the past decades, but remain a constraint to widespread market penetration. While the cost-effectiveness of renewable energy technologies does not depend integrally on fuel costs (except for biomass technologies), this risk-reduction benefit is often missing from economic comparisons. Inadequate market infrastructure contributes to increased costs for renewable technologies (Painuly, 2001). 
- As renewable technologies rapidly advance to achieve per-unit cost reductions, the market for these renewable power and fuels technologies faces increasing returns. This dynamic environment leads to market risks associated with uncertain costs of particular technologies relative to competitors. Some renewable power generation technologies such as wind and solar also have increased perceived risk related to the variability of the resource. Biomass power and fuels are also subject to a perceived high resource risk related to availability of long-term supply. Cellulosic biomass technologies suffer from "first of a kind" risk in deploying these technologies. Investors need assurance that commercial operation of these technologies is possible, by obtaining engineering guarantees, permits, etc.

- Renewable fuels and power technologies face infrastructure limitations in the form of supply chain gaps and complementary technology shortages. For example, with PV systems there is a lack of purchasing channels and trained installers. PV products are difficult to find and are often not available as complete, certified, and guaranteed systems; PV systems would benefit in the market if they could be purchased, installed, and serviced by nationwide retailers. Expansion of renewable sources for electricity production, such as wind power, will require parallel expansion in transmission capability and a general improvement in the operation of the country's electrical infrastructure. Similarly, transporting biofuels from production facilities to consumers may become a limiting factor as volumes of biofuels increase. Current pipeline infrastructure is designed to carry fuels from ports to population centers while most renewable fuels are produced in the heartland, and it is also unsuitable due to ethanol absorbing water and impurities present in petroleum pipelines

- On-again/off-again tax credits contribute to fiscal uncertainty, which negatively influences production needs. Developers end up focusing on an accelerated timetable instead of optimizing production over the long run by, for instance, investing in longer-term facility scale-up needs, systems, and personnel training. Specifically, the renewable production tax credit (PTC), which provides a tax credit for each kWh of electricity generated by qualified wind, solar, geothermal, closed-loop biomass, or poultry waste resources have been available for the first ten years of operation for all qualifying plants that entered service from 1992 through mid-1999, later extended to 2001, then to 2003, and again with EPAct to 2007 and subsequently to 2009. Similarly, the small ethanol producer tax credit was seldom used because it was considered uncertain and complicated for 15 years; this tax credit and the small agri-biodiesel tax credits now provide \$.10 per gallon tax credit to producers (Renewable Fuels Association, 2006). Further, variability across states for incentives and programs for renewable energy and energy efficiency can be seen as a barrier. $^{76}$

- Interconnection requirements have been reformed in some states, but many states and utilities still have high backup or standby rates for small electric generating units and expensive equipment and inspection requirements that undermine these efforts. Time of use rates and other mechanisms to compensate PV and other technologies for generating electricity or reducing demand during peak periods when their generation is most valuable are not widely used. These practices, sometimes regulated and sometimes exhibited by deregulated or municipal utilities, make up unfavorable fiscal policies impacting renewable power technologies.

- Renewable portfolio standards that create markets for renewable energy exist in some states, vary widely in the amount of renewable energy required, and often have uneven incentives for different technologies - for example some recognize solar water heating, and some do not. Very few states have instituted rate structures that decouple utility compensation from the volume of their electricity sales; without decoupling, utilities have no incentive to encourage small renewable

\footnotetext{
${ }^{76}$ State incentives can be found through the Database for State Incentives for Renewables \& Efficiency (DSIRE) Database of State Incentives for Renewables \& Efficiency. (DSIRE) www.dsireusa.org/index.cfm?EE=1\&RE=1 (updated 2/1/07)
} 
power installations. Similarly, fuels requirements vary between and within states. Variability across and within states contributes to statutory uncertainty and creating additional compliance burdens for businesses operating in these industries.

- Decision makers and the general public face incomplete and imperfect information and remain largely unaware of renewable power and fuels technologies as well as their uses and benefits. Without greater trusted information, it may be difficult to move these technologies out of niche markets.

Renewable power and fuels technologies also face limitations posed by the industry structure, technical risks, and regulatory uncertainty. The existing electric grid and utility infrastructure assumes large generation sources and wide load balancing areas - making inclusion of smaller, non-continuous generation sources problematic. Imbalance penalties (tariffs) charged by existing utilities pose challenges to renewable power profitability because of the variability of wind and solar PV. Technical risks abound; for example, each biofuel feedstock requires specific processing, photovoltaic materials require special handling, and some of these technologies face "first of a kind" risks in deployment. Furthermore, environmental permitting for renewable power projects falls under the purview of (highly variable) regulations promulgated by states, counties, and local municipalities.

\subsubsection{Nuclear Fission}

While the nuclear power industry is taking the first steps to construct new nuclear plants, several factors may slow or deter final investment decisions. Among the most pressing are: uncertainty associated with long-term waste disposal; the high capital costs associated with design and construction of the first few plants; constraints in the supply chain infrastructure; and the possible shortage of trained workers. These factors are elaborated upon below:

- The Federal Government continues to move forward to seek a license for a long-term storage facility for high-level wastes and spent fuel from nuclear power plants. Significant expansion of the reactor fleet is dependent on the existence of a site for long-term storage of these wastes. Approval of the Yucca Mountain site will remove significant regulatory uncertainty.

- Nuclear power plants are capital intensive but have low operating costs. New nuclear fission power plants potentially face extraordinarily high costs if the planned construction durations end up being extended due to delays, which could dilute utility earnings and thus reduce investment returns. This risk should become more manageable with completion and commissioning of the first few new plants.

- The manufacturing infrastructure for major nuclear plant components has shrunk substantially in recent decades when no new nuclear plants were ordered in the U.S. and only a few were being started worldwide. These supply chain gaps present the nuclear industry with a key infrastructure limitation. At present there is only one location in the world where the large forgings for reactor vessels can be made. With time, as manufacturers see the potential for new reactor construction growing, investments in infrastructure may also grow. This constraint could slow the construction of new nuclear plants in the U.S., especially considering the competition for supply chain resources resulting from the large nuclear expansion expected in China and other Asian countries.

- A lack of specialized knowledge may impede new nuclear power plants. Most notably, there has been a shrinkage of trained workforce, both in the engineering and supporting trades needed to construct plants to NRC specifications and to operate and maintain them. Modular construction techniques used already in Asia may help overcome this risk to timely construction and 
competent operation of new plants. (Workforce specialization shortages are magnified by the number of plants being built.)

Deployment of new nuclear fission power plants will hinge on these critical barriers along with other barriers that may increase costs to the industry, especially first movers. These other barriers include licensing uncertainty associated with a new regulatory regime as well as transmission capacity limitations. Nuclear power plant siting, construction, and operation are regulated by the Nuclear Regulatory Commission (NRC). Before 1992, plant developers were required to first obtain a construction license and then an operating license, which put utilities in a position of having no guarantee that a plant, once constructed, would be licensed to operate. Under new rules put in place in 1992, plant developers apply for a combined construction and operating license (COL), which provides significantly more certainty to the process, However, this regime has never been tested, and it is still possible that construction and commissioning delays may occur. Government incentives are in place to partially compensate the operators of new nuclear power plants for commissioning delays and those risks that plant developers have little control over during construction.

Transmission capacity limitations in some parts of the United States can make construction of large capacity generation facilities such as nuclear reactors more difficult, or even preclude them entirely. Capacity constraints have been alleviated somewhat by increased investment in transmission, which began in 2004, and also by plans to locate the first new reactors at the sites of existing plants. Resolving this issue more fundamentally will require a long lead time.

\subsection{CARBON CAPTURE AND SEQUESTRATION}

Deployment of technologies to capture and store or sequester GHG is intricately linked with the goal of reducing GHG emissions - especially in the near to mid term as we bridge from emitting to non-emitting energy supply technologies and fuels. There are already five federal deployment activities that expressly address barriers to carbon capture and storage; four of these measures include some form of technology demonstration and help to overcome the technical risks associated with the CCS endeavor.

Even with these existing federal programs, widespread deployment of CCS technologies is not possible without clear and consistent policies that address external benefits and costs as well as policy uncertainty. Without a market (or price) for GHGs, there is no incentive to capture or attempt to store carbon or other GHGs; these gases remain externalities. Other barriers to deployment of CCS technologies exist. Mitigation of these barriers present additional opportunities including identification of liable parties and beneficiaries, proof of principle in scale-up of first of a kind facilities, and development of critical infrastructure. When, or if, CCS technologies become more widespread, policies and measures may need to change to meet the needs of the new environment.

\subsubsection{Carbon Capture}

For carbon capture, the key barriers appear to be external benefits, technical risks, high costs, and infrastructure limitations, which make expansion of this industry difficult. These are elaborated upon below:

- Carbon capture and compression is a costly and complex process - by far the most expensive part of carbon capture and storage - requiring investors to assume there will be a market for captured carbon or a cost imposed for emissions. Because the benefits of carbon capture technology cannot be fully realized by investors, they face an external benefits problem. 
- Investors face technical risks associated with capture technology options as well as uncertainty regarding geologic storage or other uses for captured carbon. Carbon capture technologies also add to the auxiliary electric load on the power plant, which reduces available power for sale.

- Currently, carbon capture, separation and compression can add as much as 50-80 percent to the costs of a power plant (CCTP 2006). Because there is no way to recover these high costs and no price on carbon, there is little incentive to undertake these costs.

- There are infrastructure limitations associated with carbon capture. Pipeline and geologic storage as well as chemical separation areas will have to be developed. Additionally, expanded production of chemicals for transforming gas streams into usable carbon dioxide may be needed.

\section{Suitable Carbon Capture Technologies: Post- and Pre-Combustion Examples}

Post-combustion - This capture method involves separation of $\mathrm{CO}_{2}$ from flue gases, which can be accomplished using amine-based chemical absorbents. This method is being used now, but more for process applications than for $\mathrm{CO}_{2}$

capture.

Pre-combustion - Pre-combustion capture involves processing the primary fuel to separate $\mathrm{CO}_{2}$ and hydrogen, such as in gasification reactions. Pre-combustion capture is already commercial on a limited basis.

Source: CCTP, 2007, Chapter 3

Box 7.8 Carbon capture

Policy uncertainty regarding GHG impedes this sector as well primarily because $\mathrm{CO}_{2}$ emissions are not currently regulated. The U.S. Supreme Court has recently determined that the Environmental Protection Agency (EPA) has the authority to regulate $\mathrm{CO}_{2}$ and possibly other GHGs, but how this will affect policy remains unknown.

\subsubsection{Geologic Storage}

Geologic storage and associated enhanced recovery of oil and natural gas are promising for long-term $\mathrm{CO}_{2}$ mitigation; research efforts, combined with current knowledge, are helping to push this technology forward. However, there are barriers to the expansion of geologic storage - most notably external benefits, technical risks, and uncertainty.

- Geologic sequestration investors cannot appropriate the spill-over benefits from climate change mitigation; because geologic storage is primarily providing a good without a market for GHG reduction, investors face an external benefits problem. The result is a suboptimal investment in $\mathrm{CO}_{2}$ sequestration.

\section{Suitable Geologic Storage Technologies: Injection and Storage Examples}

Injection and Storage Technologies - Many technologies required for storing $\mathrm{CO}_{2}$ are borrowed from the petroleum industry, which uses $\mathrm{CO}_{2}$ injection for enhanced oil recovery. Technologies involving $\mathrm{CO}_{2}$ processing, transport, compression, and subsurface reservoir engineering and characterization can also be leveraged from the petroleum industry. (CCTP, 2005)

\section{Box 7.9 Geologic storage}


- The technical risks associated with geologic storage stem from a lack of knowledge of the amount of carbon dioxide that can be safely stored underground, for how long and with what level of potential leakage, if any back to the surface.

- A driving force needed for geologic storage will be clear policy regarding emissions of carbon dioxide. So long as there is policy uncertainty associated with GHG emissions remains uncertain, investment will be limited.

- Statutory uncertainty pertaining to property rights must be removed to deploy geologic storage. Property rights, specifically with regard to deep subsurface spaces, vary between and within states. Clear property ownership is seen as necessary to attract investment in geologic storage.

Geologic storage of large quantities of $\mathrm{CO}_{2}$ will require a significant expansion of the $\mathrm{CO}_{2}$ transport system that faces infrastructure limitations. While there is understanding of $\mathrm{CO}_{2}$ injection as a result of more than three decades of enhanced oil recovery, issues remain related to the required infrastructure. In particular, a network must be developed to transport captured $\mathrm{CO}_{2}$ from the point of emission to the underground storage site. An additional barrier is the need to account for $\mathrm{CO}_{2}$ on a net basis. Many of the geologic storage techniques involve enhanced fossil-fuel recovery (oil, gas, and methane), and the combustion of these newly recovered fossil-fuels may emit GHGs reducing the net effect of the $\mathrm{CO}_{2}$ initially sequestered. There are also market risks related to possible liability stemming from geologic storage leaks; lack of indemnification is a barrier to growth of this technology.

\subsubsection{Terrestrial Sequestration}

While there are many cost-competitive technologies that could enhance sequestration of carbon in the terrestrial environment, numerous barriers impede their full deployment. The chief barriers to expansion of terrestrial sequestration capacity are: external benefits, large and diverse industry structure, lack of specialized knowledge, and high private costs.

- The lack of a formal carbon market deprives the owners of forests, croplands, and grasslands from capturing the full social value of the GHG benefits associated with improving the carbon sequestering capacities of their land resources. Until such a market develops, external benefits will remain a barrier, and investment in $\mathrm{CO}_{2}$ sequestration will be suboptimal. $^{77}$

- The industry is composed of many actors from large agribusiness to small private landowners. This diverse and fragmented industry structure makes effecting changes in practices and technologies related to land and resource management difficult.

\footnotetext{
${ }^{77}$ We acknowledge that there are carbon markets. For example, the Chicago Climate Exchange (CCX) has been trading GHG and facilitating voluntary but legally binding GHG reductions in North America since 2003 (chicagoclimatex.com). This market, while growing, represents a small portion of GHG in the United States. The benefits to those who can supply GHG reductions will require for there to be a demand of GHG reductions from a greater portion of emitters.
} 
- Even where cost-effective opportunities exist, many farmers and forest landowners have received inadequate technical assistance and hence lack the specialized knowledge necessary to manage and maintain their land resources to improve terrestrial sequestration capacity.

- Land owners and managers face high costs in taking terrestrial sequestration upon themselves. In addition to implementation costs which are generally low, these costs include transactions, education, and opportunity costs. The opportunity costs will include any economic losses from reduced yields caused by the adoption of sequestration practices.

Also impeding expansion and management of terrestrial sequestration are other barriers, including policy uncertainty, liability risks, unfavorable property tax structures, and remaining technical uncertainty. Legal treatment of $\mathrm{CO}_{2}$ is not yet established, presenting policy uncertainty that inhibits capacity building in terrestrial sequestration. At present, there is no formal liability structure for stored carbon (often referred to as the permanence or reversibility issue). Agreement on identifying liability for potential emissions from stored carbon could address this issue, potentially through a range of approaches, including an insurance or other system that could encourage market and landowner involvement by reducing risk in the market. Current unfavorable fiscal policies, like some property tax laws can distort incentives faced by land owners. Land owners need clear consistent long-term messages from all levels of government and from markets to land management to reduce GHG emissions. A number of measurement and monitoring issues remain - particularly in the areas of measuring changes in soil carbon stocks at the field level, and accounting for potential trade-offs between $\mathrm{CO}_{2}$ and other GHGs (notably nitrous oxide emissions related to nitrogen fertilizer use). Significant methodological work is underway to address these technical risks, however.

\section{$7.4 \mathrm{NON}-\mathrm{CO}_{2} \mathrm{GHGs}$}

Reduced emissions of other GHGs, such as methane, nitrous oxide $\left(\mathrm{N}_{2} \mathrm{O}\right)$, and high global warming potential (GWP) industrial gases, such as hydrofluorocarbons (HFCs), perfluorocarbons (PFCs) and sulfur hexafluoride $\left(\mathrm{SF}_{6}\right)$, afford significant near-term opportunities for addressing the underlying causes of climate change. Many of these GHGs have GWPs far higher than that of $\mathrm{CO}_{2}$. A diverse array of primary technologies, many of which are process-specific, can be deployed today to mitigate emissions of these gases. The bulk of current Federal deployment activities addressing these barriers encompass a wide range of voluntary programs, tax policies and other financial incentives; education, outreach and information dissemination; and effecting change through public-private alliances and coalitions, including international partnerships. Development of codes and standards, technology demonstrations, and legislation also play a role in selected circumstances.

However, important deployment gaps and opportunities remain. As is the case in so many technology areas, external benefits and costs, high costs, and technical risks hinder progress. In addition, lack of specialized knowledge among stakeholders is a key barrier. For example, substitutes exist for high-GWP gases in aluminum, magnesium and other industries, but they require a relatively high level of skill and industry-specific expertise to implement successfully and economically. It is likely that new or expanded Federal programs will be needed to overcome the complex barriers inherent to reduction of non- $\mathrm{CO}_{2}$ gases, which largely reside outside the mainstream of other mitigation efforts. Further work is needed to assess and design the most cost-effective strategies for each.

\subsubsection{Methane from Energy and Waste}

Multiple barriers prevent the deployment of methane-reducing technologies in the U.S. energy and waste sectors. Fluctuating energy prices can negatively impact investment in new technology and impede the infrastructure development that is required to deliver methane to energy markets. In some cases, 
complicated land ownership and mineral rights laws make it difficult for owners to capitalize on the recovery of methane.

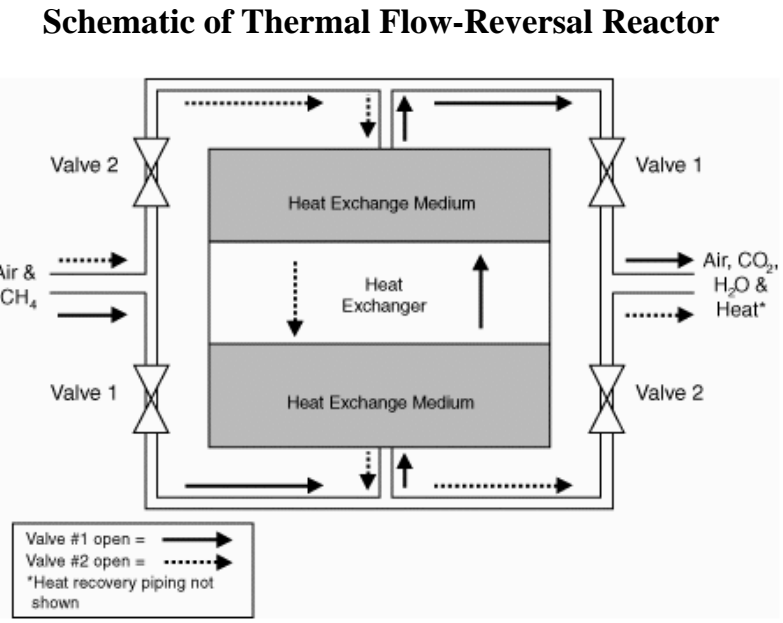

Source: http://www.epa.gov/cmop/vam/overview.html

\section{Suitable Methane Reduction Technologies: Measurement and Recovery Examples}

Landfill Gas - In recent years, bioreactor landfills have gained recognition as an innovation in solid-waste management. The National Energy Technology Lab funded a study of the Yolo County Pilot Bioreactor Landfill Demonstration to look for new ways to capture greenhouses gases from a bioreactor landfill. The results showed a tenfold increase in methane recovery and an associated reduction in time required for waste stabilization and composting of the landfill. (CCTP, 2005)

Coal Mine Methane - Flow reversal reactors have been applied for oxidation of volatile organic pollutants and have been successfully tested at small scale with ventilation air methane. In addition, a field-scale thermal reactor has been tested in Australia and is currently being tested in West Virginia.(CCTP, 2007, Chapter 3).

\section{Methane Emissions from Oil and Gas Industry -} Traditional leak measurement technologies are available. Advanced technologies, like the Hi-Flow ${ }^{\mathrm{TM}}$ Sampler, are in the deployment stage (CCTP, 2007, Chapter 3).

\section{Box 7.11 Methane from energy and waste}

- Statutory uncertainty is created when there is variability among states as to the legal ownership of resources, land, and gas. For example, owners of coal, surface land, coal mine methane, and mineral rights may be different parties/entities, complicating negotiations for recovery of the gas and access to the land. In some cases, the issue of rights must be resolved through lawsuits.

- Similarly, there are existing unfavorable statutory policies. The Supreme Court found that Federal coal leases granted under the 1909 and 1910 Coal Lands Acts did not include coal mine methane as part of the coal lease, impeding potential recovery. The result of these statues contributes to the uncertainty described above.

- For some methane from energy and waste reduction technologies, high costs are an issue. Liquefying natural gas, for example, is too costly for some operations, and even if profitable, limited capital is available for high risk, lower priority investments.

- Long-term purchase agreements with customers may be needed to stimulate investment in recovery systems; these can be difficult to negotiate. Market risks arise in obtaining secure, sustainable markets for recovered gases.

- Technical risks can be an impediment as some of these technologies are not yet proven on a commercial scale or demonstrated in actual operation.

- Cost-effective technologies may not be deployed because of incomplete and imperfect information; the energy and waste industries are not aware of the mitigation technologies, how they might be implemented, and their potentially attractive return on investment. 
- Infrastructure limitations can be a barrier to methane recovery because in many cases, there is no direct market for the gas or a pipeline nearby. Given the lack of infrastructure and access to market, flaring, venting or reinjection (in the oil and gas sector) may be the only viable options.

\subsubsection{Methane and Nitrous Oxide Emissions from Agriculture}

The high costs of technology investment in a low margin industry, getting information out to the widely dispersed farming community, and the lack of specialized knowledge necessary to implement energyrelated technology all constitute significant barriers in this sector.

- High costs are a significant barrier, depending on the application and market or regional issues. A technology might be cost-effective in some applications (e.g., regions where electricity is expensive) but not others. The economics for methane recovery from livestock and poultry are more challenging than in the landfill or oil and gas sector, where it is already practiced; $\mathrm{m}$. Methane recovery is also not a core component of the agricultural business model. Building a digester and energy generation system usually requires considerable capital and might not be feasible for smaller operations. In some cases (e.g., precision agriculture), initial high investment costs must be absorbed by the farming operation prior to any financial benefit from use, which can be challenging for smaller farms in particular (Colorado 2005).

- Incomplete and imperfect information is one of the most pervasive barriers to deployment of GHG-reducing technologies in this sector. The community is so fragmented, which contributes to poor information flow. There is a lack of awareness of the many cost-effective technologies that could be deployed, and the energy, economic, environmental, or other benefits are not clearly communicated and understood.

- Lack of specialized knowledge is an issue for methane recovery in agriculture. Operators lack specialized knowledge, including information, training and technical expertise in methane reduction and/or recovery systems and practices, which are outside of most core agricultural production competencies. Farmers and ranchers may require outside technical expertise to design and install methane recovery systems. The same is true for precision agriculture, where the farmer must undergo training to use the tools, and then understand how to interpret the data consistently and apply it. Imperfect information also results from poor records management by producers, which can result in missed opportunities to improve livestock productivity and decrease GHG emissions.

- Difficulty with accurately measuring and accounting for emission reductions in the agriculture sector poses technical risks to new technologies in this sector. This is particularly true with enteric fermentation and soil $\mathrm{N}_{2} \mathrm{O}$ reductions because accurate measurement approaches are difficult or expensive or require frequent and large sample sizes due to high variability in 
measurement results. Measurement quality is also impacted by methodology and the experimental design, as methodologies often do not include the entire production system within the measurement boundary. By limiting the boundary to only a part of the production system, such as a barn or waste impoundment, GHG and carbon accounting may be flawed as important losses and chemical transformations that may occur outside of the measurement boundary are not accounted for especially with regards to the measurement boundary.

- Market Risks are an obstacle to reducing GHG emissions from agriculture. An example would be downstream information asymmetry; beef consumers may be reluctant to purchase grass fed beef vs. feedlot finished beef because of price differences and therefore no clearly provided benefit. Downstream consumer preferences, as in this example, can impact the incentives for agriculture to utilize methane reducing practices.

The structure of the agricultural community, which is comprised of many thousands of autonomous farmers and ranchers, also constitutes a barrier to technological change in general as it contributes to critical barriers of higher risks, incomplete information, and lack of specialized knowledge. The fragmented agricultural market is not sufficiently rewarded or informed of the technologies and practices that could reduce emissions. Additionally, agricultural practices which reduce or recover methane and nitrous oxide emissions have impacts that are external to the marketplace as they relate to GHG reduction; the inability to capture these external benefits for abatement (or bear external costs of emissions) inhibits progress in this sector.

\subsubsection{Emissions of High Global-Warming Potential Gases}

\section{Flow Diagram for a Secondary Loop Refrigeration System}

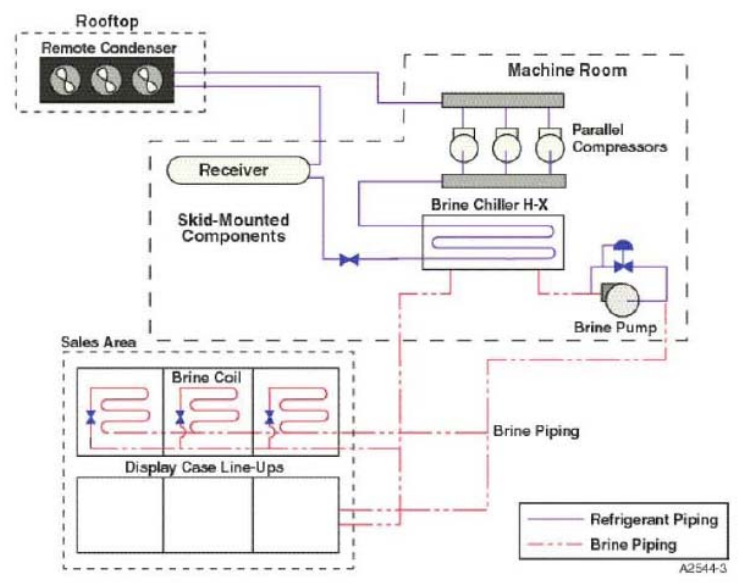

Source: http://www.energy.ca.gov/reports/2004-0423_500-04-013.PDF

\section{Suitable High GWP Reducing Technologies: Refrigeration and Air Conditioning Examples}

Supermarket Refrigeration - Technologies under development include distributed refrigeration, which reduces the need for excessive refrigerant piping (and hence emissions), and secondary-loop refrigeration, which segregates refrigerantcontaining equipment to a separate central location while using a benign fluid to transfer heat from food display cases.

Motor Vehicle Air Conditioning - R\&D is underway to commercialize low-GWP refrigerants, mainly $\mathrm{CO}_{2}(\mathrm{GWP}=1)$ and $\mathrm{HFC}-152 \mathrm{a}$ $(\mathrm{GWP}=120)$. These have been tested with some success in full-scale vehicles and are being used to replace CFC-12, an ozone depleting substance with a GWP of 8500.

Source: CCTP, 2007, Chapter 3

Box 7.13 Emissions of high global-warming potential gases

Although these technologies show promise and have demonstrated performance through testing of full or near-full scale prototypes, their widespread penetration can be hindered by numerous barriers. To reduce emissions of high-GWP gases, three strategies are generally proposed: 1) use of alternative substances; 2) process design to avoid the emission; and 3) abatement or control once emitted or to prevent emission. The deployment challenges are highly specific to the technology and industry where they will be applied, and to the strategy employed. In some cases, climate protection strategies may produce cost savings and 
accelerate rather than inhibit the deployment of the technology. For example, when electric utilities successfully identify and repair $\mathrm{SF}_{6}$ leaks from high voltage transmission equipment, cost savings are realized. In other cases, however, such as in the installation of PFC abatement devices, the technology deployment adds to the cost of production and is less attractive.

- High costs are a cross-cutting deployment barrier: if the alternative gases and technologies were less expensive, GHG replacement would be occurring more rapidly. Some of the incremental costs are required for risk mitigation: for example, the high-pressure and toxic effects of $\mathrm{CO}_{2}$ and the flammability of HFC-152a necessitate additional safety engineering to allow use of these alternative refrigerants. In addition, technologies that involve changeover and slow-down of manufacturing processes can result in revenue losses.

- It is difficult to change industry practices when the primary benefit - the reduction of high-GWP gases - is a social good that may not generate any return on investment to the manufacturer. These external benefits and costs prevent industry from innovating, since the principal driver for investing in improved processes is increased profit. However, as noted, climate technology strategies in some cases may produce cost benefits to the technology user.

- Incomplete and imperfect information presents a key barrier to the deployment of new technologies in this sector. Awareness of the performance and availability of alternatives is often lacking.

- Similarly, deployment is hindered by a lack of specialized knowledge. In many industries, there are no simple drop-in substitutes for the high-GWP gases. Some are more toxic or may produce toxic byproducts resulting in health and safety issues; others require thermal abatement and the collection of off-gases from exhausts. A high level of workforce knowledge is required to master the safe and effective use of these substitutes.

Other barriers include market risks from global competition and anti-competitive patent practices. The migration and globalization pressures on some of the industries (for example, aluminum) that use and/or emit high-GWP gases making it difficult for companies to undertake the significant facility upgrades necessary to eliminate emissions. Intellectual property barriers are posing an emerging issue to one alternative to $\mathrm{SF}_{6}$ for magnesium melt protection, Novec ${ }^{\mathrm{TM}}$ 612, a patented $3 \mathrm{M}$ fluorinated ketone. The company has designed their patent to retain the legal rights to future emission reduction credits, creating a large element of uncertainty for magnesium companies concerning the patent's validity.

\subsubsection{Nitrous Oxide Emissions from Combustion and Industrial Sources}

In general, the barriers to deployment of technologies that reduce nitrous oxides from combustion and industry are similar to the barriers for reducing carbon emissions in the relevant sectors (transportation, electricity generation, industry). These include high risks associated with technology performance, and in some cases, outdated fiscal policies that inhibit rather than encourage investment.

- Technical risks in general impede the adoption of new technologies in the industrial sector, particularly where processing performance, productivity, or product quality may be impacted and the effects are uncertain or not well-demonstrated. For both stationary (power plant) and mobile sources (primarily transportation) of emissions, adoption of advanced pollution control technologies may require demonstration and/or validation to overcome high risks of adoption and development.

- Adoption of more efficient technologies that could potentially reduce $\mathrm{N}_{2} \mathrm{O}$ emissions in vehicles faces market risks related to uncertain energy prices. New engine technologies, for example, 
could reduce emissions from freight transport, but market penetration of these is greatly influenced by energy costs.

- Unfavorable fiscal policies such as outdated tax depreciation schedules may adversely influence adoption of new technology in industry by providing disincentives to investment.

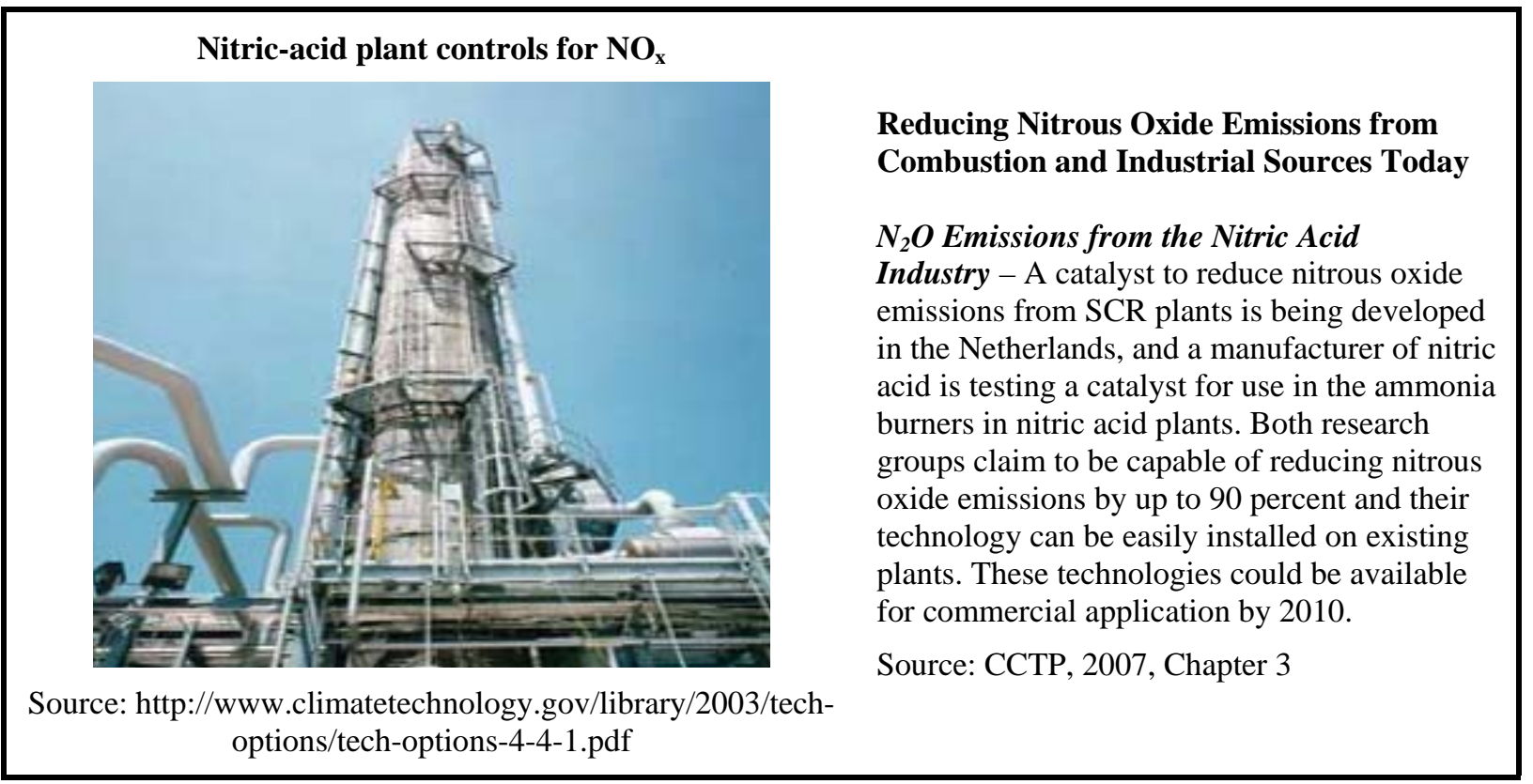

Box 7.14 Nitrous oxide emissions from combustion and industrial sources

Other barriers also may be minimizing the potential of advanced technologies to reduce $\mathrm{N}_{2} \mathrm{O}$ emissions from combustion and industry. These include for example, incomplete and imperfect consumer information and the use of more efficient automotive technologies to support higher levels of weight, acceleration performance, and utility rather than fuel economy. In addition, the long capital lifetimes of existing industrial equipment could delay the adoption of new technology in both the combustion and acid production areas.

\subsection{THE MOST COMMON AND CRITICAL BARRIERS}

Based on the technology vignettes presented in this section, it is clear that many of deployment barriers affect relatively limited numbers of technologies, while others are systemic and economy-wide. For a summary of the breadth of impact of the 20 barriers, see Fig. 7.2, which tallies the number of sectors where each barrier is viewed as either important or critical.

Of the 20 types of barriers listed in Fig. 7.2, the four intellectual property barriers along with fiscal uncertainty and misplaced incentives are found to be important deterrents to technology deployment in two or fewer of the 15 technology sectors. Thus, one can conclude that wholesale elimination of these six barriers would not likely result in widespread deployment of a broad range of GHG-reducing technologies.

On the other hand, there are systemic and economy-wide barriers to the deployment of GHG-reducing technologies that could produce broad deployment benefits if effectively addressed. The most notable among them are external benefits and costs, high costs, and technical risks, which present critical barriers to ten or more of the technology sectors. Extending the discussion to those barriers that were found to be 
critical or important to at least a third of the technology sectors expands the discussion to 10 barriers. This demarcation highlights external benefits and costs, high costs, technical and market risks, lack of specialized knowledge, incomplete and imperfect information, infrastructure limitations, industry structure, unfavorable fiscal policies, and policy uncertainty. Referring back to the six broad categories of barriers, this means that all five of the cost-effectiveness barriers are included along with four of the five "other" barriers. In contrast, only one barrier from the other four categories is found to have broad impact: unfavorable fiscal policy (see Fig. 7.2).

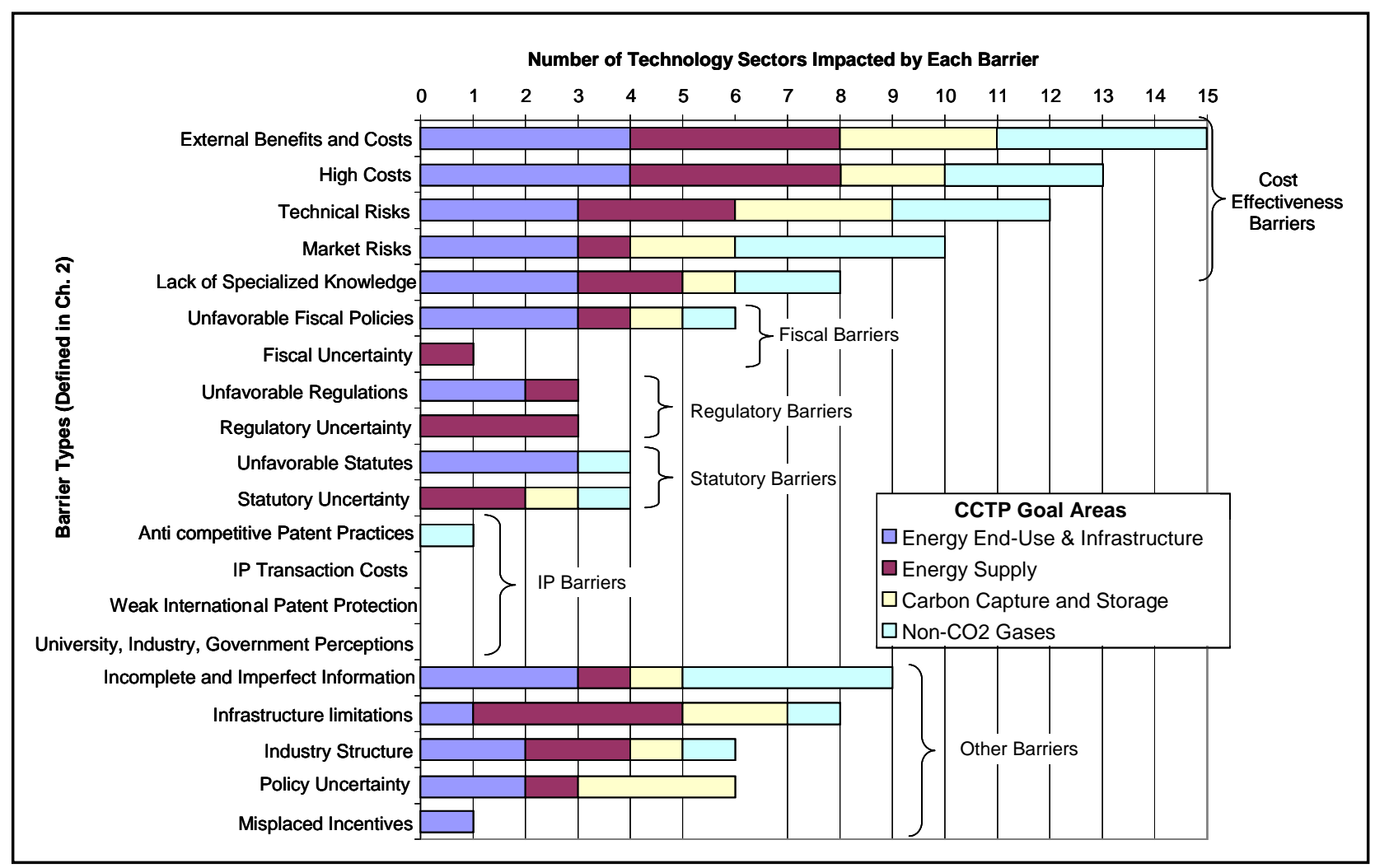

Fig. 7.2. Critical and important barriers by CCTP goal area

High costs associated with the production, purchase and use of many low-carbon technologies appear to critically hamper their commercialization and deployment in 13 CCTP sectors. Recall from Chapter 2 that high costs refer not only to intrinsic features of a technology that raise the costs required to produce or use it (such as extra components needed to deliver the added value or unusually high levels of precision manufacturing), but also to price penalties deriving from related barriers (such as market and technical risks that raise the raise the cost of financing). Costs are also a relative term that depends on the life cycle of a technology: for instance, until learning curves through large-scale production are able to bring costs down, it is often difficult for new technologies to compete with fully-depreciated existing products (Kammen and Nemet 2007).

Technical risks are critical deterrents to the deployment of 10 technology sectors (important in 12), and market risks are critical to seven sectors (important to 10). Together with high costs, all 15 CCTP sectors are handicapped by at least one of these barriers. The deployment of most novel technologies is hindered by technical risks because their performance characteristics are uncertain. Until the technology has been deployed in a full-scale demonstration that resembles a potential user's operational setting, technical uncertainties may forestall adoption and use. Limited market demand is typical of new and emerging 
technologies, where liability and indemnification issues have often not been fully addressed (e.g., the case of plug-in hybrid electric vehicles that void original automaker warranties). Investors may also be concerned that a superior technology could emerge, making the newly commercialized technology obsolete before its useful lifespan has ended. This market risk (also known as dynamic increasing returns) pervades the highly competitive electric and liquid fuels markets where numerous alternatives are being promoted.

External benefits and costs critically constrain the commercialization and deployment of technologies in 10 CCTP sectors and are important deterrents in each of the five others sectors. When the principal benefit provided by a technology is external to the marketplace, as with substitutes for many high GWP gases and for carbon capture and sequestration technologies, significant market penetration is difficult for the technology to achieve without some form of public intervention. Examples include technologies that capture carbon dioxide from waste streams and the storage of carbon dioxide in geologic formations. In several CCTP sectors, prices for emission-reducing technologies are high in comparison to the low price of fossil fuels simply because the latter does not reflect the external costs of GHG emissions. Examples include wind energy and power generated from recycled heat. They produce essentially no greenhouse gas emissions, but they must compete head-to-head with electricity from coal plants that emit large quantities of carbon dioxide without any penalty.

Incomplete and imperfect information (critical in seven sectors and important in eight) and lack of specialized knowledge (critical in five sectors and important in eight) represent another cluster of important barriers. The shortage of technology performance information coupled with decision-making complexities and bundled benefits present key deployment barriers for half of the CCTP sectors. Similarly, inadequate workforce competence compounded by the high cost of developing specialized knowledge throughout the supply chain poses barriers to the deployment for half of CCTP technology sectors.

Infrastructure limitations pose strong obstacles to the deployment of five types of climate change technologies. Supply chain issues and other infrastructure limitations are characteristic of new technologies, which often require new methods of delivering parts, services, and supplies. The underdeveloped infrastructure for delivering alternative transportation fuels to users is a case in point. Wind resource expansion (and any large-scale renaissance of nuclear power) also requires the addition of transmission infrastructure capacity.

Industry structure is critical in two sectors and important in six. On the one hand, industry fragmentation in the buildings industry and agriculture/forestry slows technological change, inhibits coordination, and limits investment. On the other hand, natural monopoly in utilities inhibits the success of distributed generation and energy efficiency in buildings and industry.

Unfavorable fiscal policies are critical barriers to deployment in three technology sectors and are important obstacles in five. For example, distortionary tax subsidies, outdated tax depreciation schedules, and state and local variability in tax incentives and property tax policies are obstacles, as are the tariffs levied by utilities on distributed generators. 
Table 7.1 Major barriers inhibiting deployment of GHG-reducing technologies

\begin{tabular}{|c|c|c|c|c|c|c|c|c|c|c|c|}
\hline $\begin{array}{c}\text { CCTP Goal } \\
\text { Area }\end{array}$ & CCTP Sector & 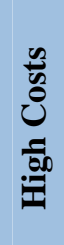 & 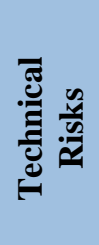 & 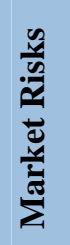 & 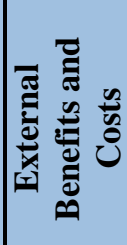 & $\mid \begin{array}{l} \\
\end{array}$ & 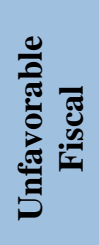 & 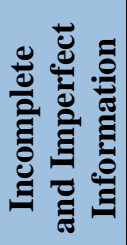 & 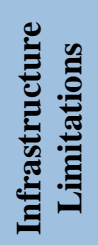 & 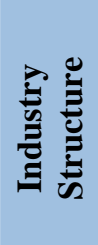 & 总 \\
\hline \multirow{4}{*}{$\begin{array}{l}\text { Energy End- } \\
\text { Use and } \\
\text { Infrastructure }\end{array}$} & Transportation & $\bullet$ & $\bullet$ & $\bullet$ & $\bullet$ & O & & $\bullet$ & $\bullet$ & & \\
\hline & Buildings & $\bullet$ & $\bullet$ & $\bullet$ & O & O & $\bullet$ & $\bullet$ & & $\bullet$ & O \\
\hline & Industry & $\bullet$ & $\bullet$ & $\bullet$ & $\bullet$ & $\bullet$ & O & $\bullet$ & & & \\
\hline & $\begin{array}{l}\text { Electric Grid \& } \\
\text { Infrastructure }\end{array}$ & • & & & $\bullet$ & & $\bullet$ & & & O & O \\
\hline \multirow{4}{*}{$\begin{array}{l}\text { Energy } \\
\text { Supply }\end{array}$} & $\begin{array}{l}\text { Low-Emission, } \\
\text { Fossil-Based } \\
\text { Fuels and Power }\end{array}$ & • & $\bullet$ & & $\bullet$ & & & & O & 0 & O \\
\hline & Hydrogen & $\bullet$ & $\bullet$ & & $\bullet$ & O & & & $\bullet$ & & \\
\hline & $\begin{array}{c}\text { Renewable } \\
\text { Energy \& Fuels }\end{array}$ & $\bullet$ & O & • & $\bullet$ & & • & $\bullet$ & $\bullet$ & O & \\
\hline & Nuclear Fission & $\bullet$ & & & 0 & $\bullet$ & & & $\bullet$ & & \\
\hline \multirow{3}{*}{$\begin{array}{c}\text { Carbon } \\
\text { Capture and } \\
\text { Sequestration }\end{array}$} & Carbon Capture & $\bullet$ & $\bullet$ & & $\bullet$ & & & & $\bullet$ & & O \\
\hline & $\begin{array}{l}\text { Geologic } \\
\text { Storage }\end{array}$ & & • & 0 & $\bullet$ & & & O & O & & • \\
\hline & $\begin{array}{c}\text { Terrestrial } \\
\text { Sequestration }\end{array}$ & $\bullet$ & O & O & $\bullet$ & $\bullet$ & O & & & $\bullet$ & O \\
\hline \multirow{4}{*}{$\begin{array}{c}\text { Non- } \mathrm{CO}_{2} \\
\text { Greenhouse } \\
\text { Gases }\end{array}$} & $\begin{array}{c}\text { Methane } \\
\text { Emissions from } \\
\text { Energy and } \\
\text { Waste }\end{array}$ & • & • & • & O & & & $\bullet$ & $\bullet$ & & \\
\hline & $\begin{array}{c}\text { Methane and } \\
\text { Nitrous Oxide } \\
\text { Emissions from } \\
\text { Agriculture } \\
\end{array}$ & • & $\bullet$ & $\bullet$ & O & • & & $\bullet$ & & 0 & \\
\hline & $\begin{array}{c}\text { Emissions of } \\
\text { High Global- } \\
\text { Warming } \\
\text { Potential Gases } \\
\end{array}$ & • & & 0 & $\bullet$ & • & & $\bullet$ & & & \\
\hline & $\begin{array}{c}\text { Nitrous Oxide } \\
\text { Emissions from } \\
\text { Combustion and } \\
\text { Industry } \\
\end{array}$ & & • & $\bullet$ & O & & $\bullet$ & O & & & \\
\hline \multicolumn{2}{|c|}{ Totals } & 13 & 12 & 10 & 15 & 8 & 6 & 9 & 8 & 6 & 6 \\
\hline
\end{tabular}

*This table lists the 10 barriers judged to be critical $(\bullet)$ or important $(O)$ obstacles to the deployment of five or more of the 15 types of technologies (i.e., CCTP sectors). Symbols indicate that a barrier is judged to be a critical or important obstacle to the deployment of technologies in a particular CCTP sector. 
Policy uncertainty is most imperative to those technologies which stand to gain (or their competitors to lose) substantial ground from implementation of consistent policies regarding GHG emissions. While it is assumed to be critical to only one technology sector, geologic storage, uncertainty for future GHG treatment is important to a third of the technology sectors. Like high costs, policy uncertainty increases risks for technologies and retards progress in development of GHG mitigating technologies.

Tackling these ten common obstacles in a broad fashion could significantly accelerate and expand the uptake of GHG-reducing technologies. In some instances, economy-wide actions may be more efficient in addressing common barriers than targeted, specific policy instruments.

Characterizing barriers more broadly by CCTP goal area reinforces some of the key differences (Table 7.2). While all four CCTP goal areas are impacted by high costs and technical risks, the deployment barriers they face are otherwise quite distinct. For example:

- Unfavorable fiscal policies are important barriers to deployment in the energy end-use areas. Because most utilities lack cost-recovery mechanisms for energy-efficiency investments, electric utilities and wires companies in most states experience revenue erosion when they promote energy efficiency. This impedes utility investments in programs to promote efficient buildings and industrial practices.

- Incomplete and imperfect information is a major deterrent to the deployment of end-use technologies and non- $\mathbf{C O}_{2}$ GHG emission reduction. Energy end users lack trusted and reliable information and face decision-making complexities. Familiarity with the performance and availability of substitutes for high-GWP gases, and ways to reduce GHG emissions from agriculture and from industrial combustion is often lacking.

- Infrastructure limitations are a key obstacle to carbon capture and storage technologies, which require the development of carbon dioxide pipelines or other means of transport as well as the creation of an industrial supply chain. Similarly, all four low-carbon energy supply sectors are impacted by infrastructure limitations including the lack of a long-term nuclear waste repository, underdeveloped distribution systems for alternative transportation fuels, and insufficient grid capacity to connect regions of high renewable resources with urban concentrations of electricity demand. Infrastructure limitations are also present as supply chain gaps in most of these same sectors.

- Industry structure is an important hindrance to energy end-use and infrastructure technologies and to low-carbon energy supply technologies. Industry fragmentation in the buildings industry slows technological change, inhibits coordination and limits investment. Natural monopolies in the power industry is such that newer, smaller types of power production are often overlooked in favor of large power sources.

- Policy uncertainty is a critical barrier to the deployment of carbon capture and storage technologies. As long as there is policy uncertainty associated with GHG emissions, investment in technologies to capture and sequester $\mathrm{CO}_{2}$ will be limited.

The uniqueness of the barriers faced by different types of technologies suggests that a portfolio of numerous, highly differentiated deployment activities may be required. At the same time, economy-wide actions can be more efficient in addressing common barriers in a broad, systematic fashion in ways that could significantly accelerate and expand the uptake of GHG-reducing technologies. This tension between highly specific versus general policy interventions requires careful consideration. 
Table 7.2. Major barriers inhibiting deployment by CСTP goal area*

\begin{tabular}{|c|c|c|c|c|c|c|c|c|c|c|}
\hline $\begin{array}{l}\text { CCTP Goal } \\
\text { Area }\end{array}$ & 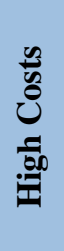 & 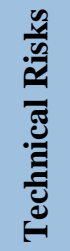 & 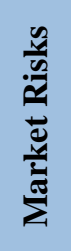 & 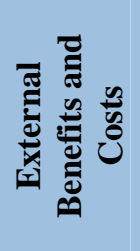 & 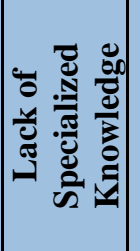 & 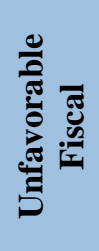 & 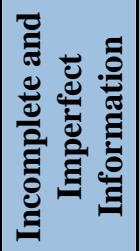 & 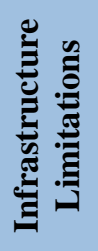 & 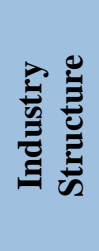 & 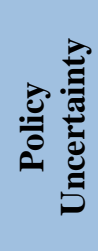 \\
\hline $\begin{array}{l}\text { Energy End-Use } \\
\text { and Infrastructure }\end{array}$ & $\checkmark$ & $\checkmark$ & $\checkmark$ & $\checkmark$ & $\checkmark$ & $\checkmark$ & $\checkmark$ & & $\checkmark$ & $\checkmark$ \\
\hline Energy Supply & $\checkmark$ & $\checkmark$ & & $\checkmark$ & $\checkmark$ & & & $\checkmark$ & $\checkmark$ & \\
\hline $\begin{array}{l}\text { Carbon Capture } \\
\text { and Sequestration }\end{array}$ & $\checkmark$ & $\checkmark$ & $\checkmark$ & $\checkmark$ & & & & $\checkmark$ & & $\checkmark$ \\
\hline Non- $\mathrm{CO}_{2}$ GHGs & $\checkmark$ & $\checkmark$ & $\checkmark$ & $\checkmark$ & $\checkmark$ & & $\checkmark$ & & & \\
\hline
\end{tabular}

*Checks indicate that a barrier is judged to be a critical or important obstacle to the deployment of two or more CCTP sectors within a particular CCTP goal area.

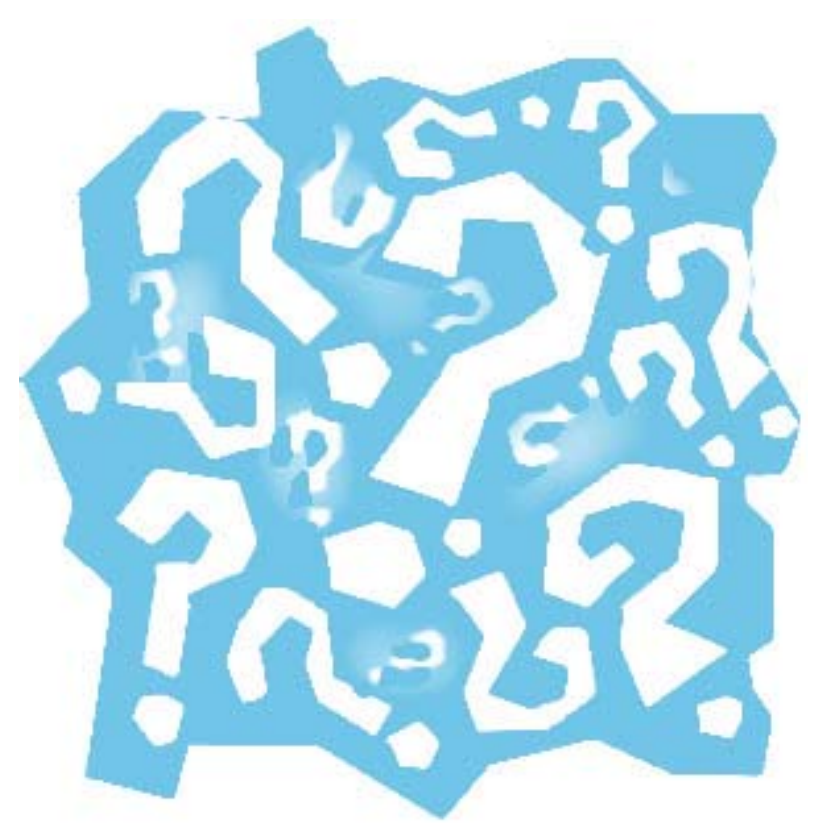




\section{8}

\section{A thorough \\ understanding of \\ technology \\ deployment barriers \\ is a necessary \\ precondition for the \\ effective design and \\ continuous \\ improvement of \\ climate policy.}

\section{Conclusions and Recommendations}

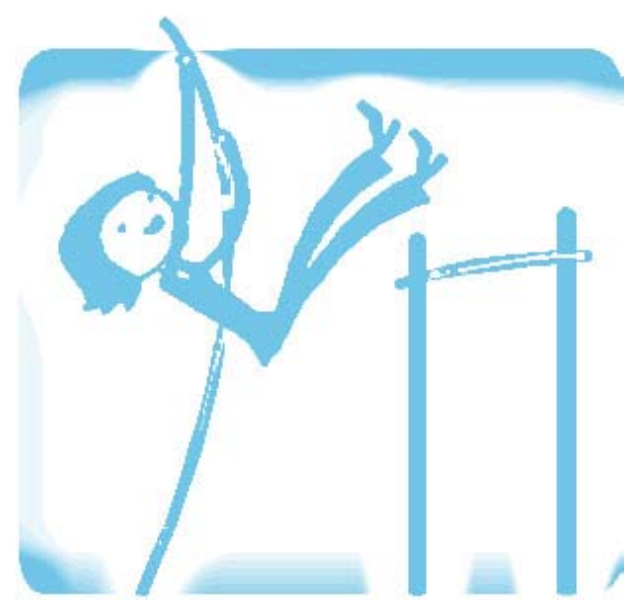

Having described the scope and range of barriers to deployment, this section considers how easily and effectively each barrier can be addressed. It does this by first considering whether or not deployment barriers are part of an interrelated system of impediments or simply a sum of numerous isolated effects. We then describe some of the policy and program options available to address each of the six categories of barriers. This section ends by offering some overarching conclusions about the need to address deployment barriers in order to prevent large-scale global climate disruption. 


\subsection{INTER-RELATED SYSTEMS OF BARRIERS}

Market forces and individual economic interests have created U.S. energy markets that are adept at absorbing new technologies, particularly in contrast to the more sluggish technology advancement typical of developing countries. Nevertheless, there is much room for improvement. Most of the 50 or so barriers to deployment identified in this report are components of inter-related and reinforcing systems that hinder technology commercialization and deployment. In aggregate, they "lock-in” carbon-intensive technologies by:

- providing support systems for incumbent technologies,

- escalating the business risks of innovation, and

- increasing transaction costs associated with change.

These powerful and reinforcing influences are illustrated in Fig. 8.1.

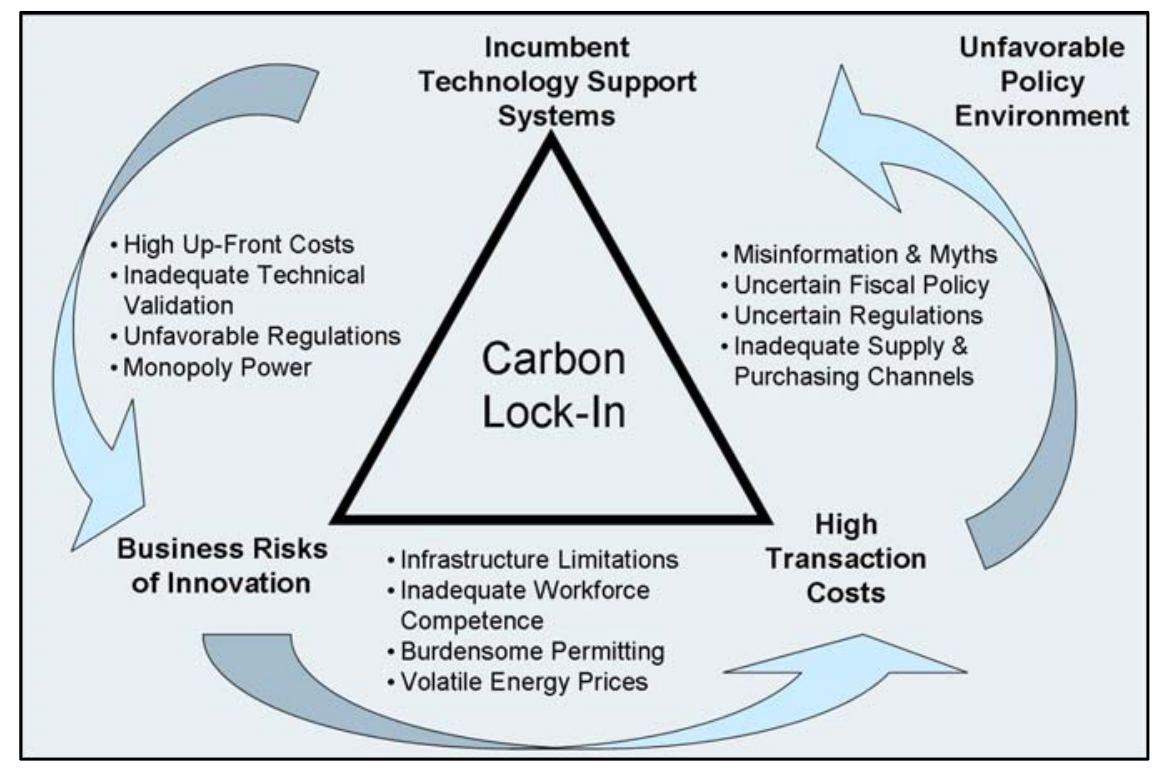

Fig. 8.1 Iron triangle of barriers

Incumbent technology support systems. A general resistance to change contributes to technological inertia and support for the status quo even in the face of superior substitutes. Newer technologies generally come with different infrastructure and supply chain requirements and often rely on complementary technologies that may or may not yet exist (e.g., energy storage technologies to address the intermittency of wind power). Existing regulatory and fiscal policies can also impede the transformation of energy systems by favoring incumbent technologies. To explain this system of barriers, Unruh (2000) notes that positive feedback between government institutions and existing technological systems can deter change and can lock-out alternative technologies for extended periods. Lock-in is also reinforced by financial institutions, which prefer to make loans to companies with collateral and the ability to repay debts - characteristics of successful firms with incumbent technologies.

Business risks of innovation. Inventions and innovations face an array of obstacles in the marketplace, and since many GHG-reducing technologies are relatively new, these obstacles can strongly impact them. In general, these barriers decline as technologies mature. Experience gained by manufacturers, technical 
workers, and early adopters can alleviate some risks, and this learning process generally results in lower costs. Further, as technologies become better known, bankers, insurers, and regulators also gain confidence in them. Technological improvements drive costs down, and early commercial deployments can stimulate these improvements. When business risks are not addressed, they can remain as barriers and stifle or indefinitely delay commercialization and/or deployment.

High transaction costs. Transaction costs associated with the adoption of new technologies are often high because streamlined regulatory processes, user-friendly sources of information, and full-service vendors are not yet available. The costs of gathering and processing information, developing a patent portfolio, and designing and enforcing contracts relating to the purchase and installation of GHG-reducing technology can all be prohibitive. These costs are real, in the sense that they must be borne by the consumer, and should be considered part of the cost of the GHG-reducing measure. A key question is whether there are institutional interventions that can reduce these costs for individual consumers. For example, ENERGY STAR ${ }^{\circledR}$ labeling of additional appliances, standardized procedures for obtaining offshore wind permits, and clarifying property laws relative to methane and carbon dioxide would all reduce transaction costs.

These three types of influences operate in a policy environment that can hinder technological progress. GHG-reducing technologies are often subjected to unfavorable treatment by fiscal, regulatory and statutory policies, and they are impacted by policy uncertainty that causes marketplace inefficiencies and a reluctance to innovate. GHG-reducing technologies are often subjected to unfavorable treatment by regulations and statutes. Distortionary policies are not necessarily intentional, but rather often develop incrementally over time as historical systems are gerry-rigged to deal with new circumstances. A particularly important attribute of today's policy environment is the lack of policy mechanisms to internalize the positive and negative externalities associated with GHG emissions. Finally, the current environment of policy uncertainty is causing marketplace inefficiencies and a reluctance to innovate, which hinders the deployment of novel carbon-mitigation technologies.

Tackling these systematic forces requires different forms of intervention. For example, overcoming lockin of incumbent technologies suggests the need to ensure that channels of communication to policymakers extend beyond lobbyists for incumbent technologies. Overcoming business risks of innovation requires reduction of costs and financing hurdles and would benefit greatly from an expanded public-private program of pilot-scale energy demonstrations. To reduce the high transaction costs that hinder new technologies and products, streamlining the policy process to expedite permitting and other "qualifying" procedures would be helpful. A vigorous campaign of policy reform is needed to create a consistent, effective, and predictable policy environment where clear and reinforcing signals encourage the infusion of GHG-reducing technologies. Although policy and program recommendations were not the main focus of this report, the concluding chapter does describe some of the options available to address the numerous barriers and forces that impede the progress of GHG-reducing technologies. Many of these policy options are described in the following section.

\subsection{POTENTIAL SOLUTIONS AND METHODS TO REDUCE BARRIERS}

The "market-failure model” guiding public policy debates today suggests that markets should be left alone by government unless market failures are discovered (Taylor and Van Doren, 2007). In competitive and efficient markets, suppliers produce what consumers want and are willing to pay for. However, when market failures exist, prices do not accurately reflect total costs, and it is legitimate to consider public intervention. This review of barriers has shown that numerous imperfections exist related to features of markets, institutions, producers and consumers that distort market prices and inhibit socially optimal levels of investment in GHG-reducing technologies. 
The "market-failure model” also notes that the existence of market failures is not a sufficient justification for government involvement. In some instances, feasible, low-cost policies can be implemented, enabling markets to operate more efficiently to the benefit of society. But in other instances, policies may not be feasible; they may not fully eliminate or compensate for the targeted barrier or imperfection; or they may be very costly (Bozeman, 2002; Brown et al., 2001; Prindle, 2007). Only where feasible and costeffective policies are available, is public intervention justified.

In a recent study to evaluate policies for encouraging deployment of renewable or more efficient energy technologies, Lund (2007, p. 636) found that subsidy-type measures were an order of magnitude more effective than catalytic-type measures, which are "procurement and business development support"). He offers that this result may be due to the difference in technologies addressed by the measures as subsidytype measures were mostly used for energy supply and catalytic-type for end-use technologies. This analysis appears to be the most comprehensive policy evaluation attempted for deployment activities for clean energy technologies as it covers 20 policy cases from several countries and sectors and compares their lifetime energy impact and cost-effectiveness.

Some analysts have concluded that many energy policies to date have not been low cost (Newell, 2006). Others note that energy policies and programs have rarely been thoroughly evaluated. ${ }^{78}$ This report enumerates a broad range of "policy failures" in the form of unfavorable fiscal, regulatory, and statutory policies. It has also identified numerous policy inconsistencies across states, over time, between energy resources, and across technologies that are a hindrance to the smooth operation of markets and the deployment of GH- reducing technologies. Thus, one overarching solution is to move toward a more consistent, uniform, and predictable policy portfolio that will provide a supportive national environment for expanding the uptake of GHG-reducing technologies.

Federal deployment activities already focus on many of the specific barriers that prevent new technologies and practices from gaining widespread commercial use. By addressing these key barriers, the activities help to enable market entry of GHG-reducing technologies such as hybrid cars, highefficiency buildings, industrial processes, coal-based integrated gasification-combined cycle power plants, and methane capture and use technologies. In the following sections, we provide an overview of some of the policy options that might be considered to address the remaining six types of barriers described in this report.

\subsubsection{Potential Solutions to Cost-Effectiveness Barriers}

The absence of a market price for GHG emissions and the high cost of climate mitigation technologies relative to existing alternatives are the two most notable barriers identified in this study. Unlike many of the barriers that are specific to individual technologies or sectors, these obstacles are economy-wide. A carbon cap and trade system, carbon tax, or other policy mechanisms for internalizing externalities in energy prices could help address cost-effectiveness barriers connected to unpriced costs and benefits related to carbon emissions. For instance, the federal government could institute an economy-wide carbon cap and trade system on carbon emissions, as has been proposed by the National Commission on Energy Policy (2007). Such an approach would increase the competitiveness of low-carbon fuels and would place greater value on carbon capture and sequestration projects.

High costs are also a function of technical risks, which suggest policy interventions such as increased support for public-private R\&D collaborations and demonstrations as well as greater documentation of

\footnotetext{
${ }^{78}$ In addition, many argue that policies have not been adequately evaluated by measuring consumer surplus (i.e., the difference between how much a consumer is willing to pay for a commodity such as global climate change mitigation and the amount that the consumer actually pays when a policy is implemented) (Braithwait and Caves, 1994).
} 
technology performance. Given the impact of "learning by doing,” stronger local, state, and federal government procurement policies that create early markets for GHG-reducing technologies can also be effective.

Insufficient investment and lack of capital could be addressed by expanded RD\&D activities, and by more aggressive tax subsidies, loan guarantees, and low-interest federal loans for GHG-reducing technologies. In addition, federally funded scholarships for engineers and scientists wishing to pursue careers in fields related to GHG mitigation, such as advanced energy production sciences, agriculture management, or forestry could at least partially address the lack of specialized knowledge.

\subsubsection{Potential Solutions to Fiscal Barriers}

To respond to fiscal policy uncertainties, a decade-long extension of federal production tax credits for renewable, clean coal, and nuclear power generation would stabilize investment trends in these industries. Private-sector investment will respond to market-based incentives created by federal policy only to the extent that these federal policies are perceived to be credible, lasting, and reasonably stable.

To respond to fuel price risks and distortionary fiscal policies, a federal renewable portfolio standard (RPS) or sustainable energy portfolio standard (SEPS) could be introduced (Cooper and Sovacool, 2007; Brown, York, and Kushler, 2007). If the federal RPS or SEPS included a national credit trading scheme, such a proposal would further increase the vitality of clean energy investments by letting the market tap the abundance of clean energy resources (including energy efficiency improvements) wherever they are located. Such a proposal would encourage GHG-reducing technologies to be adopted in the most economical locations.

Slow capital turnover is another barrier that has broad implications and where fiscal measures could be impactful. Capital turnover can be accelerated by taxing consumption more and income less. This could be accomplished, for instance, by decreasing taxes on income from capital investments. There is a variety of policy choices that could reduce the effective marginal tax rate on capital investments.

\subsubsection{Potential Solutions to Regulatory Barriers}

Most of the regulatory barriers identified in this report affect relatively limited portions of the market. As a result, the remedies are also more highly targeted. While such remedies may have limited impacts individually, reforming all of the regulatory obstacles could significantly accelerate the deployment of carbon mitigating technologies.

For example, uniform guidelines for regulating carbon capture and storage (CCS) projects would facilitate deployment of this key GHG-reducing technology. A national guideline (instead of state-to-state guidelines) on net-metering policies would also give favorable signals to GHG-reducing technologies. Streamlining the permitting processes for off-shore wind development and for certifying nuclear waste confidence would also be helpful. A review of the universal ban on private electric wires crossing public streets would open up an important discussion that could enable greater waste heat utilization via distributed generation systems. In addition, the nation's current regulatory approach to air pollution using "input-based emission standards" and exempting older power plants from meeting New Source Performance Standards - needs to be reformed. Finally, fixing distortionary features of CAFE standards could significantly improve the energy efficiency of new vehicles. 


\subsubsection{Potential Solutions to Statutory Barriers}

As with regulatory barriers, the statutory barriers identified in this report affect relatively limited portions of the market. As a result, the remedies are also more highly targeted, but their overall impact could be significant.

Upgrading state building codes and strengthening their enforcement could greatly improve the energy integrity of new buildings. Clarifying the property ownership of subsurface resources and eliminating other uncertainties regarding the legal status of GHGs and property ownership could promote methane recovery and carbon sequestration technologies. Finally, modernizing state procurement policies to enable energy-saving performance contracts would facilitate the financing of GHG-reducing technologies.

Another key to substantial GHG reductions is to get all policies, funding, incentives, practices, rules, codes, and regulations pointing in the same direction to create the right conditions for smart urban growth. Zoning ordinances and land use planning need to enable mixed-use transit-oriented development in contrast to today's low-density, carbon intensive, automobile-dominated urban environments.

\subsubsection{Policy Options to Address Intellectual Property Issues}

Non-exclusive and compulsory licensing, “obligations to use," cross licenses, patent pools, and trade agreements have been proposed as potential remedies to some of the intellectual property barriers discussed in this report. To respond to anti-competitive patent practices such as warehousing, suppression, and patent blocking, Wiener (2006) notes that the government can force companies to create nonexclusive or compulsory licenses for products that have a significant public health context. ${ }^{79}$

As another potential solution to suppression and patent blocking, Rayle (2000) notes that Germany has initiated an "obligation to use" mandate for all new patents. Even though such a mandate could reduce the incentives for firms to patent or innovate in the first place, Rayle argues that the "obligation to use" requirement drastically cut down on the number of patent applications, triggering relief for the German Patent Office and the Federal Patent Court, and restricted the use of both warehousing and suppression. The requirement also increased the efficiency of German innovation in science and technology, since patents were only issued to technologies being diffused into the marketplace. The obligation prevents the proprietor from enforcing their trademark rights if they do not use the patent within five years of registration. Further, any person has standing to seek legal action for cancellation of a patent that has not been used.

Patent pools may help reduce patent blocking as long as holders of blocking patents are incentivized to join. Such pools occur when two or more companies control patents but at least some of the potential manufacturers do not hold licenses to use such patents. A patent pool or package license incorporates an entire group of patent holders so that they operate according to a single license, or jointly license complementary patents and divide up the proceeds. ${ }^{80}$

\footnotetext{
${ }^{79}$ Section PP5-6 of the World Trade Organization's Declaration on Trade Related Aspects of Intellectual Property (TRIPS) supports the ability for governments to compulsory license products in furtherance of public interest. The idea is also supported by the United Nation's Agenda 21. Davis (2004) notes that the U.S. has used compulsory licensing before in 1956 to require the American Telephone and Telegraph Company and International Business Machines to cross-license their fundamental patents to all qualified applicants at reasonable fees.

${ }^{80}$ One classic example is the creation of the Manufacturers Aircraft Association in 1917 to license a number of patents necessary for the production of airplanes (patents had previously been controlled separately by the Wright-Marin Aircraft Corporation and the Curtiss Aeroplane \& Motor Corporation). More recently, Gallini (2002) notes that the Department of Justice has recently approved patent pools necessary for the diffusion of MPEG-2 video compression technology and DVDs.
} 
To overcome weak international IPR protection, the Office of the U.S. Trade Representative (2006) recommends creating bilateral or multilateral trade agreements to complement and enhance international standards for the protection of intellectual property rights.

\subsubsection{Potential Solutions to Other Barriers}

The "other" barriers highlighted in this section pertain to incomplete and imperfect information, infrastructure limitations, industry structure, and misplaced incentives. As with the barriers already discussed, some of these are amenable to policy intervention while the policy solutions for others are less straightforward.

Information programs are key to helping producers and consumers make more informed decisions. These programs can take three basic forms: generic information applicable to all energy decision (such as how to calculate life-cycle savings and forecasts of future energy prices), comparative information on alternative technology and product choices (such as product ratings and labeling); and producer- and consumer-specific recommendations for investment or changes in practices (such as industrial energy assessments of manufacturing facilities and building energy audits).

A transmission portfolio standard (TPS) could respond to the grid infrastructure gap hindering the growth of distributed generation. In addition, flexible firm pricing could make better use of the existing grid as an interim fix to the addition of more transmission capacity.

The natural monopoly of electric utilities in many states has created a number of tariffs, pricing policies, rate structures, and rules that contribute to the "lock-in" of incumbent technologies. These barriers to innovation need to be tackled one-by-one. The barriers to innovation that are inherent in highly fragmented industries such as construction and agriculture make information exchange difficult. The federal government can address information gaps by providing reliable and user-friendly information about the performance and availability of GHG-reducing technologies.

Misplaced incentives are difficult to solve through voluntary or information programs, and their existence is often cited as justification for regulatory interventions such as building codes and appliance standards.

\subsection{CONCLUSIONS}

This report has identified and described more than 50 barriers to the commercialization and deployment of GHG-reducing technologies. These barriers impede progress across the range of GHG-reducing technologies and operate at every stage of the commercialization and deployment process. While many of these barriers are critical only to a handful of technology areas, some of them have economy-wide impacts. At a high level of aggregation, it is useful to think about the numerous barriers in terms of their overlapping and reinforcing impacts relating to: support systems for incumbent technologies, business risks of innovation, and high transaction costs, all operating within an environment of policy uncertainty regarding the treatment of greenhouse gases.

A thorough understanding of technology deployment barriers is a necessary precondition for the effective design and continuous improvement of climate policy. Many traditional policy mechanisms have proven effective in the past, innovative climate policies are being launched in local and state testbeds, and novel approaches are being considered at the federal scale and in other countries. By designing these policies to address the specific commercialization and deployment barriers impeding the progress of GHG-reducing technologies, the immense economic and technical potential of these technologies can be more fully realized. 



\section{References}

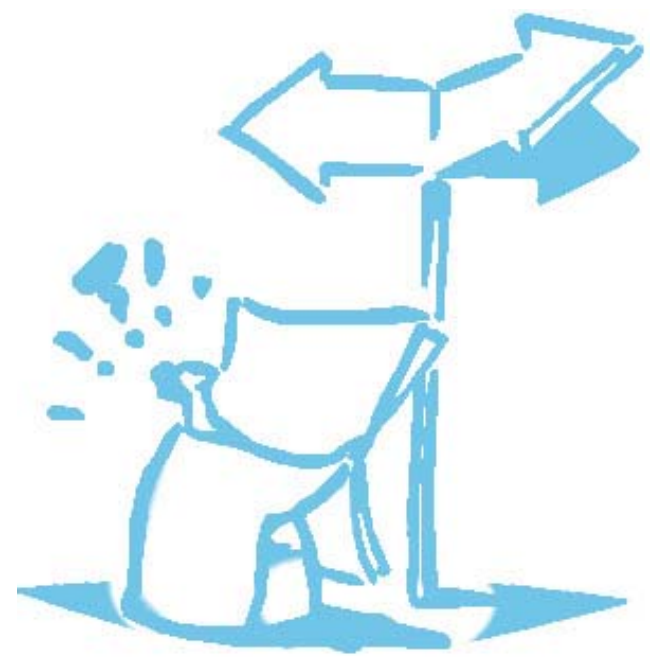

Ag Energy Working Group. 2004. Agriculture’s role in ensuring U.S. energy independence. www.agenergy.info/, accessed 7/3/07.

Agres, Ted. 2006. "USPTO Proposes Controversial Patent Filing Changes,” The Scientist 20(3): 80.

Alderfer, R. Brent and Thomas J. Starrs. 2000. "Making Connections: Case Studies of Interconnection Barriers and Their Impact on Distributed Power Projects.” National Renewable Energy Laboratory Report NREL/SR-200-28053. Golden, CO: NREL.

Allen, Anthony. 2002. "The Legal Impediments to Distributed Generation.” Energy Law Journal, 23: 505-523. 
Alliance to Save Energy. 2005a. Sales Tax Holiday for Energy-Efficient Products. http://www.ase.org/content/article/detail/2643, accessed 11/29/06.

Alliance to Save Energy. 2005b. Blueprint for Energy-Efficiency Acceleration Strategies for Buildings in the Western Hemisphere, Washington, DC: Alliance to Save Energy.

American Wind Energy Association (AWEA). 2007. U.S. Installed Wind Capacity, 1981 to 2006. http://www.awea.org/projects/, accessed 7/12/07.

Appleby, A.J. 1996. “Fuel Cell Technology: Status and Future Prospects,” Energy 21 (7/8): 521-653.

Arent, Doug. 2006. Personal communication (telephone interview). Center Director, Strategic Energy Analysis Center, National Renewable Energy Laboratory (NREL), 10/27.

Argyres, Nicholas S. and Julia Porter Liebeskind. 1998. "Privatizing the Intellectual Commons: Universities and the Commercialization of Biotechnology," Journal of Economic Behavior \& Organization 35: pp. 427-454.

Astebro, Thomas B., Massimo G. Colombo, and Raffaello Seri. 2005. “The Diffusion of Complementary Technologies: An Empirical Test,” http://papers.ssrn.com/sol3/papers.cfm?abstract_id=690981, accessed 7/3/07.

Baer W.S., L.L. Johnson, and E.W. Merrow. 1977. “Government sponsored demonstrations of new technologies," Science 196(4293): 950-957.

Bane, P. William and Nathan Blain. 2001. "Surviving the Valley of Death,” Telephony 240: 1270.

Banales-Lopez, Santiago and Vicki Norberg-Bohm. 2002. "Public Policy for Energy Technology Innovation: A Historical Analysis of Fluidized Bed Combustion Development in the USA," Energy Policy 30: 1173-1180.

Barash, Irv. 2007. Personal communication (telephone interview). President, Vencon Management, Inc., 1/19.

Bastani, Behfar and Dennis Fernandez. 2002. “Intellectual Property Rights in Nanotechnology,” Thin Solid Films 420: pp. 472-477.

Beck, F. and E. Martinot. 2004. "Renewable Energy Policies and Barriers” in Encyclopedia of Energy, Cutler Cleveland, ed. Academic Press/Elsevier Science.

Berg, D.R. and Ferrier, G. 1998. "Meeting the challenge: U.S. industry faces the 21 century. The U.S. environmental industry final report.” Technical Report PB--99-111593/XAB. Department of Commerce, Washington, DC.

Bishop, J.T. 1998. The Economics of Non-Timber Forest Benefits: An Overview. International Institute for Environment and Development, Environmental Economics Programme.

Blind, Knut and Nikolaus Thumm. 2004. "Interrelation Between Patenting and Standardization Strategies: Empirical Evidence and Policy Implications,” Research Policy 33: 1583-1598. 
Bliss, Kevin. 2005. Carbon Capture and Storage: A Regulatory Framework for States Summary of Recommendations. Oklahoma City, OK: Interstate Oil and Gas Compact Commission.

Bird, L and B. Swezey. 2006. Green Power Marketing in the United States: A Status Report (9th Ed.). http://www.eere.energy.gov/greenpower/resources/pdfs/40904.pdf, accessed 11/8/07.

Bozeman, Barry. 2002. “Public-Value Failure: When Efficient Markets May Not Do,” Public Administration Review, 62(2), 134-151.

Braithwait, S., and D. Caves. 1994. "Three biases in cost-efficiency tests of utility energy efficiency programs.” The Energy Journal 15(1): 95-120.

Braitsch, Jay. 2007. Personal communication (telephone interview). Director of Strategic Planning, Fossil Energy, U.S. Department of Energy, 2/5.

Branscomb, L. M. 1993. "National Laboratories: The Search for New Missions and New Structures," in L.M. Branscomb, ed. Empowering Technology: Implementing A U.S. Strategy. Cambridge, MA: MIT Press, pp. 103-134.

Brent, Richard. 2003. “A Blueprint for DG: Presenting a Fair and Simple Distributed Generation Plan for Utilities and Policymakers.” Public Utilities Fortnightly January 1, p. 28-41.

Brent, Richard. 2006. Personal communication (telephone interview). Vice President, Solar Turbines, Inc., 11/8.

Brooks, Harvey. 1993. "Research Universities and the Social Contract for Science," in L.M. Branscomb, ed. Empowering Technology: Implementing A U.S. Strategy. Cambridge, MA: MIT Press, pp. 202-234.

Brooks, H. 1994. "What we know and do not know about technology transfer," in Marshalling Technology for Development. Natural Resource Council and the World Bank.

Brown, David. 2007. Personal communication (telephone interview). Exelon Corporation, 2/1.

Brown, M.A. 2001. "Market Failures and Barriers as a Basis for Clean Energy Policies,” in Energy Policy, 29 (14): 1197-1207.

Brown, M.A. 2004. “Obstacles to Energy Efficiency,” Encyclopedia of Energy, Elsevier, London, U.K., Volume 4, pp. 465-475.

Brown, M.A. 2007. Energy Myth One - Today’s Energy Crisis is "Hype” in Sovacool, B. K. and Brown, M. A. (eds.) Energy and American Society - Thirteen Myths. New York: Springer Publishing Company, pp. 23-50.

Brown, Marilyn A., Harold C. Livesay, David S. Lux and C. Robert Wilson, 1993. "Demonstrations: The Missing Link in Government-Sponsored Energy Technology Deployment,” Technology in Society, 15 (2), 185-205.

Brown, M.A., M.D. Levine, W. Short, and J.G. Koomey. 2001. "Scenarios for a Clean Energy Future,” Energy Policy, 29(14): 1197-1207. 
Brown, Marilyn A., Frank Southworth and Therese K. Stovall. 2005. "Towards a Climate-Friendly Built Environment,” Pew Center on Global Climate Change. http://www.pewclimate.org/docUploads/Buildings\%5FFINAL\%2Epdf, accessed 11/9/06.

Brown, M.A., M. Antes, C. Franchuk, B.H. Koske, G. Michaels, J. Pellegrino. 2006. "Results of a Technical Review of the U.S. Climate Change Technology Program's R\&D Portfolio,” Oak Ridge, TN: Oak Ridge National Laboratory, www.ornl.gov/eere/PDFs/CCTP_Wkshp_Rpt_6-28Final.pdf, accessed 8/1/07.

Brown, M.A., Dan York, Martin Kushler. 2007. “Are RPS Ready for the National Stage?” the Electricity Journal, Vol. 20, Issue 4, 62-72.

California. 2006. AB32: An act to add Division 25.5 (commencing with Section 38500) to the Health and Safety Code, relating to air pollution. http://www.leginfo.ca.gov/pub/05-06/bill/asm/ab_00010050/ab_32_bill_20060927_chaptered.pdf, accessed 11/27/06.

Canepa, A. and P. Stoneman. 2004. "Financing Constraints in the Inter Firm Diffusion of New Process Technologies." The Journal of Technology Transfer 30:1 159-169.

Carbon Trust. 2005. The UK Climate Change Programme: Potential Evolution for Business and the Public Sector. http://www.carbontrust.co.uk, accessed 11/13/07.

Casten, T.R. and R.U. Ayres. 2007. Energy Myth Eight - Worldwide Power Systems are Economically and Environmentally Optimal in Sovacool, B. K. and Brown, M. A. (eds.) Energy and American Society - Thirteen Myths. New York: Springer Publishing Company, pp. 201-237.

Clarke, L., M. Wise, M. Placet, C. Izaurralde, J. Lurz, S. Kim, S. Smith, and A. Thomson. 2006. Climate Change Mitigation: An Analysis of Advanced Technology Scenarios. Richland, WA: Pacific Northwest National Laboratory.

Coakley, Sue. 2006. Personal communication (telephone interview). Director, Northeast Energy Efficiency Partnerships, 11/13.

Cohen, Linda R. and Roger G. Noll. 1996. “The Future of the National Laboratories,” Proceedings of the National Academy of Sciences 93(23): 12678-12685.

Cohen, Wesley M. Richard R. Nelson, and John P. Walsh. 2000. "Protecting Their Intellectual Assets: Appropriability Conditions and Why U.S. Manufacturing Firms Patent (Or Not)," National Bureau of Economic Research Working Paper 7552.

Cohen, Wesley M. Akira Goto, Akiya Nagata, Richard R. Nelson, and John P. Walsh. 2002. "R\&D Spillovers, Patents, and the Incentives to Innovate in Japan and the United States," Research Policy 31: pp. 1349-1367.

Colorado. 2005. Colorado Agricultural IOF Technology Assessments: Precision Agriculture and Anaerobic Digestion. State of Colorado, Governor's Office of Energy Conservation and Management. http://ewb-kansas-state.wikispaces.com/space/showimage/Anaerobic+Digestion+Typical+Plant.pdf, accessed 11/8/07. 
Congressional Budget Office (CBO). 2003. The Economics of Climate Change: A Primer. Washington, DC, http://www.cbo.gov/ftpdocs/41xx/doc4171/04-25-ClimateChange.pdf, accessed $7 / 21 / 07$

Cook, J.H., Beyea, J., and Keeler, K.H. 1991. Potential impacts of biomass production in the United States on biological diversity. Annual Review of Energy and the Environment, 16, 401-431.

Cooper, Christopher and Benjamin Sovacool. 2007. "Renewing America: The Case for Federal Leadership on a National Renewable Portfolio Standard (RPS),” Network for New Energy Choices, Report No. 01-07. Foreward by Marilyn A. Brown. http://www.newenergychoices.org/dev/uploads/RPS\%20Report_Cooper_Sovacool_FINAL_HILL.pdf, accessed 6/7/07.

Council on Competitiveness. 2007. Competitiveness Index 2006: Where America Stands. Washington, DC.

Cowan, R. 1990. “Nuclear Power Reactors: A Study in Technological Lock-in.” Journal of Economic History, 50(3), pp. 541-567.

Cowart, Richard. 2001. "Efficient Reliability: The Critical Role of Demand-Side Resources in Power Systems and Markets.” Report to the National Association of Regulatory Utility Commissioners, Regulatory Assistance Project. http://www.raponline.org/Pubs/General/EffReli.pdf, accessed 11/9/06.

Crow, Michael and Barry Bozeman. 1998. Limited By Design: R\&D Laboratories in the U.S. National Innovation System. New York: Columbia University Press.

Csere, C. 2004. "Saving gas through semantic definitions.” Car and Driver.

Cummings, M. 1999. An Interpretation of Technology Diffusion Patterns for the U.S. Department of Energy's Environmental Management Program. U.S. Department of Energy.

Davis, Lee. 2004. “Intellectual Property Rights: Strategy and Policy,” Econ. Innov. New. Techn. 13(5): 399-415.

Davis, Stacy C. and Susan W. Diegel. 2007. Transportation Energy Data Book: Edition 26. http://cta.ornl.gov/data/index.shtml, accessed 7/17/07.

DeLaquil III, P. 1996. Progress commercializing solar-electric power systems. Paper presented at the World Renewable Energy Congress, Denver, CO, June 15-21.

DeMeo, Edgar. 2006. Personal communication (telephone interview). President, Renewable Energy Consulting Services, Inc., 11/8.

Dias, Sergio. 2006. Personal communication (telephone interview). Senior Manager of Industrial Efficiency, Northwest Energy Efficiency Alliance, 11/8.

DiMascio, Nicholas. 2007. "Credit Where Credit is Due: The Legal Treatment of Early Greenhouse Gas Emissions Reductions.” Duke Law Journal, 56 Duke L.J. 1587.

Dodgson, M., Gann, D., and Salter, A. 2005. Think, play, do: technology, innovation, and organization. Oxford University Press, New York. 
Dooley, J.J., R.T. Dahowski, C.L. Davidson, M.A. Wise, N. Gupta, S.H. Kim, and E.L. Malone. 2006. "Carbon Dioxide Capture and Geologic Storage: A Technology Report of the Second Phase of the Global Energy Technology Strategy Program.” http://www.pnl.gov/gtsp/docs/ccs_report.pdf, accessed 7/5/07.

Duffy, John F., Hayden Gregory, Robert Rines, Herbert Wamsley, and Douglas Wyatt. 1998. "Early Patent Publication: A Boon or Bane?” Cardozo Arts \& Entertainment Law Journal 16: 601-641.

Duncan, E. 2007. Cleaning up: A special report on business and climate change. The Economist, 383.

Edmonds J.A., J.F. Clarke, J.J. Dooley, S.H. Kim, and S.J. Smith. 2004. "Modeling Greenhouse Gas Energy Technology Responses to Climate Change.” Energy 29 (9-10 (Special Issue):1529-1536.

Elliott, Neal. 2001. Federal tax strategies to encourage the adoption of Combined Heat and Power. Washington, DC: American Council for an Energy Efficient Economy (ACEEE), Report No. ACEEEIE015.

Elliott, Neal. 2006. Personal communication (telephone interview). Industrial Program Director, American Council for an Energy Efficient Economy. 10/27.

ENERGY STAR ${ }^{\circledR}, 2007$. Compact Fluorescent Light Bulbs. http://www.energystar.gov/index.cfm?c=cfls.pr_cfls, accessed 11/15/07.

Ewing, R., K. Bartholomew, S. Winkelman, J. Walters, and D. Chen. 2007. Growing Cooler: The Evidence on Urban Development and Climate Change. Chicago, IL: Urban Land Institute.

Federation of Tax Administrators (FTA). 2006. State Tax Holidays. http://www.taxadmin.org/fta/rate/sales_holiday.html\#chart, accessed 11/28/06.

Follett R.F., J.M. Kimble, and R. Lal. 2001. The potential of US grazing lands to sequester carbon and mitigate the greenhouse effect. New York: Lewis Publishers.

Foray, Dominique. 1997. “Generation and Distribution of Technological Knowledge,” in Charles Edquist, ed. Systems of Innovation: Technologies, Institutions, and Organizations. London: Pinter Publishing, pp. 64-85.

Foster, R.N. 1986. Innovation: The Attacker's Advantage. Summit Books.

Freedman, S. and S.Watson. 2003. Output Based Emissions Standards: Advancing Innovative Technologies. Washington, DC: The Northeast Midwest Institute.

Friedman, Thomas. 2007. “The Power of Green,” New York Times Magazine.

Fulton, W., R. Pendall, M. Nguyen, and A. Harrison. 2001. Who Sprawls Most? How Growth Patterns Differ Across the U.S. Washington, DC: Brookings Center on Urban and Metropolitan Policy.

Gallagher, K.S., J.P. Holdren, J. P., and A.D. Sagar. 2006. Energy-Technology Innovation. Annual Review of Environment, 31, 193-237. 
Gallini, Nancy T. 2002. “The Economics of Patents: Lessons from Recent U.S. Patent Reform,” The Journal of Economic Perspectives 16(2): 131-154.

Gehl, R.J. and C.W. Rice. 2007. "Emerging technologies for in situ measurement of soil carbon.” Climatic Change, 80: 43-54.

Giampietro, M., S. Ulgiati, and D. Pimentel. 1997. Feasibility of large-scale biofuel production Does an enlargement in scale change the picture? Bioscience, 47, 587-600.

Gottlieb, Paul. 2006. Personal communication (telephone interview). Assistant General Counsel for Technology Transfer and Intellectual Property, U.S. Department of Energy, 11/28.

Grady, Robert E. 2007. Personal communication. Managing Partner, Carlyle Venture Partners, The Carlyle Group; Former Executive Associate Director of the Office of Management and Budget, 7/19.

Green, B., and G. Nix. 2006. Geothermal - the energy under our feet. http://www.nrel.gov/docs/fy07osti/40665.pdf, accessed 8/10/07.

Greene, David. 2006. Personal communication (telephone interview). Corporate Fellow, Center for Transportation Analysis, Oak Ridge National Laboratory. 10/31.

Greene, N., Celik, F., Dale, B., Jackson, M., Jayawarhana, K., Jin, H., Larson, E., Laser, M., Lynd, L.R., MacKenzie, D. Mark, J., Mcbride, J., McLaughlin, S., and Saccardi, D. 2004. Growing Energy: How Biofuels can Help End America’s Oil Dependence. New York: Natural Resources Defense Council.

Gremillion, T. 2007. “Case Comment: Environmental Defense V. Duke Energy Corporation,” The Harvard Environmental Law Review, 31 Harv. Envtl. L. Rev. 333.

Grubb, M. 2004. "Technology Innovation and Climate Change Policy: an overview of issues and options.” Keio Economic Studies 41:2 103-132.

Grubb, M., C. Carraro and J. Schellnhuber. 2006 "Technological change for atmospheric stabilization: Introductory overview to the innovation modeling comparison project." The Energy Journal Special Issue: Endogenous technological change and the economics of atmospheric stabilisation (1-16).

Guerin, Turlough F. 2001. “Transferring Environmental Technologies to China: Recent Developments and Constraints,” Technological Forecasting and Social Change 67: 55-75

Guena, Aldo and Lionel J.J. Nesta. 2006. "University Patenting and Its Effects on Academic Research: The Emerging European Evidence,” Research Policy 35: 790-807.

Gunning, Paul. 2006. Personal communication (telephone interview). Chief of the Non- $\mathrm{CO}_{2}$ Programs Branch, Climate Change Division, U.S. Environmental Protection Agency, 11/8.

Hanel, Petr. 2006. "Intellectual Property Rights Business Management Practices: A Survey of the Literature,” Technovation 26: 895-931.

Harrington, Cheryl and Catherine Murray. 2003. "Who Should Deliver Ratepayer Funded Energy Efficiency?” Regulatory Assistance Project Survey and Discussion Paper. http://www.raponline.org/Pubs/RatePayerFundedEE/RatePayerFundedEEPartI.pdf, accessed 11/9/06. 
Harris, Jeff. 2006. Personal communication (telephone interview). Vice President for Programs, Alliance to Save Energy. 11/17.

Hassell, S., A. Wong, A. Houser, D. Knopman, and M.A. Bernstein. 2003. Building Better Homes: Government Strategies for Promoting Innovation in Housing: Rand Corporation.

Heller, Michael A. and Rebecca S. Eisenberg. 1998. "Can Patents Deter Innovation? The Anticommons in Biomedical Research,” Science 280(5364): 698-701.

Herrick, John A. 2003. "Federal Project Financing Incentives for Green Industries: Renewable Energy and Beyond,” Natural Resources Journal 43: 77-109.

Hickman, Cliff. 2007. Restructuring of US Industrial Timberland Ownership - REITS and TIMO's, http://64.226.56.33/documents/TIMO_REIT_Paper_PDC.pdf, accessed 10/26/07.

Hirsh, R. F. and B.K. Sovacool. 2006. "Technological Systems and Momentum Change: American Electric Utilities, Restructuring, and Distributed Generation,” Journal of Technology Studies 32(2): 7285.

Hirst, Eric, and Marilyn A. Brown. 1990. "Closing the efficiency gap: barriers to the efficient use of energy.” Resources, Conservation and Recycling, 3: 267-281.

Hoffert, Martin I., Ken Caldeira, Gregory Benford, David R. Criswell, Christopher Green, Howard Herzog, Atul K. Jain, Haroon S. Kheshgi, Klaus S. Lackner, John S. Lewis, H. Douglas Lightfoot, Wallace Manheimer, John C. Mankins, Michael E. Mauel, L. John Perkins, Michael E. Schlesinger, Tyler Volk, Tom M.L. Wigley. 2002. “Advanced Technology Paths to Global Climate Stability: Energy for a Greenhouse Planet,” Science, Vol. 298, pp. 981-987.

Holdren, John P. 2006. Quoted in the New York Times, 10/30 "Budgets Falling in Race to Fight Global Warming,” p. A14.

Hovorka, Susan. 2006. Personal communication (telephone interview). Research Scientist, Bureau of Economic Geology, University of Texas, 11/14.

Huesemann, M.H. 2004. The failure of eco-efficiency to guarantee sustainability: Future challenges for industrial ecology. Environmental Progress, 23, 264-270.

Intergovernmental Panel on Climate Change (IPCC). 2005. IPCC Special Report on Carbon Dioxide Capture and Storage. Prepared by Working Group III of the Intergovernmental Panel on Climate Change [Metz, B., O. Davidson, H. C. de Coninck, M. Loos, and L. A. Meyer (eds.)]. Cambridge University Press, Cambridge, United Kingdom and New York, NY, USA, 442 pp. http://arch.rivm.nl/env/int/ipcc/pages_media/SRCCSfinal/IPCCSpecialReportonCarbondioxideCaptureandStorage.htm, accessed 11/8/07.

Interlaboratory Working Group. 2000. "Scenarios for a Clean Energy Future” (Oak Ridge, TN; Oak Ridge National Laboratory and Berkeley, CA; Lawrence Berkeley National Laboratory), ORNL/CON476 and LBNL-44029.

International Atomic Energy Agency (IAEA). 2006. "Nuclear Power Reactors in the World." http://www-pub.iaea.org/MTCD/publications/PDF/RDS2-26_web.pdf, accessed 11/8/07. 
International Energy Agency (IEA). 2005. International Energy Technology Collaboration and Climate Change Mitigation-Synthesis Report. Paris: Organization for Economic Cooperation and Development, COM/ENV/EOPC/IEA/SLT(2005)11.

International Energy Agency (IEA). 2006. World energy outlook 2006. Paris: International Energy Agency.

Izaurralde, R. C. C. and C. W. Rice (2006). "Methods and Tools for Designing a Pilot Soil Carbon Sequestration Project.” United States, R. Lal, C.C. Cerri, M. Bernoux, J. Etchevers, and E. Cerri; Haworth Press, New York, NY; Pacific Northwest National Laboratory (PNNL), Richland, WA.

Jackson, Jerry. 2007. “Are US utility standby rates inhibiting diffusion of customer-owned generating systems?” Energy Policy 35:1896-1908.

Jaffe, Adam B. and John Lerner. 2001. "Reinventing Public R\&D: Patent Policy and the Commercialization of National Laboratory Technologies,” The RAND Journal of Economics 32(1): pp. 167-198.

Jaffe, A., R. Newell, and R. Stavins. 2005. A tale of two market failures: Technology and environmental policy. Ecological Economics, 54, 164-174.

Jenkins, Alec, Richard Chapman, and Hugh Reilly. 1999. Tax barriers to four renewable technologies. California Energy Commission. www.energy.ca.gov / papers/ CEC-999-1996-003, accessed 8/14/07.

Jin, Yunhui and Xue Liu. 1999. Clean Coal Technology Acquisition: Present Situation, Obstacles, Opportunities and Strategies for China. Peking University: Working Group on Trade and Environment.

Joyce, L.A. and R. Birdsey, eds. 2000. “The impact of climate change on American's forests: a technical document supporting the 2000 USDA Forest Service RPA assessment,” 133. Gen. Tech. Rep. RMRS-GTR-59. Fort Collins, Colorado: U.S. Department of Agriculture. http://www.fs.fed.us/rm/pubs/rmrs_gtr059.pdf, accessed 11/16/07.

Kakaras, E., A. Doukelis, D. Giannakopoulos, and A.Koumanakos. 2007. "Economic implications of oxyfuel application in a lignite-fired power plant.” Fuel, Vol 86 Issue 14, pp. 2151-2158.

Kamen, A. 2003. A Hummerdinger of a Tax Loophole. Washington Post, p. A25, September 26.

Kammen, D. M., and G. F. Nemet. 2007. Energy Myth Eleven - Energy R\&D Investment Takes Decades to Reach the Market, in Sovacool, B. K. and Brown, M. A. (eds.) Energy and American Society - Thirteen Myths. New York: Springer Publishing Company pp. 289-310.

Katz, M. and C. Shapiro. 1985. "Network externalities, competition, and compatibility,” American Economic Review 75:424-440.

Kennedy, Donald. 2000. “Science and Secrecy,” Science 289(54800): 724.

Kheshgi, H.S., Prince, R.C., and Marland, G. 2000. "The potential of biomass fuels in the context of global climate change: Focus on transportation fuels,” Annual Review of Energy and the Environment, 25: 99-244. 
Koehler, Mike. 2007. "Developing Wind Power Projects in Massachusetts: Anticipating and Avoiding Litigation in the Quest to Harness the Wind," Suffolk Journal of Trial and Appellate Advocacy, 12 Suffolk J. Trial \& App. Adv.

Koonin, Steven E. 2006. "Energy Trends and Technologies in the Coming Decades,” seminar given at Oak Ridge National Laboratory (Oak Ridge, TN) by the Chief Scientist of BP, November 21.

Kruger, Diana. 2006. Personal communication (telephone interview). Director, Climate Change Division, U.S. Environmental Protection Agency, 11/8.

Kuhn, Thomas. 1970. The Structure of Scientific Revolutions. Chicago University Press, Chicago IL.

Kushler, Martin, Dan York, and Patti Witte. 2004. Five Years In: An Examination of the First HalfDecade of Public Benefits Energy Efficiency Policies. Washington, DC: American Council for an Energy Efficient Economy, Table 5.

Lal, R., J.M. Kimble, R.F. Follett, and C.V. Cole. 1998. The potential of U.S. cropland to sequester carbon and mitigate the greenhouse effect. Chelsea, MI: Ann Arbor Press.

Lane, Lee. 2006. Personal communication (telephone interview). Director, Climate Policy Center, $11 / 16$.

Lapsa, M.V., L.C. Maxey, D.D. Earl, D.L. Beshears, C.D. Ward, J.E. Parks. 2007. "Hybrid Solar Lighting Provides Energy Savings and Reduces Waste Heat,” Journal of Energy Engineering, Vol. 104, No. 4 (June/July).

Leadership Group. 2006. National Action Plan for Energy Efficiency. Washington, DC: U.S. Department of Energy and U.S. Environmental Protection Agency. http://www.epa.gov/cleanrgy/pdf/napee/napee_report.pdf, accessed 7/16/07.

Lerner, Joshua. 1995. "Patenting in the Shadow of Competition," Journal of Law and Economics 38(2): 463-495.

Levine, M. D., J.G. Koomey, L. Price, H. Geller, and S. Nadel. 1995. "Electricity end-use efficiency: Experience with technologies, markets, and policies throughout the world.” Energy 20(1), 37-61.

Logan, Sam. 2007. Personal communication (telephone interview). CEO, Logan Energy. 1/29.

Loper, Joe, Lowell Ungar, David Weitz and Harry Misuriello. 2005. "Building on Success: Policies to Reduce Energy Waste in Buildings.” Report to the Alliance to Save Energy. http://www.ase.org/images/lib/buildings/Building\%20on\%20Success.pdf, accessed 11/9/06.

Lovins, Amory B., 2007. "Energy Myth Nine - Energy Efficiency Improvements have Already Reached their Potential,” in Sovacool, B. K. and Brown, M. A. (eds.) Energy and American Society Thirteen Myths. (New York: Springer Publishing Company), pp. 239-264.

Lovins, A.B., E.K. Datta, O.E. Bustnes, J.G. Koomey, and N.J. Glasgow. 2004.Winning the Oil Endgame. Snomass, CO: Rocky Mountain Institute. www.oilendgame.com, accessed 7/2/07.

Luiten, E. 2001. Beyond Energy Efficiency: Actors, networks, and government intervention in the development of industrial process technologies. Utrecht University, Utrecht, The Netherlands. 
Lund, Peter. 2006. “Market penetration rates of new energy technologies,” Energy Policy 34: 33173326.

Lund, Peter. 2007. "Effectiveness of policy measures in transforming the energy system,” Energy Policy 35:627-639.

Lynd, L.R., Laser, M.S., McBride, J., Podkaminer, K., and Hannon, J. 2007. Energy Myth ThreeHigh land requirements and unfavorable energy balance preclude biomass ethanol from playing a large role in providing energy services in Sovacool, B. K. and Brown, M. A. (eds.) Energy and American Society - Thirteen Myths. New York: Springer Publishing Company, pp. 75-101.

Maréchal, Kevin. 2007. “The economics of climate change and the change of climate in economics,” Energy Policy 35:5181-5194.

Marechaux, Toni. 2006. Personal communication (telephone interview). Consultant, Strategic Analysis, Inc., 11/28.

Markham, S. 2002. "Moving technologies from lab to market," Research-Technology Management 45: 6 31-43.

Marlay, 2005. Presentation to the Climate Change R\&D Portfolio Assessment Integration Workshop. Held at Oak Ridge National Laboratory, December 15.

Mazzoleni, Robert and Richard R. Nelson. 1998. "The Benefits and Costs of Strong Patent Protection: A Contribution to the Current Debate,” Research Policy 27: 273-284.

Mintz, M., Folga, S., Molburg, J., and Gillette, J. 2002. Cost of Some Hydrogen Fuel Infrastructure Options, presentation to the Transportation Research Board, January 16. Argonne, IL: Argonne National Laboratory.

Massachusetts Institute of Technology (MIT), 2007. The Future of Coal (Cambridge, MA: MIT).

Montgomery, W. David. 2006. Prepared statement for hearing on "The Role of Science in the AsiaPacific Partnership” before the Committee on Commerce, Science and Transportation Subcommittee on Global Climate Change and Impacts. United States Senate. Washington DC.

Mooney, S., J. Antle, S. Capalbo, and K. Paustian. 2004. "Design and Costs of a Measurement Protocol for Trades in Soil Carbon Credits,” Canadian Journal of Agricultural Economics, 52:3 257-287.

Mowery, David C. and Arvids A. Ziedonis. 2000. "Numbers, Quality, and Entry: How Has the BayhDole Act Affected U.S. University Patenting and Licensing?” in Adam B. Jaffe, Josh Lerner, and Scott Stern, eds. Innovation and the Economy. Cambridge, MA: MIT Press, pp. 187-220.

Mulder, P., H. DeGroot, and M. Hofkes. 2001. "Economic growth and technological change: a comparison of insights from a neo-classical and an evolutionary perspective,” Technological Forecasting and Social Change 68:151-171.

Mueller, Steffen. 2006. "Missing the spark: An investigation into the low adoption paradox of combined heat and power technologies,” Energy Policy 34: 3153-3164. 
Murphy L. and P. Edwards. 2003. Bridging the Valley of Death: Transitioning from Public to Private Sector Financing, Golden, CO: National Renewable Energy Laboratory. http://www.cleanenergystates.org/CaseStudies/NREL-Bridging_the_Valley_of_Death.pdf, accessed 11/9/06.

Murray, Brian. 2006. Personal communication (telephone interview). Director for Economic Analysis, Nicholas Institute for Environmental Policy Solutions, Duke University, 11/7.

Nakicenovic, N. and K. Riahi. 2003. Model Runs with MESSAGE in the Context of the Further Development of the Kyoto-Protocol (Berlin, Germany: WBGU).

National Academy of Engineering (NAE). 2004. The Hydrogen Economy: Opportunities, Costs, Barriers, and R\&D Needs. Washington, DC: The National Academies Press.

http://www.nap.edu/books/0309091632/html/, accessed 7/3/07.

National Academies. 2001. Energy Research at DOE:Was It Worth It? Energy Efficiency and Fossil Energy Research 1978 to 2000.” Committee on Benefits of DOE R\&D on Energy Efficiency and Fossil Energy, Commission on Engineering and Technical Systems, National Research Council.

National Academies Press. 2002. Effectiveness and Impact of Corporate Average Fuel Economy (CAFE) Standards. Board of Energy and Environmental Systems (BEES).

National Commission on Energy Policy (NCEP). 2004. "Ending the Energy Stalemate: A bipartisan strategy to meet America's energy needs,” http://www.energycommission.org/files/contentFiles/report_noninteractive_44566feaabc5d.pdf, accessed 7/3/07.

National Commission on Energy Policy (NCEP). 2006. Siting Critical Energy Infrastructure: An Overview of Needs and Challenges, http://www.energycommission.org, accessed 9/3/06.

National Commission on Energy Policy (NECP). 2007. Energy Policy Recommendations to the President and the 110th Congress of the United States. Washington, DC: National Commission on Energy Policy, http://www.energycommission.org/site/page.php?index, accessed 8/5/07.

National Renewable Energy Laboratory (NREL). 2002. Proceedings of the 2002 U.S. DOE Hydrogen and Fuel Cells Annual Program/Lab R\&D Review, May 6-10, 2002, Golden, Colorado. Golden, CO, NREL/CP-610-32405. http://www.nrel.gov/docs/fy02osti/32405.pdf, accessed 7/16/07.

Nemet G. 2006. "Beyond the learning curve: factors influencing cost reductions in photovoltaics," Energy Policy 34 3218-3232.

New Mexico Business Weekly. 2006. UNM helps build bridge over financial 'valley of death.' http://sanjose.bizjournals.com/albuquerque/stories/2006/10/02/story10.html, accessed 10/8/07.

Newell, Richard. 2006. Personal communication (telephone interview). Gendell Associate Professor of Energy and Environmental Economics, Duke University, 11/21.

Nicholson, C. 2004. "Protecting the Environment - A Business Perspective.” Keynote address given at the $4^{\text {th }}$ Speciality Conference on Environmental Progress, Bahrain. Text of speech provided by BP Global Press at http://www.bp.com/genericarticle.do?categoryId=98\&contentId=2017173, accessed 11/13/07. 
Norberg-Bohm V. 2000. "Creating: incentives for environmentally enhancing technological change: lessons from 30 years of U.S. energy technology policy,” Technological Forecasting and Social Change 65(2), 125-148.

Norton, J.A. and F.M. Bass. 1987. “A Diffusion Thory Model of Adoption and Substitution for Successive Generational of High-Technology Product.” Management Science, 33(9), pp. 1069-1086.

Nye, D. 1997. Consuming Power: A Social History of American Energies. Cambridge, MA.: The MIT Press.

Office of the United States Trade Representative. 2006. Report on Trade-Related Barriers to the Export of Greenhouse Gas Reducing Technologies. Washington, DC: Executive Office of the President.

Ogden, J.M. 1999. "Prospects for Building a Hydrogen Energy Infrastructure," chapter in Annual Review of Energy and the Environment, vol. 24, pp. 227-79.

Ottinger, Richard L. and Rebecca Williams. 2002. “2002 Energy Law Symposium: Renewable Energy Sources for Development.” Environmental Law 32, 331-362.

Pacala, Stephen W. and Robert H. Socolow. 2004. "Stabilization wedges: solving the climate problem for the next 50 years with current technologies,” Science 305: 968-972.

Painuly, J.P. 2001. "Barriers to renewable energy penetration, a framework for analysis,” Renewable Energy 24:73-89 (2001).

Parry, I. and J. Darmstadter. 2004. “The Costs of US Oil Dependency,” National Commission on Energy Policy. http://www.energycommission.org/site/page.php?report=27, accessed 7/30/07.

Perlack, R.D., Wright, L.L., Turhollow, A.F., and Graham, R.L. 2005. Biomass as feedstock for a bioenergy and bioproducts industry: the technical feasibility of a billion-ton annual supply. Washington, D.C.: U.S. Department of Energy and U.S. Department of Agriculture.

http://feedstockreview.ornl.gov/pdf/billion_ton_vision.pdf, accessed 7/3/07.

Pew. 2007. "What's Being Done in Congress."

http://www.pewclimate.org/what_s_being_done/in_the_congress, accessed 11/13/07.

Philibert, Cedric and Jacek Podkanski. 2005. “Case Study 4: Clean Coal Technologies,” International Energy Technology Collaboration and Climate Change Mitigation. Paris: International Energy Agency / Organization for Economic Cooperation and Development, COM/ENV/EPOC/IEA/SLT(2005)4).

Popp, David. 2006 "International Innovation and Diffusion of Air Pollution Control Technologies: The Effects of $\mathrm{No}_{\mathrm{x}}$ and $\mathrm{SO}_{2}$ Regulation in the U.S., Japan, and Germany," Journal of Environmental Economics and Management 51: 46-71.

Potts, Jerry R. 2006. "What Does it Cost to Obtain a Patent,” available at http://pw1.netcom.com/ patents2/What\%20Does\%20It\%20Cost\%20Patent.htm, accessed 7/3/07.

Powell, Walter W. and Jason Owen-Smith.1998. "Universities and the Market for Intellectual Property in the Life Sciences,” Journal of Policy Analysis and Management 17(2): 253-277. 
Prindle, B. 2007. Quantifying the Effects of Market Failures in the End-Use of Energy (Washington, DC: American Council for an Energy-Efficient Economy), ACEEE Report Number E071, http://www.aceee.org/energy/IEAmarketbarriers.pdf, accessed 8/5/07.

Quinn, Eugene R. 2006. “Cost of Obtaining a Patent,” Intellectual Property Watchdog, available at http://www.ipwatchdog.com/patent_cost.html, accessed 7/3/07.

Rand, Sally. 2006. Personal communication (telephone interview). Non- $\mathrm{CO}_{2}$ Programs Branch, Climate Change Division, U.S. Environmental Protection Agency, 11/20.

Rappert, Brian, Andrew Webster, and David Charles. 1999. "Making Sense of Diversity and Reluctance-Industrial Relations and Intellectual Property,” Research Policy 28: 873-890.

Rayle, Rudolf. 2000. “The Trend Towards Enhancing Trademark Owners’ Rights-A Comparative Study of U.S. and German Trademark Law,” Journal of Intellectual Property Law 7: 227-273.

Regional Greenhouse Gas Initiative (RGGI). 2006. http://www.rggi.org/index.htm, accessed 11/28/06.

Reisert, Roger. 2006. Personal communication (interview). President, C2 Biofuels. 11/28.

Renewable Fuels Association. 2006. The Enhanced Small Ethanol Producer Tax Credit I.R.C. Sec. 40(b)(3).

http://www.ethanolrfa.org/policy/regulations/federal/septc/documents/SEPTCPublication0601.pdf, accessed 8/10/07.

Richels, Richard. 2007. "The Cost of Climate Change Mitigation: Scenario Analysis of the CCSP 2.1 Report," Presentation given to the Laboratory Energy R\&D Working Group, Washington, DC, November 7.

Robertson, Kate, Jette Findsen, and Steve Messner. 2006. International Carbon Capture and Storage Projects-Overcoming Legal Barriers. National Energy Technology Laboratory, DOE/NETL-2006-1236.

Rohatgi, Ajeet. 2006. Personal communication (telephone interview). Regents’ Professor; Georgia Power Distinguished Chair; Director, University Center of Excellence for Photovoltaic Research and Education, Georgia Institute of Technology, 11/20.

Rosenzweig, Robert M. 1985. "Research as Intellectual Property: Influences within the University,” Science, Technology, \& Human Values 10(2): 41-48.

Rushton, Jim. 2006. Personal communication (telephone interview). Director of Nuclear Science and Technology, Oak Ridge National Laboratory, 11/8.

Ruth, M. 1995. “Technology change in the US iron and steel production,” Resources Policy, 21:3 199-214.

Sabety, Ted. 2005. "Nanotechnology Innovation and the Patent Thicket: Which IP Policies Promote Growth?” Albany Law Journal of Science \& Technology 15: 477-515.

Sabino, A. M. 2007. “Supreme court distinguishes “Coal” from "gas” in Amoco.” Natural Gas 16:1 $1-6$. 
Sagar A. and van der Zwaan, B. 2006. "Technological innovation in the energy sector: R\&D, deployment, and learning-by-doing,” Energy Policy 34 2601-2608.

Saunders, Kurt M. and Linda Levine. 2004. "Better, Faster Cheaper-Later: What Happens When Technologies are Suppressed,” Michigan Telecommunications and Technology Law Review 11: 23-69.

Schmalensee, Richard. 2006. Personal communication (telephone interview). Howard W Johnson Professor of Economics and Management, MIT Sloan School of Management, 11/29.

Shapiro, Carl. 2000. "Navigating the Patent Thicket: Cross Licenses, Patent Pools, and Standard Setting," in Adam B. Jaffe, Josh Lerner, and Scott Stern, eds. Innovation and the Economy. Cambridge, MA: MIT Press, pp. 119-150.

Shapiro, C., and H.R. Varian. 1999. Information Rules: A Strategic Guide to the Network Economy: Harvard Business School Press.

Smith, P. 2004. Smith, P. (2004). Monitoring and verification of soil carbon changes under Article 3.4 of the Kyoto Protocol. Soil Use and Management, 20, 264-270.

Soloman, Barry D. and Abhijt Banerjee. 2006. "A Global Survey of Hydrogen Energy Research Development and Policy,” Energy Policy 34: 781-792.

Sovacool, B. K. 2006. “The Power Production Paradox: Revealing the Socio-technical Impediments to Distributed Generation Technologies,” Ph.D. Thesis, Science and Technology Studies Department, Virginia Polytechnic Institute \& State University, Doctoral Dissertation, Blacksburg, VA, [online] http://scholar.lib.vt.edu/theses/available/etd-04202006-172936/, accessed 7/06.

Sovacool, B. K. and Brown, M. A. (eds.). 2007. Energy and American Society - Thirteen Myths. New York: Springer Publishing Company.

Sovacool, B. and R. Hirsch. 2007. Energy Myth Seven- The Barriers to New and Innovative Energy Technologies are Primarily Technical: The Case of Distributed Generation in Sovacool, B. K. and Brown, M. A. (eds.) Energy and American Society - Thirteen Myths. New York: Springer Publishing Company, pp. 145-169. 29.

Stavins, Robert N. 2006. "Vintage-Differentiated Environmental Regulation,” 25 STAN. ENVTL. L.J.

Stavros, Richard. 1999. “Distributed Generation: Last Big Battle for State Regulators?” Public Utilities Fortnightly 137 (October 15): 34-43.

Stern, Nicholas. 2006. Stern Review: The Economics of Climate Change, www.sternreview.org.uk, accessed 11/8/07.

Taylor, Jerry and Peter Van Doren. 2007. Energy Myth Five - Price Signals are Insufficient to induce Efficient Energy Investments, in Sovacool, B. K. and Brown, M. A. (eds.) Energy and American SocietyThirteen Myths, New York: Springer Publishing Company, 125-144.

Tempchin, Rick. 2007. Personal communication (in person interview). Director of Retail Distribution Policy, Edison Electric Institute, 7/23. 
Teresko, John. 2007. “The Hydrogen Economy: Lift Trucks First?” Industry Week, July 1.

The Sunday Times. 2007. “Powering the Future.” London, UK, June 17.

Thresher, Robert. 2006. Personal communication (telephone interview). Director, National Wind Technology Center, National Renewable Energy Laboratory. 11/3.

Train, K. 1985. “Discount Rates in Consumers' Energy-Related Decisions: A Review of the Literature.” Energy, 10(12), 1243-1253. http://are.berkeley.edu/ sstohs/Refrigerators/misc/Train1985.pdf, accessed 11/8/07.

Tuskan, G.A., and M.E. Walsh. 2001. "Short-rotation woody crop systems, atmospheric carbon dioxide and carbon management: a U.S. case study.” The Forestry Chronicle 77:259-264.

U.S. Climate Change Technology Program (CCTP). 2005. Technology options for the near and long term. Washington, DC: U.S. Department of Energy. http://www.climatetechnology.gov/library/2005/techoptions/index.htm, accessed 10/31/07.

U.S. Climate Change Technology Program (CCTP). 2006. Strategic Plan. Washington, DC: U.S. Department of Energy, DOE/PI-0005, http://www.climatetechnology.gov, accessed 7/3/07.

U.S. Climate Change Technology Program (CCTP). 2007. National Strategy for the Commercialization and Deployment of Greenhouse Gas-Reducing Technologies. Washington, DC: U.S. Department of Energy, draft, October.

U.S. Department of Agriculture (USDA). 1998. Precision Agriculture: Information Technology for Improved Resource Use. http://www.ers.usda.gov/publications/agoutlook/apr1998/ao250f.pdf, accessed 11/16/07.

U.S. Department of Agriculture (USDA). 2006. Energy Estimator, Energy Consumption Awareness Tool, http://nfat.sc.egov.usda.gov/Help.aspx, accessed 11/16/07.

U.S. Department of Energy, Office of Energy Efficiency and Renewable Energy (DOE/EERE). 2003a. The Green Power Network, Green Power Markets, “Net Metering Policies” webpage, http://www.eere.energy.gov/greenpower/markets/netmetering.shtml, accessed 7/17/07.

U.S. Department of Energy, Office of Energy Efficiency and Renewable Energy (DOE/EERE). 2003b. Buildings Energy Databook. Washington, DC, 5-1, Table. 5.1.1.

U.S. Department of Energy, Office of Energy Efficiency and Renewable Energy (DOE/EERE). 2007. Energy Technology Solutions: Public-Private Partnerships Transforming Industry. http://www1.eere.energy.gov/industry/bestpractices/pdfs/itp_successes.pdf, accessed 11/13/07.

U.S. Department of Energy (DOE). 2000. From invention to innovation. http://www.nrel.gov/docs/fy00osti/26620.pdf, accessed 10/06.

U.S. Department of Energy (DOE). 2004. Frio Formation Test Well Injected With Carbon Dioxide. http://www.fossil.energy.gov/news/techlines/2004/tl_frio_injection.html, accessed 11/8/07.

U.S. Department of Energy (DOE). 2005. Energy Efficiency and Renewable Energy, Building Technologies Program Multi-Year Program Plan, Research, Development, and Demonstration Plan: 
Planned Program Activities for 2006 - 2011.

http://www.eere.energy.gov/buildings/about/mypp_2006.html, accessed 11/8/07.

U.S. Department of Energy (DOE). 2006a. National Electric Transmission Congestion Study, http://nietc.anl.gov/documents/docs/Congestion_Study_2006-9MB.pdf, accessed 7/6/07.

U.S. Department of Energy (DOE). 2006b. Hydrogen Posture Plan, an Integrated Research, Development, and Demonstration Plan. Washington, DC: U.S. Department of Energy. http://www.hydrogen.energy.gov/pdfs/hydrogen_posture_plan_dec06.pdf, accessed 11/8/07.

U.S. DOE Nuclear Energy Research Advisory Committee (BERAC) and the Generation IV International Forum (GIF). 2002. “A Technology Roadmap for Generation IV Nuclear Energy Systems.” http://gif.inel.gov/roadmap/pdfs/gen_iv_roadmap.pdf, accessed 11/8/07.

U.S. Energy Information Administration (EIA). 2005. Annual energy outlook 2005: with projections to 2025, DOE/EIA-0383(2005). Washington, DC: U.S. Department of Energy.

U.S. Energy Information Administration (EIA). 2006a. Annual Energy Outlook 2006, DOE/EIA0383(2006). Washington, DC: U.S. Department of Energy.

U.S. Energy Information Administration (EIA). 2006b. International Energy Outlook, DOE/EIA0484(2006). Washington, DC: U.S. Department of Energy.

U.S. Energy Information Administration (EIA). 2007a. Annual Energy Outlook 2007 with Projections to 2030 - Overview, DOE/EIA-0383(2007). http://www.eia.doe.gov/oiaf/aeo/index.html, accessed $7 / 16 / 07$.

U.S. Energy Information Administration (EIA). 2007b. International Energy Outlook 2007, DOE/EIA-0484(2007). http://www.eia.doe.gov/oiaf/ieo/index.html, accessed 11/8/07.

U.S. Energy Information Administration (EIA). 2007c. Renewable Energy Trends, 2005. http://www.eia.doe.gov/cneaf/solar.renewables/page/trends/rentrends.html\#_ftn11, accessed 11/8/07.

U.S. Environmental Protection Agency (EPA). 2006. "Mountaintop Removal/Valley Fill,” http://www.epa.gov/maia/html/issue-valley.html, accessed 7/30/07.

U.S. Environmental Protection Agency (EPA), Office of Air and Radiation, Climate Protection Partnerships Division. 2007. National Awareness of ENERGY STAR® for 2006: Analysis of 2006 CEE Household Survey. U.S. EPA. http://www.energystar.gov/ia/news/downloads/National_Awareness041607.pdf , accessed 8/6/07.

U.S. Fuel Cell Council. 2007. Federal Fuel Cell Tax Incentives; An investment in clean and efficient technologies. www.usfcc.com/resources/, accessed 7/14/07.

U.S. General Accounting Office. 2002. Intellectual Property: Federal Agency Efforts in Transferring and Reporting New Technology. Washington, DC, GAO-03-47.

Unruh, G. 2000. Understanding carbon lock-in. Energy Policy, 28, 817-830.

Unruh, G. 2002. “Escaping Carbon Lock-in.” Energy Policy, 30, pp. 317-325. 
van Mierlo, B. and B. Oudshoff, B. 1999. Literature survey and analysis of non-technical problems for the introduction of building integrated photovoltaic systems: IVAM Environmental Research, University of Amsterdam by order of IEA PVPS Task 7. http://www.ieapvps.org/products/download/rep7_01.pdf, accessed 7/5/07.

van der Veer, J. 2003. "Hydrogen - Fuel of the Future,” remarks at Making Hydrogen Available to the Public Rekjavic, Iceland, April 24.

Weber, L. 1997. "Some reflections on barriers to the efficient use of energy.” Energy Policy, 25(10), 833-835.

Weeks, Ann Brewster. 2007. "Subseabed Carbon Dioxide Sequestration as a Climate Mitigation Option for the Eastern United States: A Preliminary Assessment of Technology and Law,” Ocean and Coastal Law Journal, 12 Ocean \& Coastal L.J. 245.

Weimer, David and Aidan R. Vining. 2005. Policy Analysis: Concepts and Practice ( $4^{\text {th }}$ Edition) New York : Prentice Hall.

Wiener, Jason R. 2006. "Sharing Potential and the Potential for Sharing: Open Source Licensing as a Legal and Economic Modality for the Dissemination of Renewable Energy Technology,” Georgetown International Environmental Law Review 18: 277-303.

Weissman, J.M., and K. Laflin. 2006. Trends In Practitioner Training For The Renewable Energy Trades. In proceedings of American Solar Energy Society Conference, July 2006, Denver, CO.

Weyant, John P. (ed.). 2004. "Special Issue EMF 19 Alternative technology strategies for climate change policy.” Energy Economics 26(4).

Wilson, J.O. 2004. "The Answer, My Friends, Is in the Wind Rights Contract Act: Proposed Legislation Governing Wind Rights Contracts,” Iowa Law Review, Volume 89, Number 5.

Wong, B. 2003. “It's not just a Hummer, it's a tax break.” Seattle Post-Intelligencer, January 17.

World Nuclear Association (WNA). 2006. Plans for New Reactors Worldwide. http://www.worldnuclear.org/info/inf17.htm, accessed Jan. 3, 2007.

Worrell, E. and G. Biermans. 2005. "Move over! Stock turnover, retrofit and industrial energy efficiency,” Energy Policy 33:7 949-962.

World Energy Congress (WEC). 2001. World Energy Assessment: Energy and the Challenge of Sustainability.

Yacobucci, Brent D. 2007. “Fuel Ethanol: Background and Public Policy Issues.” Congressional Research Service (CRS) Report for Congress, RL 33290, http://www.nationalaglawcenter.org/assets/crs/RL33290.pdf, accessed 7/9/07.

Yeh, Sonia and Edward Rubin. 2007. "A centurial history of technological change and learning curves for pulverized coal-fired utility boilers,” Energy 32:1996-2005. 
Zain, Saami. 2006. "Suppression of Innovation or Collaborative Efficiencies? An Antitrust Analysis of Research \& Development Collaboration that Led to the Shelving of a Promising Drug," John Marshall Law School Review of Intellectual Property Law 5: 347-383. 



\section{APPENDIX A}

\begin{tabular}{|c|c|}
\hline \multicolumn{2}{|c|}{ List of Experts Interviewed on Deployment Barriers } \\
\hline Technical Expert (Organization) & Area of Expertise \\
\hline Tim Stout (National Grid) & Transmission and Distribution \\
\hline Richard Brent (Solar Turbines - VP) & Distributed Generation \\
\hline Doug Arent (National Renewable Energy Laboratory) & Biofuels \\
\hline Roger Reisert (C2 Biofuels) & Biofuels \\
\hline Jeff Harris (Alliance to Save Energy) & Buildings Efficiency \\
\hline Sue Coakley (Northeast Energy Efficiency Alliance) & Buildings Efficiency \\
\hline Susan Hovorka (Bureau of Economic Geology - Texas) & Carbon Capture and Storage \\
\hline Jay Braitsch (U.S. Department of Energy) & Low-Emission Fossil \\
\hline Sam Logan (LOGANEnergy) & Hydrogen and Fuel Cells \\
\hline Richard Schmalensee (Massachussetts Institute of Technology) & Economics and Management \\
\hline Lee Lane (Climate Policy Center) & Economics and Management \\
\hline Richard Newell (Duke University) & Energy Efficiency \\
\hline Brian Murray (Nicholson Institute - Duke University) & Forestry and Agriculture \\
\hline Neil Elliott (American Council for an Energy Efficient Economy) & Industrial Energy Efficiency \\
\hline Sergio Dias (Northwest Energy Efficiency Alliance) & Industrial Energy Efficiency \\
\hline Jim Rushton (Oak Ridge National Laboratory) & Nuclear Power \\
\hline David Brown (Exelon Corporation) & Nuclear Power \\
\hline Paul Gunning (Environmental Protection Agency) & Other Gases \\
\hline Dina Kruger (Environmental Protection Agency) & Other Gases \\
\hline Sally Rand (Environmental Protection Agency) & Other Gases \\
\hline Ajeet Rohatgi (Georgia Institute of Technology) & Solar Photovoltaics \\
\hline David Greene (Oak Ridge National Laboratory) & Transportation Efficiency \\
\hline Robert Thresher (National Renewable Energy Laboratory) & Wind \\
\hline Edgar DeMeo (Renewable Energy Consulting Services) & Wind \\
\hline Paul Gottlieb (U.S. Department of Energy) & Intellectual Property \\
\hline Toni Marechaux (Strategic Analysis Inc.) & Intellectual Property \\
\hline Irv Barash (Vencon Management Inc.) & Venture Capital \\
\hline
\end{tabular}





\section{APPENDIX B \\ Fiscal, Regulatory, and Statutory Impediments to Clean Energy Technologies}

\section{Unfavorable Fiscal Policies}

The internal revenue code provides business deductions for the purchase of large light trucks.

The gas-guzzler tax on cars (but not on light trucks) has discouraged the purchase of cars and encouraged the purchase of SUVs.

Tax Subsidies

Oil and gas depletion allowances allow owners to claim a depletion deduction for loss of their reserves.

Government support for research on the production of liquid fuels from coal and the production of petroleum from shale oil and tar sands promotes carbonintensive fuels.

The link between federal transportation funding and vehicle miles traveled rewards the growth of transportation energy use.

The federal tax code discourages capital investments in general, as opposed to direct expensing of energy costs.

Unequal taxation of capital and operating expenses

Unfavorable tariffs

Utility pricing policies
The federal tax code forces firms to depreciate energy efficiency investments over a longer period of time than many other investments.

Capital-intensive technologies (e.g., renewables and nuclear power plants) have a differentially higher tax burden than expense-intensive technologies (e.g., coal and natural gas plants).

The import tariff for ethanol raises the cost of ethanol blends produced by domestic refineries.

Utilities impose tariffs (including standby charges, buyback rates, and uplift fees) on small generators seeking to connect to the grid.

Unfavorable electricity pricing policies present obstacles for an array of clean energy technologies; these include the regulated rate structure, lack of real-time pricing, and imbalance penalties.

In traditionally regulated electricity markets, electric utilities face little incentive to promote energy efficiency or non-dispatchable distributed generation because utility company profits are a function of sales.

\section{Ineffective Fiscal Policies}

The IRS has yet to establish guidelines that clarify the eligibility criteria and spell out procedures for claiming tax credit for fuel cells authorized in the Energy Policy Act of 2005.

Tax credits intended to promote the purchase of hybrid electric vehicles and residential photovoltaic systems have limited value because of the Alternative Minimum Tax, which sets a floor for tax liability.

The IRS code requires that in any tax year a company may not reduce its payable taxes by more than 50 percent, which prevents many firms from benefiting from tax deductions for clean energy investments.

Many states have property tax laws that provide incentives for landowners to develop their forestland for higher use rather than leave the forest standing or continue timber production. 
Carbon Lock-In

Fiscal, Regulatory, and Statutory Impediments to Clean Energy Technologies (cont'd)

\section{Fiscal Uncertainty}

Fiscal incentives

\begin{tabular}{ll}
\hline & Investors face uncertain future costs for GHG emissions; when these possible \\
Fiscal penalties & future costs are weighed against certain higher capital costs for cleaner \\
technologies, cleaner technologies are not likely to win.
\end{tabular}

\section{Unfavorable Regulatory Policies}

Exempting existing facilities from strict emissions requirements placed on new

Performance

Standards plants discourages what would be naturally occurring technological progress.

Emissions standards that are input based rather than output based discourage process improvements that would result in lower emissions.
The ban on private electric wires crossing public streets penalizes local
Connection Standards generation of electricity, which could reduce transmission losses and increase overall efficiency.

\section{Ineffective Regulations}

Federal CAFE standards exempt vehicles over 8500 pounds gross vehicle weight, encouraging automakers to make heavier - rather than more efficient, trucks.

Regulatory Loopholes States are prevented from setting more restrictive fuel economy standards than those in the federal CAFE legislation, so state policy innovation is limited.

Federal CAFE standards also credit vehicles for flexible fuel (E-85 capability) regardless of how they are fueled after purchase or their fuel mileage.

\begin{tabular}{ll}
\hline $\begin{array}{l}\text { Poor land-use } \\
\text { planning }\end{array}$ & Zor \\
\hline
\end{tabular}

Zoning for low-density urban development contributes to sprawl and locks in dependence on cars rather than multi-user transit.

Burdensome permitting processes

Several clean energy technologies, such as carbon capture and hydrogen, are challenged by inadequate regulatory frameworks.

Environmental permitting for land-based wind projects falls under the purview of regulations promulgated by a maze of local, county, state, and federal agencies, while off-shore wind faces a lack of permitting procedures.

\section{Regulatory Uncertainty}

Regulatory uncertainty - regarding whether or not GHG will be regulated or how current technologies will fare under new regulatory processes - impedes rational investment decisions.

\section{Unfavorable Statutes}

Lack of modern and enforceable building codes

Building codes that are not enforced, are based on outdated technology, or allow tradeoffs that mitigate use of existing technology discourage adoption of clean energy technologies.

When state agencies cannot contract over more than one fiscal year, they are unable to take on capital improvements that are cost-effective in the long-run. 
Fiscal, Regulatory, and Statutory Impediments to Clean Energy Technologies (cont'd)

\begin{tabular}{|c|c|}
\hline \multicolumn{2}{|l|}{ Statutory Uncertainty } \\
\hline $\begin{array}{l}\text { Variable Clean Energy } \\
\text { Portfolio Standards }\end{array}$ & $\begin{array}{l}\text { Many states have adopted renewable or efficiency portfolio standards for electric } \\
\text { generation, but these vary greatly - making it difficult for utility investors to } \\
\text { reduce emissions or improve efficiency through the most cost-effective means. }\end{array}$ \\
\hline $\begin{array}{l}\text { Uncertain property } \\
\text { rights }\end{array}$ & $\begin{array}{l}\text { Property rights for subsurface and above-surface areas are unclear. In some } \\
\text { cases, particularly coal-bed methane, geologic storage of carbon dioxide, and } \\
\text { wind energy, property rights for these areas must be defined to provide } \\
\text { investment certainty. }\end{array}$ \\
\hline
\end{tabular}


